\title{
Ambient air pollution: A global assessment of exposure and burden of disease
}


WHO Library Cataloguing-in-Publication Data

Ambient air pollution: a global assessment of exposure and burden of disease.

1.Air Pollution. 2.Environmental Exposure. 3.Urban Health. 4.Epidemiologic Studies. 5.Cost of Illness. I.World Health Organization.

ISBN 9789241511353

(NLM classification: WA 754)

All rights reserved. Publications of the World Health Organization are available on the WHO website (http://www.who.int) or can be purchased from WHO Press, World Health Organization, 20 Avenue Appia, 1211 Geneva 27, Switzerland (tel.: +41 22 791 3264; fax: +41 22791 4857; email: bookorders@who.int).

Requests for permission to reproduce or translate WHO publications - whether for sale or for non-commercial distributionshould be addressed to WHO Press through the WHO website (http://www.who.int/about/licensing/copyright_form/index.html).

The designations employed and the presentation of the material in this publication do not imply the expression of any opinion whatsoever on the part of the World Health Organization concerning the legal status of any country, territory, city or area or of its authorities, or concerning the delimitation of its frontiers or boundaries. Dotted and dashed lines on maps represent approximate border lines for which there may not yet be full agreement.

The mention of specific companies or of certain manufacturers' products does not imply that they are endorsed or recommended by the World Health Organization in preference to others of a similar nature that are not mentioned. Errors and omissions excepted, the names of proprietary products are distinguished by initial capital letters.

All reasonable precautions have been taken by the World Health Organization to verify the information contained in this publication. However, the published material is being distributed without warranty of any kind, either expressed or implied. The responsibility for the interpretation and use of the material lies with the reader. In no event shall the World Health Organization be liable for damages arising from its use.

Editing: Inis Communication (www.iniscommunication.com).

Design and layout by: atelier5b, Geneva, Switzerland .

Printed by the WHO Document Production Services, Geneva, Switzerland.

Cover photo: $\odot$ Joonas Virtanen 


\section{Ambient air pollution: A global assessment of exposure and burden of disease}




\title{
Content
}

\author{
List of tables 7 \\ List of figures 7 \\ List of annexes $\mathbf{9}$ \\ Preface 11 \\ Abbreviations 13 \\ Summary 15 \\ 1. Introduction 19 \\ 2. Exposure to ambient air pollution 23
}

2.1. Exposure: ground measurements of $P M_{10}$ and $P M_{2.5} \mathbf{2 3}$

2.1.1. Methods $\mathbf{2 3}$

2.1.2. Results 25

2.1.3. Discussion $\mathbf{3 1}$

2.2 Exposure: modelled estimates of $P M_{2.5} 32$

2.2.1. Methods $\mathbf{3 2}$

2.2.2. Results $\mathbf{3 2}$

2.2.3. Discussion $\mathbf{3 7}$

3. Burden of disease attributable to ambient air pollution $\mathbf{3 9}$

\subsection{Methods 39}

3.1.1. Source of datas $\mathbf{3 9}$

3.1.2. Estimation of the disease burden $\mathbf{3 9}$

3.1.3. Uncertainty analysis $\mathbf{4 0}$

\subsection{Results $\mathbf{4 0}$}

\subsection{Discussion 47}

4. Conclusion and way forward $\mathbf{4 9}$

References $\mathbf{5 1}$

Acknowledgment 55

Annex 1. Modelled population exposure to particulate matter $\left(P M_{2.5}\right)$, by country $\mathbf{5 7}$

Annex 2. Deaths, YLL's and DALY'S Attributable to Ambient Air Pollution, by country 63 

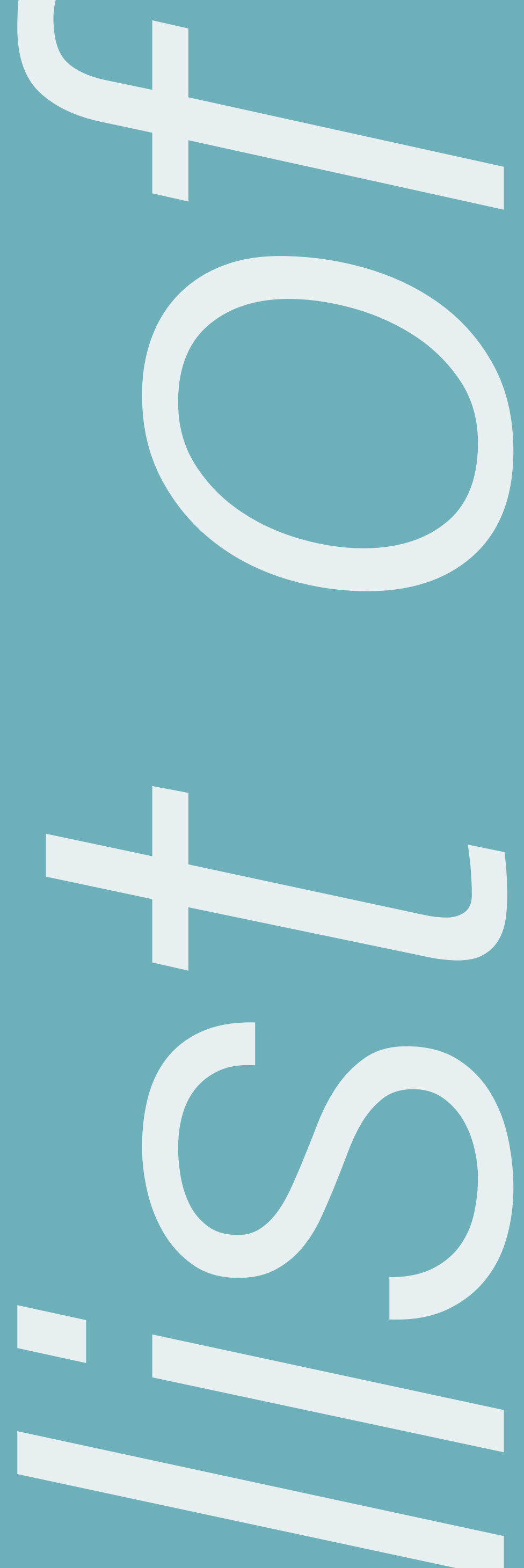


\section{List of tables}

Table 1: $\quad$ Ambient air pollution database : Proportion of settlements by population size

Table 2: $\quad$ Total number of towns and cities in AAP database, 2016 version, by region

Table 3: $\quad$ Number of cities included for the $\mathrm{PM}_{2.5}$ and $\mathrm{PM}_{10}$ comparison over a five-year period (mostly 2008-2013), by region

Table 4: $\quad$ Trend for the five-year period (mostly 2008-2013) in $\mathrm{PM}_{2.5}$ or $\mathrm{PM}_{10}$ based on cities available in several versions of the database, by region

Table 5: $\quad$ Deaths attributable to AAP in 2012, by disease, age and sex

Table 6: Disability-adjusted life years (DALYs) attributable to AAP in 2012, by disease, age and sex

Table 7: $\quad$ Population attributable fraction for disability-adjusted life years attributable to AAP in 2012, by disease, age, sex and region

Table A1: Annual median concentration of particulate matter of an aerodynamic diameter of $2.5 \mu \mathrm{m}$ or less $\left(\mathrm{PM}_{2.5}\right)$ with lower and upper bound, population-weighted and modelled, by area and country

Table A2.1: Deaths attributable to AAP in 2012 in both sex, by disease and country

Table A2.2: Deaths attributable to AAP in 2012 in women, by disease and country

Table A2.3: Deaths attributable to AAP in 2012 in men, by disease and country

Table A2.4: Years of life lost (YLLs) attributable to AAP in 2012 in both sex, by disease and country

Table A2.5: Years of life lost (YLLs) attributable to AAP in 2012 in women, by disease and country

Table A2.6: Years of life lost (YLLs) attributable to AAP in 2012 in men, by disease and country

Table A2.7: Disability-adjusted life years (DALY) attributable to AAP in 2012 in both sex, by disease and country

Table A2.8: Disability-adjusted life years (DALY) attributable to AAP in 2012 in women, by disease and country

Table A2.9: Disability-adjusted life years (DALY) attributable to AAP in 2012 in men, by disease and country

\section{List of figures}

Figure 1: $\quad$ Number of towns and cities with accessible $\mathrm{PM}_{10}$ and $\mathrm{PM}_{2.5}$ data in 2016 per urban population

Figure 2: $\quad$ Location of the monitoring stations and $\mathrm{PM}_{2.5}$ concentration in nearly 3000 human settlements, 2008-2015 
Figure 3: $\quad \mathrm{PM}_{10}$ levels by region and city size, for available cities and towns latest year in the period 2008-2015

Figure 4: $\quad \mathrm{PM}_{10}$ levels for selected cities by region, for the last available year in the period 2011-2015

Figure 5: $\quad \mathrm{PM}_{10}$ levels for available mega-cities of more than 14 million habitants for the last available year in the period 2011-2015

Figure 6: Annual mean particulate matter concentration of the assessed towns and cities compared to the WHO Air Quality Guidelines a

Figure 7: $\quad$ Percentage of cities with increasing and decreasing $\mathrm{PM}_{2.5}$ or $\mathrm{PM}_{10}$ annual means over a five-year period (mostly 2008-2013), by region

Figure 8: $\quad$ Percentage of city population experiencing increasing and decreasing $\mathrm{PM}_{25}$ or $\mathrm{PM}_{10}$ annual means over a five-year period (mostly 2008-2013), by region

Figure 9: Global map of modelled annual median concentration of $\mathrm{PM}_{2.5}$, in $\mu \mathrm{g} / \mathrm{m}^{3}$

Figure 10: Annual median exposure to ambient (outdoor) $\mathrm{PM}_{2.5}$ in $\mu \mathrm{g} / \mathrm{m}^{3}$, by region urban and rural population, 2014

Figure 11: Annual median exposure to ambient (outdoor) $\mathrm{PM}_{2.5}$ in $\mu \mathrm{g} / \mathrm{m}^{3}$, by region urban population only, 2014

Figure 12: $\quad$ Median $\mathrm{PM}_{2.5}$ concentration, by geographic region - urban and rural areas combined, 2014

Figure 13: Modelled annual median particulate matter concentration compared to the WHO Air Quality Guidelines (AQG)

Figure 14: Deaths attributable to AAP in 2012, by disease and region

Figure 15: Age-standardized deaths per capita attributable to AAP in 2012, by disease and region

Figure 16: Deaths attributable to AAP in 2012, by country

Figure 17: $\quad$ DALYs attributable to AAP in 2012, by country

Figure 18: Age-standardized deaths per 100000 capita attributable to AAP in 2012, by country

Figure 19: Age-standardized DALYs per 100000 capita attributable to AAP in 2012, by country

Figure 20: Deaths attributable to AAP in 2012, by disease

\section{List of annexes}

Annex 1: $\quad$ Modelled population exposure to particulate matter of $\mathrm{PM}_{2.5}$, by country

Annex 2: Deaths, YLLs and DALYs attributable to ambient air pollution, by country 

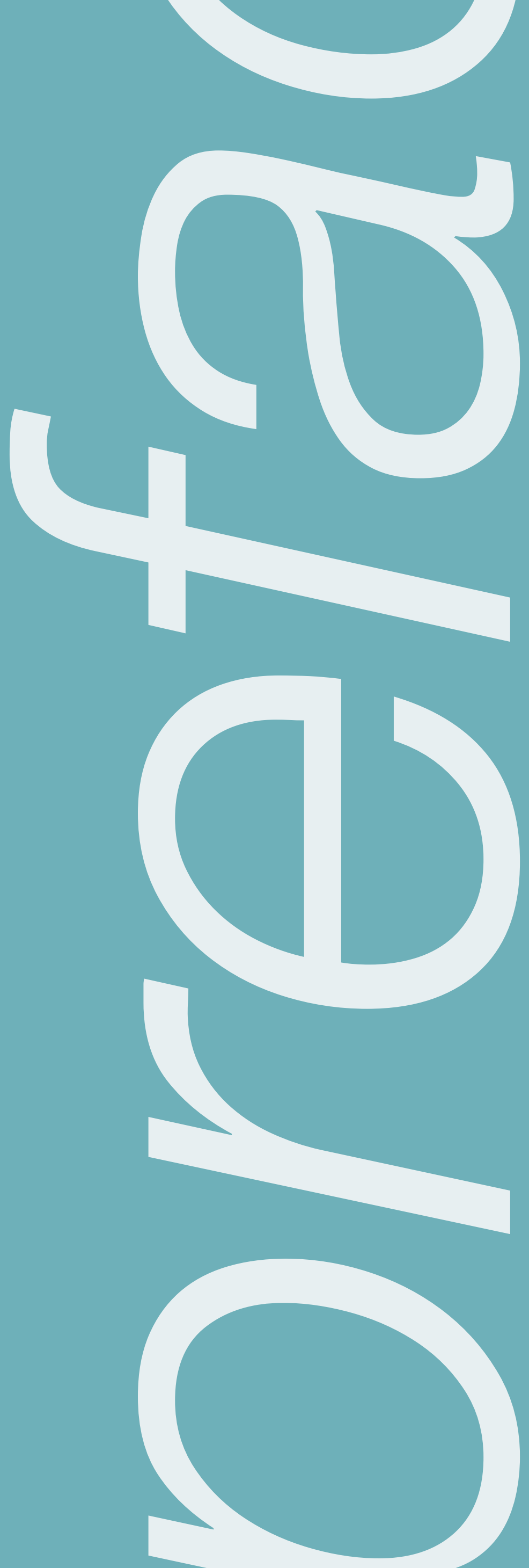
This report presents a summary of methods and results of the latest World Health Organization (WHO) global assessment of ambient air pollution exposure and the resulting burden of disease.

Air pollution has become a growing concern in the past few years, with an increasing number of acute air pollution episodes in many cities worldwide. As a result, data on air quality is becoming increasingly available and the science underlying the related health impacts is also evolving rapidly.

To date, air pollution - both ambient (outdoor) and household (indoor) - is the biggest environmental risk to health, carrying responsibility for about one in every nine deaths annually. Ambient (outdoor) air pollution alone kills around 3 million people each year, mainly from noncommunicable diseases. Only one person in ten lives in a city that complies with the WHO Air quality guidelines. Air pollution continues to rise at an alarming rate, and affects economies and people's quality of life; it is a public health emergency.

Interventions and policies for tackling air pollution issues exist and have been proven to be effective. The implementation of $\mathrm{WHO}$ resolution WHA68.8, which maps out a road map for enhanced global responses to the adverse effects of air pollution, provides an essential framework for decision-makers to choose and implement the most efficient policies.

Air pollution has also been identified as a global health priority in the sustainable development agenda. WHO has responsibility for stewarding three air pollution-related indicators for monitoring progress against the Sustainable Development Goals (SDGs) : in health (Goal 3), in cities (Goal 11) and in energy (Goal 7).
Air pollution affects practically all countries in the world and all parts of society.

The role of the health sector is crucial, and there is a need to engage with other sectors to maximize the co-benefits of health, climate, environment, social and development. Saving people's lives is the overarching aim to implement policies aiming at tackling air pollution in the health, transport, energy, and urban development sectors.

\section{Dr Maria Neira \\ Director of Public Health, Environmental and Social Determinants of Health}

World Health Organization 


\section{Abbreviations}

\begin{tabular}{|c|c|}
\hline AAP & ambient air pollution \\
\hline AFR & Africa Region \\
\hline ALRI & acute lower respiratory disease \\
\hline AMR & Americas Region \\
\hline AQG & Air quality guidelines \\
\hline BoD & burden of disease \\
\hline COPD & chronic obstructive pulmonary disease \\
\hline DALY & disability-adjusted life year \\
\hline DIMAQ & data integration model for air quality \\
\hline EMR & Eastern Mediterranean Region \\
\hline EUR & European Region \\
\hline GBD & global burden of disease \\
\hline HAP & household air pollution \\
\hline $\mathrm{HIC}$ & high-income countries \\
\hline IER & integrated exposure risk \\
\hline $\mathrm{IHD}$ & ischeamic heart disease \\
\hline LMIC & low-and middle-income countries \\
\hline PAF & population attributable fraction \\
\hline $\mathrm{PM}_{2.5}$ & particulate matter of diameter of less than $2.5 \mu \mathrm{m}$ in $\mu \mathrm{g} / \mathrm{m}^{3}$ \\
\hline $\mathrm{PM}_{10}$ & particulate matter of diameter of less than $10 \mu \mathrm{m}$ in $\mu \mathrm{g} / \mathrm{m}^{3}$ \\
\hline $\mathrm{RR}$ & relative risk \\
\hline SDGs & Sustainable Development Goals \\
\hline SEAR & South East Asia Region \\
\hline UN & United Nations \\
\hline YLD & year lived with disability \\
\hline YLL & year of life lost \\
\hline WHO & World Health Organization \\
\hline WPR & Western Pacific Region \\
\hline
\end{tabular}




\section{Summary}

Air pollution represents the biggest environmental risk to health. In 2012, one out of every nine deaths was the result of air pollution-related conditions. Of those deaths, around 3 million are attributable solely to ambient (outdoor) air pollution. Air pollution affects all regions, settings, socioeconomic groups, and age groups. While all people living in a given area breathe from the same air, there are nevertheless important geographical differences in exposure to air pollution. Citizens in Africa, Asia or the Middle East breathe much higher levels of air pollutants that those in living other parts of the world. Some places have air pollution levels that are several times higher than those considered safe by the World Health Organization (WHO) Air quality guidelines.

Air pollution is used as a marker of sustainable development, as sources of air pollution also produce climate-modifying pollutants (e.g. $\mathrm{CO}_{2}$ or black carbon). Policies to address air pollution also generate a range of benefits to human health, not only through air quality improvements but also other health benefits, such as injury prevention or enabling physical activity.

Consequently, concerns about air pollution are reflected in the Sustainable Development Goals (SDGs): Air pollution levels in cities is cited as an indicator for urban sustainable development (SDG 11); access to clean energy - particularly clean household fuels and technologies - is highlighted as an indicator for sustainable energy (SDG 7); and mortality due to air pollution (ambient and household) is used an indicator for the health SDG goal (SDG 3). Reliable estimates of exposure to and impacts from air pollutants are key to better inform policy-makers, as well as development partners. These figures are necessary to track progress in air quality improvements and to help evaluate the effectiveness of policies aiming at reducing air pollution, as well as assessment of how much they are contributing to protect health.
In 2015, to respond to this major global public health threat, the 194 WHO Member States adopted the first World Health Assembly resolution to "address the adverse health effects of air pollution". The following year, Member States agreed on a road map for "an enhanced global response to the adverse health effects of air pollution".

Among the main elements of this road map are the monitoring and reporting of air pollution, and enhanced systems, structures and processes for monitoring and reporting health trends associated with air pollution and its sources.

The current report presents methods and data for two of the SDG indicators reported by $\mathrm{WHO}$ :

- SDG Indicator 11.6.2: Annual mean levels of fine particulate matter $\left(\mathrm{PM}_{2.5}\right)$ in cities (population-weighted); and

- SDG Indicator 3.9.1: Mortality rate attributed to household and ambient air pollution.

This report presents the updated results of mortality and morbidity attributed to ambient air pollution (also known as 'burden of disease due to air pollution'). It includes information on the sources of data on air pollution available to the $\mathrm{WHO}$, on the methodology used to estimate human exposure to air pollution and related burden of disease, as well as the actual estimates of human exposure to particulate matter of a diameter less than 2.5 micrometres $\left(\mathrm{PM}_{2.5}\right)$ for countries and for the globe; and the related national burden of disease attributable to long-term exposure to ambient (outdoor) air pollution for the year 2012.

The global exposure assessment to air pollution consists of modelled data of populationweighted annual mean $\mathrm{PM}_{2.5}$ concentrations. Data are modelled through combining remote satellite sensing data with ground measurements from the 2016 WHO ambient (outdoor) air quality database, which serves for calibration of the satellite data. 
This database compiles information on $\mathrm{PM}_{2.5}$ and $\mathrm{PM}_{10}{ }^{1}$ from measurements for about 3000 cities and towns worldwide. The modelled estimates indicate that in 2014 only about one in ten people breathe clean air, as defined by the WHO Air quality guidelines.

The burden of disease attributed to ambient air pollution was estimated using methodology developed for the Comparative Risk Assessment study. This methodology is based on combining estimates of exposure to air pollution and its distribution in the population, with results from epidemiological studies that indicate the additional disease burden from different levels of exposure to air pollution, after adjusting for other risk factors (e.g. tobacco smoke).

The results are refered to by epidemiologists as exposure-risk estimates at each level of exposure. Health outcomes, for which there is enough epidemiological evidence to be included in the analysis, comprise acute lower respiratory, chronic obstructive pulmonary disease, stroke, ischeamic heart disease and lung cancer. Many other diseases have been associated with air pollution, but are not included in this assessment because the evidence was not considered sufficiently robust.

The actual impact of air pollution on health presented here is a conservative figure, as it does not include the separate impacts of health from other air pollutants such as nitrogen oxides (NOx) or ozone $\left(\mathrm{O}_{3}\right)$, and excludes health impacts where evidence is still limited (e.g. pre-term birth or low birth weight).

Through this combined approach, the current report summarizes three sets of data and the interrelationship between them: 1) The compilation of the $\mathrm{PM}_{2.5}$ and $\mathrm{PM}_{10}$ measurements data in the 2016 WHO ambient (outdoor) air quality database; 2) the modelled estimates of $\mathrm{PM}_{2.5}$; and 3 ) the associated burden of disease.

\footnotetext{
${ }^{1}$ Particulate matter of a diameter less than 25 and 10
} micrometres respectively. 


\section{Introduction}

This document summarizes the methods and the results of the latest $\mathrm{WHO}$ global assessment of air pollution exposure and related burden of disease.

Exposure to air pollutants can affect human health in various ways, leading to increased mortality and morbidity (1). Epidemiological evidence on the health effects of air pollution is growing and evolving quickly. Today, air pollution is the largest environmental risk factor (2).

Reliable estimates of exposure to air pollutants and related impacts on health are key to better inform policy-makers, as well as other health and development partners. Such information is essential to implementing, monitoring and evaluating policies that help to tackle air pollution while also protecting health.

The 194 WHO Member States recently adopted a resolution to respond to the adverse health effects of air pollution (3), as well as a road map for an enhanced global response (4). The road map outlines goals and approaches for monitoring and reporting of air pollution, as well as enhancing systems, structures and processes necessary to support monitoring and reporting on health trends associated with air pollution and its sources.

Air pollution is a clear marker for sustainable development, as sources of air pollution also produce climate pollutants (like $\mathrm{CO}_{2}$ or black carbon).

Policies to address air pollution generate a number of benefits to human health, not only through air quality improvements but also other health benefits, such as injury prevention or enabling physical activity. Adressing air pollution therefore features highly in the global agenda.

In September 2015, the United Nations (UN) General Assembly adopted Transforming our world: The 2030 Agenda for sustainable development, which paves the way for a renewed global commitment to combat the world's most persistent development issues over the next 15 years (5). A framework of indicators for the 17 SDGs and 169 SDG-related targets has been developed, and includes three air pollution-related indicators, which fall under WHO's reporting responsibility:

- SDG Indicator 3.9.1: Mortality rate attributed to household and ambient air pollution for the health goal (SDG 3).

- SDG Indicator 11.6.2: Annual mean levels of fine particulate matter $\left(\mathrm{PM}_{2.5}\right)$ in cities (population-weighted) for the urban sustainable development goal (SDG 11).

- SDG Indicator 7.1.2: Proportion of population with primary reliance on clean fuels and technologies for the sustainable energy goal (SDG 3).

Reporting for Indicators 3.9.1 and 11.6.2 are based on the methods and results presented in the current document, while the methods for estimating SDG Indicator 7.1.2. are presented elsewhere (6).

While a number of air pollutants are associated with significant excess mortality or morbidity, including NOx, ozone, carbon monoxide and sulfur dioxides in particular, $\mathrm{PM}_{2.5}$ is the air pollutant that has been most closely studied and is most commonly used as proxy indicator of exposure to air pollution more generally (1).

Particulate matter consists of a complex mixture of solid and liquid particles of organic and inorganic substances suspended in the air. The major components of PM are sulphates, nitrates, ammonia, sodium chloride, black carbon, mineral dust and water. The most health-damaging particles are those with a diameter of $10 \mu \mathrm{m}$ or less, which can penetrate and lodge deep inside the lungs. Both short- and long-term exposure to air pollutants have been associated with health impacts. 
Small particle pollution has health impacts even at very low concentrations - indeed no threshold has been identified below which no damage to health is observed. Therefore, the WHO Air quality guidelines (AQGs) recommend aiming for, and achieving, the lowest concentrations of PM possible (1). The guideline values are:

$\begin{array}{ll}P M_{2.5} & P M_{10} \\ 10 \mu \mathrm{g} / \mathrm{m}^{3} \text { annual mean } & 20 \mu / \mathrm{m}^{3} \text { annual mean } \\ 25 \mu \mathrm{g} / \mathrm{m}^{3} \text { 24-hour mean } & 50 \mu \mathrm{g} / \mathrm{m}^{3} \text { 24-hour mean }\end{array}$

Reflecting the rising number of air pollution episodes in cities worldwide - and the resulting increased awareness about its impacts on health - $\mathrm{PM}_{2.5}$ is increasingly measured and monitored by national air quality monitoring networks. WHO has been compiling annual mean concentrations for $\mathrm{PM}_{2.5}$ and $\mathrm{PM}_{10}$ in cities since $2011(7,8)$.

A summary of a recent update of the $\mathrm{WHO}$ ambient (outdoor) air quality database (9) containing average annual estimates for $\mathrm{PM}_{2.5}$ exposure globally, by region and for 3000 specific human settlements is presented as part of this report.

The present work on global exposure modelling further develops recent innovations in global exposure estimates for $\mathrm{PM}_{2.5}(10,11)$, as used to model global burden of disease attributable to ambient air pollution (2, 12-14).

It was also presented and reviewed at the Global Platform on Air Quality and Health, initiatied by WHO and other partners in 2014 (15).

Academic researchers, scientists and international organizations have combined efforts to harmonize in developing comprehensive and reliable models of population exposure to $\mathrm{PM}_{2.5}$, which can be used for health impact estimation.
Coverage of the entire exposure range for longterm exposure to $\mathrm{PM}_{2.5}$ has been achieved through the development of the integrated exposure risk (IER) functions (16) that have been developed for the Global Burden of Disease Study (17).

This allows for the integration of available relative risks information from studies of ambient air pollution, household air pollution, second-hand smoke and active smoking. The IERs have been used to derive estimates for both householdand ambient air pollution-attributable burden of disease for the GBD Project $(12,14,18)$ and by the $\mathrm{WHO}(2,6)$.

They currently cover cause-specific mortality such as acute lower respiratory in children under five years of age, and chronic obstructive pulmonary disease (COPD), ischeaemic heart disease (IHD), stroke and lung cancers in adults.

Other health outcomes have been associated with long-term exposure to particulate matter, such as adverse birth outcomes, childhood respiratory disease, diabetes, atherosclerosis, and neurodevelopment and cognitive function, but are not considered here (19).

The current report presents the latest national mortality and morbidity estimates attributable to ambient air pollution. 



\section{Exposure to ambient air pollution}

\subsection{Exposure: ground measurements of $P M_{10}$ and $P M_{2.5}$}

\subsubsection{Methods}

\section{Description of methods}

The database compiles ground measurements of annual mean concentrations of particulate matter of a diameter of less than $10 \mu \mathrm{m}\left(\mathrm{PM}_{10}\right)$ or $2.5 \mu \mathrm{m}\left(\mathrm{PM}_{2.5}\right)$ and aims to compile an average for each city/town. Years of measurements range from 2010 to 2015 , unless the latest available data precede these times, in which case the most recent was used.

\section{Scope of data}

The database covers 3000 human settlements ranging in size from a few hundred to more than 10 million inhabitants. Most of these are urban areas of 20000 inhabitants or more - hence reference to an "urban air quality data base". However, about $25 \%$ of settlements in the database are smaller areas of up to 20000 residents, and a limited proportion (mostly in Europe) are settlements of only a few hundred to a few thousand inhabitants - although these may also be located in proximity to larger urban agglomerations (see Table 1).

Table 1. Ambient air pollution database: Proportion of settlements by population size

\begin{tabular}{ll}
$\begin{array}{l}\text { Percentages } \\
\text { of observations }\end{array}$ & Settlement size \\
\hline $1 \%$ & 0 \\
$5 \%$ & 1240 \\
$10 \%$ & 4173 \\
$25 \%$ & 20000 \\
$41 \%$ & 50000 \\
$50 \%$ & 80756 \\
$75 \%$ & 314719 \\
$90 \%$ & 1150153 \\
$95 \%$ & 2313328 \\
$99 \%$ & 8741365 \\
\hline Mean settlement size & 543664 \\
\hline Number of settlements & 2977
\end{tabular}

\section{Data sources}

Primary sources of data include official reporting from countries to $\mathrm{WHO}$, official national/ sub-national reports and national/sub-national web sites containing measurements of $\mathrm{PM}_{10}$ or $\mathrm{PM}_{2.5}$. Furthermore, measurements reported by the following regional networks were used: Clean Air Asia for Asia (20), and the Air quality e-reporting database (21) from the European Environment Agency for Europe. In the absence of the above-mentioned data, data from UN agencies, development agencies, articles from peer reviewed journals and ground measurements compiled in the framework of the Global Burden of Disease Project (17) were used. ${ }^{2}$

The data was compiled between September-November 2015 from the above-mentioned sources/partners, or from web searches when not availbable. The web search strategy included the following approaches:

1. Screening of the web sites of respective ministries of environment, health, and statistics offices.

2. Web searches with the terms "air quality", «air pollution», «suspended particles», «monitoring », « $\mathrm{PM}_{10} », \ll \mathrm{PM}_{2.5} »$.

Language variations used included English, French, Spanish, Portuguese, Italian, and German.

\section{Type of data used}

The database incorporated annual mean concentrations of particulate matter $\left(\mathrm{PM}_{10}\right.$ or $\mathrm{PM}_{2.5}$ ) based on daily measurements, or other data that could be aggregated into annual mean values. In the absence of annual means, measurements covering a more limited period of the year were exceptionally used and extrapolated.

${ }^{2}$ For the full list of references, please refer to the online version of the WHO database (9). 
In order to derive air quality that is largely representative of human exposure in urban contexts, mainly data from urban background readings, residential areas, and commercial (or mixed) area measurements were used. Air quality stations characterized as covering particular 'hot spots' or exclusively industrial areas were not included, unless they were contained in reported city means and could not be disaggregated.

This selection is in accordance with the aim of capturing representative values for average human exposure. In contrast, measurements from hot spots and industrial areas are often captured for the purpose of identifying the highest exposure areas, and were deemed to be less representative of mean exposures for most of the urban population. Hot spots were either designated as such by the original reports, or were qualified as such due to their exceptional nature (e.g. exceptionally busy roads etc.). Omitting these, may, however, have led to an underestimation of the mean air pollution levels of a given city.

Where the data from various sources were available, only the latest data and most reliable sources were used. Only data measured since 2008 were included in the database.

It was not always possible to retrieve or use all publicly available data of interest. Reasons included language barriers, or incomplete information on data or data quality (e.g. missing year of reference). Data were used as presented in original sources. The indicated numbers of monitors do not necessarily correspond to the total number of existing or operational stations in the cities, but to the numbers of stations used for deriving the indicated city data.

\section{Data processing and reporting}

Where available, urban means reported by the original sources are included in the database. Where no urban means were available, the eligible city data were averaged using appropriate denominators.
Population data - used for weighting and for estimating the share of urban population covered - were either based on: UN population statistics when available for all human settlements covered (22), or census data from national statistical offices (23).

For completeness, cities with only $\mathrm{PM}_{10}$ (or resp. $\mathrm{PM}_{2.5}$ ) reported, $\mathrm{PM}_{2.5}$ (or $\mathrm{PM}_{10}$ ) concentration was calculated from $\mathrm{PM}_{10}$ (resp. $\mathrm{PM}_{2.5}$ ) using national conversion factors $\left(\mathrm{PM}_{2.5} / \mathrm{PM}_{10}\right.$ ratio) either provided by the country or estimated as population-weighted averages of urban-specific conversion factors for the country. Urbanspecific conversion factors were estimated as the mean ratio of $\mathrm{PM}_{2.5}$ to $\mathrm{PM}_{10}$ of stations for the same year. If national conversion factors were not available, regional ones were used, which were obtained by averaging country-specific conversion factors.

As exposure to $\mathrm{PM}_{2.5}$ serves as indicator for burden of disease calculation, $\mathrm{PM}_{2.5}$ data were converted from $\mathrm{PM}_{10}$ in the absence of their measurement because they were used to calibrate the model described below.

As the conversion factor $\mathrm{PM}_{2.5} / \mathrm{PM}_{10}$ may vary according to location (generally between 0.4 and 0.8 ), the converted $P M_{10}$ value for individual settlements may deviate from the actual value, and should only be considered as approximations.

The temporal coverage represents the number of days per year covered by measurements, or any alternative qualification (as provided in the original sources). If data from several monitoring stations in one city or town were available, their average temporal coverage was used for the overall average. Information on temporal coverage was not always available; however reporting agencies often respect a specific reporting threshold for the number of days covered before reporting on a given measurement value, or using it for estimating the city annual mean. 


\subsubsection{Results}

\section{Data availability}

The 2016 version of the WHO ambient (outdoor) air quality database consists mainly of urban air quality data - annual means for $\mathrm{PM}_{10}$ and/or $\mathrm{PM}_{25}$ - covering about 3000 human settlements in 103 countries, for the years 2008-2015 (9). The regional distribution and the number of settlements, and corresponding accessible data are described in Table 2 and Figure 1, respectively.

Table 2: Total number of towns and cities in AAP database, 2016 version, by region

\begin{tabular}{l|ccc} 
Region & $\begin{array}{c}\text { Number } \\
\text { of towns/cities }\end{array}$ & $\begin{array}{c}\text { Number of countries } \\
\text { with data }\end{array}$ & $\begin{array}{c}\text { Total number of } \\
\text { countries in region }\end{array}$ \\
\hline Africa (Sub-Saharan) (LMIC) & 39 & 10 & 47 \\
Americas (LMIC) & 102 & 13 & 24 \\
Americas (HIC) & 524 & 6 & 11 \\
Eastern Mediterranean (LMIC) & 53 & 8 & 15 \\
Eastern Mediterranean (HIC) & 31 & 6 & 6 \\
Europe (LMIC) & 165 & 9 & 19 \\
Europe (HIC) & 1549 & 33 & 34 \\
South-East Asia (LMIC) & 175 & 9 & 11 \\
Western Pacific (LMIC) & 225 & 4 & 21 \\
Western Pacific (HIC) & 109 & 5 & 6 \\
\hline Global & 2972 & 103 & 194
\end{tabular}

AAP: Ambient air pollution database; LMIC: Low-and middle-income countries; HIC: high-income countries.

Figure 1: Number of towns and cities with accessible $\mathrm{PM}_{10}$ and $\mathrm{PM}_{2.5}$ data in 2016 per urban population.

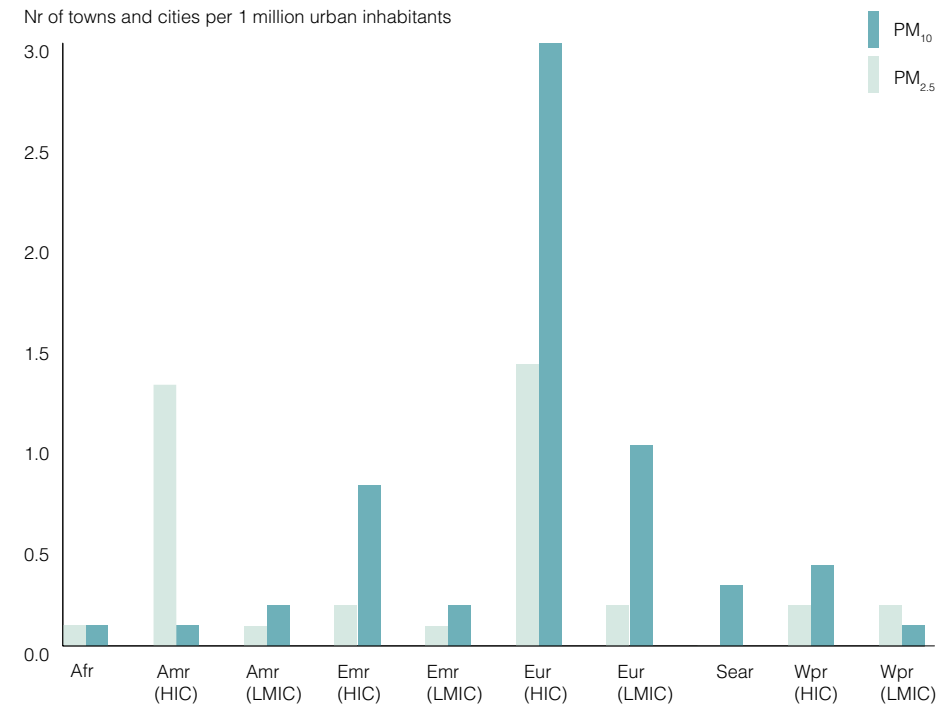

$\mathrm{PM}_{10} / 2.5$ : Fine particulate matter of 10/2.5 microns or less; Afr: Africa; Amr: Americas; Emr: Eastern Mediterranean; Eur: Europe; Sear: South-East Asia; Wpr: Western Pacific; LMIC: low- and middle-income countries; HIC: high-income countries. 
$\mathrm{PM}_{25}$ measurements can be directly linked to estimates of health risks, and are therefore of particular interest. In high-income countries, $\mathrm{PM}_{2.5}$ measurements are conducted widely. In low- and middle-income countries (LMICs), $\mathrm{PM}_{2.5}$ measures are not readily available in many countries but there have been large improvements since in the past three years.

Annual mean $\mathrm{PM}_{2.5}$ measurements were available for 339 cities, or almost five times more than in the 2014 version of the database.

Annual mean $\mathrm{PM}_{10}$ measurements could be accessed in as many as 586 cities in LMICs.
In high-income countries (HIC), 1241 cities and towns with $\mathrm{PM}_{2.5}$ measures could be accessed, compared to 1639 cities and towns with $\mathrm{PM}_{10}$ measurements.

The 3000 cities and towns currently covered by the $\mathrm{WHO}$ database represent about 1.6 billion people, or $43 \%$ of the global urban population.

Ground measurements of annual mean concentration of $\mathrm{PM}_{2.5}$ for the 3000 towns and cities is shown in Figure 2.

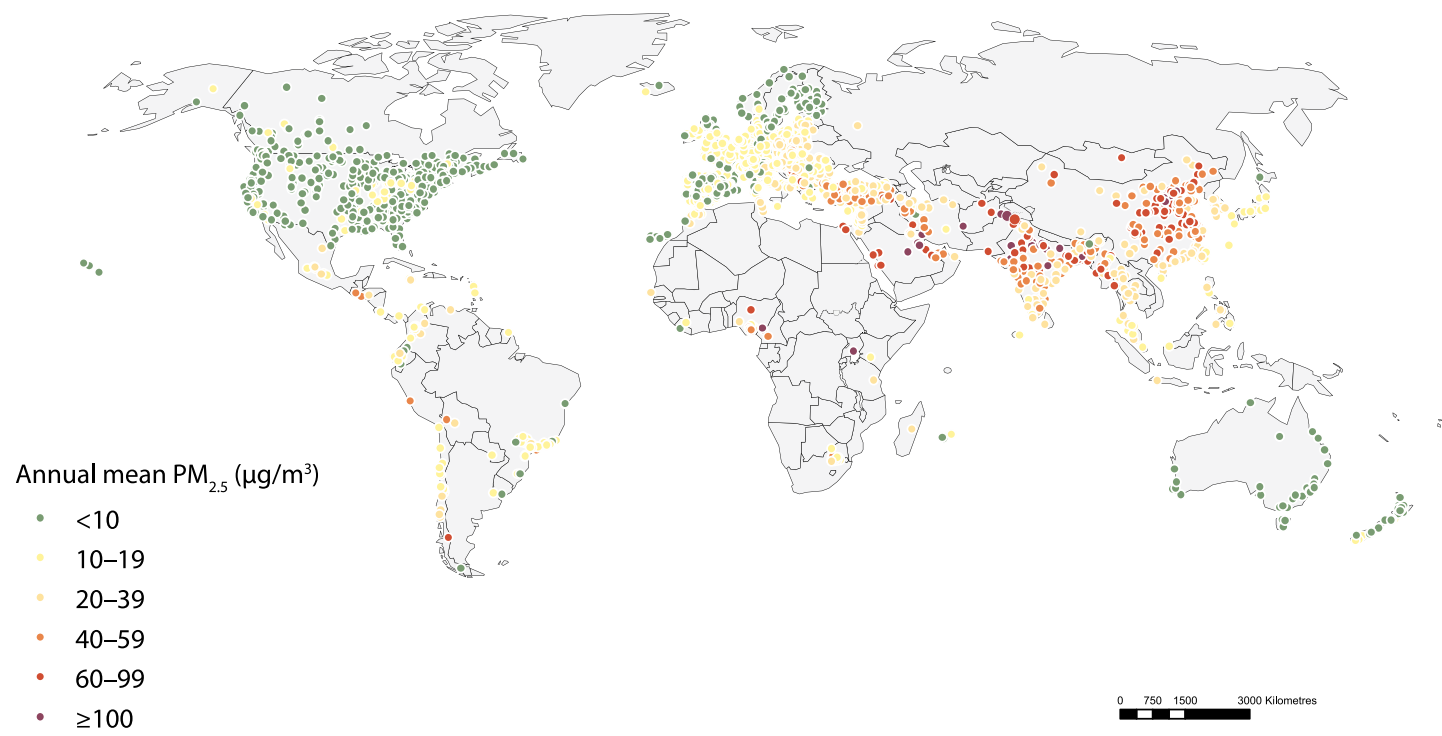

$\mathrm{PM}_{2.5}$ : Fine particulate matter of 2.5 microns or less. 


\section{Data summary}

An overview of $\mathrm{PM}_{10}$ levels for the $\mathrm{WHO}$ regions and selected cities is presented in Figures 3, 4 and 5.

Figure 3: $\mathrm{PM}_{10}$ levels by region and city size, for available cities and towns latest year in the period 2008-2015

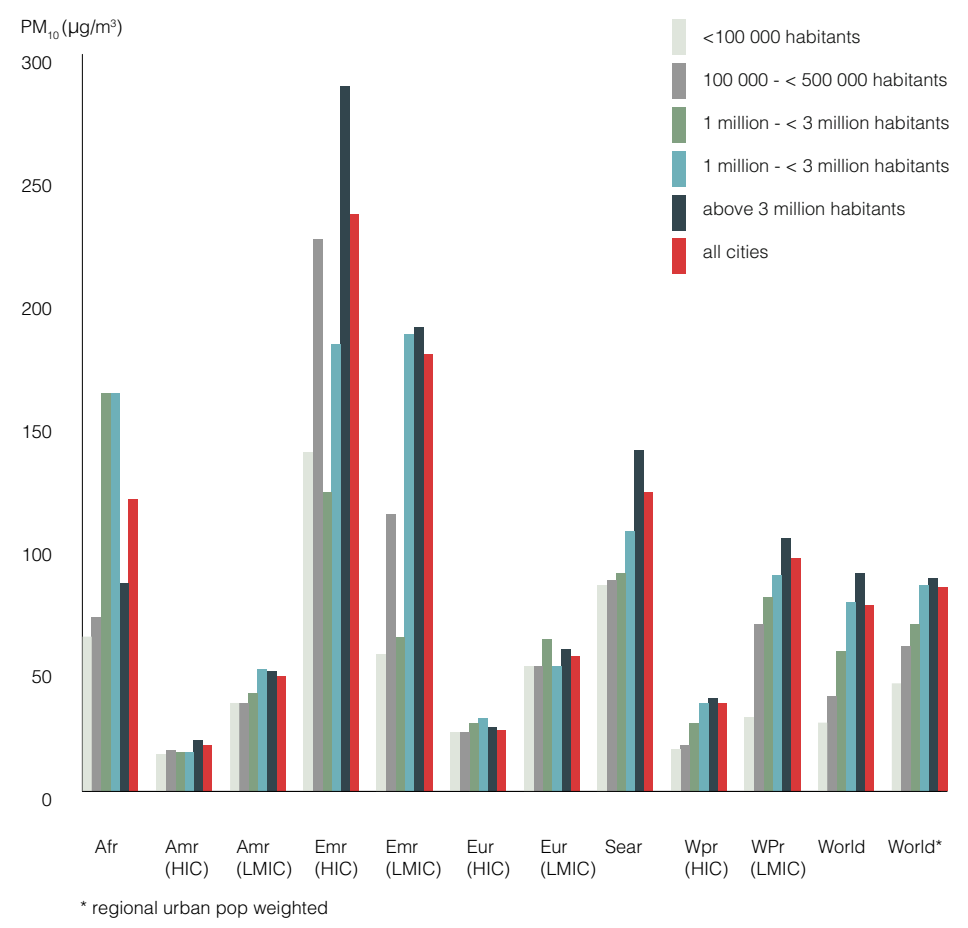

$\mathrm{PM}_{10}$ : Particulate matter of 10 microns or less; Afr: Africa; Amr: Americas; Emr: Eastern Mediterranean; Eur: Europe; Sear: South-East Asia; Wpr: Western Pacific; LMIC: low- and middle-income countries; HIC: high-income countries. PM ${ }_{10}$ values for the world are regional urban population-weighted.

Figure 4: $\mathrm{PM}_{10}$ levels for selected ${ }^{3}$ cities by region, for the last available year in the period 2011-2015

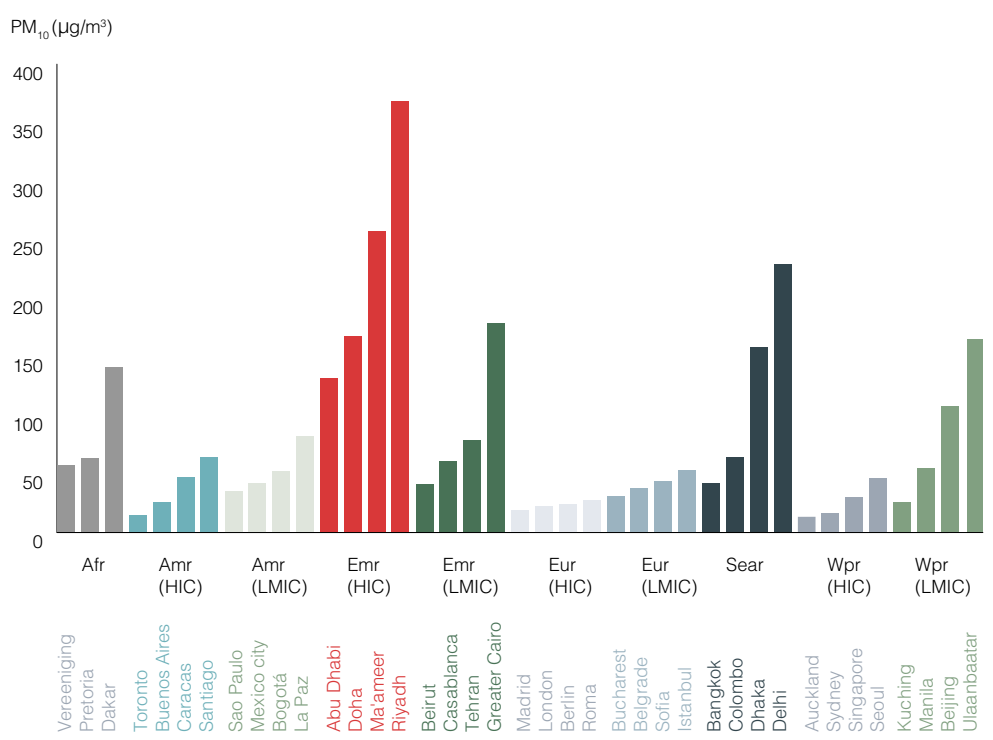

$\mathrm{PM}_{10}$ : Particulate matter of 10 microns or less; Afr: Africa; Amr: Americas; Emr: Eastern Mediterranean; Eur: Europe; Sear: South-East Asia; Wpr: Western Pacific; LMIC: low- and middle-income countries; HIC: high-income countries.

${ }^{3}$ Selection criteria: For year of measurement (2011 or more recent), the largest city or capital for each country within a region (or two cities for one country if only two countries available in the region. City size ranges from 140000 to 26 million habitants. 


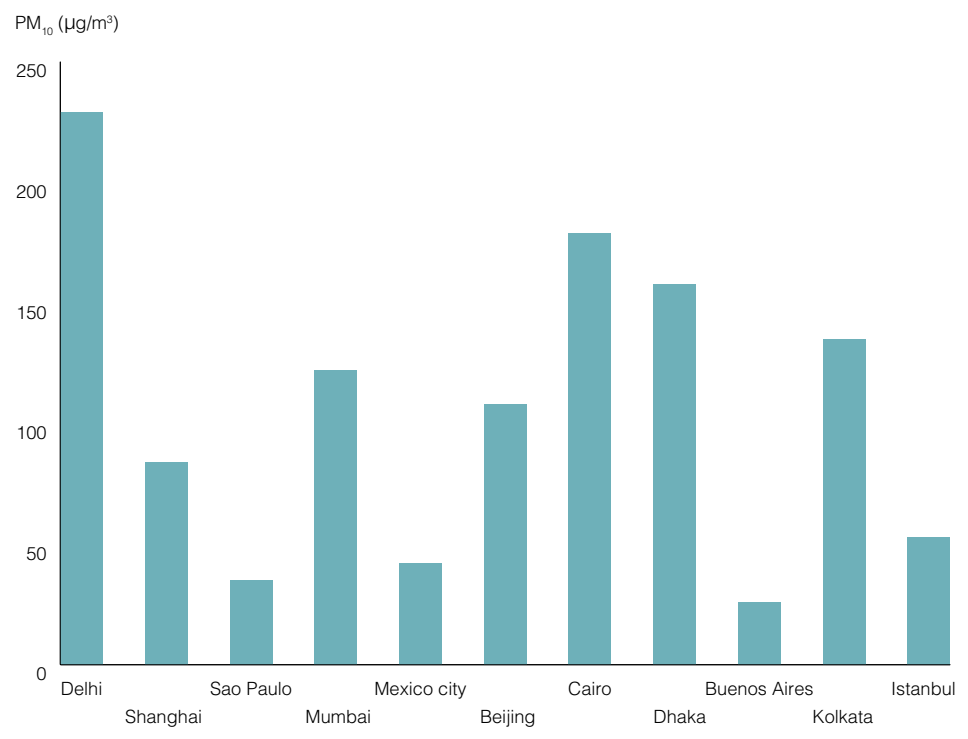

$\mathrm{PM}_{10}$ : Particulate matter of 10 microns or less.

\section{Compliance with Air Quality Guidelines}

Figure 6 shows the regional percentages of the assessed towns and cities with PM measurements experiencing $\mathrm{PM}_{10}$ or $\mathrm{PM}_{2.5}$ air pollution levels that meet or exceed the WHO Air Quality Guidelines (AQG) (i.e. annual mean values of $20 \mu \mathrm{g} / \mathrm{m}^{3}$ (for $\mathrm{PM}_{10}$ ) and $10 \mu \mathrm{g} / \mathrm{m}^{3}$ (for $\mathrm{PM}_{2.5}$ )). ${ }^{4}$ Globally, according to the currently available data, only $16 \%$ of the assessed population is exposed to $\mathrm{PM}_{10}$ or $\mathrm{PM}_{2.5}$ annual mean levels complying with AQG levels. This increases to $27 \%$ for the interim target 3 (i.e. IT-3: $30 \mu \mathrm{gg} / \mathrm{m}^{3}$ for $\mathrm{PM}_{10}$ and $15 \mu \mathrm{g} / \mathrm{m}^{3}$ for $\mathrm{PM}_{2.5}$ ) of the AQG, $46 \%$ for interim target 2 (i.e. IT-2: $50 \mu \mathrm{g} / \mathrm{m}^{3}$ for $\mathrm{PM}_{10}$ and $25 \mu \mathrm{g} / \mathrm{m}^{3}$ for $\mathrm{PM}_{2.5}$ ), and $56 \%$ for interim target 1 (IT-1: $70 \mu \mathrm{g} / \mathrm{m}^{3}$ for $\mathrm{PM}_{10}$ and $35 \mu \mathrm{g} / \mathrm{m}^{3}$ for $\mathrm{PM}_{2.5}$ ).

Figure 6: Annual mean particulate matter concentration of the assessed towns and cities, compared to the WHO Air Quality Guidelines ${ }^{a}$

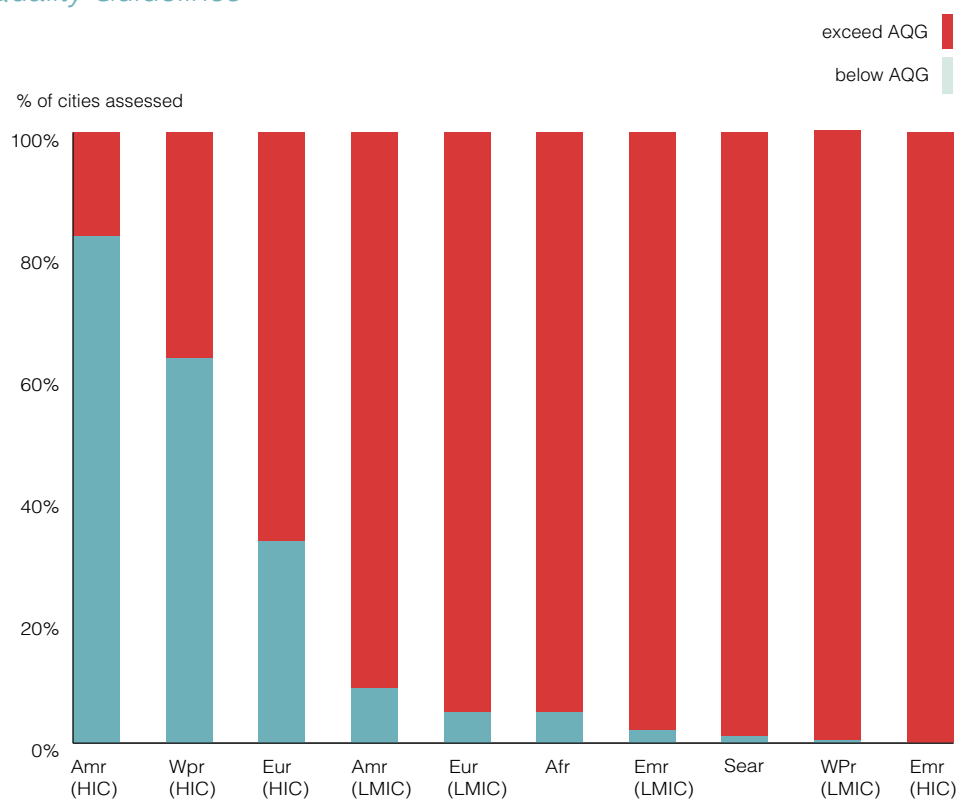

Afr: Africa; Amr: Americas; Emr: Eastern Mediterranean; Eur: Europe; Sear: South-East Asia; Wpr: Western Pacific; LMIC low- and middle-income countries; HIC: high-income countries; AQG: WHO Air Quality Guidelines.

${ }^{a}$ Annual mean $\mathrm{PM}_{10}: 20 \mu \mathrm{g} / \mathrm{m}^{3}$; Annual mean $\mathrm{PM}_{2.5}: 10 \mu \mathrm{g} / \mathrm{m}^{3}$.

${ }^{4}$ For town and cities with both $P M_{10}$ and $P M_{2.5}$ values, $P M_{2.5}$ were used. 


\section{Comparison of urban air pollution levels in recent years}

A total of 792 towns and cities in 67 countries were selected for a more refined comparison of $\mathrm{PM}_{2.5}$ (where available), or $\mathrm{PM}_{10}$ values over a period of five or more years (Table 3). The selection was made according to the following criteria: These cities/towns have either measured PM.2.5 or PM10 values in the three databases, and cover a period of three years or more; or these towns/cities are represented in the data that was collected in 2011, 2014 or 2016 and cover a period of four years or more. The 2011 version of the database contains data for 2010 or earlier and the 2014 version for 2012 or earlier. To compare levels of air pollution for the equivalent of a five-year period (mostly 2008-2013) for cities included in such a selection, a linear regression was made. Table 4 presents a regional summary by WHO region and income groups. Globally, annual PM levels are estimated to have increased by $8 \%$ during the recent five-year period in the assessed cities. (The cited global increase is weighted by the regional urban population)

Table 3: Number of cities included for the $\mathrm{PM}_{2.5}$ and $\mathrm{PM}_{10}$ comparison over a five-year period (mostly 2008-2013), by region

\begin{tabular}{lcc} 
Region & Number of town and cities & Number of countries \\
\hline Africa (Sub-Saharan) & 2 & 2 \\
America (LMIC) & 13 & 7 \\
America (HIC) & 343 & 6 \\
Eastern Mediterranean (LMIC) & 16 & 6 \\
Eastern Mediterranean (HIC) & 6 & 2 \\
Europe (LMIC) & 32 & 5 \\
Europe (HIC) & 277 & 30 \\
South-East Asia & 53 & 5 \\
Western Pacific (LMIC) & 33 & 2 \\
Western Pacific (HIC) & 21 & 3 \\
\hline Global & 796 & 68
\end{tabular}

LMIC: Low- and middle-income countries; HIC: High-income countries. Regions with less than five cities were not included in the analysis, due to poor representatation.

Figure 7 shows the percentage of towns and cities with decreasing levels of annual mean $\mathrm{PM}_{2.5}$ or $\mathrm{PM}_{10}$ (in green), increasing levels (in light orange), and levels with changes of $\leq 10 \%$ over a five-year period (in blue), by region. The variation in population living in cities with increasing or decreasing population levels is represented in Figure 8.

Table 4 : Trend for the five-year period (mostly 2008-2013) in $\mathrm{PM}_{2.5}$ or $\mathrm{PM}_{10}$ based on cities available in several versions of the database, by region ${ }^{1}$

\begin{tabular}{lr} 
Region & Trend over the mean period 2008-2013² \\
\hline Africa (Sub-Saharan) & $\mathrm{NA}$ \\
America (LMIC) & $\rightarrow$ \\
America (HIC) & $\searrow$ \\
Eastern Mediterranean (LMIC) & $\nearrow$ \\
Eastern Mediterranean (HIC) & $\nearrow$ \\
Europe (LMIC) & $\searrow$ \\
Europe (HIC) & $\nearrow$ \\
South-East Asia & $\nearrow$ \\
Western Pacific (LMIC) & $\searrow$ \\
Western Pacific (HIC) & $\nearrow$ \\
\hline Global ${ }^{3}$ & $\searrow$
\end{tabular}

1 Criteria for inclusion: cities with measured PM2.5 or PM10 values in the three database versions covering a period of three years or more, or in two versions and covering a period of four years or more.

$2 \rightarrow$ No more than $5 \%$ change over the five-year period; $\nearrow:$ More than $5 \%$ decrease over the five-year period; $\searrow:$ More than $5 \%$ increase over the five-year period.

3 Based on weighting by regional urban population. LMIC: Low- and middle-income countries; HIC : high-income countries

NA: not available. Results are based on 795 cities and are to be interpreted with caution, as: a) cities included might not ensure representativeness; a) yearly variations due for example to climatic changes can be important; and c) a five-year comparison does not necessarily represent trends, in particular when changes are limited. 
Figure 7: Percentage of cities ${ }^{1}$ with increasing and decreasing $\mathrm{PM}_{2.5}$ or $\mathrm{PM}_{10}$ annual means over a five-year period (mostly 2008-2013), by region

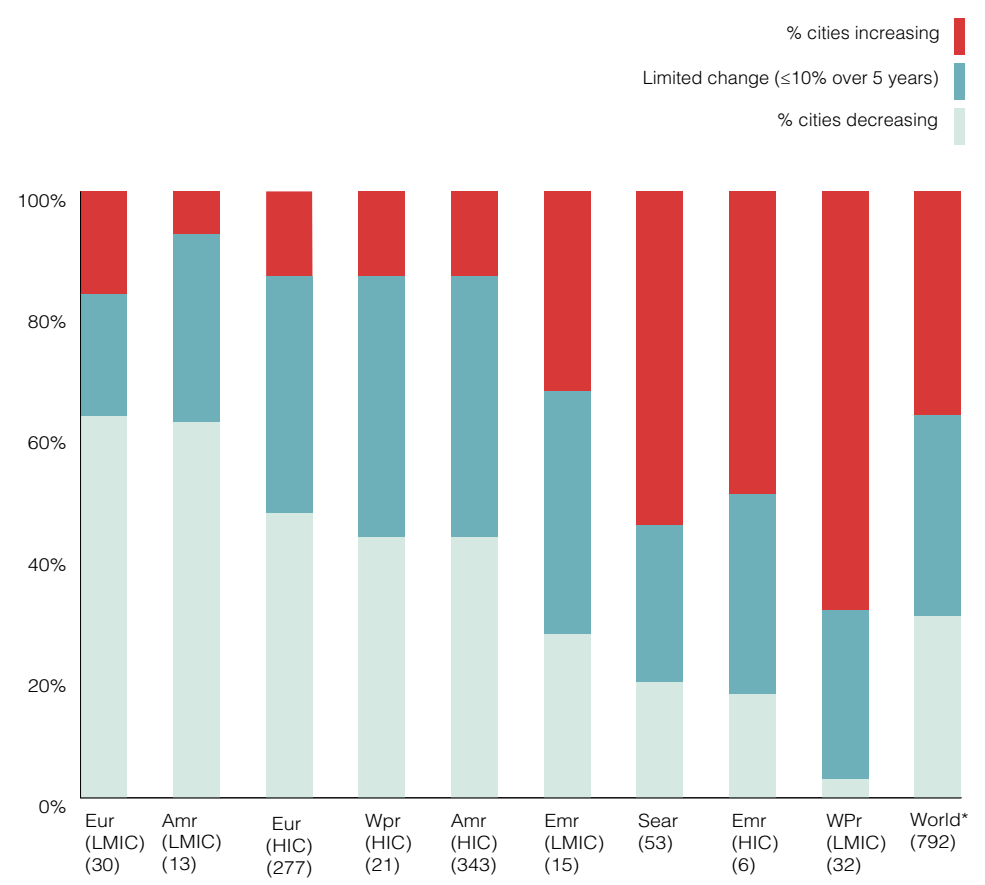

Amr: Americas; Emr: Eastern Mediterranean; Eur: Europe; Sear: South-East Asia, Wpr: Western Pacific; LMIC : Low- and middle-income countries; HIC: high-income countries. ${ }^{1}$ The number of cities is indicated in bracket. ${ }^{*}$ The world figure is regional population-weighted.

Figure 8: Percentage of city population experiencing increasing and decreasing $\mathrm{PM}_{2.5}$ or $\mathrm{PM}_{10}$ annual means over a five-year period (mostly 2008-2013), by region

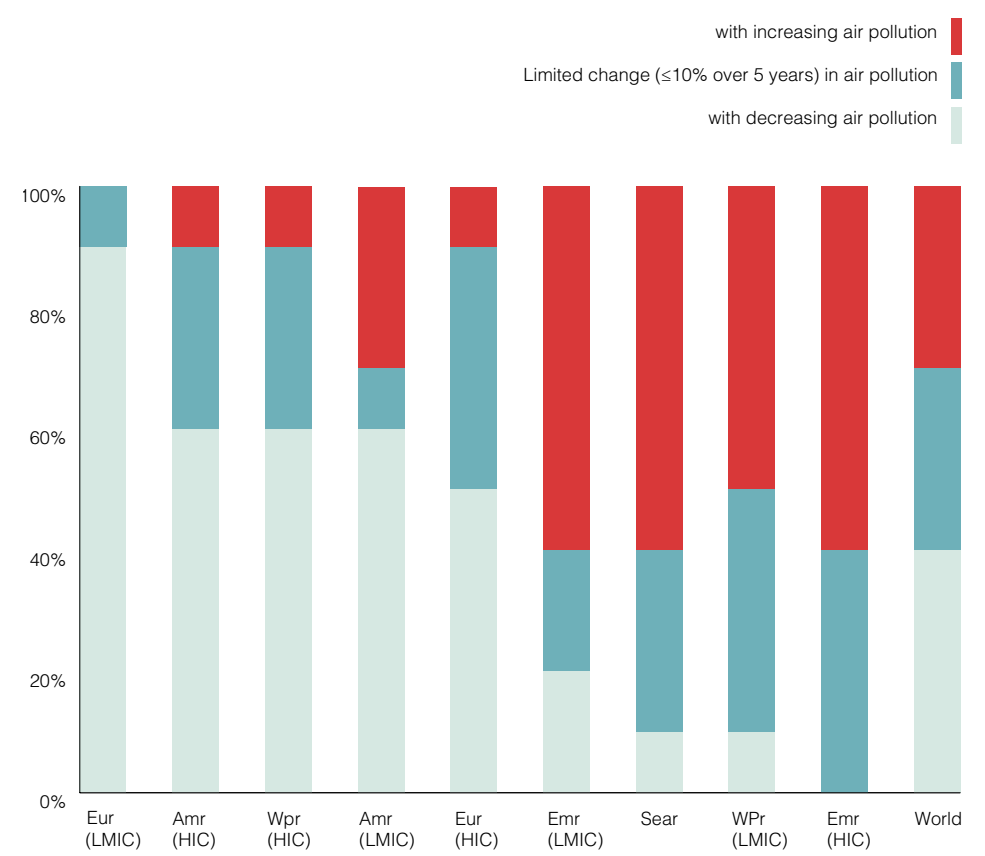

Amr: Americas; Emr : Eastern Mediterranean; Eur: Europe; Sear: South-East Asia, Wpr: Western Pacific; LMIC: Low- and middleincome countries; HIC: high-income countries. 


\subsubsection{Discussion}

The WHO urban ambient air quality database presents data on annual mean concentration of particulate matter (PM) for almost 3000 human settlements, mostly cities, in 103 countries and is the most comprehensive database of its kind to date. The number of cities and towns reporting on PM measurements has nearly doubled since the previous version of the database was published in 2014 (1 600 cities) (8) and nearly tripled since the first 2011 version (1 100 cities) (7), which indicates an increased awareness of the risks posed by air pollution. In the past two years, the number of ground measurements available in high-income countries has doubled, while there has been a $50 \%$ increase in low-and middle-income countries.

Monitoring the air quality is the first, but key, step to be taken by public authorities, both at the national and city levels, to tackle the multisectoral challenge of addressing air pollution. However, there are still huge monitoring and reporting gaps between high-income countries and low- and middle-income counterparts. Most air quality data still comes from Europe and the Americas, with regions such as Africa, South East Asia, and Eastern Mediterranean lagging behind.

The data presented in the latest database reflects a number of important limitations. The ground measurements are of limited comparability because of various reasons: a) Differing locations of measurement stations; b) varying measurement methods; c) different temporal coverage of certain measurements (i.e. if only part of the year was covered, the measurement may significantly deviate from the annual mean due to seasonal variability); d) possible inclusion of data that should not have been eligible for this database due to insufficient information to ensure compliance; e) differences in sizes of urban areas covered (i.e. for certain countries, only measurements for larger cities were found, whereas for others also cities with just a few thousand inhabitants were available); and f) varying quality of measurements.
In addition, some existing data may have been omitted, either because it could not yet be accessed due to language issues or limited accessibility. Finally, the city means presented in the database may differ from the ones calculated by the cities or municipalities themselves because they are averaged from multiple station data.

The comparison of air pollution levels for a given set of cities over the five-year period 2008-2013 shows a global increase of $8 \%$ in annual mean concentrations of $\mathrm{PM}_{2.5}$. High-income regions of the Americas, Europe and Western Pacific demonstrate decreasing air pollution, while the other regions have increasing levels.

However, such a comparison of air pollution levels has a number of limitations. First of all, when $\mathrm{PM}_{2.5}$ measurements were not available, $\mathrm{PM}_{10}$ values (converted into $\mathrm{PM}_{2.5}$ ) were used for the comparison, which may have influenced the results.

Second, the period of comparison is relatively short. Yearly variations may for example be influenced by weather patterns and data within a five-year period may not be sufficient to reflect a longer-term trend. A longer time period of comparison would be required to confirm any trends.

Third, although sampling locations are reasonably stable over time, they may have changed within the period of comparison, and variations in annual mean PM levels for a given city may reflect different sampling locations rather than a genuine trend. As the data collected is used for calibrating the model that derives global $\mathrm{PM}_{2.5}$ estimates, data quality is crucial, as well as location details and the type of monitoring stations: information that is also used in the modeling exercise. Efforts and investments should be made to encourage cities and countries to monitor air quality closely, using standard, good quality and comparable methods and instruments, as well as making this information widely available.

To date, only particulate matter concentrations have been compiled in the database. Additional pollutants - such as nitreous oxide $\left(\mathrm{NO}_{2}\right)$, ozone $\left(\mathrm{O}_{3}\right)$ or others - might be added to the database in the future. 


\subsection{Exposure: modelled estimates of $P M_{2.5}$}

\subsubsection{Methods}

Assessment of the global effects of air pollution requires a comprehensive set of estimates of exposure for all populations. Ground monitoring networks have provided the primary source of this information but, although coverage has increased, there remain regions in which there is no or very little monitoring.

Ground measurement data therefore need to be supplemented with information from other sources, such as estimates from satellite retrievals of aerosol optical depth and chemical transport models. The recently developed Data Integration Model for Air Quality (DIMAQ) incorporates data from multiple sources in order to provide estimates of exposures to $\mathrm{PM}_{2.5}$ at high spatial resolution $\left(0.1^{\circ} \times 0.1^{\circ}\right)$ globally.

Sources of data include: Ground measurements from 6003 monitoring locations around the world $(9,10)$, satellite remote sensing; population estimates; topography; and information on local monitoring networks and measures of specific contributors of air pollution from chemical transport models. The DIMAQ model calibrates data from these sources with ground measurements. The relationships between the various sources of data may be complex and will vary between regions due to differences in the composition of $\mathrm{PM}_{2.5}$, and other factors.

DIMAQ has a hierarchical structure within which calibration equations are produced for individual countries using, as a priority, data from that country where available. Where data within a country is insufficient to produce accurate estimates, it is supplemented with regional information. When calibration equations have been established and tested, the model is used to estimate exposures, together with associated measures of uncertainty across the globe. These high-resolution estimates can be used to produce air quality profiles for individual countries, regions and globally.

A full description of the model development and evaluation is available separately (24).

\subsubsection{Results}

Global exposure to $\mathrm{PM}_{2.5}$ has been modelled for the year 2014 in order to provide a comprehensive global coverage of estimates of air quality. The key parameter is the annual median concentration of $\mathrm{PM}_{2.5}$, which is highly relevant for estimating health impacts. Modelled exposure to ambient $\mathrm{PM}_{2.5}$ levels provides more comprehensive information for countries than measured data, which only provide data for a selection of towns and cities. A comprehensive set of estimated exposures such as this will be required, when estimating the health impacts of ambient air pollution for a given country.

Estimates of exposure are required for all areas, including those that may not be covered by ground monitoring networks. Estimates of air quality, expressed in terms of median concentrations of $\mathrm{PM}_{2.5}$ are now available for all regions of the world, including areas in which $\mathrm{PM}_{2.5}$ monitoring is not available (Figure 9). It can be viewed on an interactive map at www. who. int/phe/health_topics/outdoorair/databases/en. Estimates of exposure, by country, are presented in Table A1 of Annex 1. 
In the majority of regions of the world, annual median concentrations of air pollution are higher than the WHO guideline levels of 10 $\mathrm{\mu g} / \mathrm{m}^{3}$ (Figures 10 and 11). Exposures are particularly high in the Eastern Mediterranean, South-East Asian and Western Pacific Regions. Air pollution does not exclusively originate from human activity, and can be greatly influenced by dust storms, for example, particularly in areas close to deserts. This is partially illustrated in Figure 12, where modelled annual median $\mathrm{PM}_{2.5}$ concentration by area (rural/urban) is presented and where rural areas in the African and Eastern Mediterranean Regions show greater concentrations than urban ones.
Based on the modelled data, $92 \%$ of the world population are exposed to $\mathrm{PM}_{2.5}$ air pollution concentrations tha are above the annual mean WHO AQG levels of $10 \mathrm{\mu g} / \mathrm{m}^{3}$ (Figure 13). With the exception of the region of the Americas, all regions - both $\mathrm{HIC}$ and $\mathrm{LMIC}$ - have less than $20 \%$ of the population living in places in compliance with the WHO AQG.

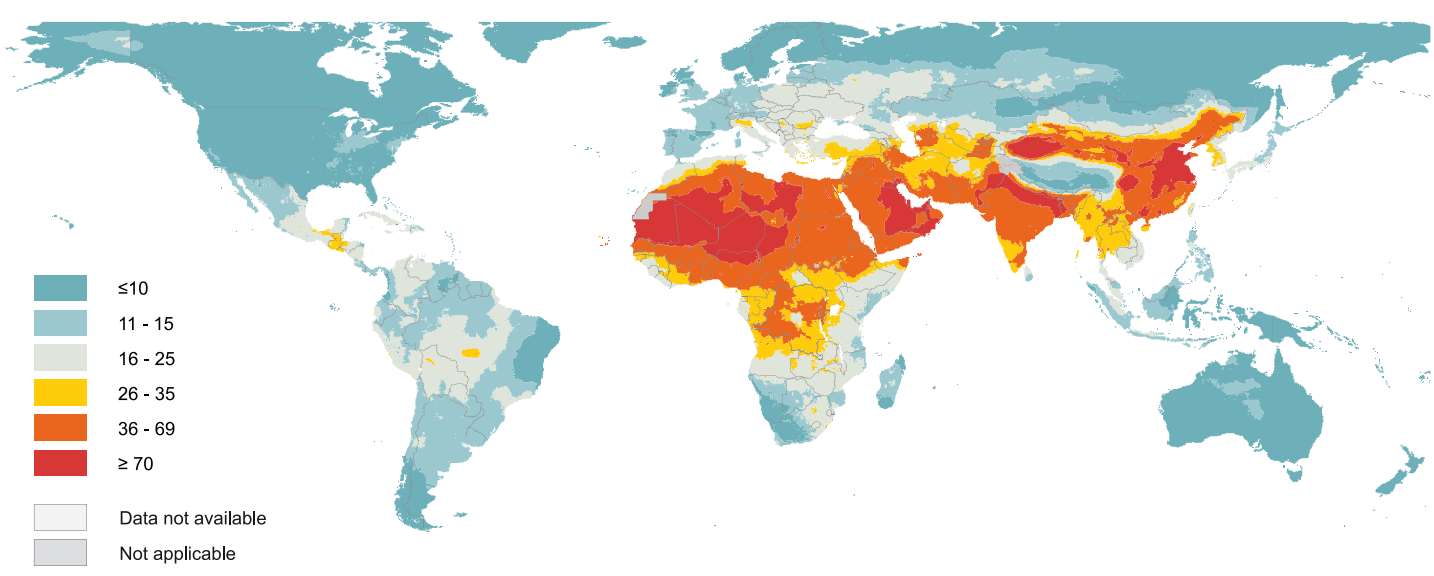

$\mathrm{PM}_{2.5}$ : Fine particulate matter of 2.5 microns or less. 
Figure 10: Annual median exposure to ambient (outdoor) mean annual concentration of $\mathrm{PM}_{2.5}$ in $\mu \mathrm{g} / \mathrm{m}^{3}$, by region - urban and rural population population, 2014

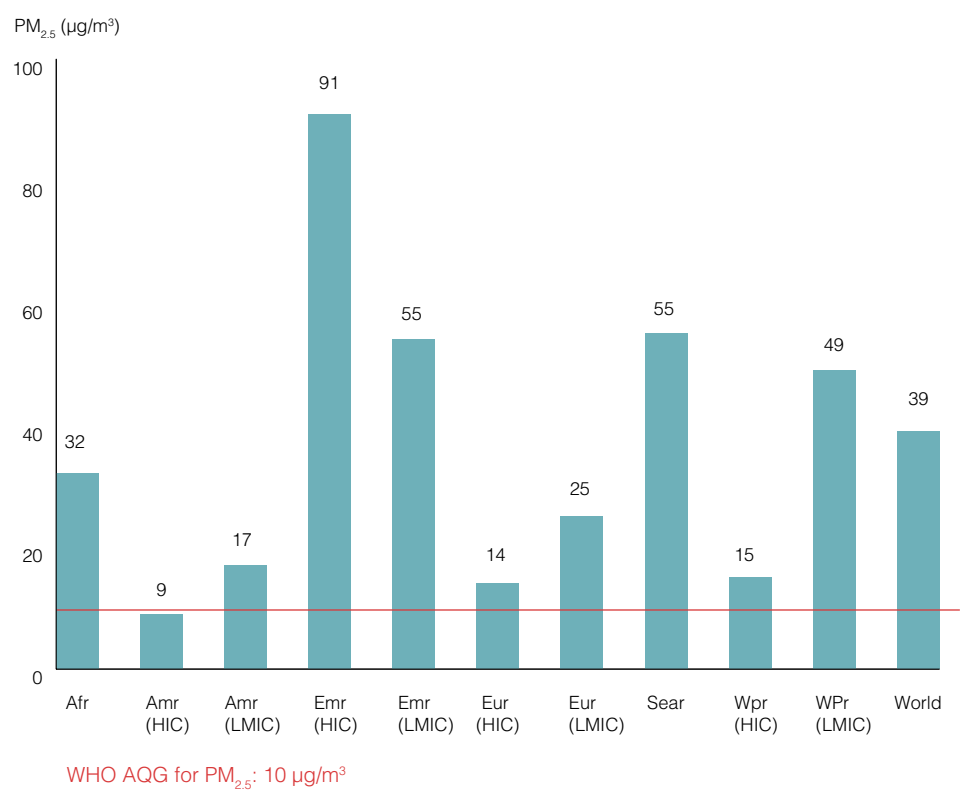

Afr: Africa; Amr: Americas; Emr: Eastern Mediterranean; Eur: Europe; Sear : South-East Asia, Wpr: Western Pacific; LMIC: low- and middle-income countries; HIC: high-income countries; $\mathrm{PM}_{2.5}$ : particulate matter with an aerodynamic diameter of $2.5 \mu \mathrm{m}$ or less. WHO AQG: WHO Air Quality Guidelines.

Figure 11: Annual median exposure to ambient (outdoor) $\mathrm{PM}_{2.5}$ in $\mu \mathrm{g} / \mathrm{m}^{3}$, by region - urban population only, 2014

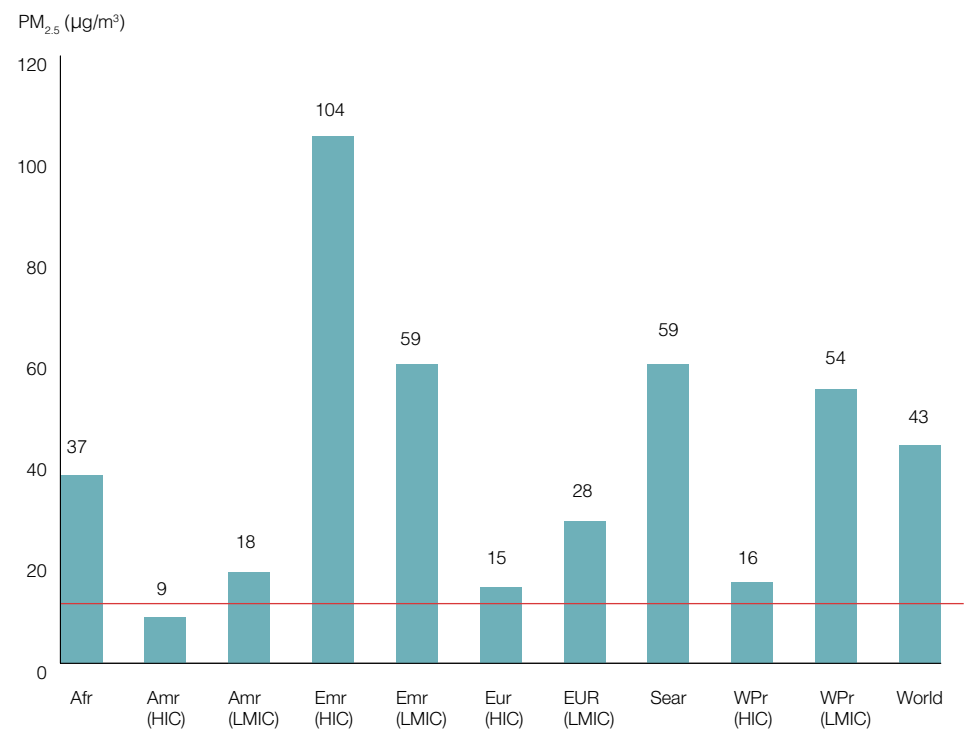

WHO AQG for $\mathrm{PM}_{25}: 10 \mu \mathrm{g} / \mathrm{m}^{3}$

Afr: Africa; Amr: Americas; Emr: Eastern Mediterranean; Eur: Europe; Sear: South-East Asia, Wpr: Western Pacific; LMIC: low- and middle-income countries; $\mathrm{HIC}$ : high-income countries. $\mathrm{PM}_{2.5}$ : particulate matter with an aerodynamic diameter of $2.5 \mu \mathrm{PM}{ }_{2.5}$ : pa. WHO AQG: WHO Air Quality Guidelines. 
Figure 12: Median $\mathrm{PM}_{2.5}$ concentration, by geographic region - urban and rural areas combined, 2014

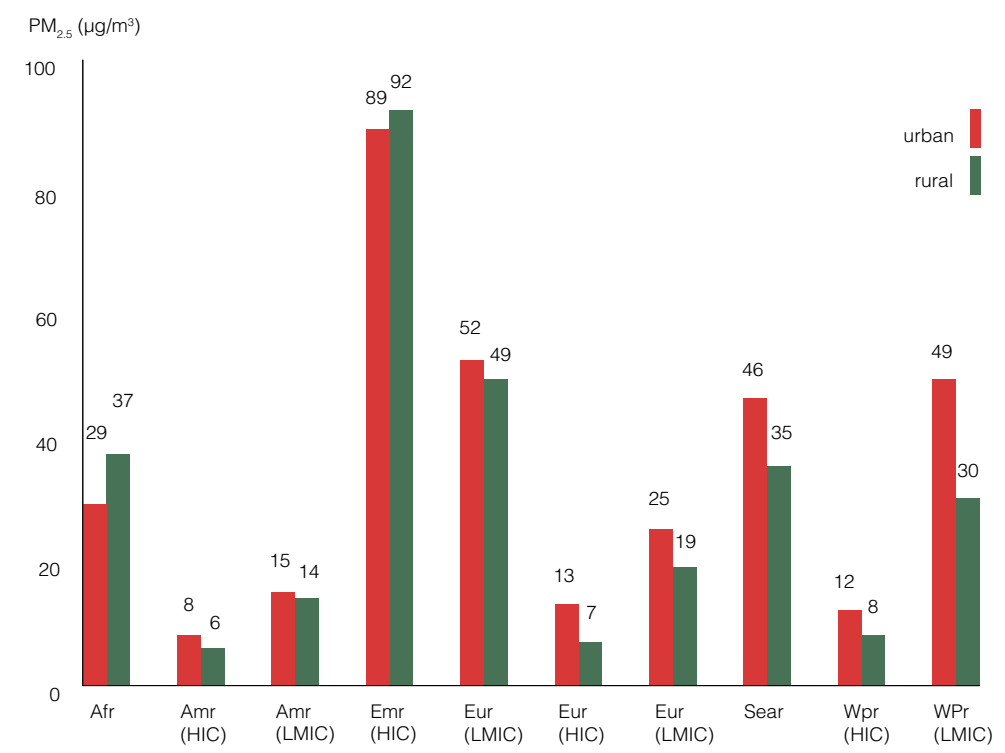

Afr: Africa; Amr: Americas; Emr : Eastern Mediterranean; Eur : Europe; Sear: South-East Asia, Wpr: Western Pacific : LMIC : low- and middle-income countries; HIC: high-income countries. Note: This graph represents the median $\mathrm{PM}_{2.5}$ of regional urban and rural areas. These estimates are not in relation to the number of people exposed to those levels.

Figure 13: Modelled annual median particulate matter concentration compared to the WHO Air Quality Guidelines (AQG) a

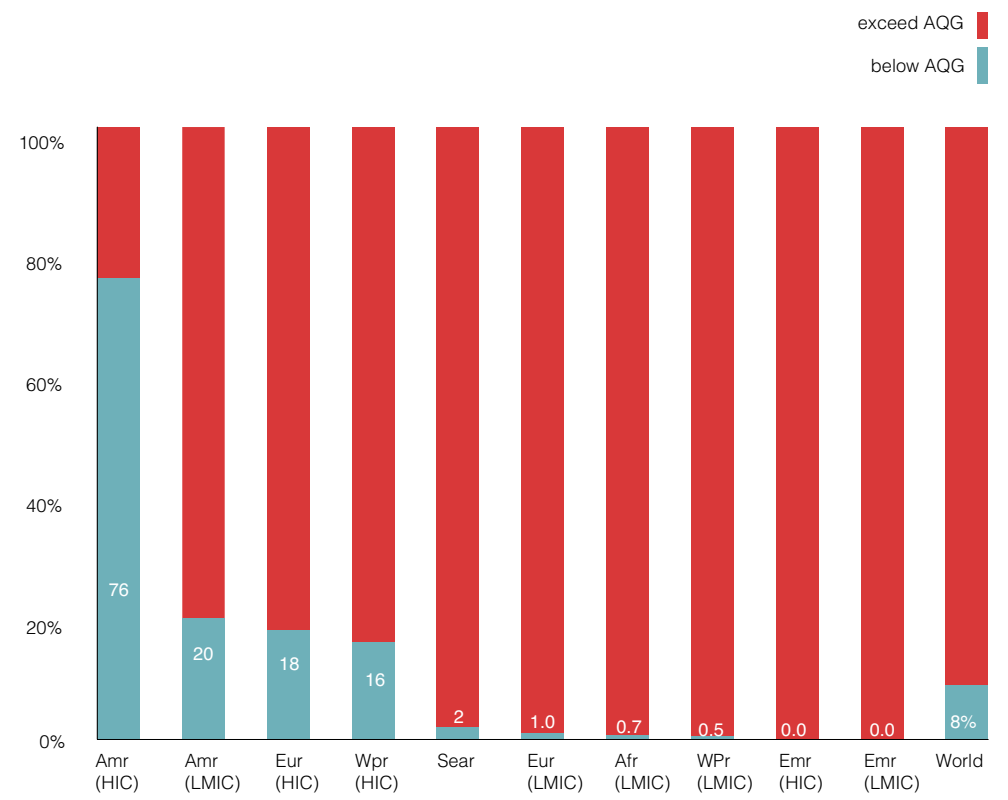

Afr: Africa; Amr: Americas; Emr: Eastern Mediterranean; Eur: Europe; Sear: South-East Asia; Wpr: Western Pacific;

LMIC: Low- and middle-income countries; HIC: high-income countries; AQG: WHO Air Quality Guidelines.a Annual mean PM ${ }_{10}$ : $20 \mu \mathrm{g} / \mathrm{m}^{3} ;$ Annual mean $\mathrm{PM}_{25}: 10 \mu \mathrm{g} / \mathrm{m}^{3}$. 


\subsubsection{Discussion}

Global population exposure to $\mathrm{PM}_{2.5}$ matter has been modelled for the year 2014 to provide a comprehensive global coverage of estimates of air quality. Annual mean concentration of $\mathrm{PM}_{25}$ is highly relevant for estimating health impacts and is used as an exposure indicator for calculating the burden of disease attributable to ambient air pollution.

The model used for this study currently has several limitations, however. The first limitation relates to population data. While the quality of estimates of population data and population density, used to calculate the average estimates of $\mathrm{PM}_{2.5}$ for urban and rural areas is generally good for high-income countries, it can be relatively poor for some low- and middle-income areas. Furthermore, the definition of urban/rural may greatly vary by country.

The second limitation relates to resolution: The grid size is $0.1^{\circ} \times 0.1^{\circ}(11 \times 11 \mathrm{~km}$ close to the equator, but smaller towards the poles). This resolution may cause limitations when considering local situations. However, finer resolutions are planned for future studies. Regarding lack of monitoring data in countries, the model produces a calibration equation for each country using country level data as a priority, with regional data being used to supplement local information for countries with sparse, or no, ground monitoring data. It is acknowledged that the estimates for data-poor countries may be relatively imprecise and that this may result in apparent changes in levels of air pollution at borders with data-poor countries. In order to achiever reduced uncertainty in modelled data it is important that countries continue and/or improve ground measurement programmes.
Finally, where measurements of $\mathrm{PM}_{2.5}$ are not available, $\mathrm{PM}_{10}$ measurements are used after conversion to $\mathrm{PM}_{2.5}$ using either city, country or regional conversion factors. Conversion factors typically range between 0.4-0.8 depending on location. Localised conversion factors are likely to be more accurate, but the ability to calculate them relies on availability of localised data. The potential for inaccuracies in conversion factors means that model outputs for areas using large numbers of converted values may be less accurate than those based on measurements of $\mathrm{PM}_{2.5}$ and extra caution should be taken in their interpretation.

Wherever possible, estimates of $\mathrm{PM}_{2.5}$ have been computed using standardized categories and methods in order to enhance cross-national comparability. This approach may result in some cases in differences between the estimates presented here and the official national statistics prepared and endorsed by individual WHO Member States. These differences between $\mathrm{WHO}$ and national statistics may be larger in countries with small cities and settlements which may not be fully represented by the resolution of the $\mathrm{WHO}$ model. This may be compounded for isolated regions where air pollution is primarily from local sources and is experienced at very local levels. 


\section{Burden of disease attributable to ambient air pollution}

\subsection{Methods}

The burden of disease attributable to ambient air pollution was estimated for the year 2012 based on Comparative Risk Assessment methods (25) and in consultation with expert groups for the Global Burden of Disease (GBD) study (12, 14). This methodology is based on combining exposure to air pollution and its distribution in the population with exposure-risk estimates at each level of exposure. This results in a population attributable fraction of disease burden, which is then applied to the health outcome of interest.

\subsubsection{Source of the data Health data}

The total number of deaths, years of life lost (YLLs), years lived with disability (YLDs) and disability-adjusted life years (DALYs) by disease, country, sex and age group have been developed by the World Health Organization (26).

\section{Exposure data}

Annual mean concentration of $\mathrm{PM}_{25}$ were modelled according to the description in the section Exposure: modelled estimates of $\mathrm{PM}_{2.5}$. The model output provided the percentage of the population exposed to $\mathrm{PM}_{2.5}$ by country, in increments of $1 \mu \mathrm{g} / \mathrm{m}^{3}$.

\section{Exposure-risk relationship}

The integrated exposure-response (IER) functions, developed for the GBD 2010 study (16) and further updated for the GBD 2013 study $(14 ; 27)$, were used for acute lower respiratory infections (ALRI), lung cancer, chronic obstructive pulmonary disease (COPD), stroke and ischaemic heart disease (IHD) and can be described with the following formula (16):
For $\mathrm{z}<\mathrm{z}_{\mathrm{c}}$

$$
R R_{\text {IER }}(\mathrm{z})=1
$$

For $z \geq z_{c f}$

$R R_{I E R}(z)=1+a\left\{1-\exp \left[-\gamma\left(z-z_{c f}\right)^{\delta}\right]\right\}$

where $z$ is the annual mean concentration of $\mathrm{PM}_{2.5}, \mathrm{z}_{\mathrm{cf}}$ is the counterfactual $\mathrm{PM}_{2.5}$ concentration, $a, \gamma$ and $\delta$ are the parameter estimates. The IERs are age-specific for both IHD and stroke.

\section{Demographic data}

Population data from the UN Population Division (21) were used.

\subsubsection{Estimation of disease burden}

The percentage of the population exposed to $\mathrm{PM}_{2.5}$ was provided by country, in increments of $1 \mathrm{\mu g} / \mathrm{m}^{3}$; relative risks were calculated for each $\mathrm{PM}_{2.5}$ increment, based on the integrated exposure-response functions (IER). The counterfactual concentration was selected to be a uniform distribution with lower and upper limits of 5.9 and $8.7 \mu \mathrm{g} / \mathrm{m}^{3}$ respectively, given by the average of the minimum and and $5^{\text {th }}$ percentiles of outdoor air pollution cohort exposure distribution, as described elsewhere $(14,16)$. The country population attributable fractions (PAF) for ALRI, COPD, lung cancer, stroke and IHD were calculated using the following formula, for each sex and age group:

$$
\mathrm{PAF}=\frac{\sum_{i=1}^{n} \mathrm{P}_{i}(R R-1)}{\sum_{i=1}^{n} \mathrm{P}_{i}(R R-1)+1}
$$

where $i$ is the level of $P M_{2.5}$ in $\mu g / \mathrm{m}^{3}$, and $P_{i}$ is the percentage of the population exposed to that level of air pollution, and RR is the relative risk. 
The attributable burden is calculated by multiplying the population-attributable fraction (PAF) by the health outcome, for each health outcome, sex and age group:

\section{$A B=P A F x$ health outcome}

where $A B$ is the attributable burden, $P A F$ is the population-attributable fraction and the health outcome of interest, e.g. deaths, DALYs, YLLs, etc. DALYs are calculated by adding the years of life lived with disability (YLDs) and the YLLs. The relative risks (RRs) for YLDs were adjusted by a scalar of 1 for ALRI, lung cancer, and COPD; of 0.141 for IHD and of 0.553 for stroke (27). The age groups included in the analysis were children less than five years of age for ALRI, and adults above 25 years for the other diseases as previously reported $(2,6)$.

\subsubsection{Uncertainty analysis}

The uncertainty intervals are based on the following sources of uncertainty: (a) Uncertainty around the exposure to air pollution; and (b) uncertainty around relative risks of the integrated exposure-function. To account for uncertainty in exposure, the upper and lower exposure was obtained from the model (24) for each country, i.e. upper and lower credible limits for the estimate of the percentage of the population exposed to $\mathrm{PM}_{2.5}$.

Alternative burden of disease estimates were calculated for each of these exposures. For the integrated exposure-response function, 1000 draws of each parameter of the function were obtained (27) and population attributable fractions were calculated for each draw.

The final uncertainty intervals were obtained as the 2.5 and 97.5 percentiles of the draws for the alternative burden of disease calculations. As uncertainty for total mortality by cause was not taken into account, this is a partial accounting of uncertainty, and is likely to be underestimated.

\subsection{Results}

Globally, 3 million deaths were attributable to ambient air pollution (AAP) in 2012. About $87 \%$ of these deaths occur in LMICs, which represent $82 \%$ of the world population.

The WHO Western Pacific and South East Asian regions bear most of the burden with 1.1 million and 799000 deaths, respectively. In other regions, about 211000 deaths occur in SubSaharan Africa, 194000 in the Eastern Mediterranean region, 190000 in Europe, and 93000 in the Americas. The remaining deaths occur in high-income countries of Europe (289 000), the Americas (44 000), Western Pacific (44 000), and Eastern Mediterranean (10 000) (Figure 14).

Age-standardized deaths and DALYs are shown in Figures 15 to 19. Age-standardized measures of deaths and disease are often used to compare countries, as they adjust for age distribution differences by applying agespecific mortality rates for each population. Country estimates of deaths, YLLs and DALYs are provided by disease and sex in Annex 2. The methods for exposure assessment and burden of disease estimation have been slightly updated compared with the previous estimate of 3.7 million deaths from AAP (2012), as released in 2014 (2).

The variation is thought to be due to: 1) Additional evidence that has become available on the relationship between exposure and health outcomes, and the use of an updated version of the integrated exposure-response functions leading to modified estimates depending on the disease; and 2) revised population exposure to air pollution leading to modified estimates according to the region. 
Figure 14: Deaths attributable to AAP in 2012, by disease and region

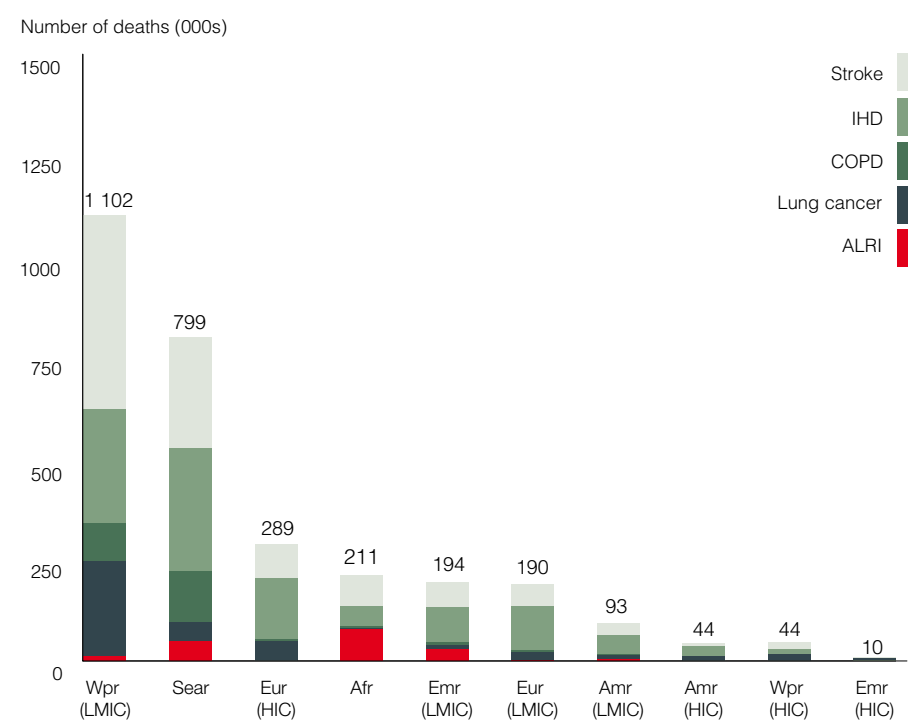

AAP: ambient air pollution; Afr: Africa; Amr: Americas; Emr: Eastern Mediterranean; Eur: Europe; Sear: South-East Asia; Wpr: Western Pacific; LMIC: Low- and middle-income countries; HIC: High-income countries

Figure 15: Age-standardized deaths per capita attributable to AAP in 2012, by disease and region

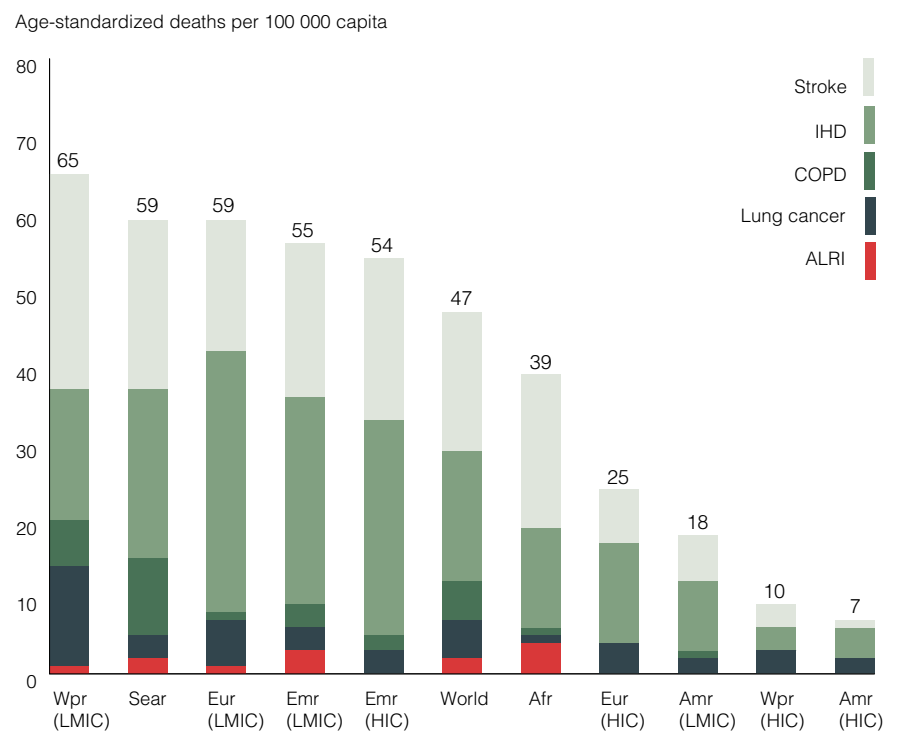

AAP: ambient air pollution; Afr: Africa; Amr: Americas; Emr: Eastern Mediterranean; Eur: Europe; Sear: South-East Asia; Wpr: Western Pacific; LMIC: Low- and middle-income countries; HIC: High-income countries. 


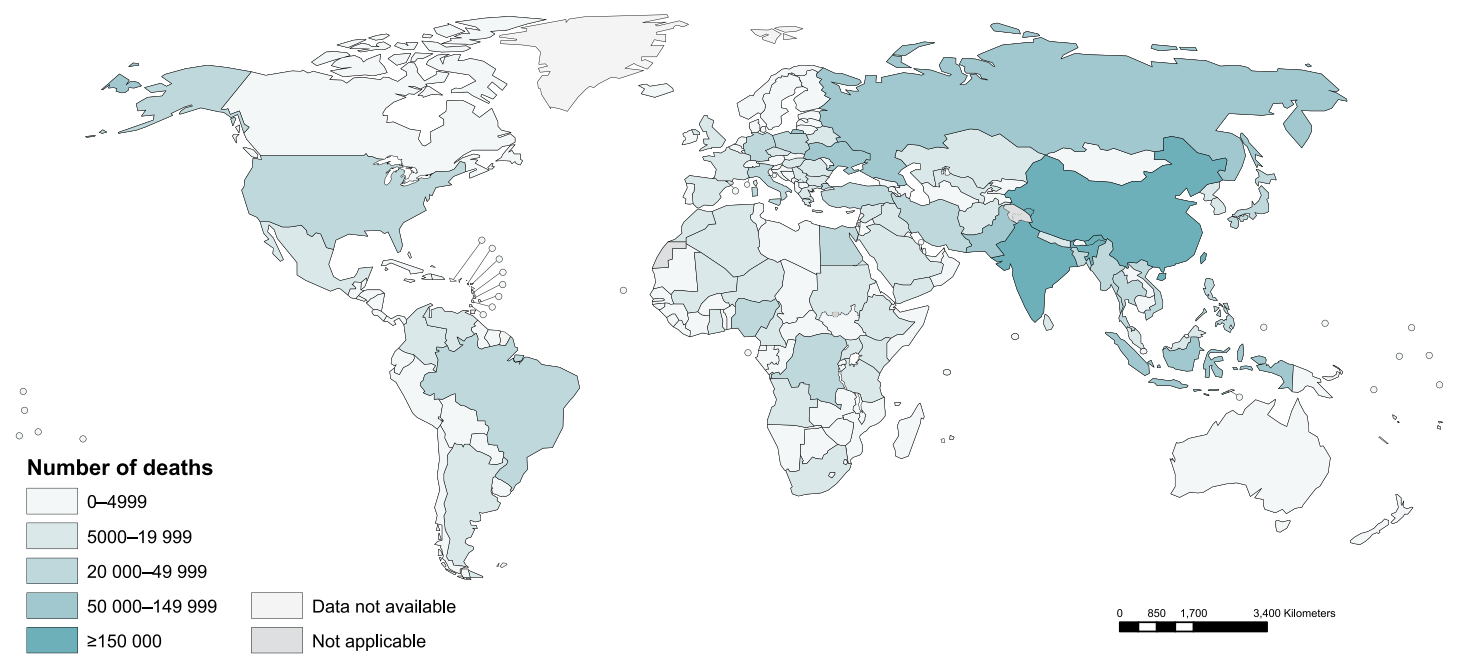

AAP : Ambient air pollution

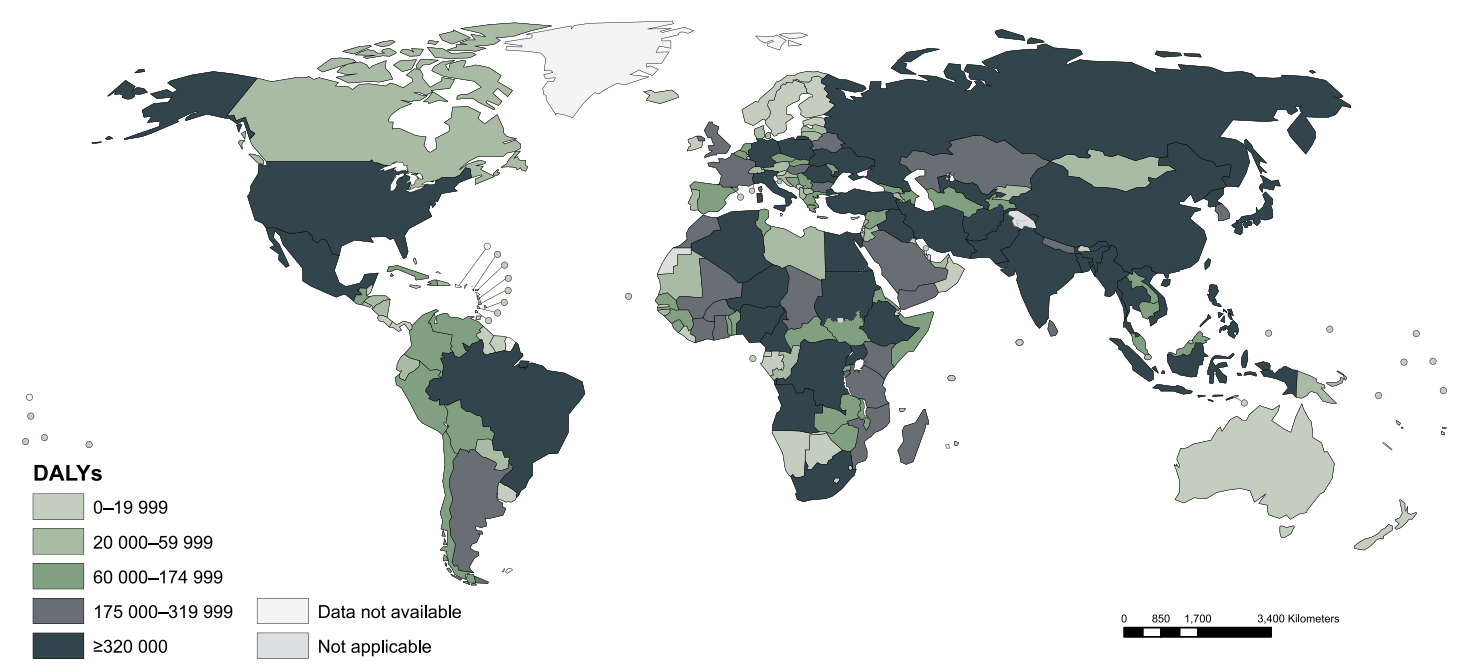

AAP: Ambient air pollution 


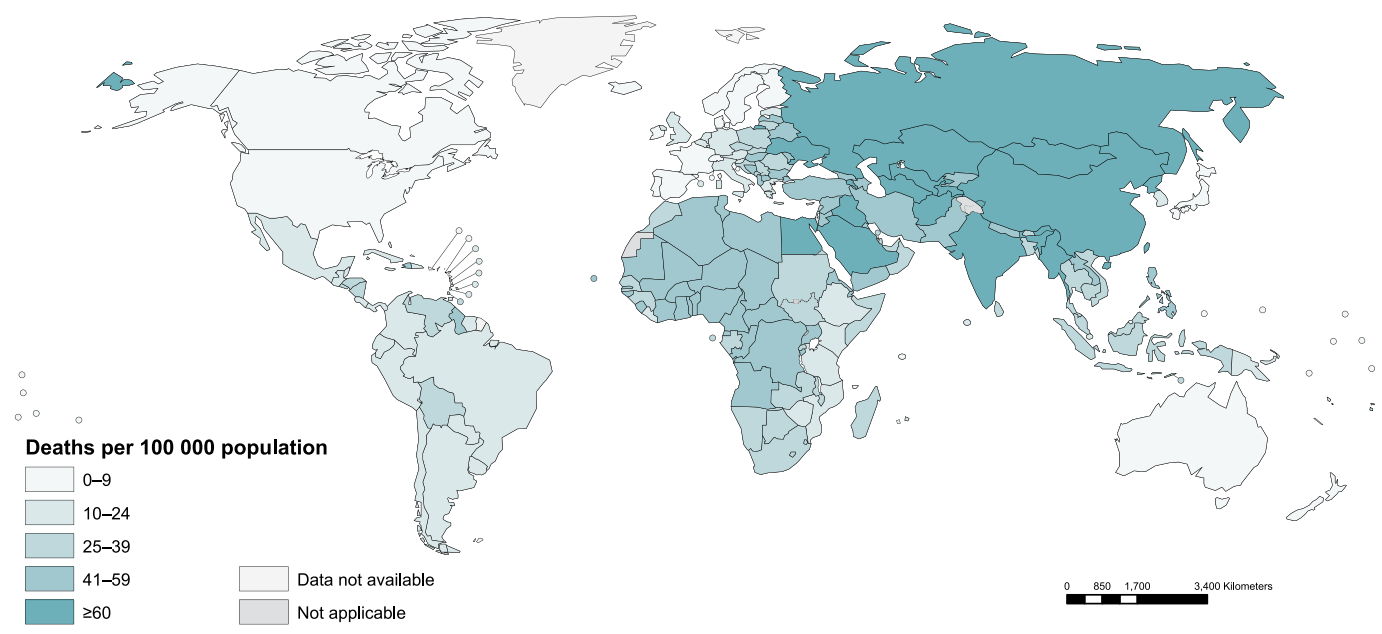

AAP: Ambient air pollution

Figure 19: Age-standardized DALYs per 100000 capita attributable to AAP in 2012, by country

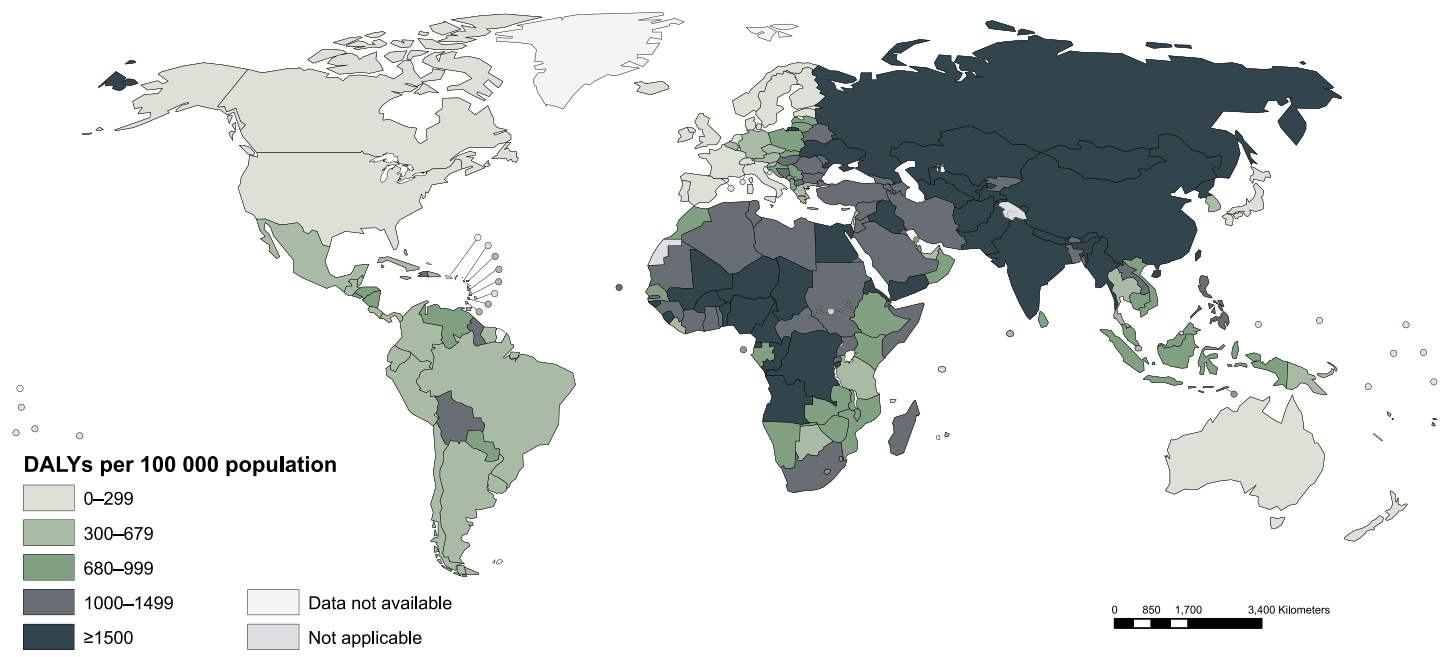

AAP: Ambient air pollution 
Almost $94 \%$ of deaths worldwide are due to noncommunicable diseases in adults, such as cardiovascular diseases (stroke and ischaemic heart disease), chronic obstructive pulmonary disease and lung cancers. The remaining deaths occur in children under five years of age due to acute lower respiratory infections (Figure 20 and Tables 5 and 6).

\section{Figure 20: Deaths attributable to AAP in 2012, by disease}

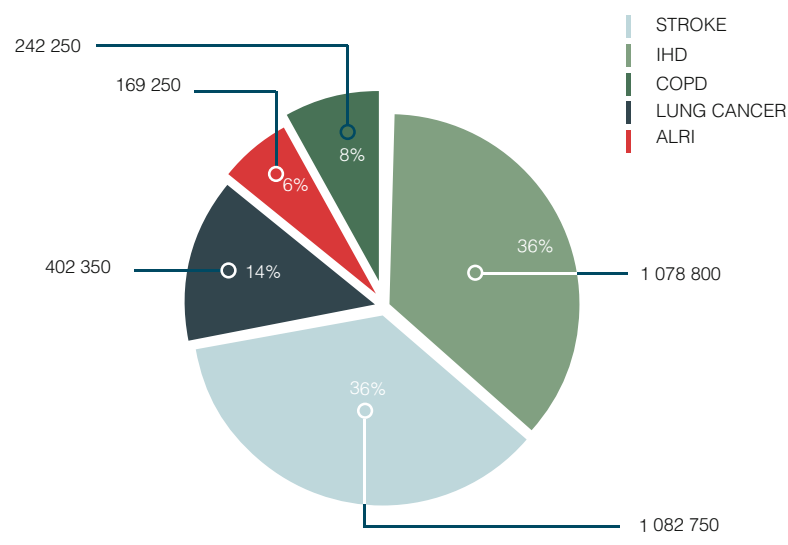

Percentage represents percentage of total AAP burden. AAP: ambient air pollution; ALRI : acute lower respiratory disease; COPD chronic obstructive pulmonary disease; IHD: ischaemic heart disease.

Table 5: Deaths attributable to AAP in 2012, by disease, age and sex

\begin{tabular}{l|llll} 
& \multicolumn{4}{l}{ Deaths } \\
\hline Disease & Children $<5$ years & Men & Women & Total \\
\hline ALRI & 169250 & - & - & 169250 \\
COPD & - & 135900 & 106350 & 242250 \\
Lung cancer & - & 285900 & 116450 & 402350 \\
$I H D$ & - & 606350 & 472450 & 1078800 \\
Stroke & - & 540600 & 542150 & 1082750 \\
\hline Total & 169250 & 1568750 & 1237400 & 2975400
\end{tabular}

AAP: ambient air pollution; ALRI: acute lower respiratory disease; COPD: chronic obstructive pulmonary disease; IHD: ischaemic heart disease. Men and women are adults of 25 years and above.

Table 6: Disability-adjusted life years (DALYs) attributable to AAP in 2012, by disease, age and sex

\begin{tabular}{l|llll}
\multicolumn{5}{|l}{ DALYs ('000s) } \\
\hline Disease & Children <5 years & Men & Women & Total \\
\hline ALRI & 15478 & - & - & 15478 \\
COPD & - & 3758 & 2862 & 6620 \\
Lung cancer & - & 7076 & 2736 & 9812 \\
IHD & - & 16782 & 10105 & 26887 \\
Stroke & - & 13927 & 12210 & 26137 \\
\hline Total & 15478 & 41544 & 27913 & 84934
\end{tabular}

DALYs: disability-adjusted life years; AAP: ambient air pollution; ALRI : acute lower respiratory disease; COPD: chronic obstructive pulmonary disease; IHD: ischaemic heart disease. Men and women are adults of 25 years and above.

The fraction of each individual disease attributable to ambient air pollution is presented in Table 7 for DALYs, and ranges from $8 \%$ for COPD to $25 \%$ for lung cancers. ALRI, stroke and IHD lie in the middle with population attributable fraction of around $16 \%$. 


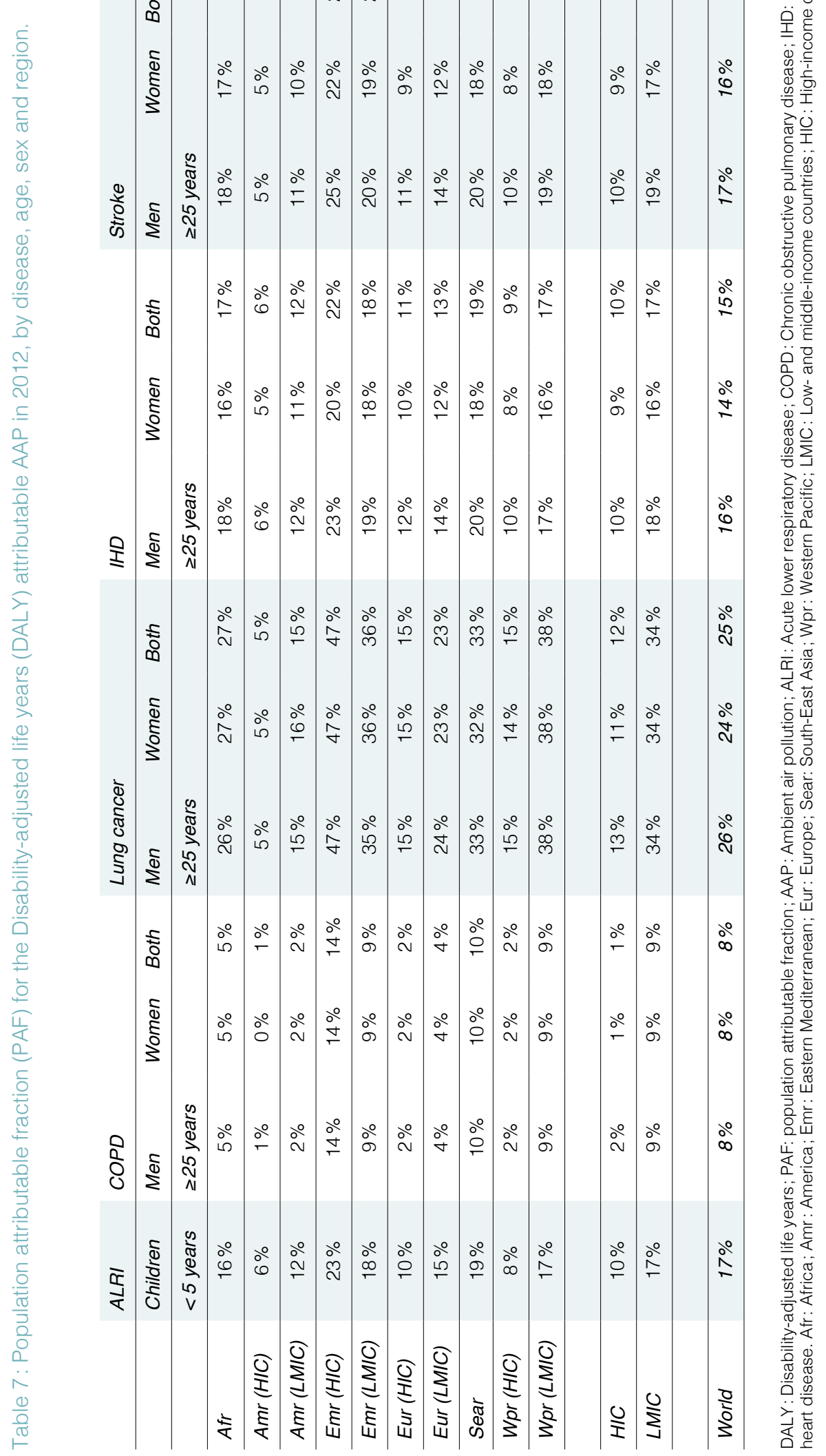




\subsection{Discussion}

In 2012, ambient air pollution from particulate matter was responsible for about 3 million deaths and 85 million DALYs. Burden of disease calculation is based on: 1) Population exposure assessment; 2) exposure-response functions; and 3) underlying health data. As data on air quality and epidemiological evidence is accumulating rapidly, and methodolodies for both points 1) and 2) are being revised on a regular basis, and these figures are evolving.

Decision-makers and researchers need accurate and reliable estimates of air pollution exposure and the related health impacts. Differing needs (cause-specific vs all-cause mortality, national or regional assessment), publication schedules and audience may lead to different approaches and data use, and therefore different results (28-31). The methods used in this report were developed for global reporting and using the latest available evidence and health data that complied with WHO standards; they may therefore differ from official national statistics prepared and endorsed by individual WHO Member States.

Some regions, such as the Eastern Mediterranean and Africa are highly affected by natural desert dust particles. This results in high health burden according to the current methods, which assume natural dust affects health the same way as $\mathrm{PM}_{2.5}$ from other sources.

The health impacts associated with exposure to dust are not yet fully understood, and are currently treated the same way as those from air pollution in industrialized countries where most of the epidemiological studies have been performed.

There is a need to for a better assessment of the health impacts from natural dust, as it could result in much lower burden than those from antropogenic particulate matter $(32,33)$.
The actual impact of air pollution on health presented here is a conservative figure. Many other diseases have been associated with air pollution but are not included in this assessment, because the evidence was not considered to be sufficiently robust, such as pre-term birth or low birth weight. Also, it does not include the separate impacts of health from other air pollutants such as nitrogen oxides ( $\mathrm{NOx}$ ) or ozone $\left(\mathrm{O}_{3}\right)$.

As data on air pollutants, methods to assess population exposure and epidemiological evidence accumulates, health effects of additional pollutants should be taken into account in the future as it has already been done for ozone (14). In addition, assessments of the health impacts from interventions to reduce air pollution using rigorous epidemiological methodology are much needed. These would be able to take account of context, of intervention packages and provide a stronger basis for assessing reallife impacts of air quality improvement efforts. 

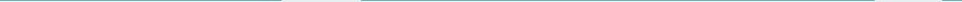


\section{Conclusion and way forward}

Ambient air pollution kills about 3 million people annually and is affecting all regions of the world, although Western Pacific and South East Asia are the most affected. About $90 \%$ of people breathe air that does not comply with the WHO Air Quality Guidelines.

The data presented here carry significant uncertainties but constitute the best evidence available to date. Air quality data and epidemiological evidence on the effects of air pollutants on health are growing quickly. They will continue to improve exposure assessment to particulate matter and other pollutants, as well as for burden of disease estimation.

More epidemiological studies of the long-term effects of exposure to air pollution in low-income settings, where air pollution reaches unacceptable levels, are urgently needed to better inform the exposure-response relationships. Additional evidence on health outcomes currently not assessed in the analysis, because of lack of knowledge, is also crucial.
In terms of monitoring and reporting, there is a huge gap in monitoring and reporting air pollutants in low and middle-income regions, especially in Africa and Asia but also other regions. Strengthening capacities of cities to monitor their air quality with standardized methods, reliable and good quality instrumentation, and sustainable structures is key. 

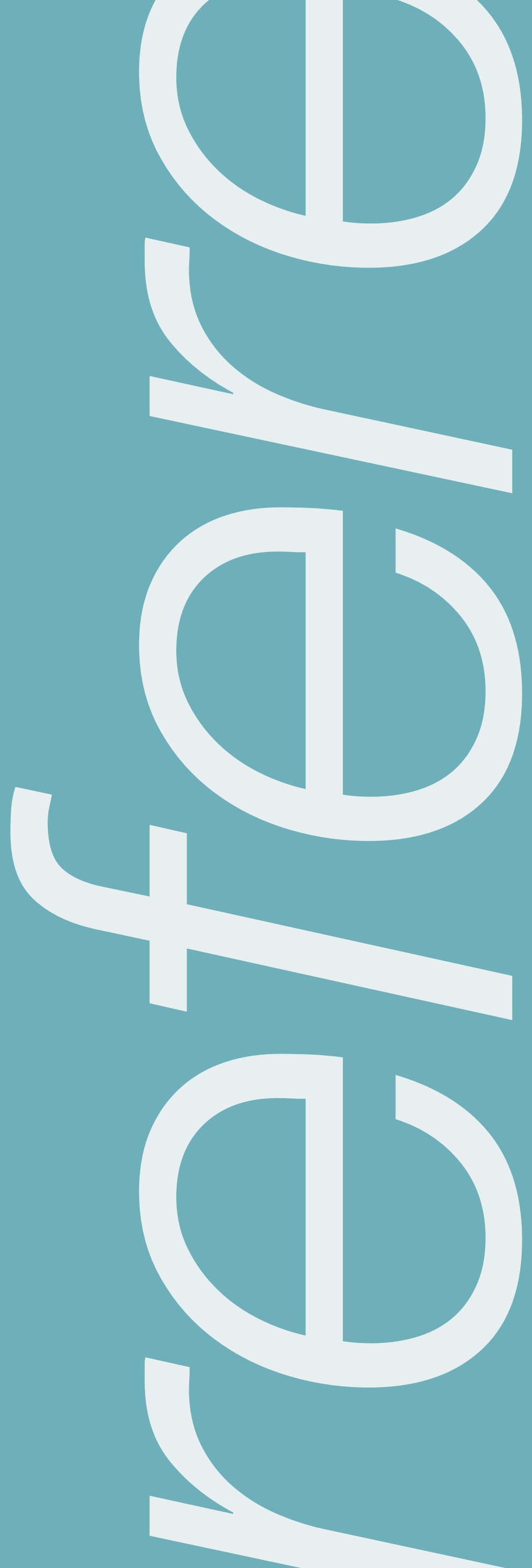


\section{References}

1. Air quality guidelines: Global update 2005. Copenhagen: WHO Regional Office for Europe; 2005.

2. Methods for burden of disease attributable to ambient air pollution for the year 2012. Geneva: World Health Organization; 2014. (http://www.who.int/phe/health_topics/ outdoorair/databases/AAP BoD methods March2014.pdf?ua=1, accessed May 2016).

3. Health and the environment: addressing the health impact of air pollution (resolution A68.8). Geneva: World Health Organization; 2015. (http://apps.who.int/gb/ebwha/pdf_files/ WHA68/A68_R8-en.pdf, accessed May 2016).

4. Health and the environment: Draft road map for an enhanced global response to the adverse health effects of air pollution (resolution A68.18). Geneva: World Health Organization; 2016. (http://apps.who.int/gb/ebwha/pdf files/ WHA69/A69_18-en.pdf, accessed July 2016).

5. Transforming our world: The 2030 Agenda for Sustainable Development (resolution A/ RES/70/1). New York: United Nations; 2015.

6. Methods for burden of disease attributable to household air pollution for the year 2012. Geneva: World Health Organization; 2014. (http://www.who.int/phe/health_topics/ outdoorair/databases/HAP_BoD_methods March2014.pdf?ua=1, accessed May 2016).

7. WHO Outdoor Air Pollution Database Geneva: World Health Organization; 2011. (http://www.who.int/phe/health_topics/outdoorair/databases/cities-2011/en/, accessed 26 May 2016).

8. WHO Ambient (Outdoor) Air Quality Database 2014. Geneva: World Health Organization; 2014. (http://www.who.int/phe/health topics/outdoorair/databases/cities-2014/en/ accessed 26 May 2016)

9. WHO Urban Ambient (Outdoor) Air Quality Database (update 2016). Geneva: World Health Organization; 2016. (http://www.who. int/phe/health_topics/outdoorair/databases/ cities/en/, accessed 19 May 2016).

10. Brauer $M$ et al. Exposure assessment for estimation of the global burden of disease attributable to outdoor air pollution. Environmental Science\&Technology. 2012; 46(2):652-60. (doi: 10.1021/es2025752).
11. Brauer $M$ et al. Ambient air pollution exposure estimation for the Global Burden of Disease 2013. Environmental Science \& Technology. 2015; 50:79-88.

12. Lim SS et al. The Lancet. 2012 ; 380(9859):2224-60. (doi:10.1016/S01406736(12)61766-8)

13. Apte $J$ et al (2015). Addressing Global Mortality from Ambient PM2.5. Environmental Science \& Technology. 2015; 49:8057-8066.

14. Forouzanfar et al (2015). Global, regional, and national comparative risk assessment of 79 behavioural, environmental and occupational, and metabolic risks or clusters of risks in 188 countries, 1990-2013: a systematic anaIysis for the Global Burden of Disease Study 2013. The Lancet. 2015; 386:2287-323.

15. WHO Global Platform on Air Quality and Health. Geneva : World Health Organization; 2016. (www. who.int/phe/health topics/outdoorair/global_plateform/en, accessed June 2016).

16. Burnett R et al. An Integrated Risk Function for Estimating the Global Burden of Disease Attributable to Ambient Fine Particulate Matter Exposure. Environmental Health Perspectives. 2014; 122, Issue 4:397-403.

17. Global burden of disease. Seattle: Institute for Health Metrics and Evaluation; 2015.(www. healthdata.org/gbd, accessed October 2015).

18. Smith KR et al. Millions dead: how do we know and what does it mean? Methods used in the Comparative risk assessment of household air pollution. Annual Review of Public Health. 2014; 35:185-206.

19. Review of evience on health aspects of air pollution - REVIHAAP Project. Technical Report. Copenhagen: WHO Regional Office for Europe; 2013.

20. Clean Air Asia. Manila: Clean Air Asia; 2015. (http://cleanairasia.org/, accessed October 2015).

21. Air quality e-reporting database. Copenhagen: European Environment Agency; 2015. (http://www.eea.europa.eu/data-and-maps/ data/aqereporting, accessed November 2015). 
22. World population prospects: 2015 revision. New York: United Nations Population Division; 2015.

23. Citypopulation (2016). (http://www. citypopulation.de, accessed February 2016).

24. Shaddick G. et al. Data Integration Model for Air Quality: A Hierarchical Approach to the Global Estimation of Exposures to Ambient Air Pollution (2016, submitted). http://arxiv.org/ abs/1609.00141, accessed September 2016.

25. Ezzati M. et al. Selected major risk factors and global and regional burden of disease. The Lancet. 2002; 360(9343):1347-60.

26. Global health estimates 2013: Deaths by cause, age and sex, by Country, 2000-2012.

Geneva: World Health Organization; 2014.

27. Institute for Health Metrics and Evaluation. Seattle: Institute for Health Metrics and Evaluation; 2016. (https://cloud. ihme. washington.edu/index.php/s/mQiXovGlaBTbaT7, accessed September 2016).

28. Health risks of air pollution in Europe - HRAPIE Project: Recommandations for concentration-response functions for cost-benefit analysis of particulate matter, ozone and nitrogen dioxide. Copenhagen: WHO Regional Office for Europe; 2013.

29. Economic cost of the health impact of air pollution in Europe: Clean air, health and wealth. Copenhagen: WHO Regional Office for Europe; 2015.

30. Air quality in Europe - 2015 report. Copenhagen: European Environement Agency; 2015.

31. The economic consequences of outdoor air pollution. Paris: OECD Publishing; 2016. (http://dx.doi.org/10.1787/9789264257474-en, accessed July 2016).

32. Giannadaki et al. Modeled global effects of airborne desert dust. Atmospheric Chemistry and Physics. 2014; 14, 957-968.

33. Lelieveld et al. The contribution of outdoor air pollution sources to premature mortality on a global scale. Nature. 2015; 525: 367. 
This document was prepared by Sophie Gumy, and Annette Prüss-Üstün (WHO Geneva), with inputs and comments from Heather Adair-Rohani, Carlos Dora and Elaine Fletcher (WHO Geneva), Gavin Shaddick and Matthew Thomas (University of Bath, United Kingdom). The interactive map and the static map of exposure to air pollution were prepared by Ravi Santhana Gopala Krishnan (WHO Geneva); all other maps were prepared by Florence Rusciano (WHO Geneva).

\section{Exposure: ground measurements of $\mathrm{PM}_{10}$ and $\mathrm{PM}_{2.5}$}

The database was compiled during 2015 with some updates in the first quarter of 2016 by Sophie Gumy, Tara Neville, Kristina Dushaj and Annette Prüss-Ustün (WHO Geneva) with contributions from Mazen Malkawi (WHO CEHA, Amman), Christian Gapp (WHO ECEH, Bonn), Alberto González Ortiz (European Environment Agency), Kaye Patdu and Candy Tong (Clean Air Asia), Michael Brauer (School of Population and Public Health, University of British Columbia, Canada), and several national institutions.

\section{Exposure: modelled estimates of $\mathrm{PM}_{2.5}$}

The model to produce the estimates was developed under the leadership of $\mathrm{WHO}$ and the University of Bath, United Kingdom, with the input and review of an expert group of 12 leading scientists in the area. The scientist leading the work was Gavin Shaddick (University of Bath) who was assisted by Matthew Thomas and Amelia Jobling (University of Bath). The expert group consisted of Gavin Shaddick, Michael Brauer (University of British Columbia), Aaron van Donkelaar (Dalhousie University), Rick Burnett (Health Canada), Howard Chang
(Emory University), Aaron Cohen (Health Effects Institute), Rita van Dingenen (Joint Research Centre, European Commission), Yang Liu (Emory University), Randall Martin (Dalhousie), Lance Waller (Emory University), Jason West (North Carolina) and Jim Zidek (University of British Columbia), in addition to Annette Prüss-Ustün, Sophie Gumy and Carlos Dora of WHO. The model was presented and reviewed at the WHO Global Platform on Air Quality, Geneva, in August 2015.

\section{Burden of disease attributable to ambient air pollution}

The burden of disease was calculated by Sophie Gumy and Annette Prüss-Ustün (WHO Geneva). 

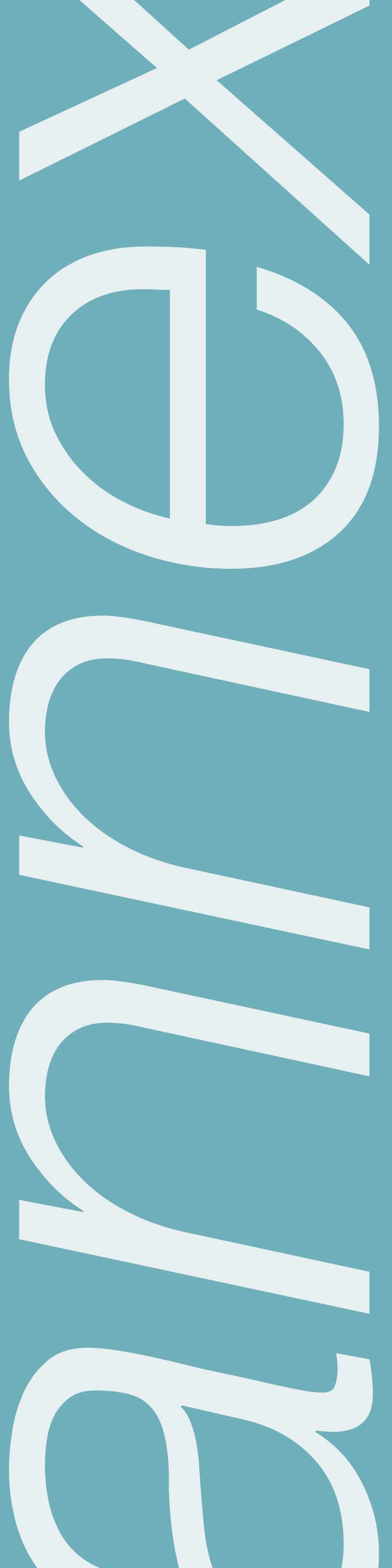


\section{Annex 1: Modelled population exposure to particulate matter $\left(P M_{2.5}\right)$, by country}

Country income grouping is based on the World Bank analytical income classification of economies ${ }^{1}$ corresponding to the year of the data.

Table A1: Annual median concentration of particulate matter of an aerodynamic diameter of $2.5 \mathrm{~mm}$ or less $\left(\mathrm{PM}_{2.5}\right)$ with lower and upper bound, population-weighted and modelled, by area and country

\begin{tabular}{|c|c|c|c|c|c|c|c|}
\hline \multirow[b]{2}{*}{ Region } & \multirow[b]{2}{*}{ Country } & \multicolumn{3}{|c|}{$P M_{2.5}\left[\mu \mathrm{g} / \mathrm{m}^{3}\right]$, urban and rural areas } & \multicolumn{3}{|c|}{$P M_{2.5}\left[\mu \mathrm{g} / \mathrm{m}^{3}\right]$, urban areas } \\
\hline & & Median & Lower & Upper & Median & Lower & Upper \\
\hline Emr (LMIC) & Afghanistan & 46 & 26 & 80 & 63 & 41 & 98 \\
\hline Eur (LMIC) & Albania & 16 & 9 & 29 & 17 & 10 & 30 \\
\hline Afr & Algeria & 27 & 9 & 74 & 25 & 8 & 73 \\
\hline Eur (HIC) & Andorra & 10 & 6 & 18 & 11 & 6 & 17 \\
\hline Afr & Angola & 27 & 8 & 95 & 42 & 9 & 182 \\
\hline $\operatorname{Amr}(H I C)$ & Antigua and Barbuda & 13 & 6 & 28 & 13 & 6 & 28 \\
\hline $\operatorname{Amr}(L M I C)$ & Argentina & 13 & 8 & 22 & 14 & 9 & 24 \\
\hline Eur (LMIC) & Armenia & 21 & 7 & 66 & 25 & 7 & 87 \\
\hline Wpr (HIC) & Australia & 6 & 4 & 8 & 6 & 4 & 9 \\
\hline Eur (HIC) & Austria & 16 & 11 & 23 & 17 & 12 & 24 \\
\hline Eur (LMIC) & Azerbaijan & 24 & 8 & 73 & 26 & 8 & 86 \\
\hline $\operatorname{Amr}(H I C)$ & Bahamas & 13 & 6 & 28 & 13 & 6 & 28 \\
\hline $\operatorname{Emr}(H I C)$ & Bahrain & 60 & 43 & 82 & 60 & 44 & 82 \\
\hline Sear & Bangladesh & 84 & 53 & 131 & 89 & 58 & 134 \\
\hline$A m r(H I C)$ & Barbados & 14 & 6 & 31 & 14 & 6 & 31 \\
\hline Eur (LMIC) & Belarus & 17 & 6 & 48 & 18 & 6 & 54 \\
\hline Eur (HIC) & Belgium & 15 & 11 & 22 & 16 & 11 & 23 \\
\hline $\operatorname{Amr}(L M I C)$ & Belize & 22 & 7 & 64 & 21 & 7 & 62 \\
\hline Afr & Benin & 31 & 9 & 107 & 28 & 7 & 106 \\
\hline Sear & Bhutan & 48 & 30 & 79 & 39 & 30 & 50 \\
\hline Amr (LMIC) & $\begin{array}{l}\text { Bolivia, Plurinational } \\
\text { States of }\end{array}$ & 27 & 17 & 45 & 32 & 20 & 49 \\
\hline Eur (LMIC) & Bosnia and Herzegovina & 42 & 23 & 76 & 55 & 30 & 100 \\
\hline Afr & Botswana & 16 & 6 & 42 & 19 & 6 & 57 \\
\hline $\operatorname{Amr}(L M I C)$ & Brazil & 10 & 7 & 16 & 11 & 8 & 17 \\
\hline Wpr HIC & Brunei Darussalam & 5 & 3 & 9 & 5 & 3 & 9 \\
\hline Eur (LMIC) & Bulgaria & 27 & 18 & 40 & 30 & 21 & 42 \\
\hline Afr & Burkina Faso & 37 & 12 & 119 & 37 & 10 & 132 \\
\hline
\end{tabular}

${ }^{1}$ For more information, see: Country classification. Washington (DC): World Bank (https://datahelpdesk. worldbank. org/knowledgebase/topics/19280-country-classification, accessed February 2016). 


\begin{tabular}{|c|c|c|c|c|c|c|c|}
\hline \multirow[b]{2}{*}{ Region } & \multirow[b]{2}{*}{ Country } & \multicolumn{3}{|c|}{$P M_{2.5}\left[\mu \mathrm{g} / \mathrm{m}^{3}\right]$, urban and rural areas } & \multicolumn{3}{|c|}{$P M_{2.5}\left[\mu \mathrm{g} / \mathrm{m}^{3}\right]$, urban areas } \\
\hline & & Median & Lower & Upper & Median & Lower & Upper \\
\hline Afr & Burundi & 38 & 11 & 136 & 49 & 12 & 198 \\
\hline Afr & Cabo Verde & 36 & 14 & 96 & NA & NA & NA \\
\hline Wpr (LMIC) & Cambodia & 23 & 7 & 75 & 25 & 6 & 99 \\
\hline Afr & Cameroon & 65 & 38 & 111 & 64 & 39 & 104 \\
\hline$A m r(H I C)$ & Canada & 7 & 5 & 10 & 7 & 5 & 10 \\
\hline Afr & Central African Republic & 39 & 12 & 129 & 56 & 15 & 217 \\
\hline Afr & Chad & 39 & 14 & 115 & 61 & 18 & 207 \\
\hline$A m r(H I C)$ & Chile & 20 & 13 & 30 & 25 & 18 & 36 \\
\hline Wpr (LMIC) & China & 54 & 37 & 80 & 59 & 42 & 84 \\
\hline$A m r(L M I C)$ & Colombia & 17 & 11 & 25 & 18 & 13 & 26 \\
\hline Afr & Comoros & 16 & 8 & 32 & 16 & 8 & 32 \\
\hline Afr & Congo & 40 & 11 & 143 & 57 & 13 & 236 \\
\hline Wpr (LMIC) & Cook Islands & NA & NA & NA & NA & NA & NA \\
\hline$A m r(L M I C)$ & Costa Rica & 18 & 12 & 27 & 19 & 13 & 27 \\
\hline Eur (HIC) & Croatia & 19 & 12 & 31 & 20 & 13 & 32 \\
\hline$A m r(L M I C)$ & Cuba & 17 & 7 & 38 & 16 & 7 & 38 \\
\hline Eur $(H I C)$ & Cyprus & 17 & 11 & 26 & 17 & 11 & 26 \\
\hline Eur $(H I C)$ & Czech Republic & 20 & 14 & 29 & 21 & 15 & 29 \\
\hline Afr & Côte d'Ivoire & 22 & 7 & 71 & 19 & 5 & 71 \\
\hline Sear & $\begin{array}{l}\text { Democratic People's } \\
\text { Republic of Korea }\end{array}$ & 27 & 8 & 92 & 31 & 8 & 118 \\
\hline Afr & $\begin{array}{l}\text { Democratic Republic } \\
\text { of the Congo }\end{array}$ & 38 & 12 & 121 & 61 & 16 & 225 \\
\hline Eur (HIC) & Denmark & 10 & 7 & 16 & 11 & 7 & 17 \\
\hline Emr (LMIC) & Djibouti & 39 & 9 & 159 & 46 & 10 & 211 \\
\hline$A m r(L M I C)$ & Dominica & 13 & 6 & 28 & 13 & 6 & 28 \\
\hline$A m r(L M I C)$ & Dominican Republic & 16 & 7 & 37 & 17 & 7 & 40 \\
\hline$A m r(L M I C)$ & Ecuador & 13 & 9 & 20 & 13 & 9 & 20 \\
\hline Emr (LMIC) & Egypt & 93 & 50 & 171 & 101 & 54 & 188 \\
\hline Amr (LMIC) & El Salvador & 35 & 20 & 62 & 37 & 22 & 64 \\
\hline Afr & Equatorial Guinea & 33 & 7 & 153 & 32 & 8 & 128 \\
\hline Afr & Eritrea & 35 & 10 & 126 & 36 & 9 & 138 \\
\hline $\operatorname{Eur}(H I C)$ & Estonia & 8 & 5 & 13 & 8 & 5 & 13 \\
\hline Afr & Ethiopia & 30 & 9 & 94 & 36 & 10 & 132 \\
\hline Wpr (LMIC) & Fiji & 6 & 2 & 22 & 6 & 2 & 22 \\
\hline Eur (HIC) & Finland & 7 & 5 & 11 & 7 & 5 & 11 \\
\hline Eur (HIC) & France & 12 & 8 & 17 & 13 & 9 & 18 \\
\hline Afr & Gabon & 30 & 8 & 115 & 36 & 7 & 169 \\
\hline Afr & Gambia & 39 & 7 & 234 & 43 & 6 & 306 \\
\hline Eur (LMIC) & Georgia & 19 & 11 & 33 & 23 & 13 & 40 \\
\hline
\end{tabular}




\begin{tabular}{|c|c|c|c|c|c|c|c|}
\hline \multirow[b]{2}{*}{ Region } & \multirow[b]{2}{*}{ Country } & \multicolumn{3}{|c|}{$P M_{2.5}\left[\mu g / m^{3}\right]$, urban and rural areas } & \multicolumn{3}{|c|}{$P M_{2.5}\left[\mu \mathrm{g} / \mathrm{m}^{3}\right]$, urban areas } \\
\hline & & Median & Lower & Upper & Median & Lower & Upper \\
\hline Eur (HIC) & Germany & 14 & 9 & 20 & 14 & 10 & 21 \\
\hline Afr & Ghana & 24 & 12 & 46 & 22 & 10 & 46 \\
\hline Eur (HIC) & Greece & 12 & 8 & 18 & 13 & 9 & 18 \\
\hline$A m r(L M I C)$ & Grenada & 14 & 6 & 31 & 14 & 6 & 32 \\
\hline$A m r(L M I C)$ & Guatemala & 32 & 20 & 51 & 33 & 23 & 49 \\
\hline Afr & Guinea & 21 & 7 & 66 & 19 & 5 & 68 \\
\hline Afr & Guinea-Bissau & 27 & 7 & 103 & 29 & 6 & 138 \\
\hline$A m r(L M I C)$ & Guyana & 15 & 5 & 45 & 16 & 5 & 54 \\
\hline$A m r(L M I C)$ & Haiti & 22 & 7 & 63 & 25 & 8 & 79 \\
\hline$A m r(L M I C)$ & Honduras & 35 & 20 & 60 & 40 & 23 & 68 \\
\hline Eur (LMIC) & Hungary & 21 & 14 & 32 & 23 & 16 & 33 \\
\hline Eur $(H I C)$ & Iceland & 8 & 5 & 12 & 8 & 5 & 12 \\
\hline Sear & India & 62 & 41 & 95 & 66 & 45 & 97 \\
\hline Sear & Indonesia & 14 & 9 & 23 & 18 & 11 & 28 \\
\hline Emr (LMIC) & Iran (Islamic Republic of) & 42 & 27 & 63 & 40 & 28 & 58 \\
\hline Emr (LMIC) & Iraq & 50 & 18 & 141 & 51 & 17 & 154 \\
\hline Eur (HIC) & Ireland & 9 & 6 & 14 & 10 & 7 & 14 \\
\hline Eur (HIC) & Israel & 19 & 13 & 28 & 19 & 14 & 27 \\
\hline Eur (HIC) & Italy & 17 & 12 & 25 & 18 & 13 & 26 \\
\hline$A m r(L M I C)$ & Jamaica & 16 & 11 & 25 & 17 & 12 & 25 \\
\hline Wpr (HIC) & Japan & 13 & 8 & 19 & 13 & 9 & 19 \\
\hline Emr (LMIC) & Jordan & 36 & 24 & 53 & 38 & 27 & 52 \\
\hline Eur (LMIC) & Kazakhstan & 15 & 6 & 43 & 21 & 7 & 67 \\
\hline Afr & Kenya & 16 & 9 & 28 & 17 & 10 & 29 \\
\hline Wpr (LMIC) & Kiribati & 5 & 1 & 20 & NA & NA & NA \\
\hline$E m r(H I C)$ & Kuwait & 75 & 50 & 112 & 78 & 53 & 116 \\
\hline Eur (LMIC) & Kyrgyzstan & 15 & 8 & 27 & 15 & 8 & 28 \\
\hline Wpr (LMIC) & $\begin{array}{l}\text { Lao People's Democratic } \\
\text { Republic }\end{array}$ & 27 & 9 & 76 & 34 & 10 & 106 \\
\hline Eur (HIC) & Latvia & 19 & 12 & 29 & 20 & 13 & 31 \\
\hline Emr (LMIC) & Lebanon & 30 & 19 & 45 & 31 & 21 & 45 \\
\hline Afr & Lesotho & 18 & 4 & 76 & 22 & 4 & 113 \\
\hline Afr & Liberia & 8 & 4 & 17 & 6 & 3 & 15 \\
\hline Emr (LMIC) & Libya & 61 & 22 & 171 & 58 & 19 & 175 \\
\hline Eur (HIC) & Lithuania & 18 & 12 & 28 & 19 & 13 & 28 \\
\hline Eur (HIC) & Luxembourg & 16 & 11 & 24 & 17 & 12 & 23 \\
\hline Afr & Madagascar & 17 & 9 & 33 & 32 & 19 & 54 \\
\hline Afr & Malawi & 22 & 7 & 72 & 26 & 7 & 95 \\
\hline Wpr (LMIC) & Malaysia & 15 & 9 & 24 & 17 & 10 & 26 \\
\hline Sear & Maldives & 16 & 8 & 29 & NA & NA & NA \\
\hline
\end{tabular}


$P M_{2.5}\left[\mu \mathrm{g} / \mathrm{m}^{3}\right]$, urban and rural areas

$P M_{2.5}\left[\mu \mathrm{g} / \mathrm{m}^{3}\right]$, urban areas

\begin{tabular}{|c|c|c|c|c|c|c|c|}
\hline Region & Country & Median & Lower & Upper & Median & Lower & Upper \\
\hline Afr & Mali & 39 & 13 & 124 & 35 & 10 & 120 \\
\hline Eur (HIC) & Malta & 14 & 9 & 21 & 14 & 10 & 20 \\
\hline Wpr (LMIC) & Marshall Islands & NA & NA & NA & NA & NA & NA \\
\hline Afr & Mauritania & 65 & 19 & 230 & 86 & 21 & 368 \\
\hline Afr & Mauritius & 14 & 9 & 23 & 14 & 8 & 24 \\
\hline$A m r(L M I C)$ & Mexico & 20 & 13 & 30 & 20 & 13 & 31 \\
\hline Wpr (LMIC) & $\begin{array}{l}\text { Micronesia (Federated } \\
\text { States of) }\end{array}$ & 6 & 2 & 22 & 6 & 2 & 23 \\
\hline Eur (HIC) & Monaco & 9 & 6 & 18 & 9 & 6 & 18 \\
\hline Wpr (LMIC) & Mongolia & 20 & 13 & 32 & 32 & 20 & 51 \\
\hline Eur (LMIC) & Montenegro & 22 & 14 & 35 & 24 & 15 & 38 \\
\hline Emr (LMIC) & Morocco & 20 & 13 & 32 & 19 & 12 & 29 \\
\hline Afr & Mozambique & 17 & 6 & 47 & 22 & 7 & 69 \\
\hline Sear & Myanmar & 51 & 32 & 80 & 57 & 35 & 90 \\
\hline Afr & Namibia & 18 & 6 & 51 & 18 & 6 & 57 \\
\hline Wpr (LMIC) & Nauru & NA & NA & NA & NA & NA & NA \\
\hline Sear & Nepal & 64 & 33 & 123 & 74 & 39 & 140 \\
\hline Eur (HIC) & Netherlands & 15 & 10 & 22 & 15 & 10 & 22 \\
\hline Wpr (HIC) & New Zealand & 5 & 4 & 8 & 5 & 4 & 8 \\
\hline$A m r(L M I C)$ & Nicaragua & 24 & 8 & 74 & 26 & 7 & 95 \\
\hline Afr & Niger & 59 & 19 & 191 & 51 & 15 & 177 \\
\hline Afr & Nigeria & 39 & 25 & 61 & 38 & 24 & 58 \\
\hline Wpr (LMIC) & Niue & NA & NA & NA & NA & NA & NA \\
\hline Eur (HIC) & Norway & 9 & 6 & 13 & 9 & 6 & 14 \\
\hline Emr (HIC) & Oman & 48 & 18 & 132 & 47 & 15 & 145 \\
\hline Emr (LMIC) & Pakistan & 60 & 37 & 97 & 68 & 43 & 107 \\
\hline Wpr (LMIC) & Palau & NA & NA & NA & NA & NA & NA \\
\hline$A m r(L M I C)$ & Panama & 12 & 7 & 20 & 13 & 7 & 23 \\
\hline Wpr (LMIC) & Papua New Guinea & 10 & 2 & 45 & 12 & 2 & 71 \\
\hline$A m r(L M I C)$ & Paraguay & 15 & 9 & 25 & 17 & 10 & 28 \\
\hline$A m r(L M I C)$ & Peru & 26 & 16 & 42 & 36 & 23 & 54 \\
\hline Wpr (LMIC) & Philippines & 22 & 14 & 35 & 27 & 17 & 43 \\
\hline Eur $(H I C)$ & Poland & 24 & 16 & 35 & 25 & 18 & 36 \\
\hline Eur $(H I C)$ & Portugal & 9 & 6 & 14 & 10 & 6 & 14 \\
\hline$E m r(H I C)$ & Qatar & 103 & 67 & 160 & 105 & 69 & 159 \\
\hline Wpr (HIC) & Republic of Korea & 27 & 18 & 39 & 28 & 19 & 40 \\
\hline Eur (LMIC) & Republic of Moldova & 17 & 5 & 59 & 17 & 4 & 68 \\
\hline Eur (LMIC) & Romania & 19 & 13 & 28 & 20 & 14 & 29 \\
\hline Eur (HIC) & Russian Federation & 15 & 8 & 27 & 17 & 9 & 31 \\
\hline Afr & Rwanda & 43 & 13 & 143 & 51 & 14 & 185 \\
\hline
\end{tabular}


$P M_{2.5}\left[\mu \mathrm{g} / \mathrm{m}^{3}\right]$, urban and rural areas

$P M_{2.5}\left[\mu \mathrm{g} / \mathrm{m}^{3}\right]$, urban areas

\begin{tabular}{|c|c|c|c|c|c|c|c|}
\hline Region & Country & Median & Lower & Upper & Median & Lower & Upper \\
\hline$A m r(H I C)$ & Saint Kitts and Nevis & NA & NA & NA & NA & NA & NA \\
\hline$A m r(L M I C)$ & Saint Lucia & 15 & 7 & 31 & 15 & 7 & 32 \\
\hline$A m r(L M I C)$ & $\begin{array}{l}\text { Saint Vincent and the } \\
\text { Grenadines }\end{array}$ & 13 & 6 & 28 & NA & NA & NA \\
\hline Wpr (LMIC) & Samoa & NA & NA & NA & NA & NA & NA \\
\hline Eur $(H I C)$ & San Marino & NA & NA & NA & NA & NA & NA \\
\hline Afr & Sao Tome and Principe & 13 & 5 & 29 & NA & NA & NA \\
\hline$E m r(H I C)$ & Saudi Arabia & 108 & 67 & 174 & 127 & 79 & 205 \\
\hline Afr & Senegal & 34 & 21 & 55 & 43 & 29 & 64 \\
\hline Eur (LMIC) & Serbia & 19 & 12 & 31 & 21 & 14 & 33 \\
\hline Afr & Seychelles & 13 & 7 & 27 & 13 & 7 & 27 \\
\hline Afr & Sierra Leone & 17 & 4 & 69 & 17 & 3 & 86 \\
\hline Wpr (HIC) & Singapore & 17 & 9 & 31 & 17 & 9 & 31 \\
\hline Eur (HIC) & Slovakia & 19 & 13 & 29 & 20 & 14 & 29 \\
\hline Eur (HIC) & Slovenia & 18 & 12 & 27 & 19 & 14 & 28 \\
\hline Wpr (LMIC) & Solomon Islands & 5 & 1 & 18 & 5 & 1 & 19 \\
\hline Emr (LMIC) & Somalia & 16 & 5 & 49 & 17 & 4 & 66 \\
\hline Afr & South Africa & 27 & 18 & 42 & 31 & 21 & 48 \\
\hline Emr (LMIC) & South Sudan & 29 & 11 & 81 & 32 & 12 & 91 \\
\hline Eur (HIC) & Spain & 9 & 7 & 14 & 10 & 7 & 14 \\
\hline Sear & Sri Lanka & 27 & 14 & 51 & 28 & 15 & 55 \\
\hline$E m r(L M I C)$ & Sudan & 44 & 14 & 137 & 53 & 16 & 178 \\
\hline$A m r(L M I C)$ & Suriname & 16 & 5 & 51 & 16 & 4 & 63 \\
\hline Afr & Swaziland & 18 & 5 & 59 & 20 & 5 & 72 \\
\hline Eur (HIC) & Sweden & 6 & 4 & 9 & 6 & 4 & 9 \\
\hline Eur (HIC) & Switzerland & 12 & 8 & 18 & 13 & 8 & 18 \\
\hline$E m r(L M I C)$ & Syrian Arab Republic & 34 & 12 & 98 & 34 & 11 & 105 \\
\hline Eur (LMIC) & Tajikistan & 41 & 12 & 138 & 51 & 14 & 187 \\
\hline Sear & Thailand & 25 & 16 & 37 & 27 & 19 & 38 \\
\hline Eur (LMIC) & $\begin{array}{l}\text { The former Yugoslav } \\
\text { Republic of Macedonia }\end{array}$ & 37 & 23 & 59 & 43 & 28 & 65 \\
\hline Sear & Timor-Leste & 15 & 3 & 65 & 15 & 3 & 69 \\
\hline Afr & Togo & 28 & 8 & 107 & 26 & 6 & 113 \\
\hline Wpr (LMIC) & Tonga & NA & NA & NA & NA & NA & NA \\
\hline$A m r(H I C)$ & Trinidad and Tobago & 13 & 6 & 28 & 13 & 6 & 28 \\
\hline Emr (LMIC) & Tunisia & 36 & 22 & 61 & 35 & 21 & 59 \\
\hline Eur (LMIC) & Turkey & 34 & 22 & 50 & 35 & 24 & 51 \\
\hline Eur (LMIC) & Turkmenistan & 25 & 8 & 76 & 26 & 7 & 95 \\
\hline Wpr (LMIC) & Tuvalu & NA & NA & NA & NA & NA & NA \\
\hline Afr & Uganda & 57 & 30 & 108 & 80 & 46 & 138 \\
\hline Eur (LMIC) & Ukraine & 16 & 6 & 44 & 17 & 6 & 48 \\
\hline
\end{tabular}




\begin{tabular}{|c|c|c|c|c|c|c|c|}
\hline \multirow[b]{2}{*}{ Region } & \multirow[b]{2}{*}{ Country } & \multicolumn{3}{|c|}{$P M_{2.5}\left[\mu \mathrm{g} / \mathrm{m}^{3}\right]$, urban and rural areas } & \multicolumn{3}{|c|}{$P M_{2.5}\left[\mu \mathrm{g} / \mathrm{m}^{3}\right]$, urban areas } \\
\hline & & Median & Lower & Upper & Median & Lower & Upper \\
\hline $\operatorname{Emr}(H I C)$ & United Arab Emirates & 64 & 39 & 104 & 64 & 39 & 106 \\
\hline Eur $(H I C)$ & United Kingdom & 12 & 8 & 18 & 12 & 8 & 18 \\
\hline Afr & $\begin{array}{l}\text { United Republic } \\
\text { of Tanzania }\end{array}$ & 22 & 11 & 42 & 24 & 12 & 47 \\
\hline$A m r(H I C)$ & United States of America & 8 & 5 & 12 & 8 & 6 & 12 \\
\hline$A m r(H I C)$ & Uruguay & 11 & 8 & 17 & 11 & 8 & 17 \\
\hline Eur (LMIC) & Uzbekistan & 32 & 10 & 102 & 38 & 12 & 128 \\
\hline Wpr (LMIC) & Vanuatu & 6 & 2 & 23 & 7 & 2 & 26 \\
\hline Amr (LMIC) & $\begin{array}{l}\text { Venezuela, Bolivarian } \\
\text { Republic of }\end{array}$ & 22 & 13 & 39 & 24 & 14 & 41 \\
\hline Wpr (LMIC) & Viet Nam & 26 & 15 & 43 & 28 & 17 & 45 \\
\hline Emr (LMIC) & Yemen & 43 & 11 & 173 & 42 & 9 & 208 \\
\hline Afr & Zambia & 23 & 9 & 64 & 29 & 10 & 90 \\
\hline Afr & Zimbabwe & 20 & 7 & 55 & 24 & 8 & 75 \\
\hline
\end{tabular}

$\mathrm{PM}_{2.5}$ : Particulate matter of a diameter of $2.5 \mathrm{~mm}$ or less; ALRI: Acute lower respiratory disease; COPD: Chronic obstructive pulmonary disease; IHD: Ischaemic heart disease. Afr: Africa; Amr: America; Emr: Eastern Mediterranean; Eur: Europe; Sear : South-East Asia; Wpr: Western Pacific; LMIC : Low- and middle-income countries; HIC : High-income countries; NA: Not available.

Wherever possible, estimates of $\mathrm{PM}_{2.5}$ have been computed using standardized categories and methods in order to enhance cross-national comparability. This approach may result in some cases in differences between the estimates presented here and the official national statistics prepared and endorsed by individual WHO Member States.

These differences between $\mathrm{WHO}$ and national statistics may be larger for occur in countries with small cities and settlements which may not be fully represented by the resolution of the WHO model. This may be compounded for isolated regions where air pollution is primarily from local sources and is experienced at very local levels. 
Annex 2: Deaths, YLLs and
DALYs attributable to ambient
air pollution, by country 


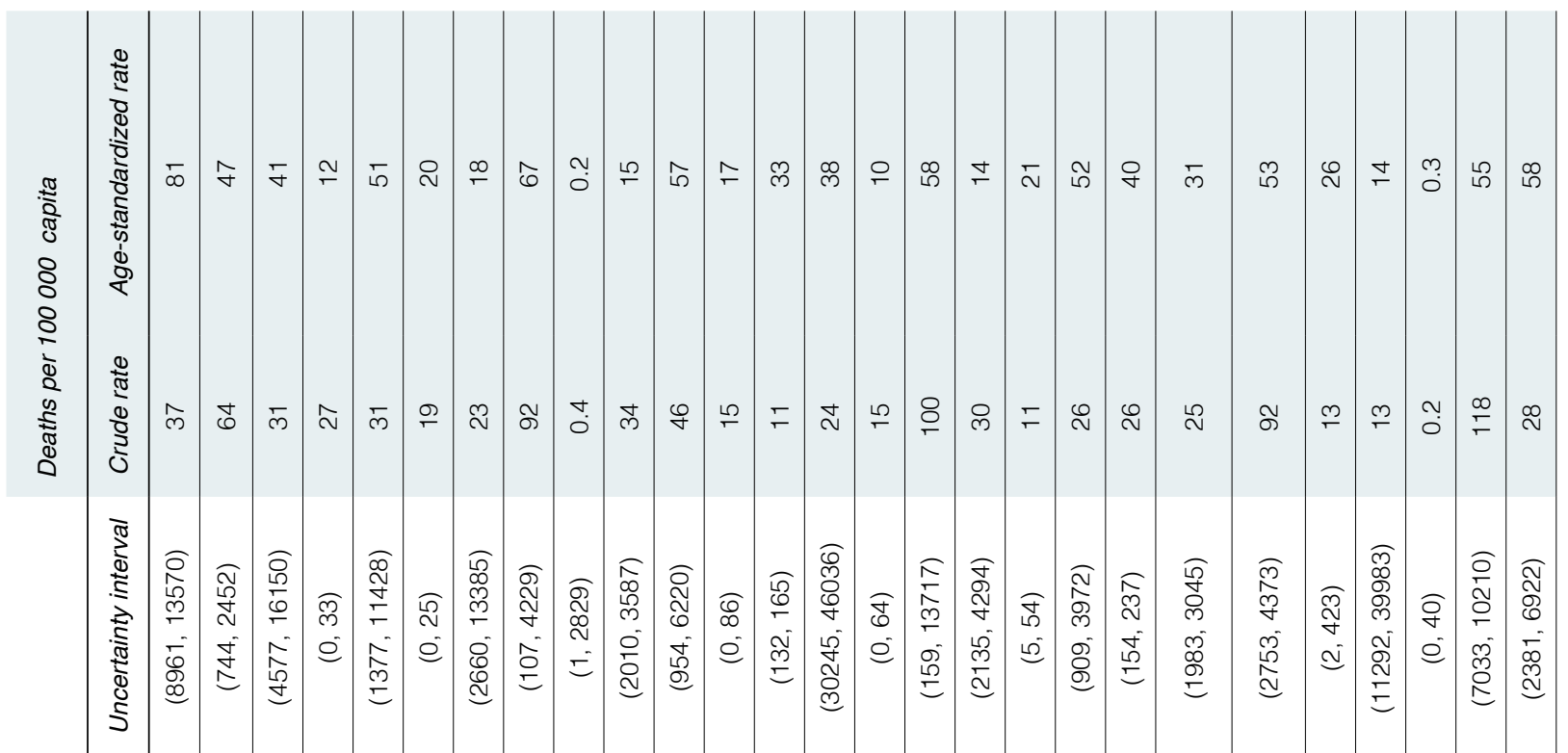

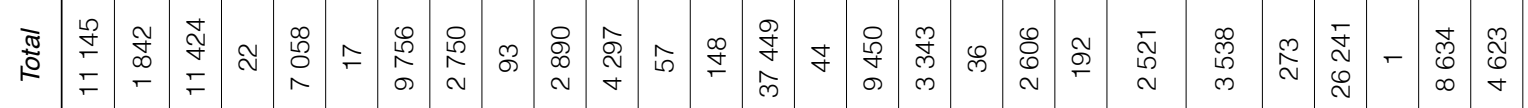

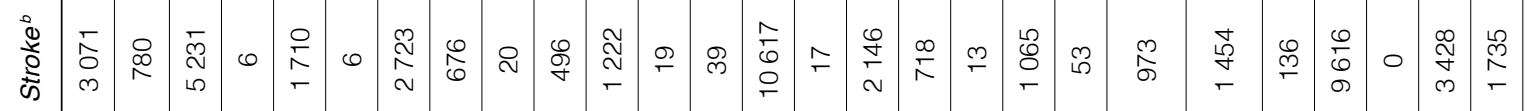

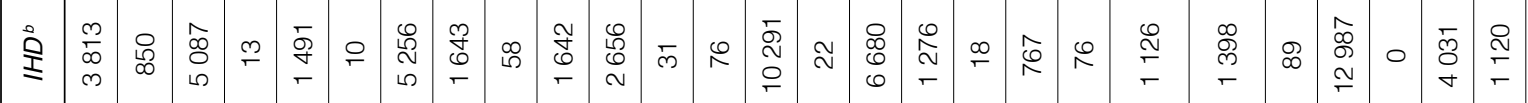

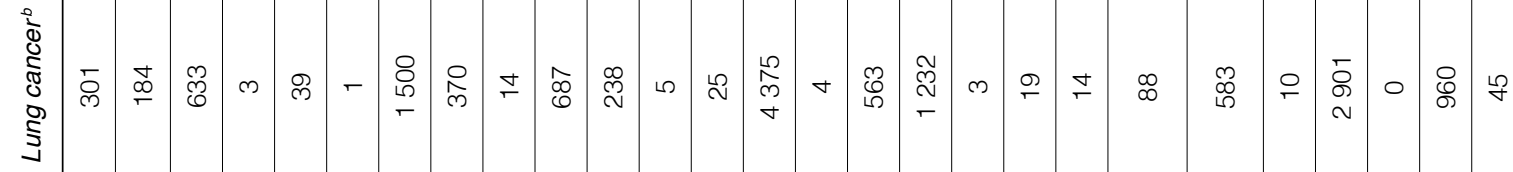

竎

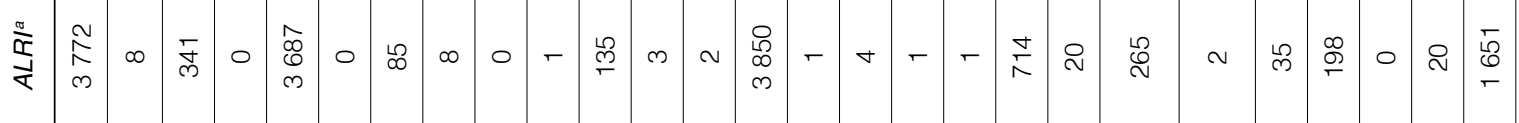

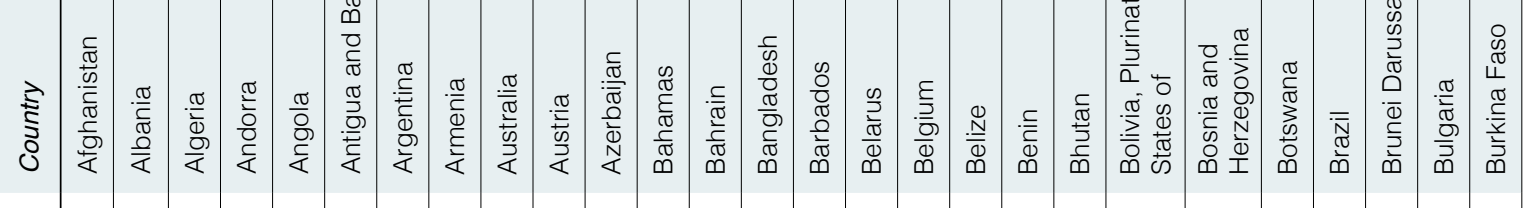

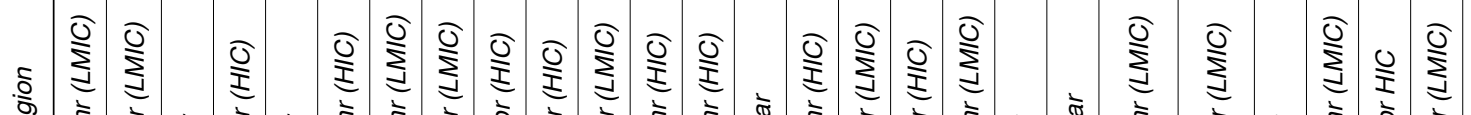

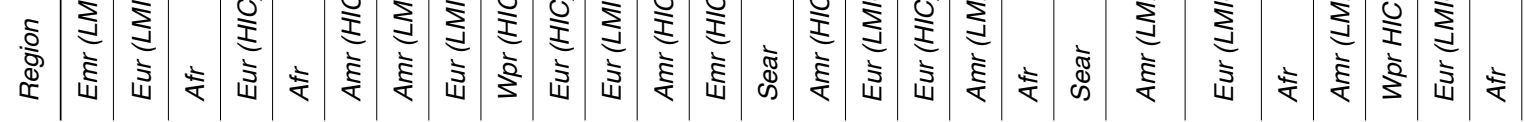




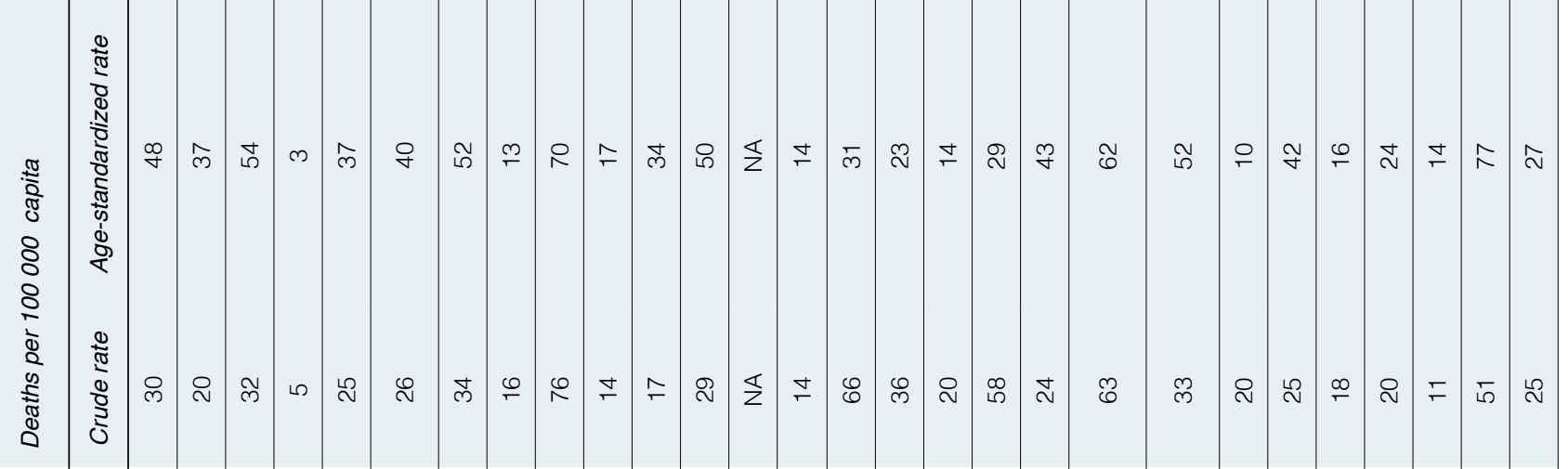

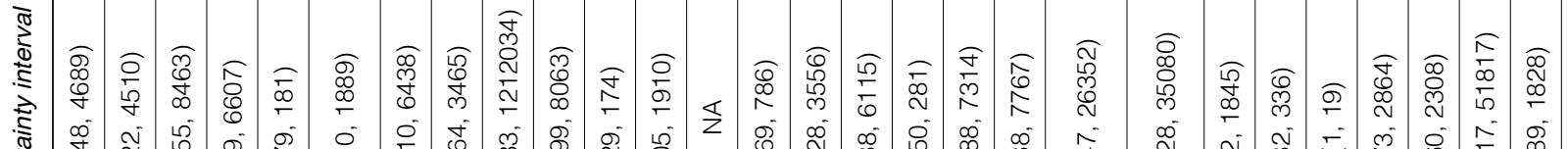

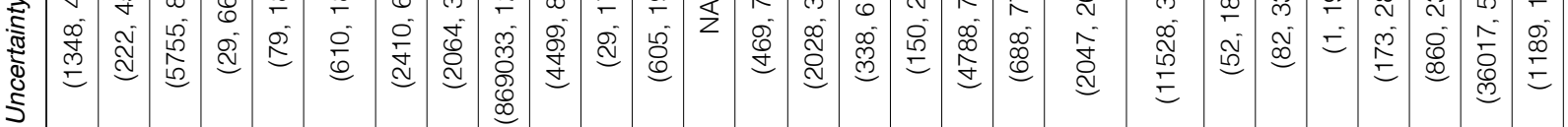

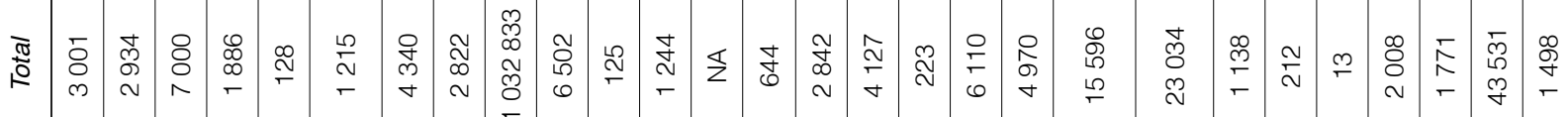

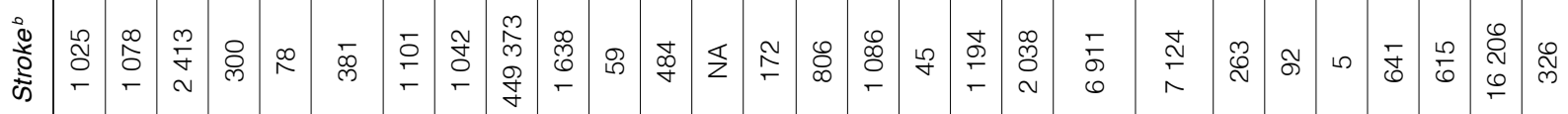

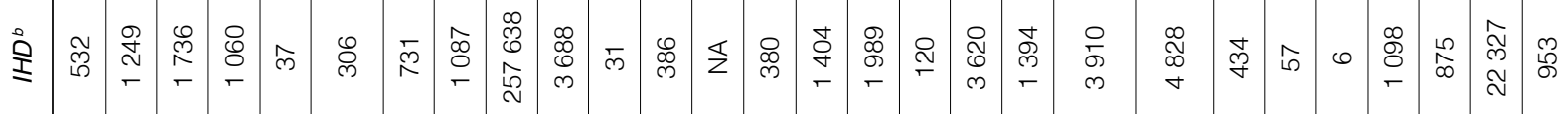

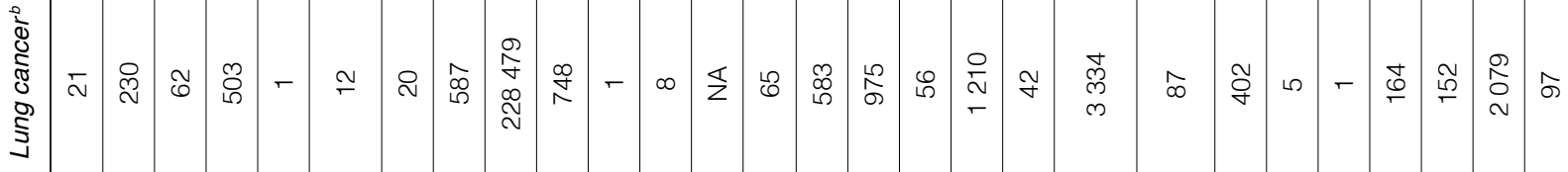

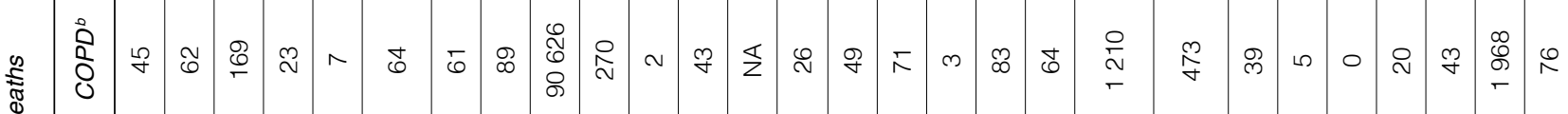

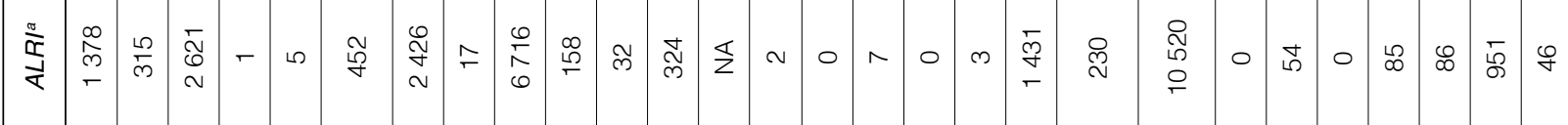

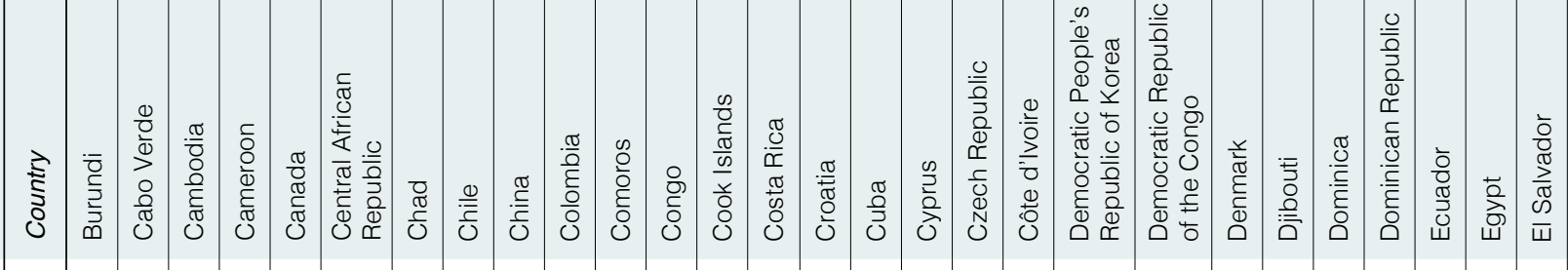

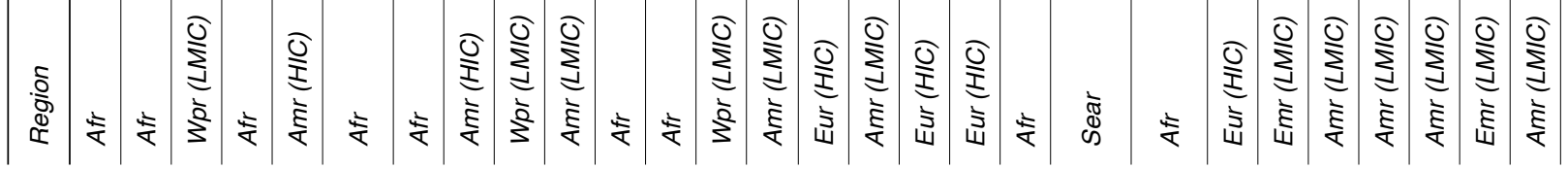




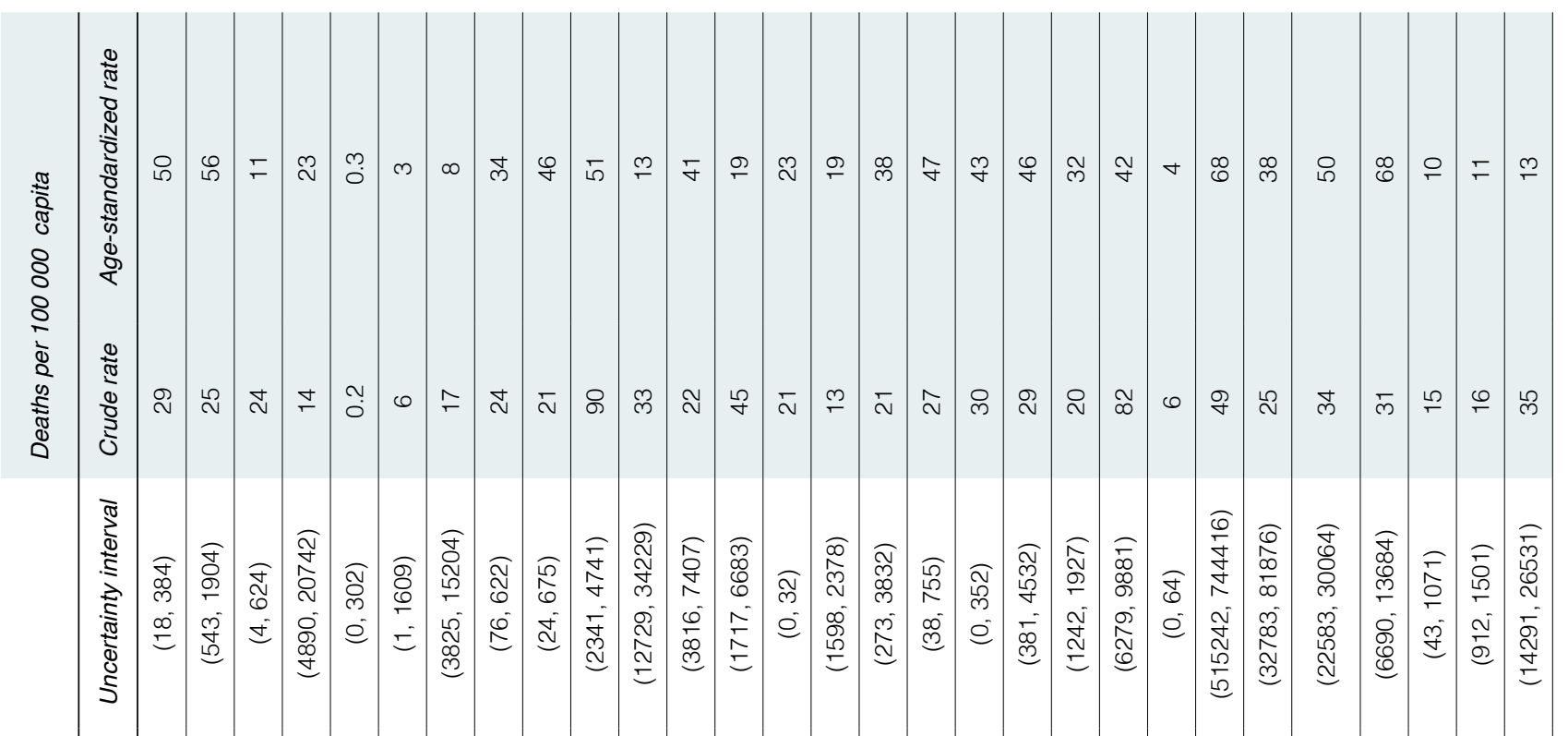

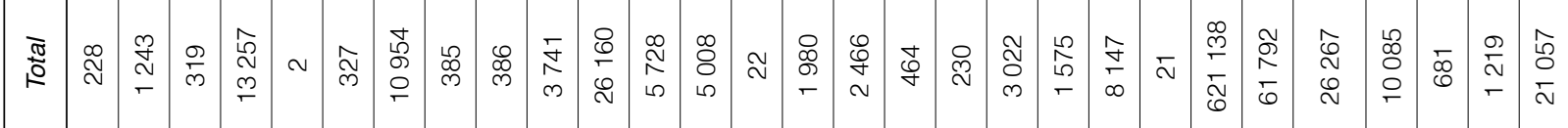

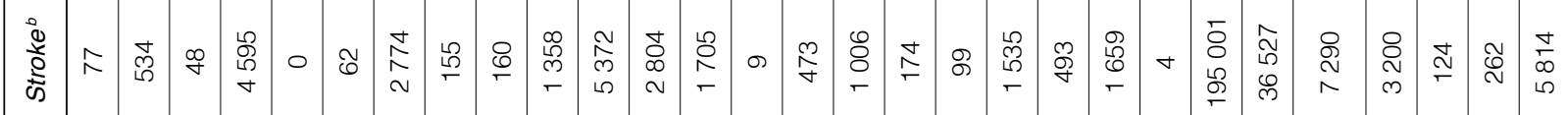

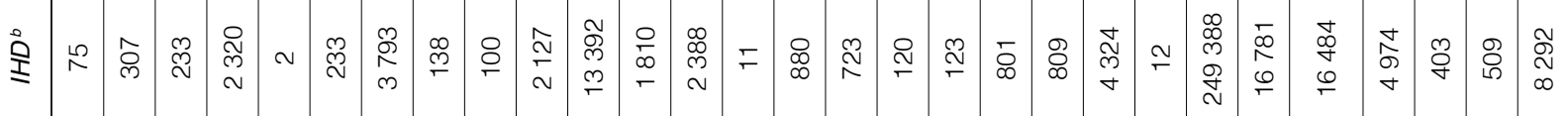

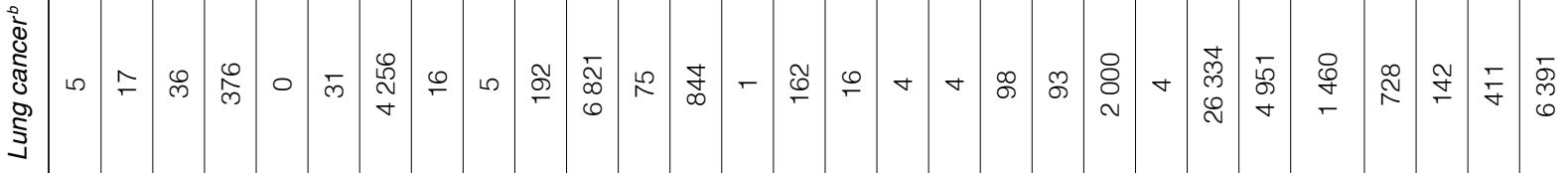

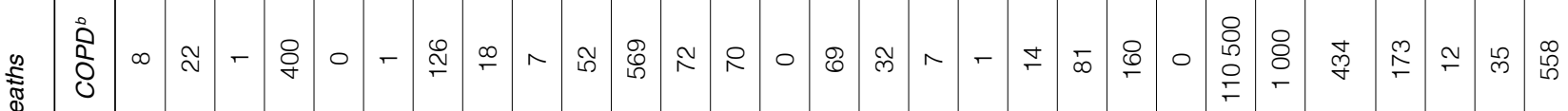

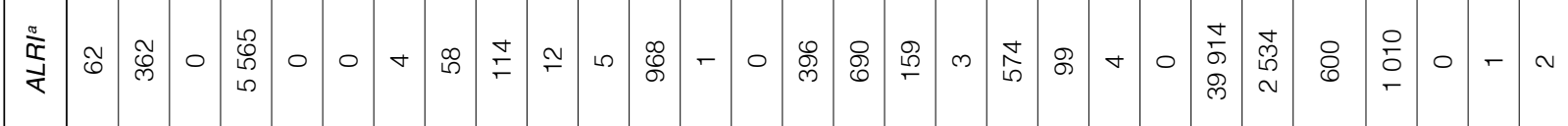

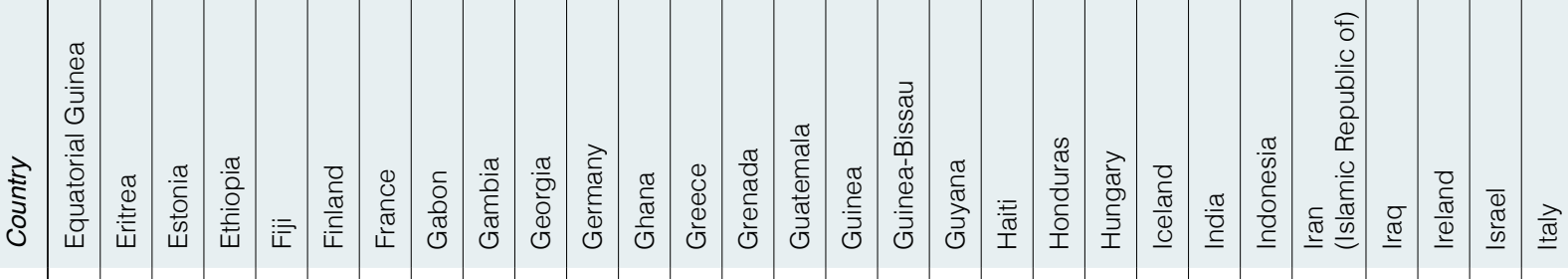

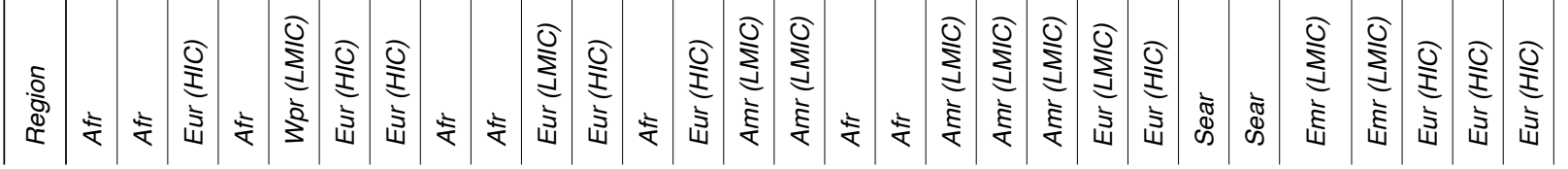




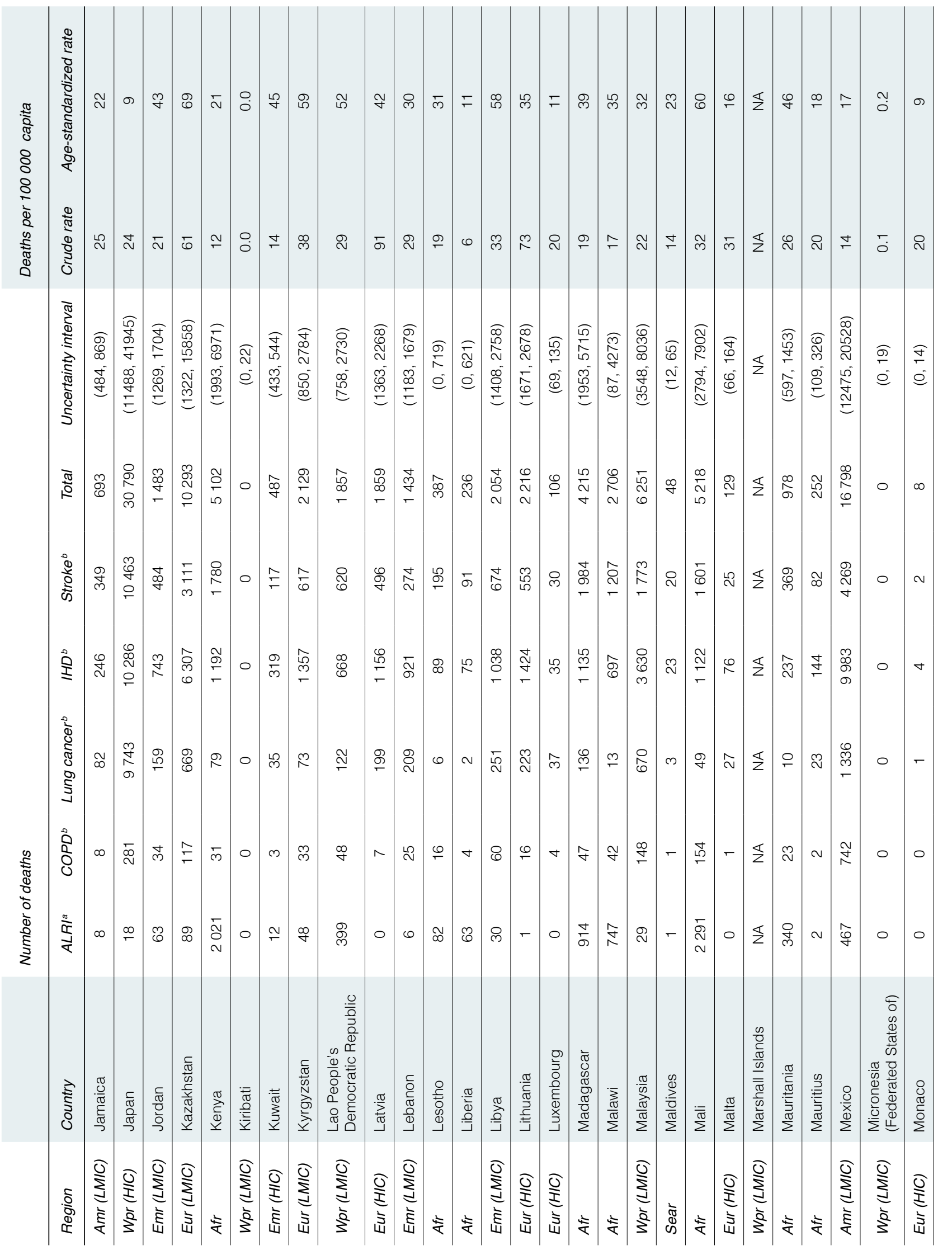




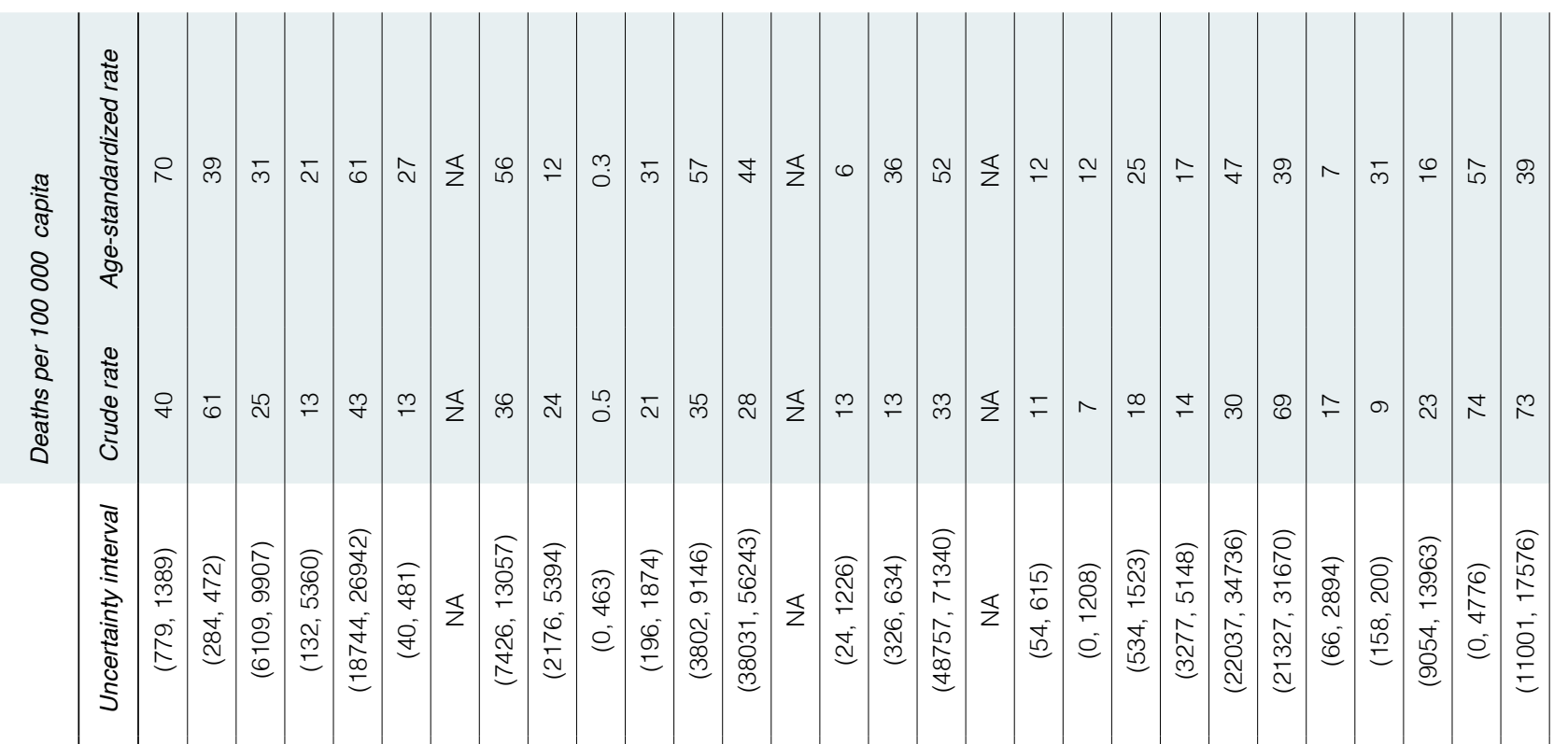

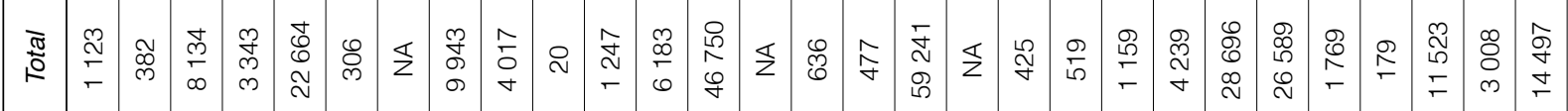

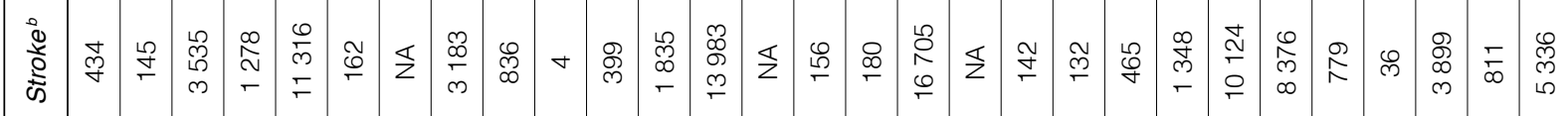

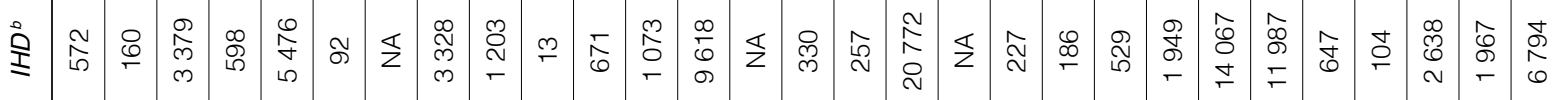

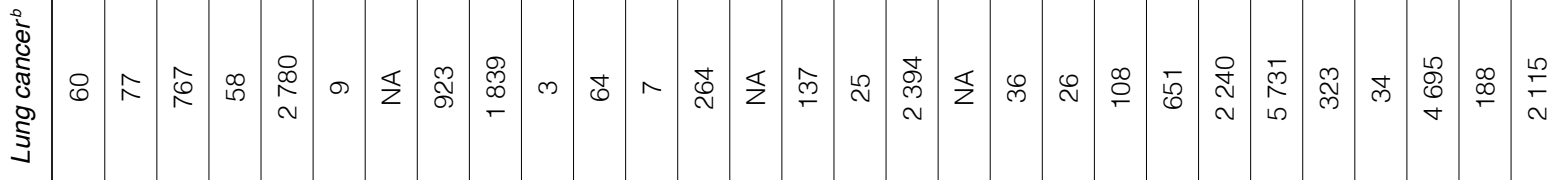

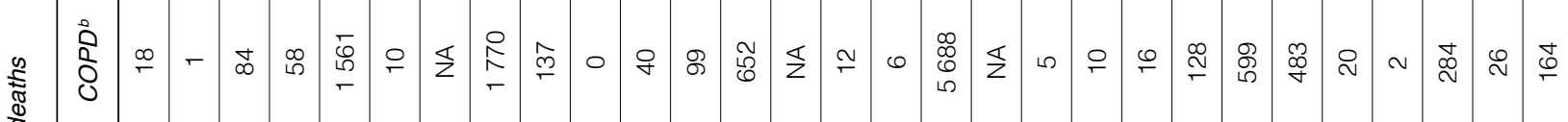

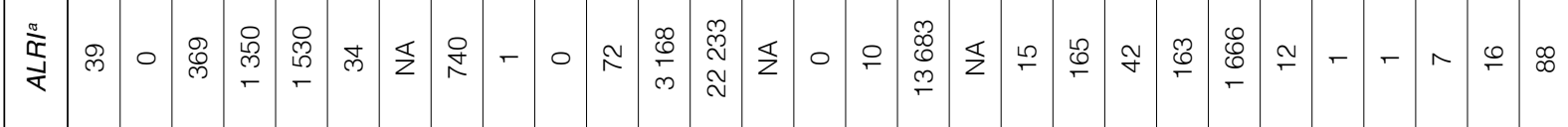

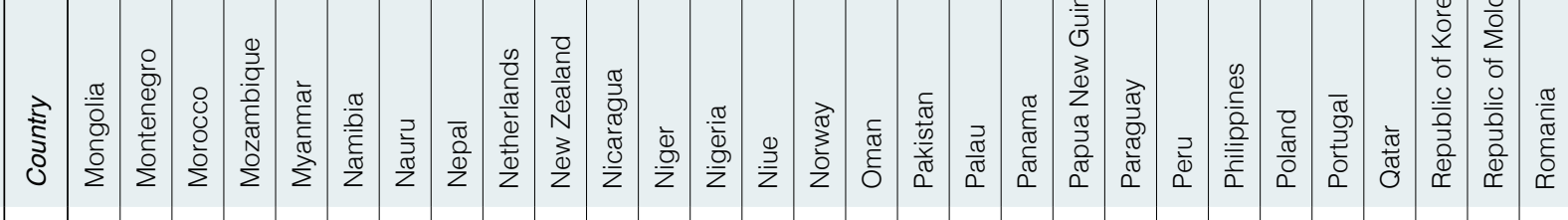

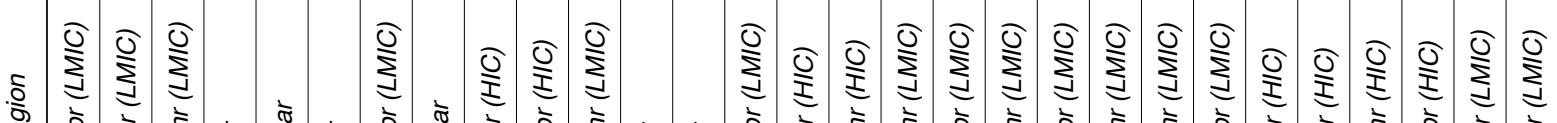

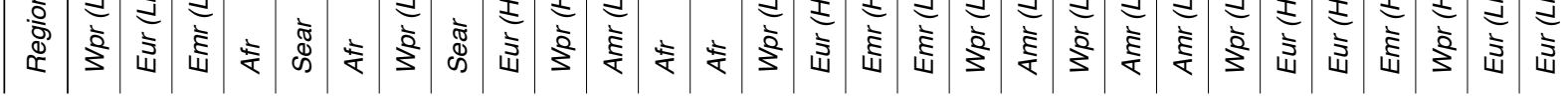




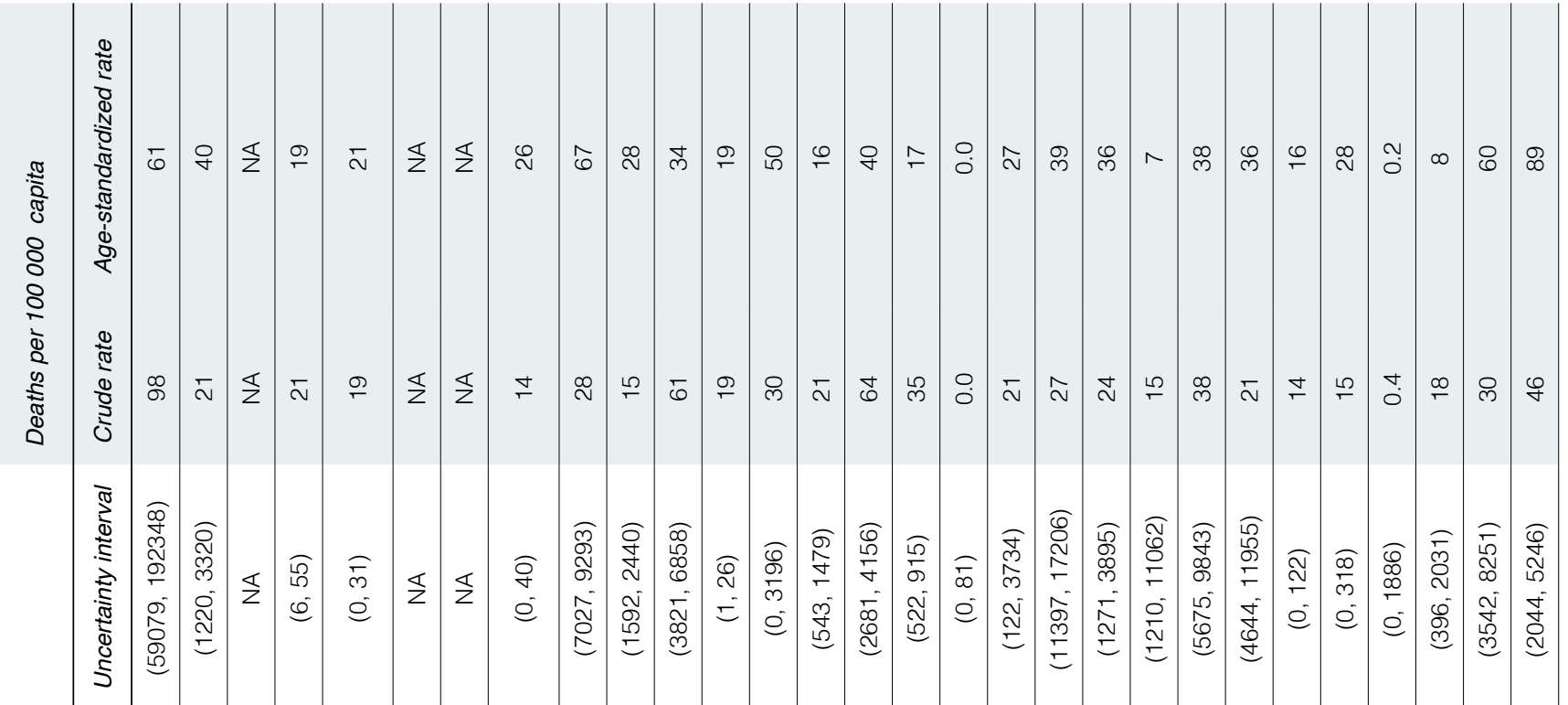

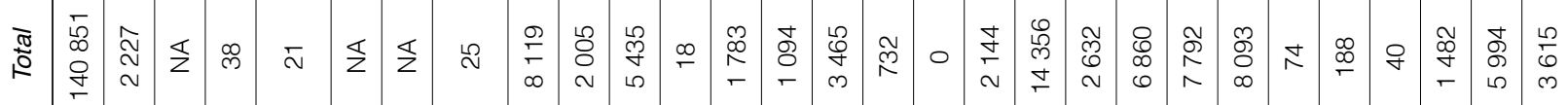

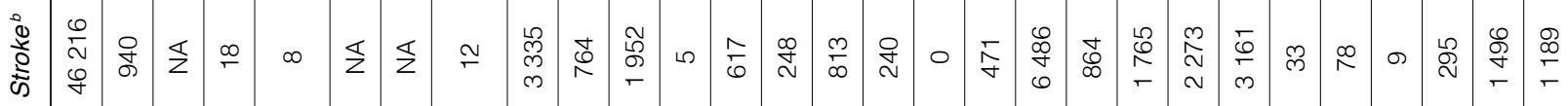

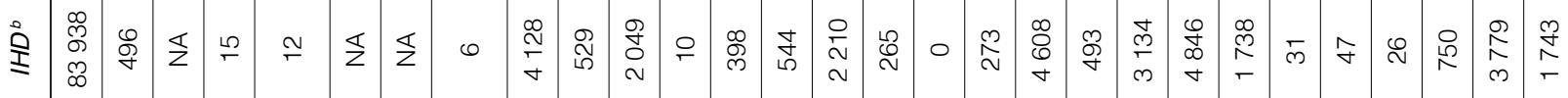

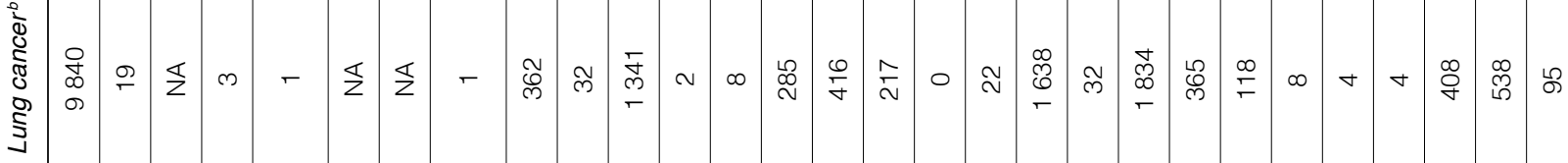
定

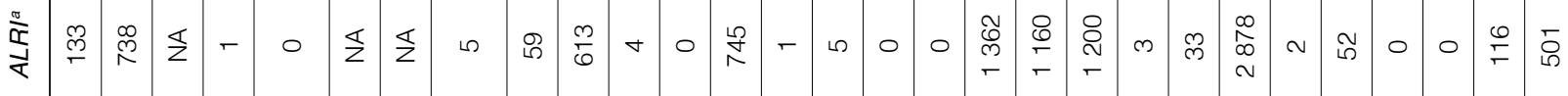

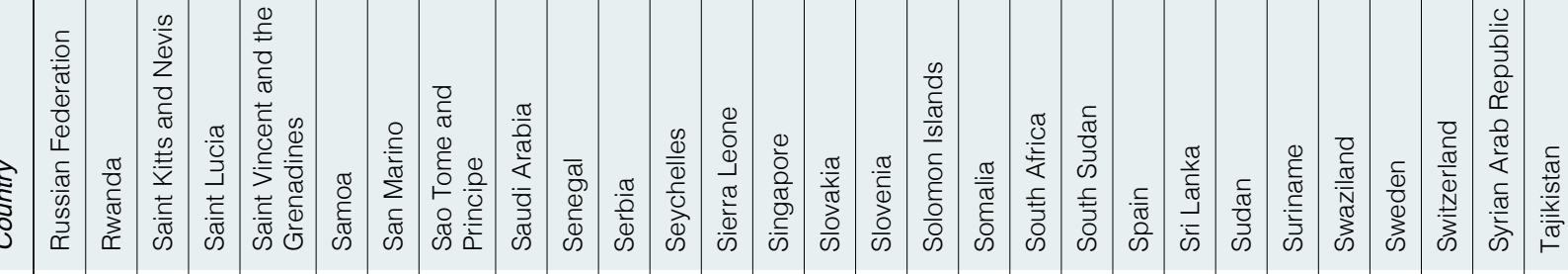
. 勇焉安产旁 


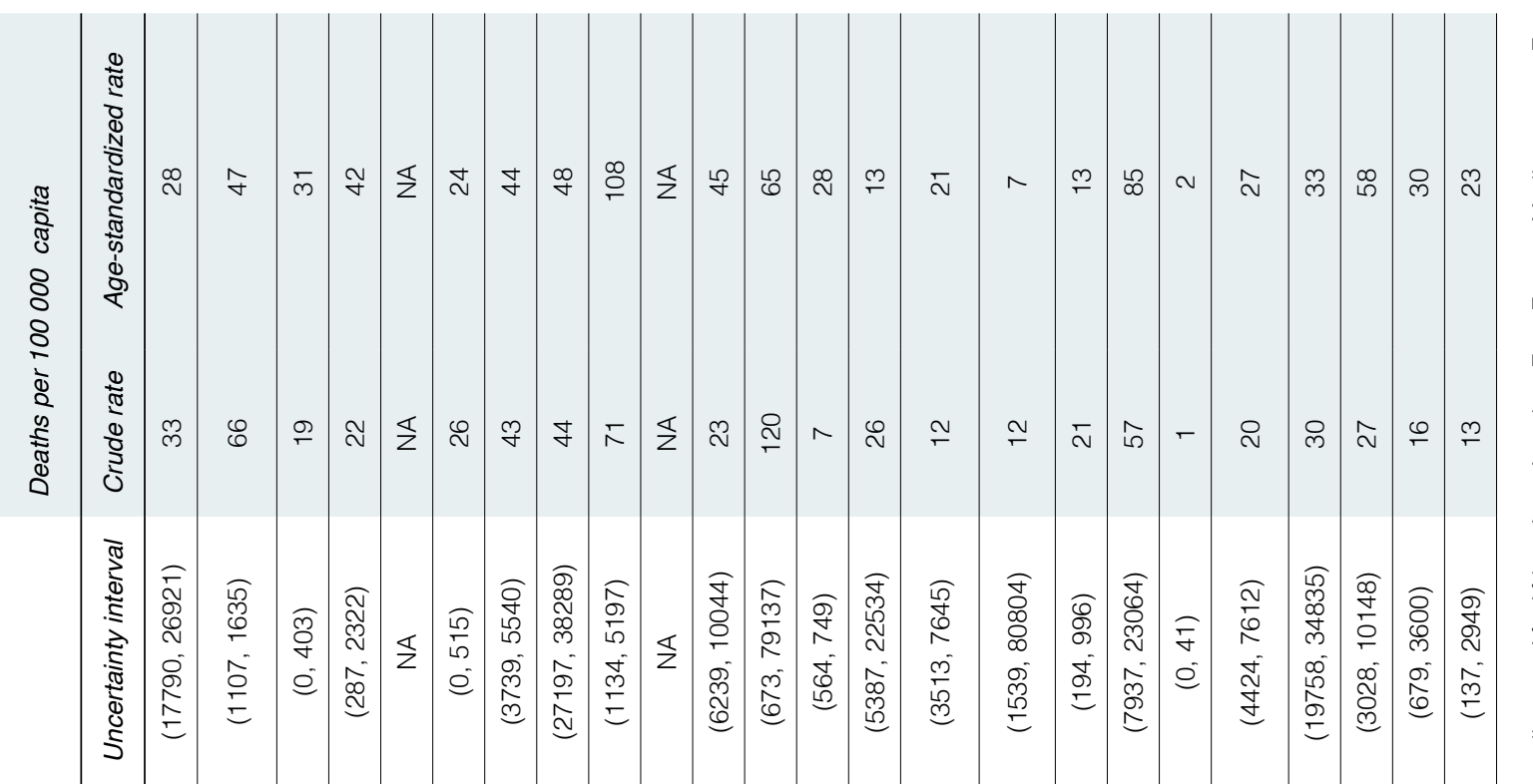

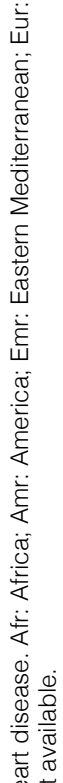

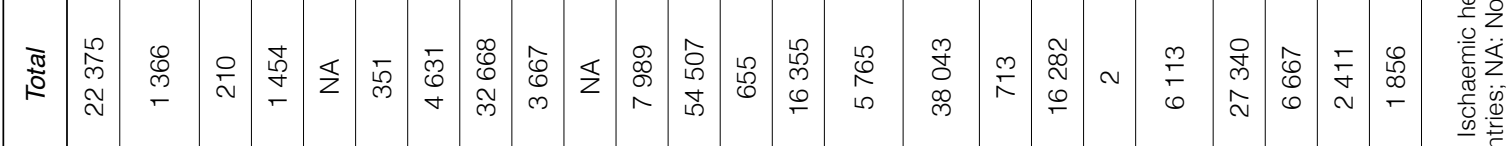

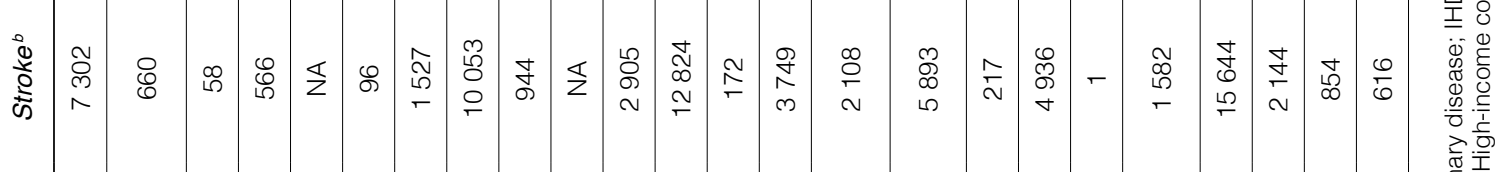

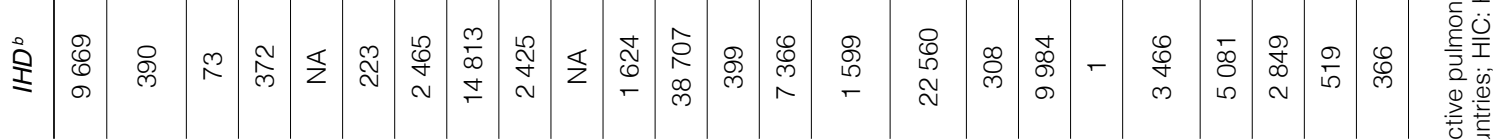

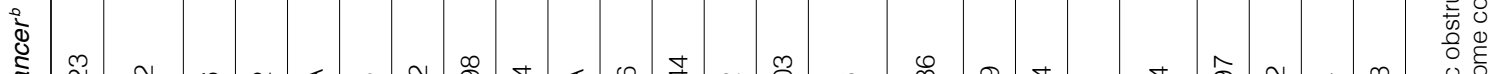

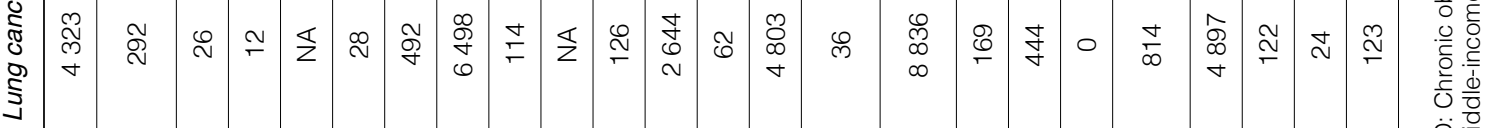

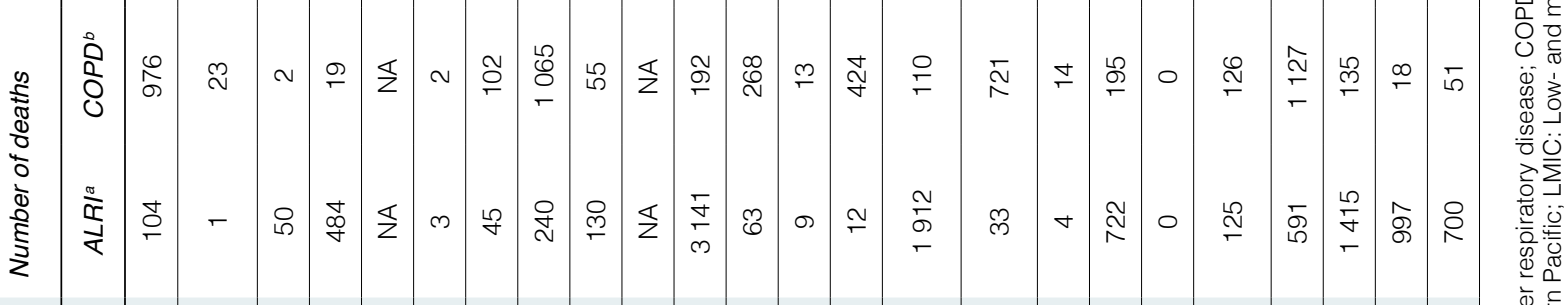

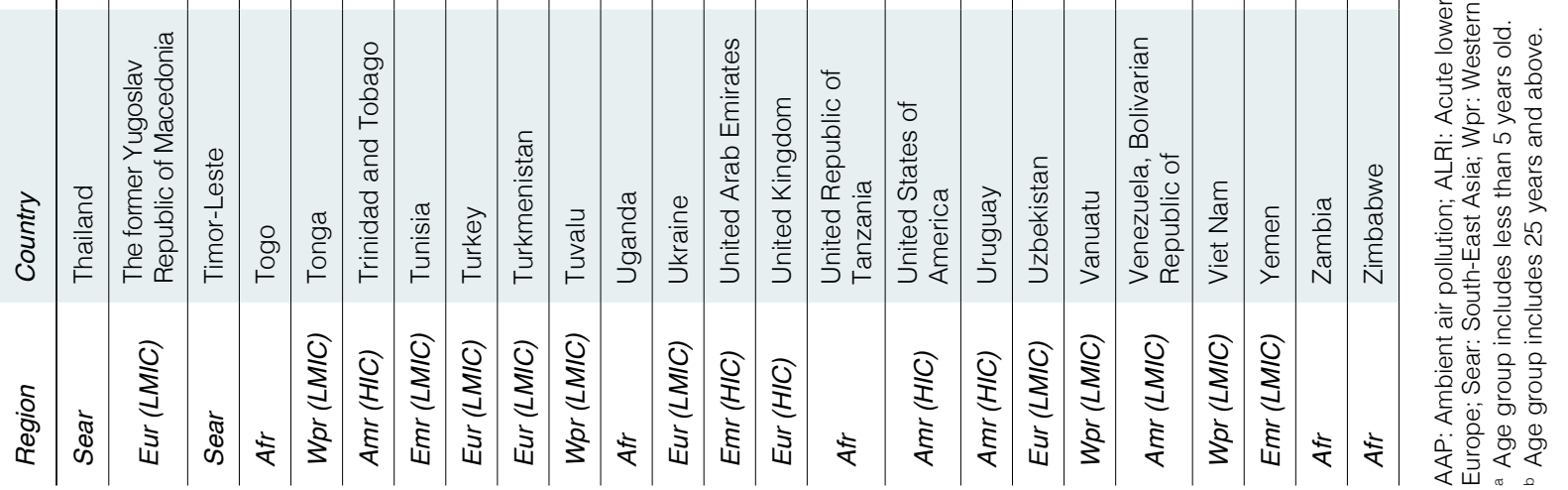




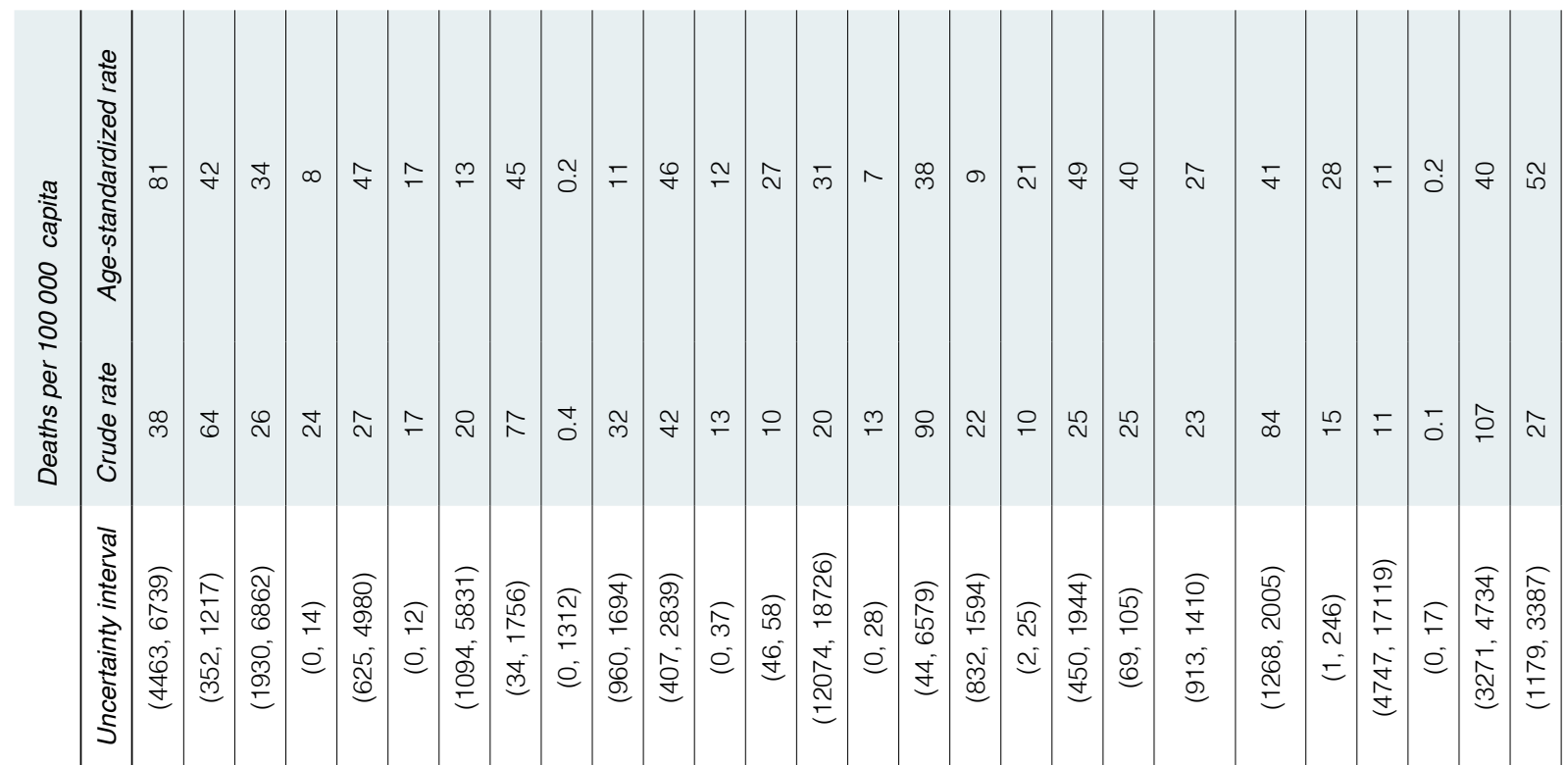

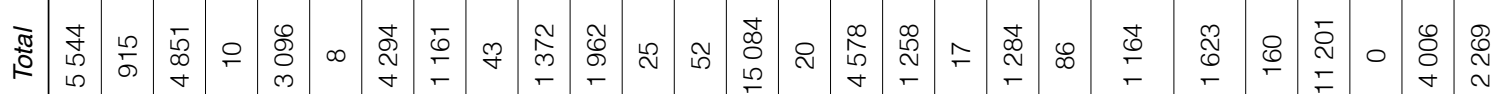

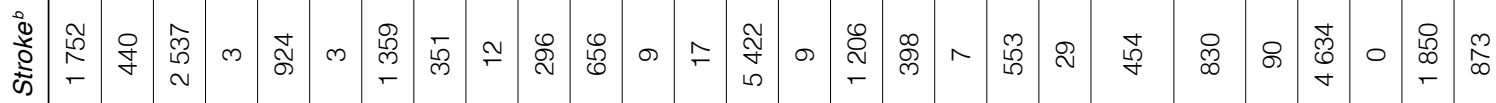

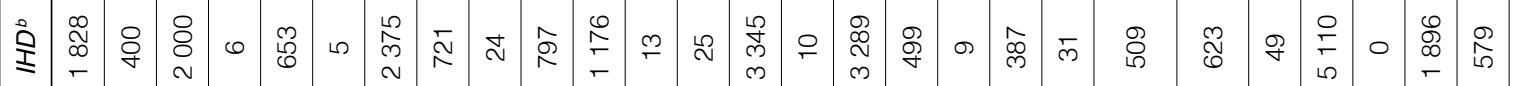

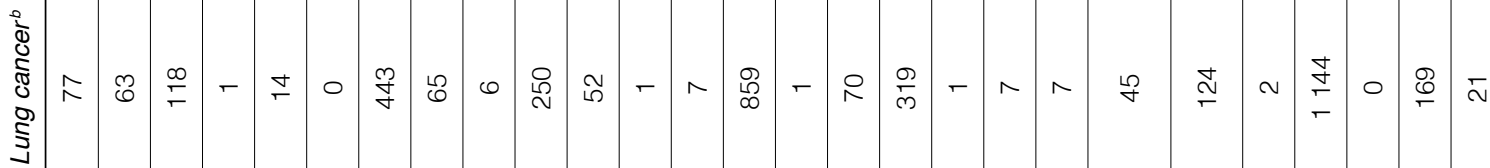

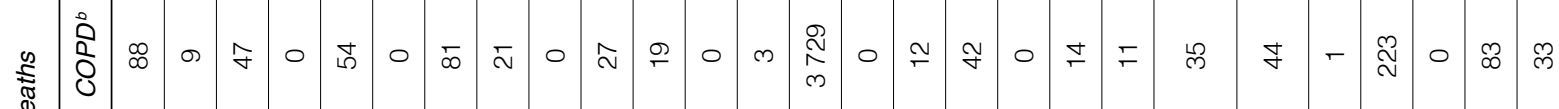

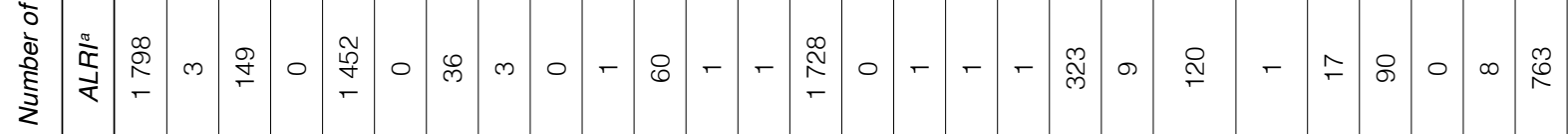

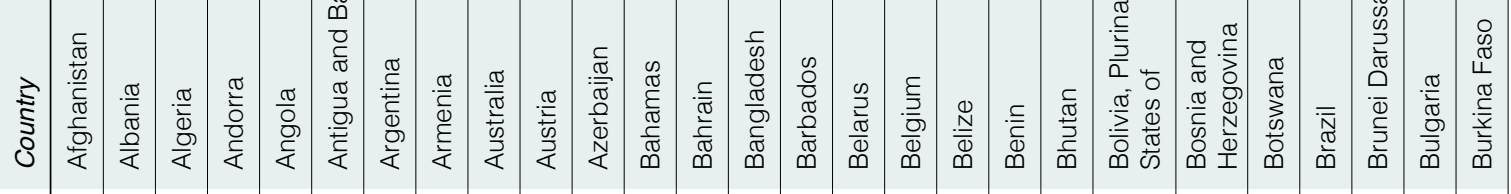

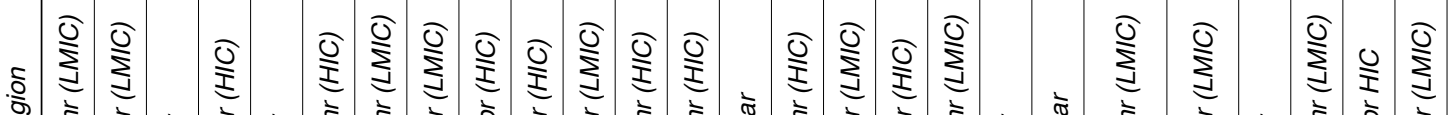

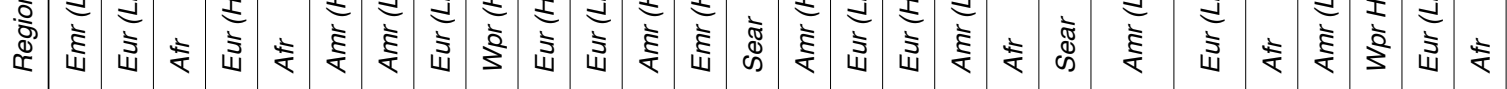




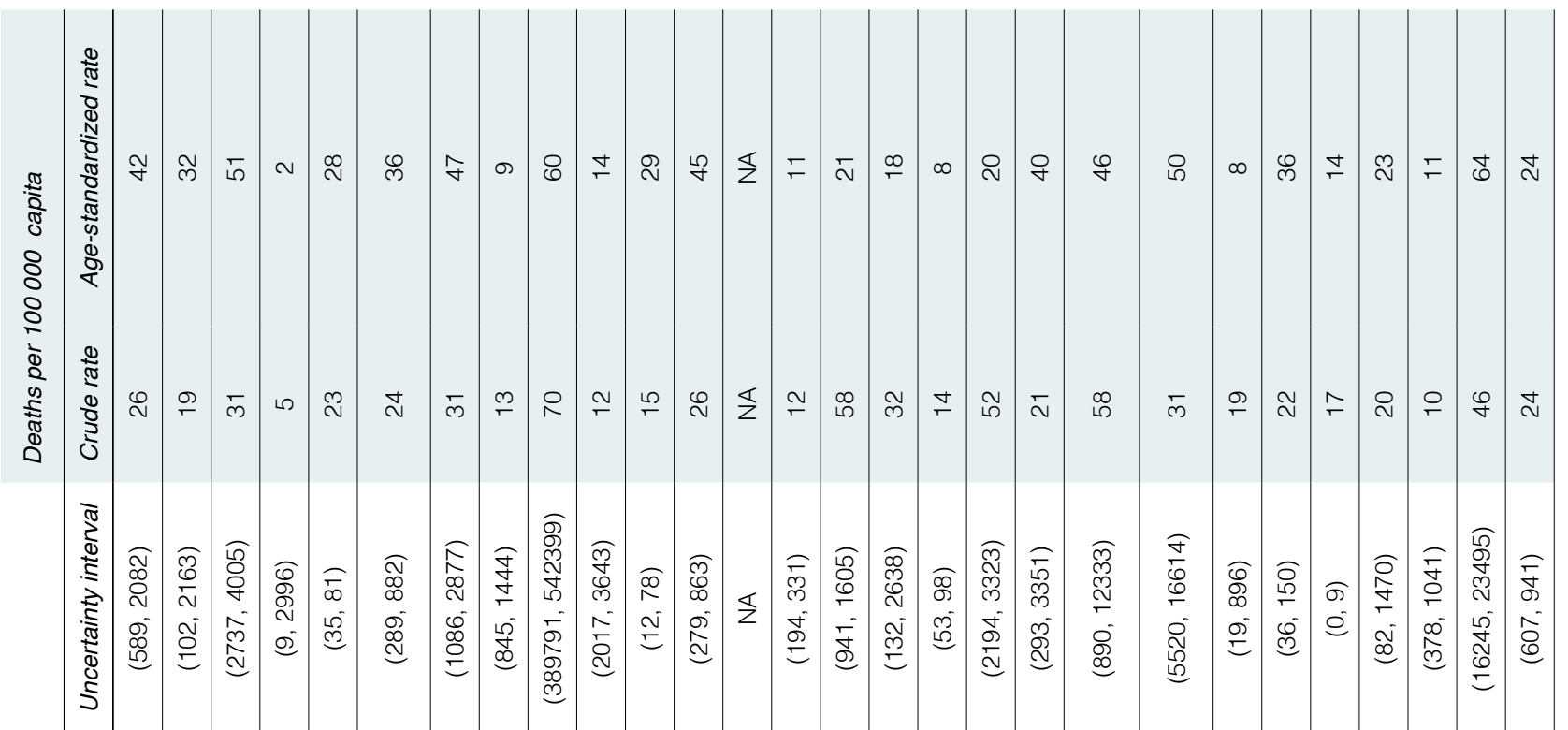

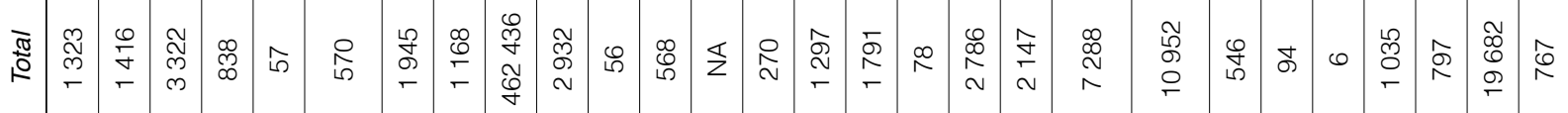

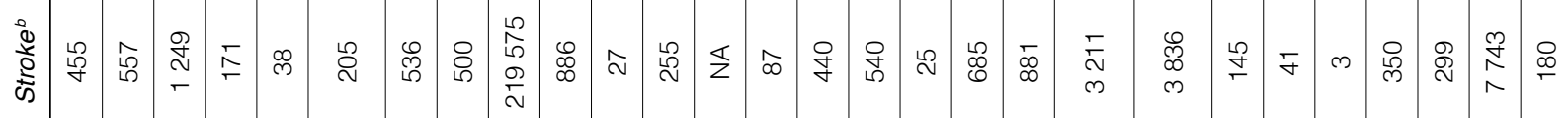

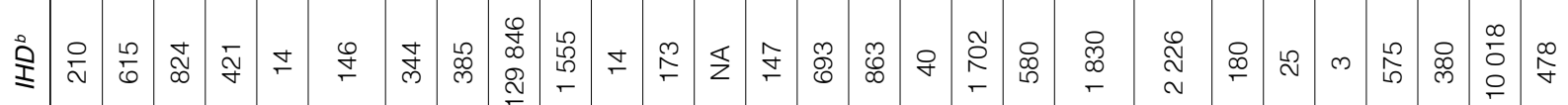

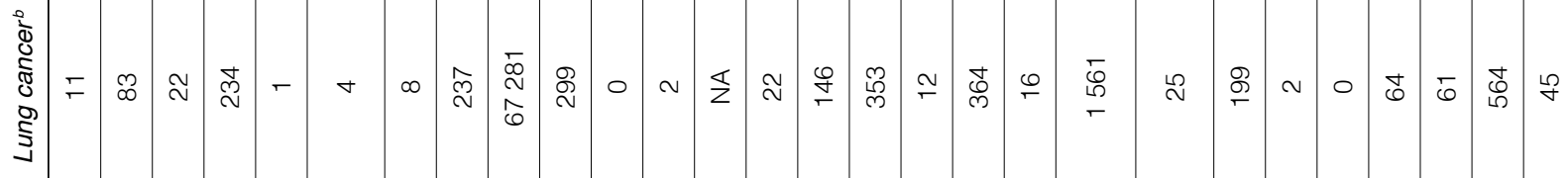

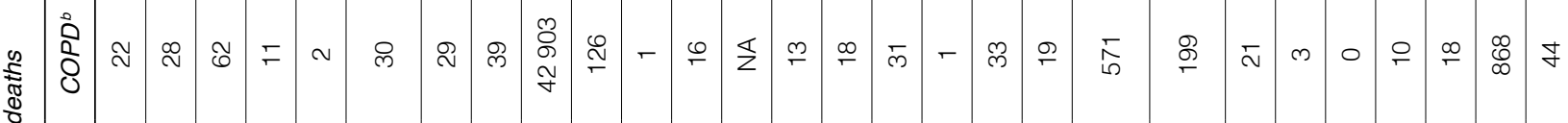

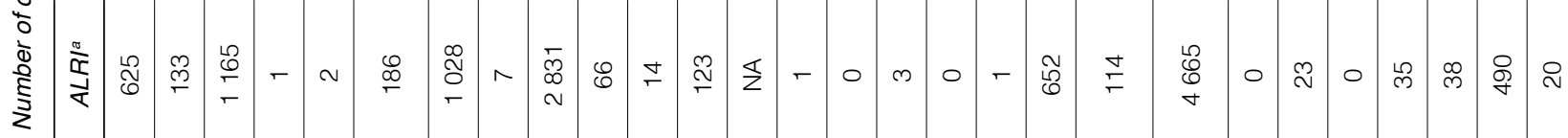

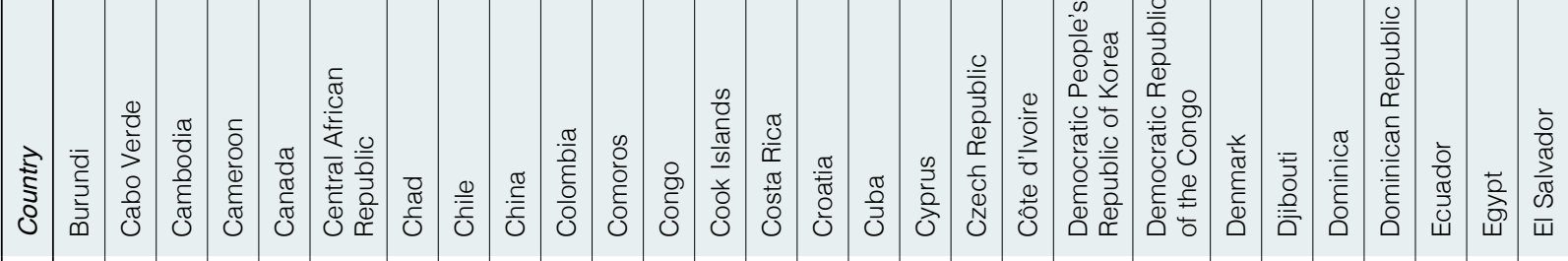

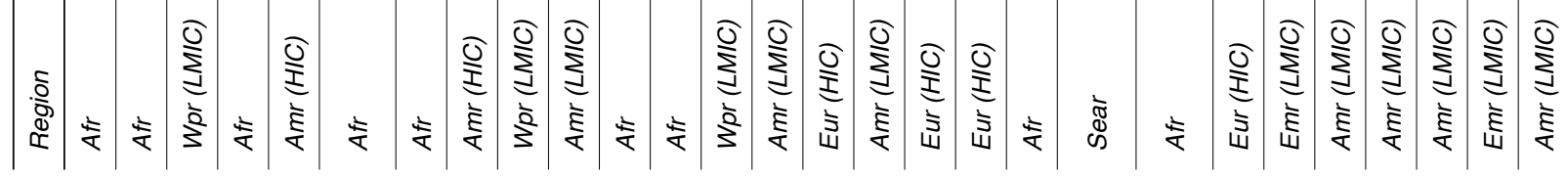




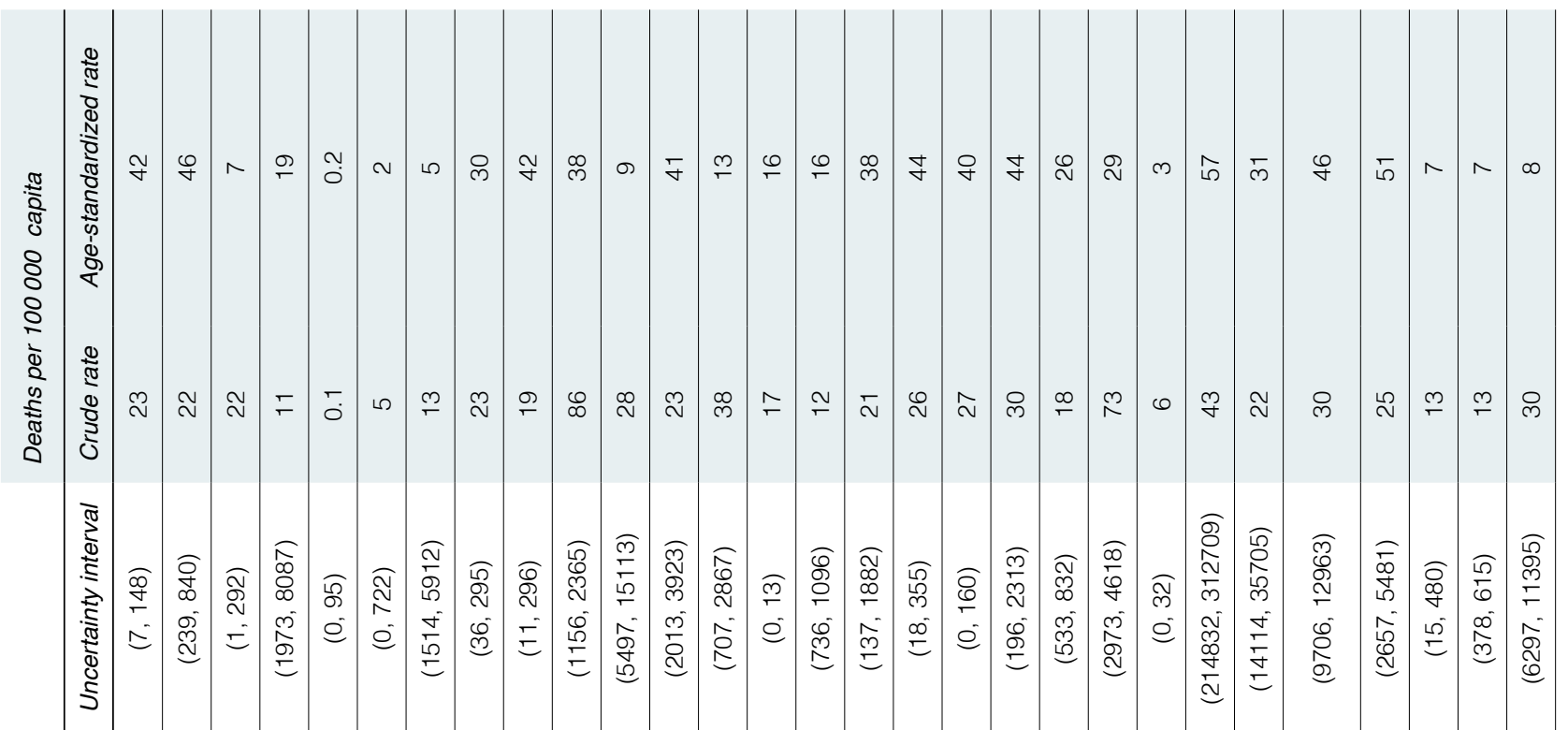

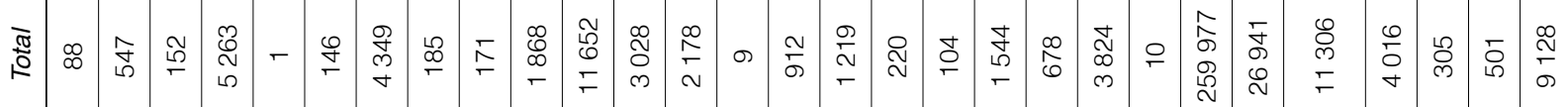
空

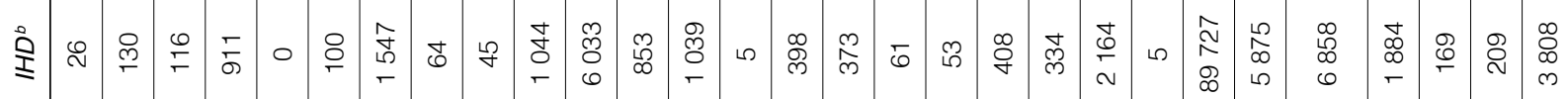

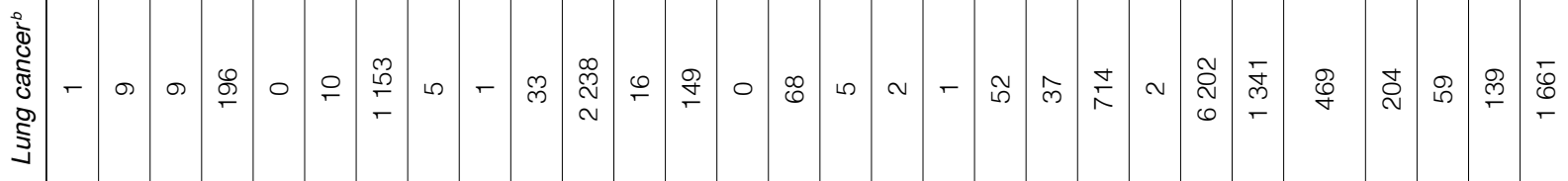

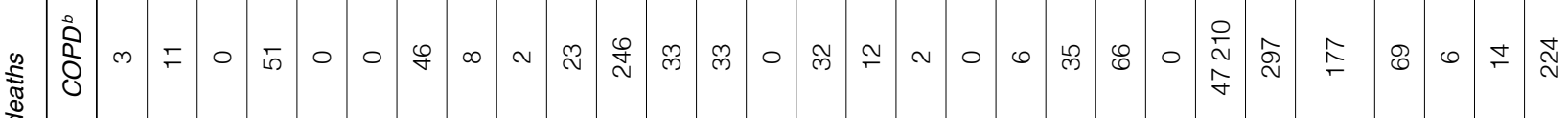

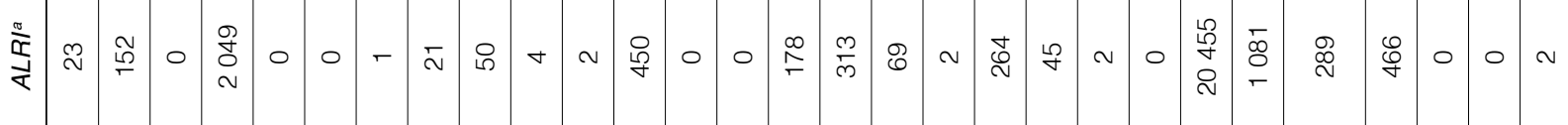

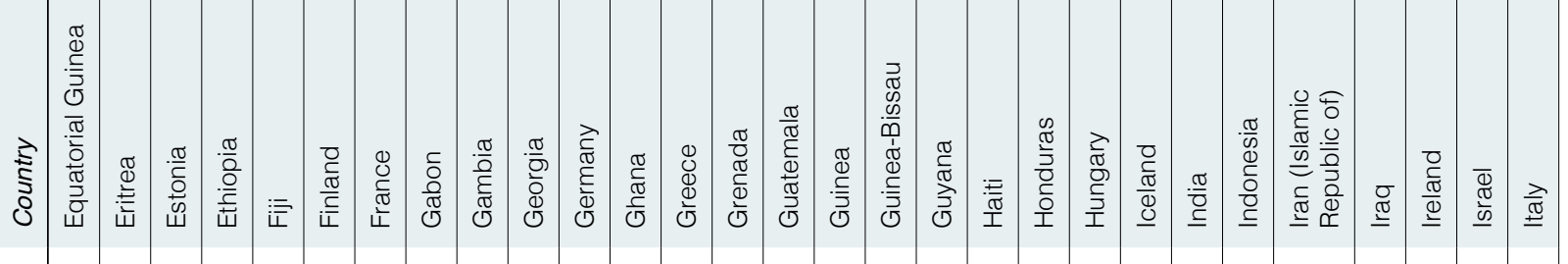

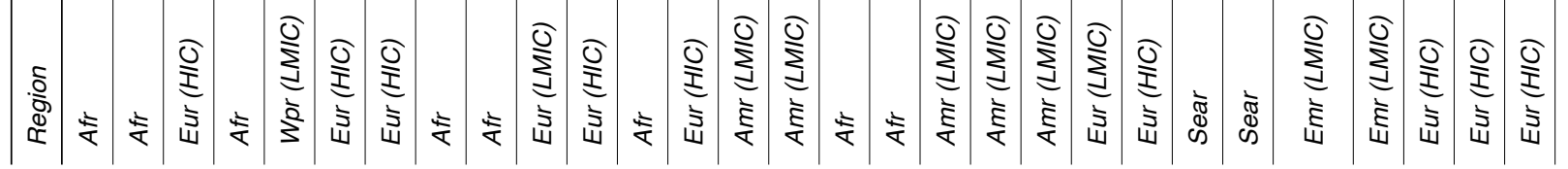




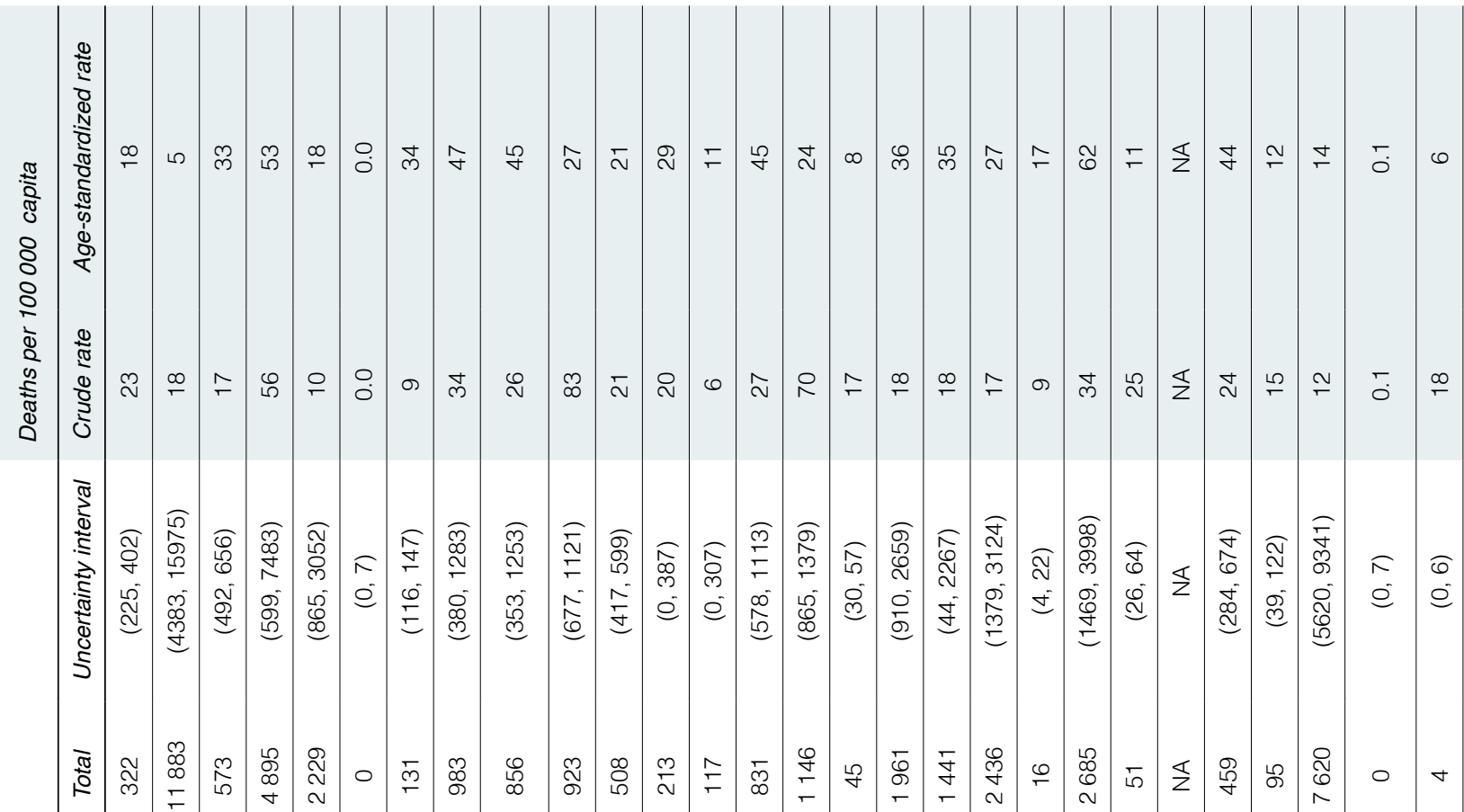

至

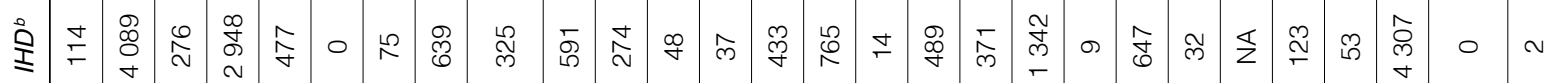

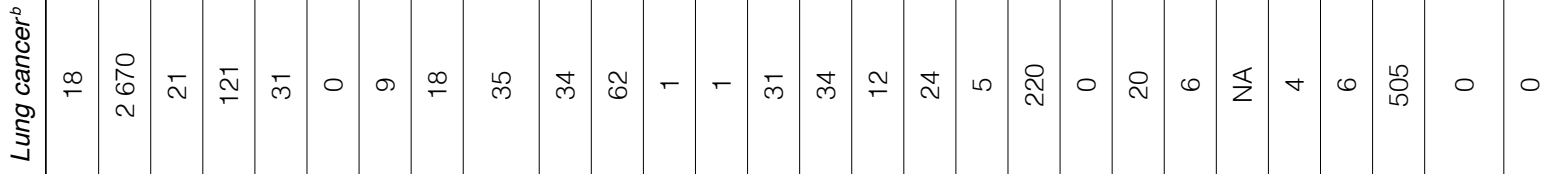

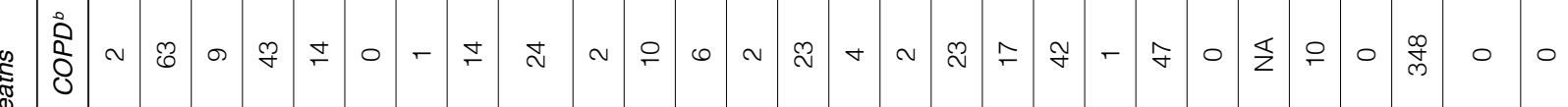
हैं

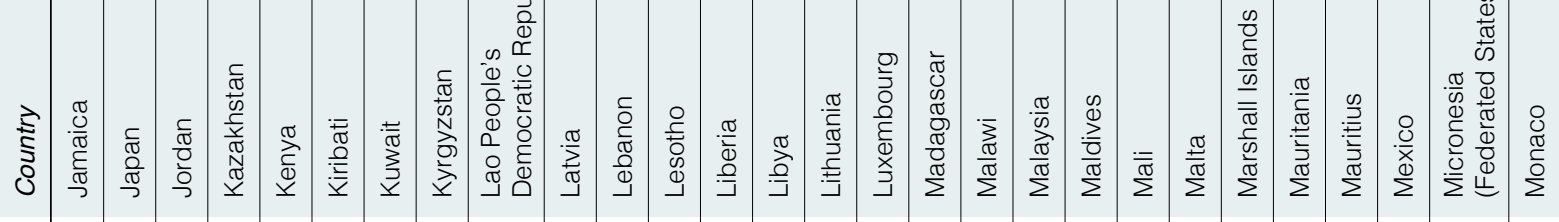

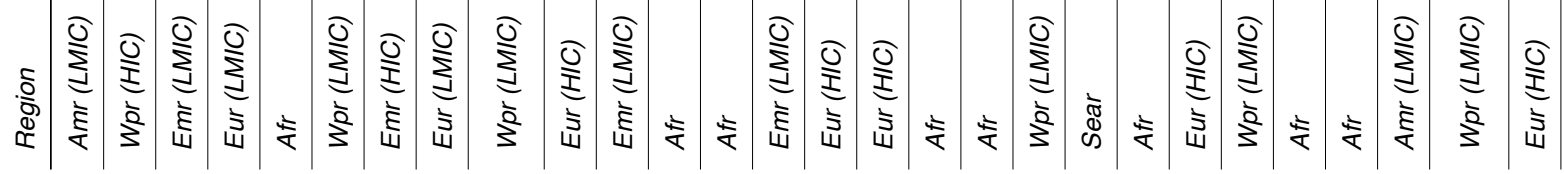




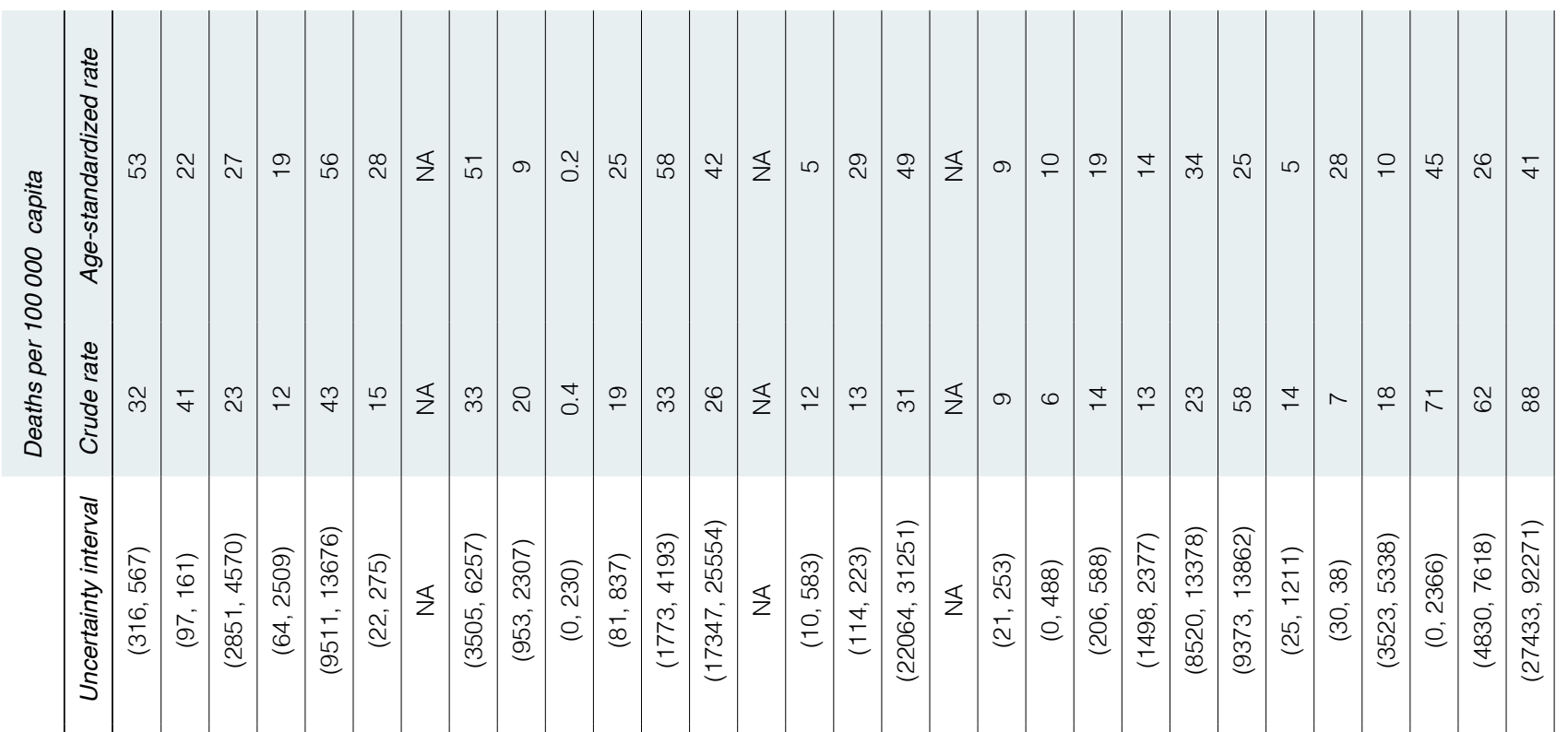

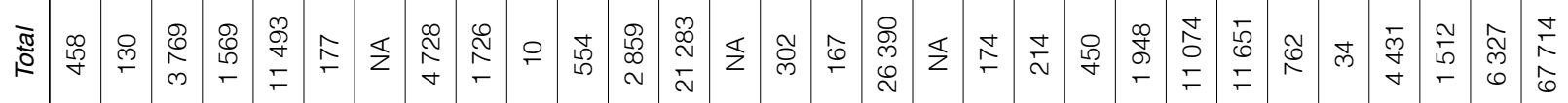

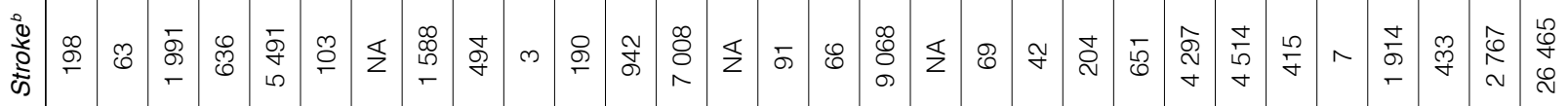

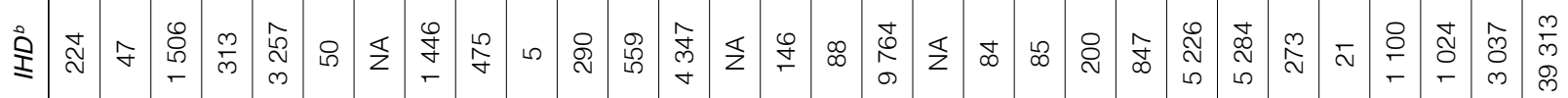

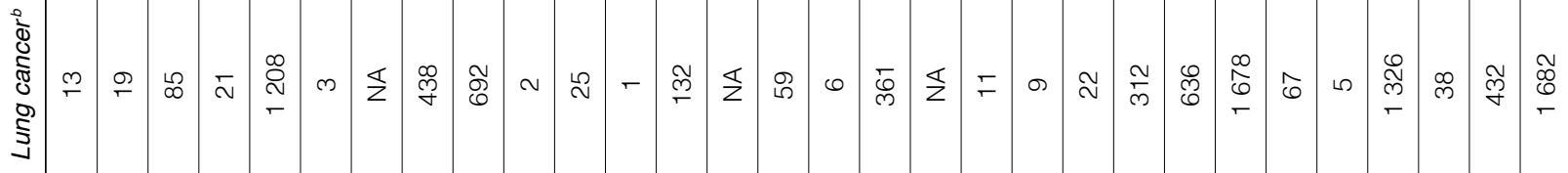

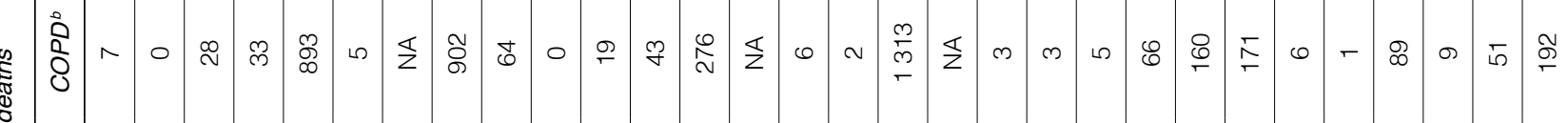

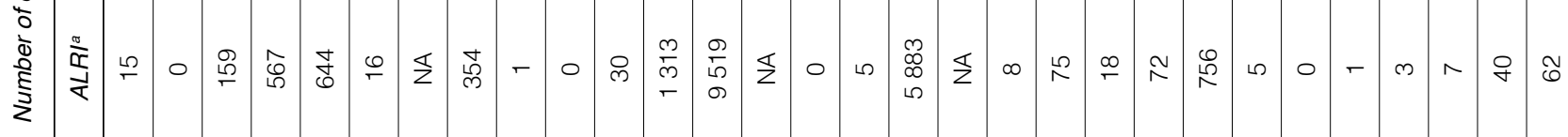

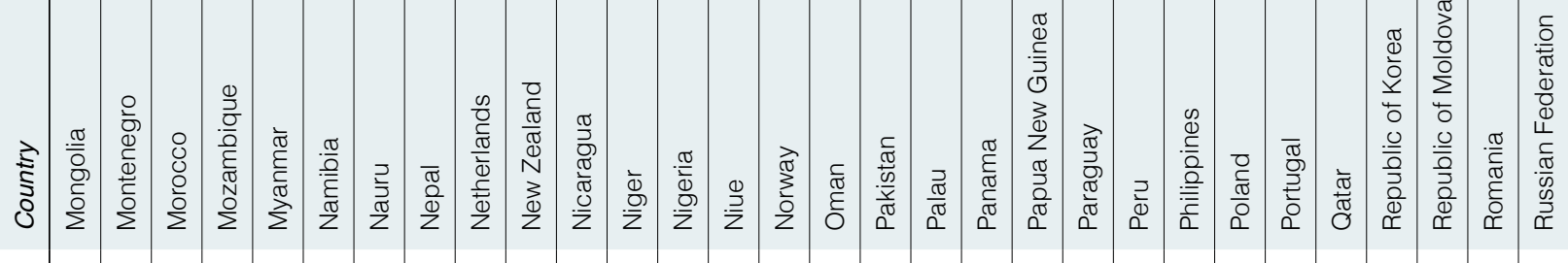

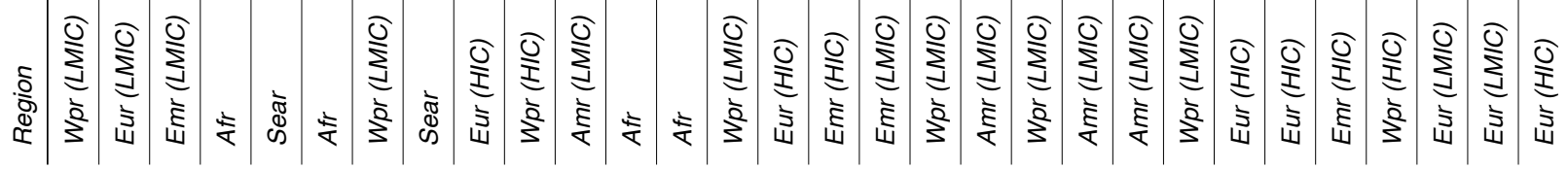




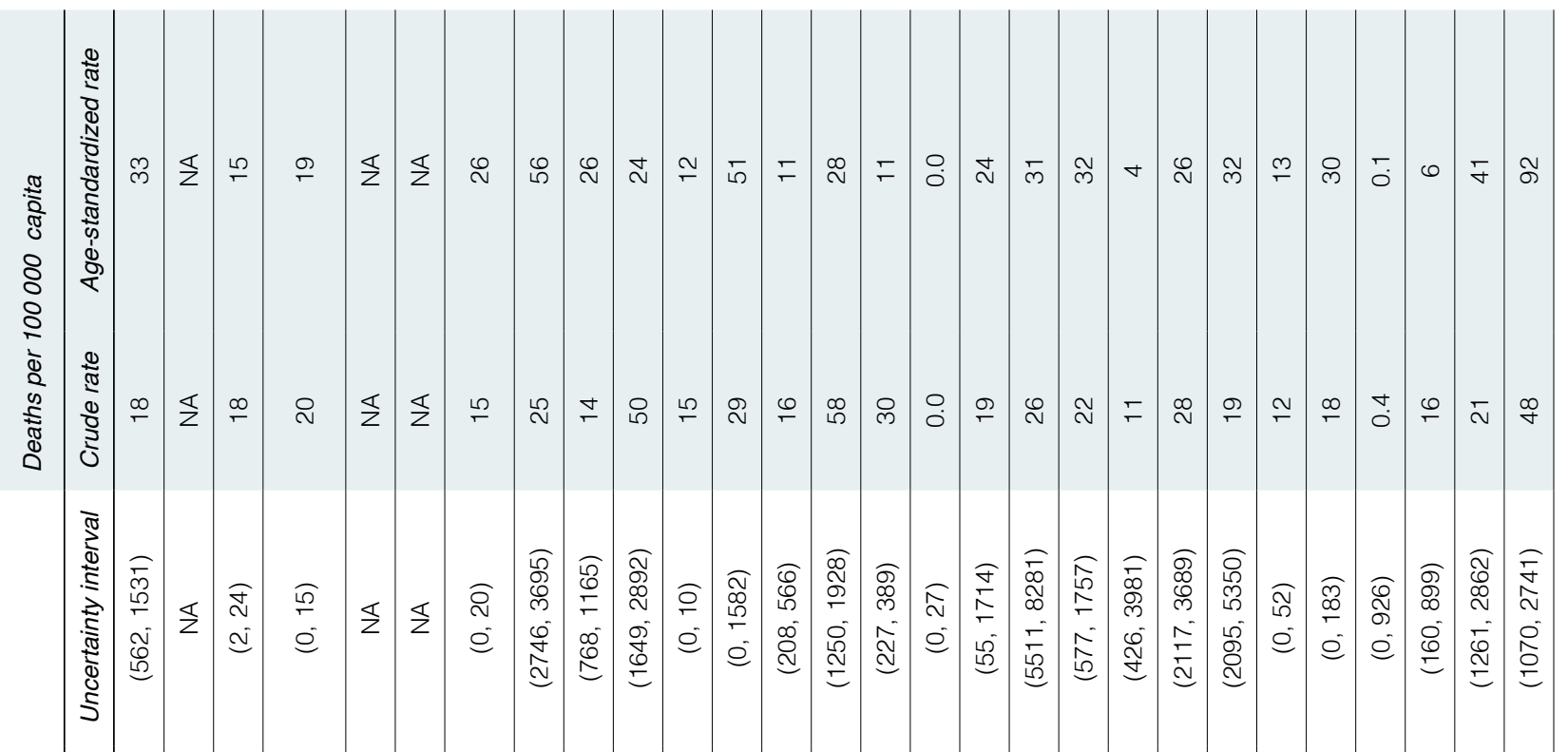

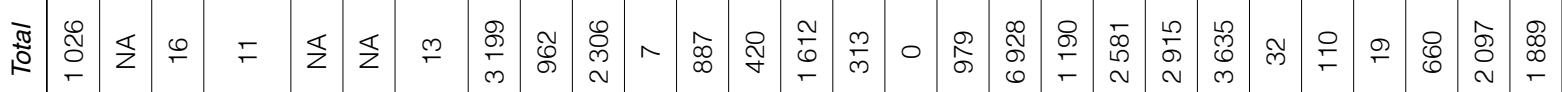

竞

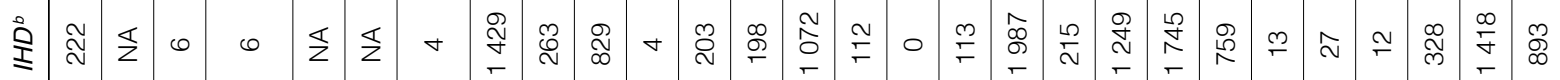

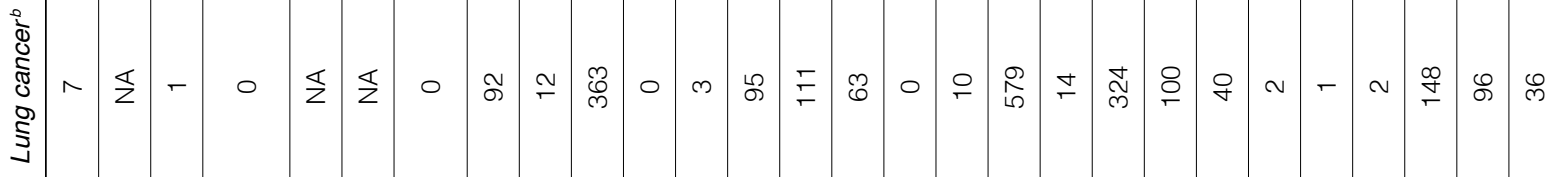

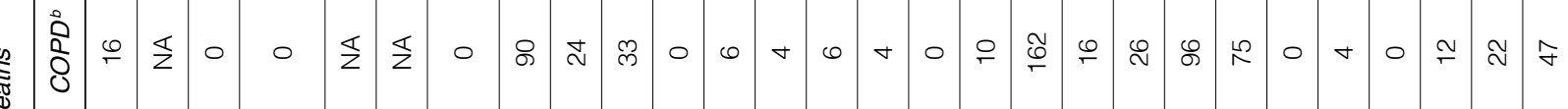
ذ。 疍

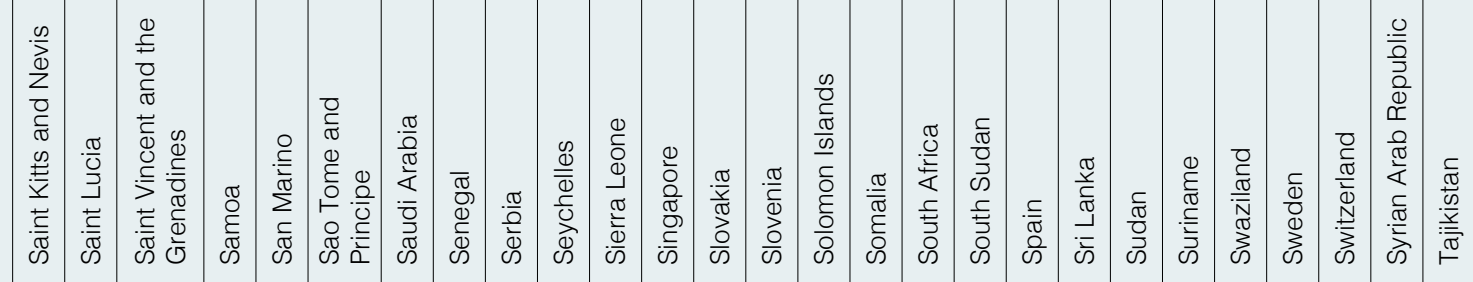

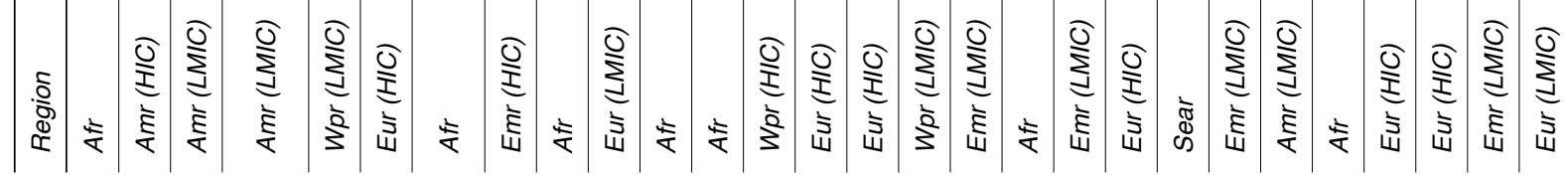




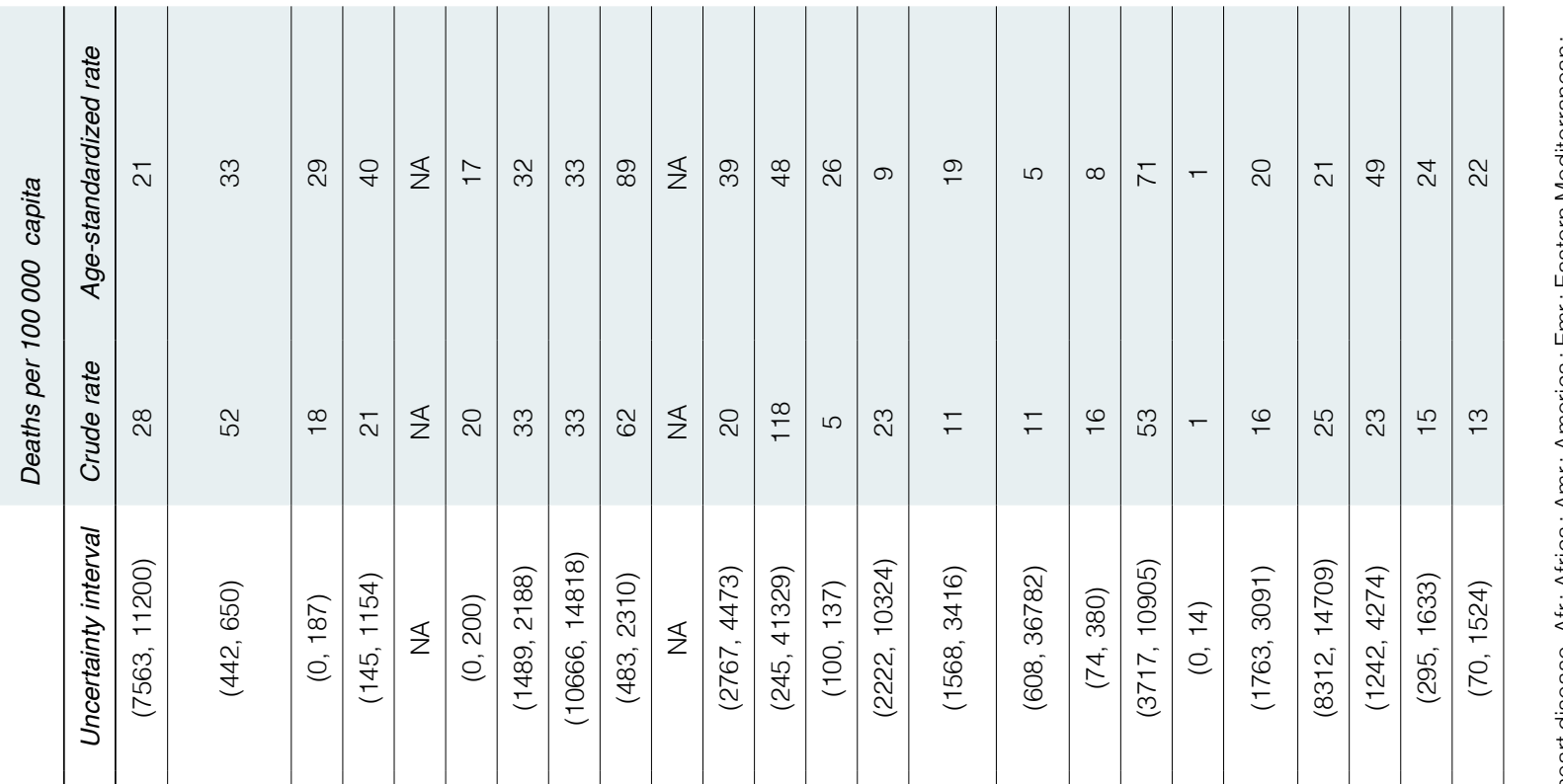

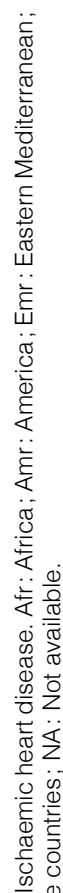

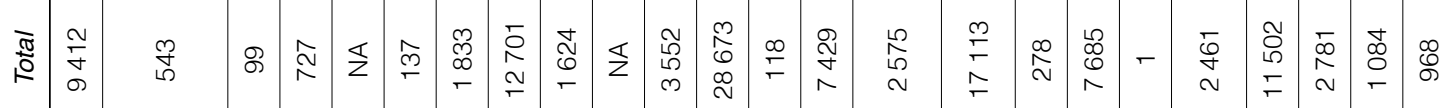

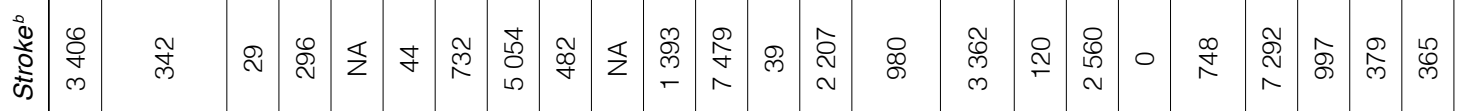

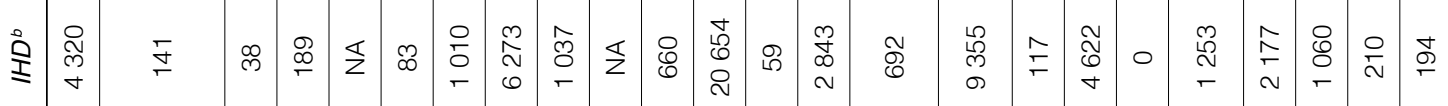

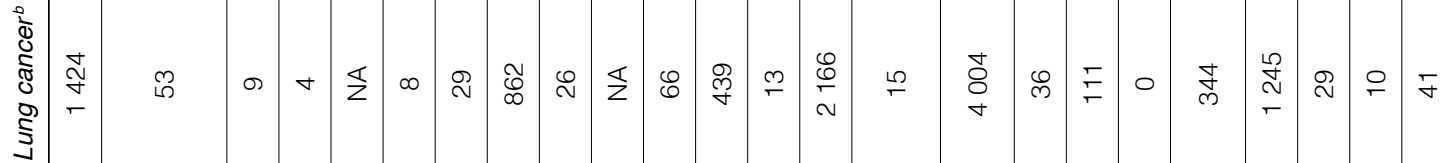

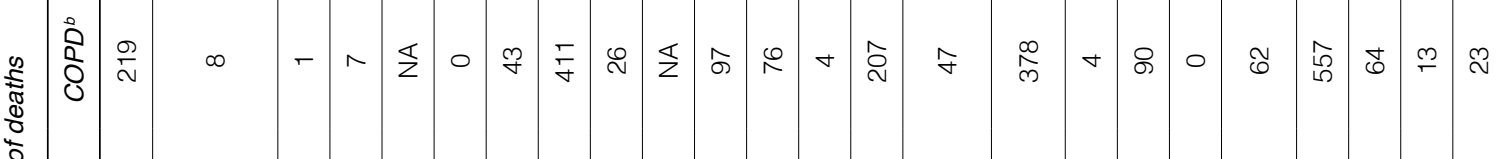

造产

ه্

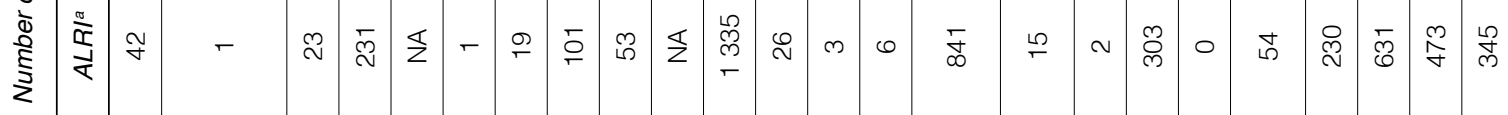

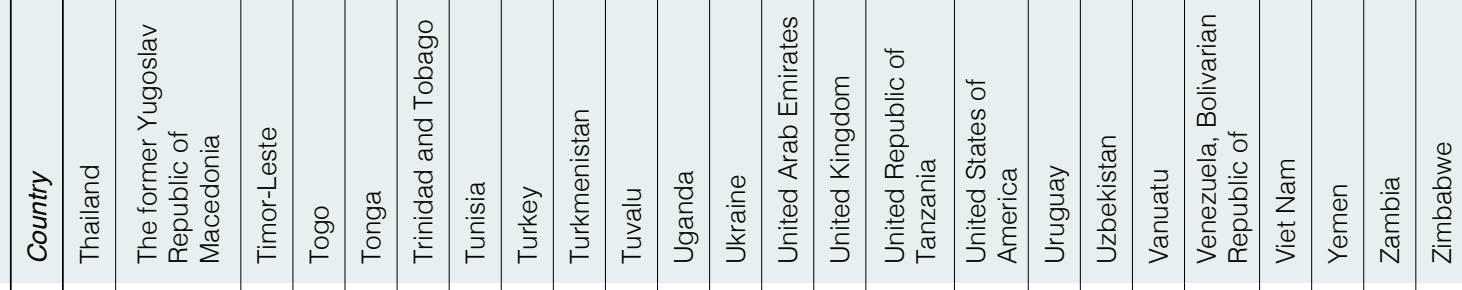

3े 음

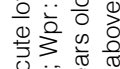

눙.

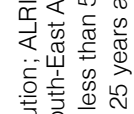

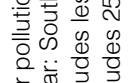

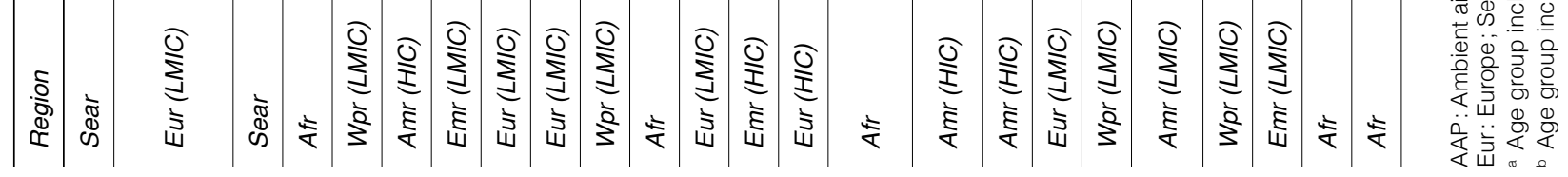




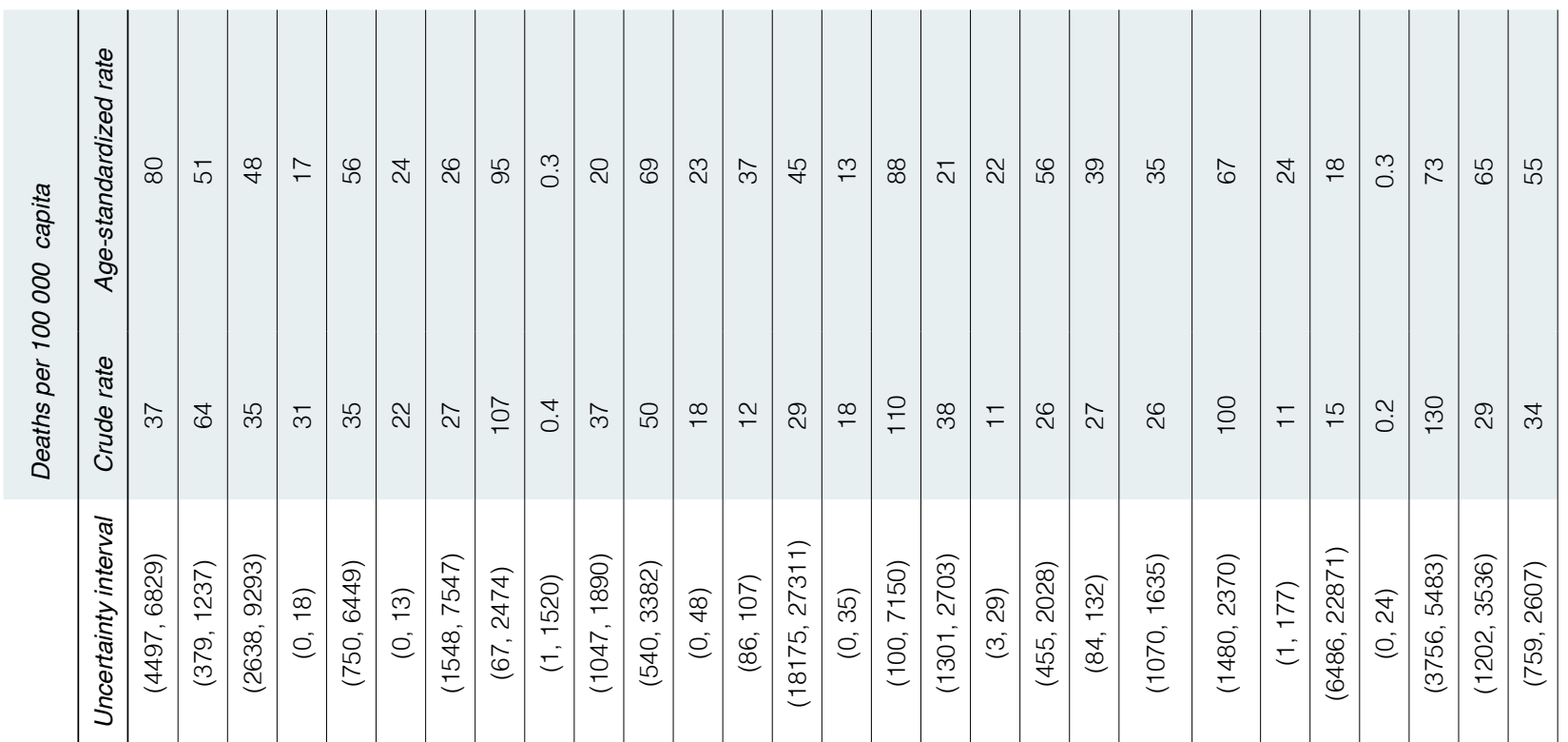

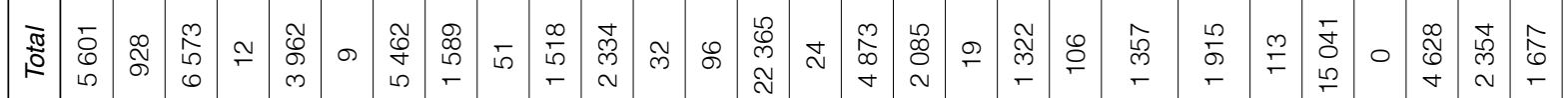

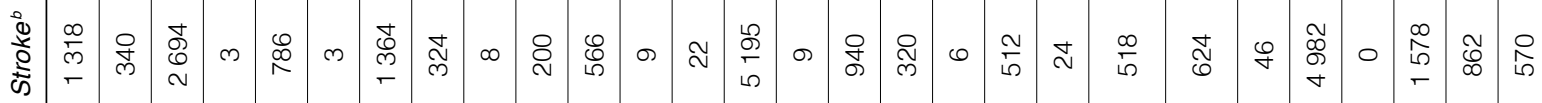

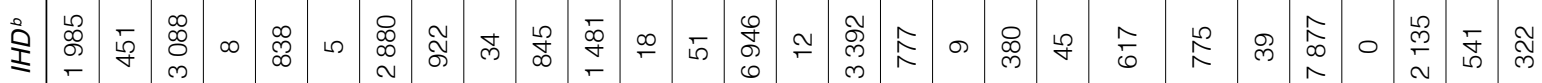

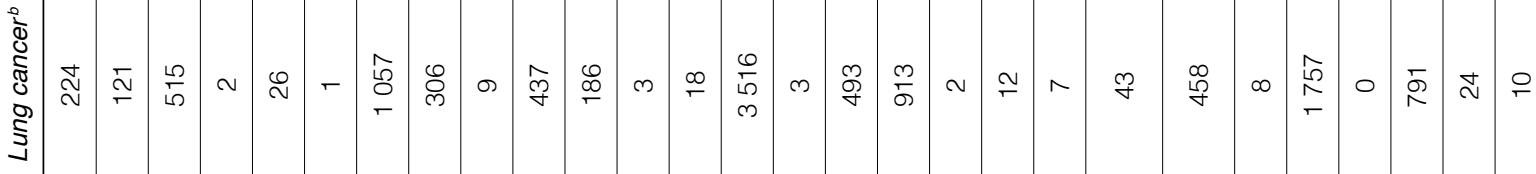

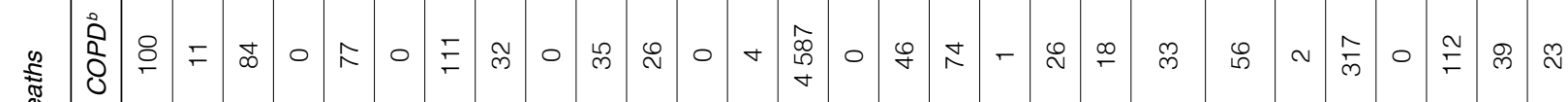

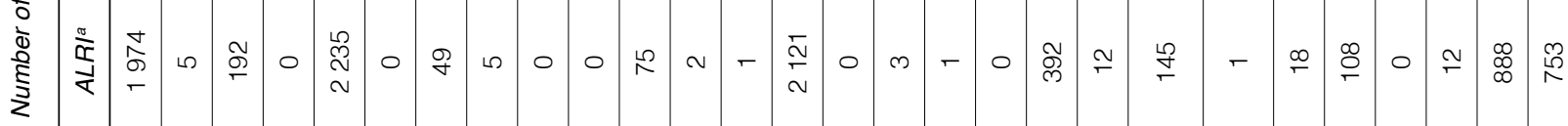

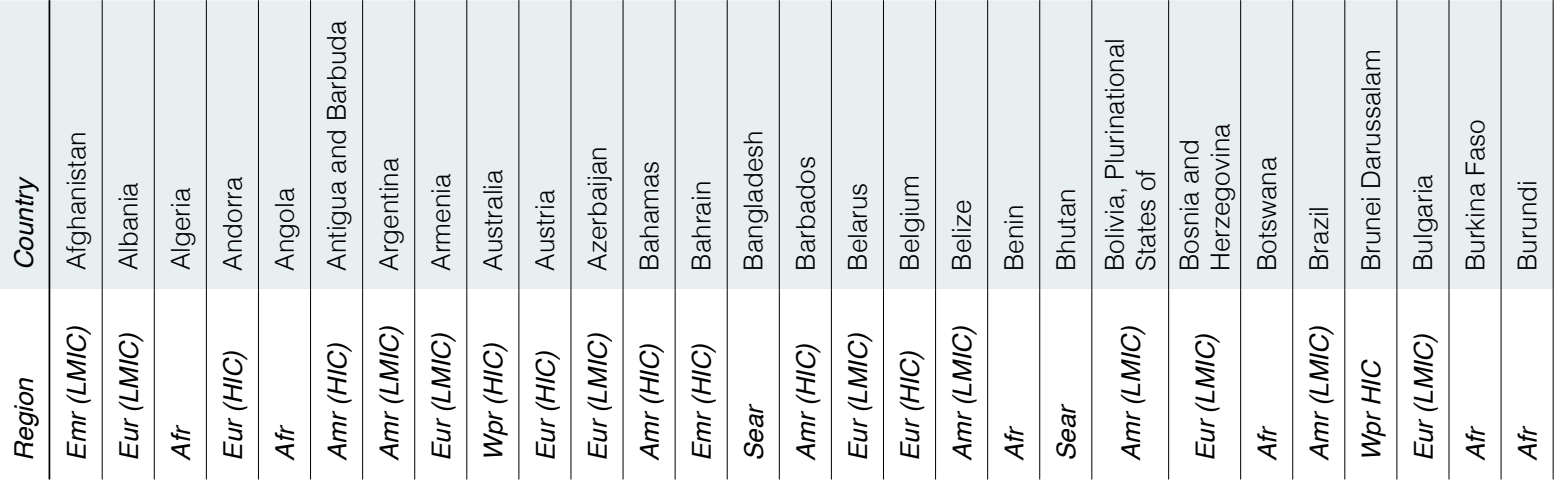




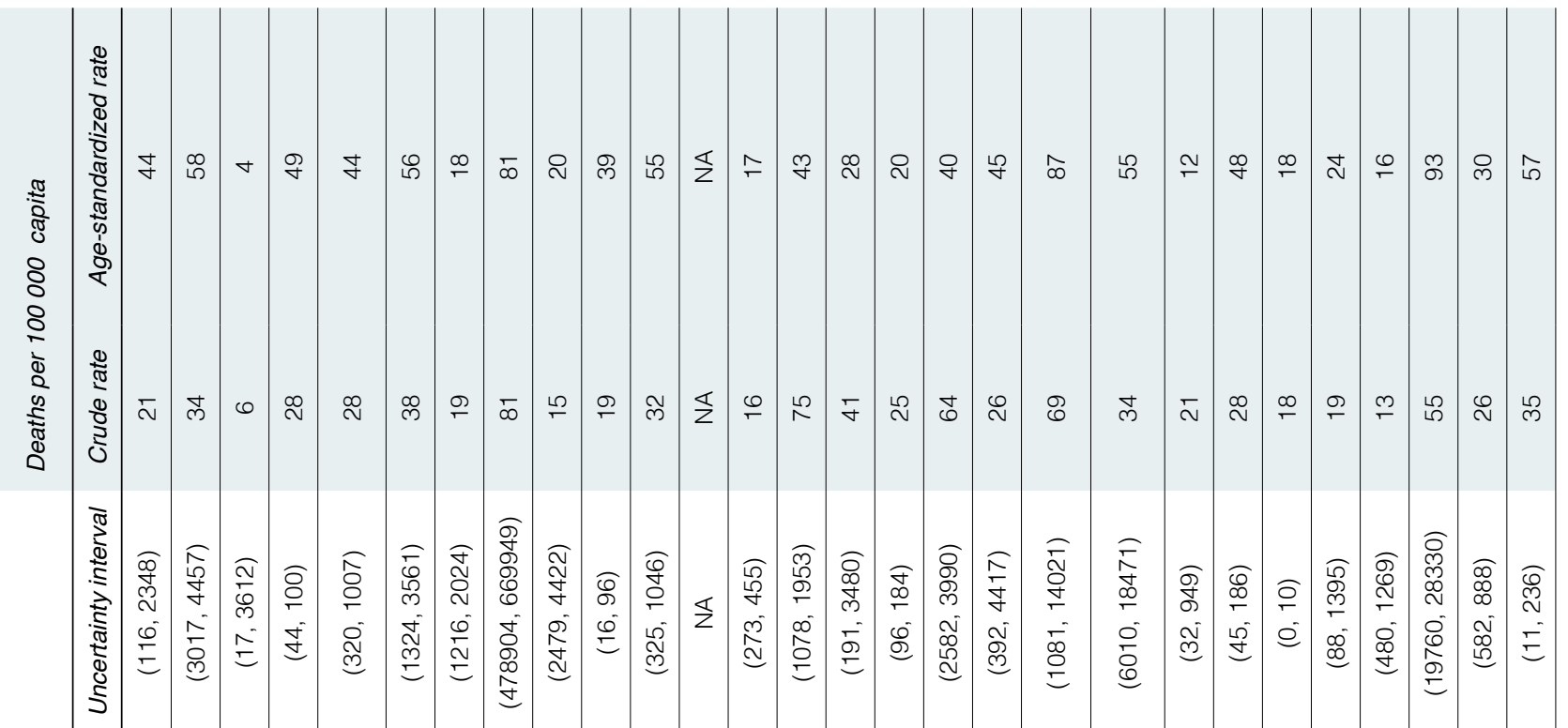

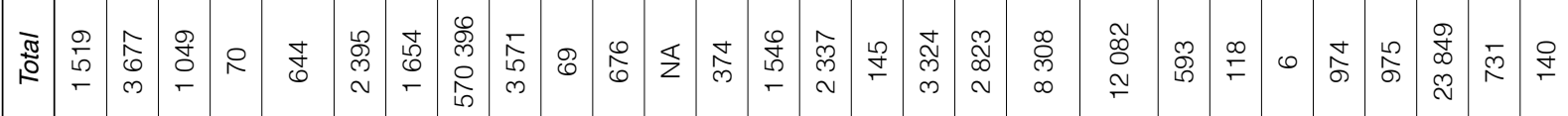

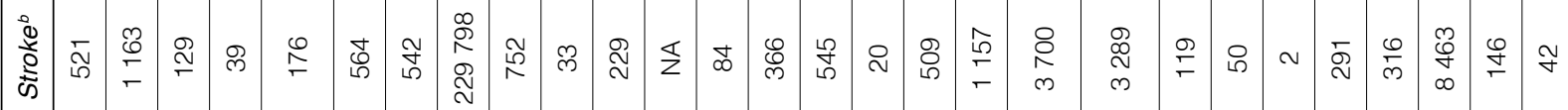

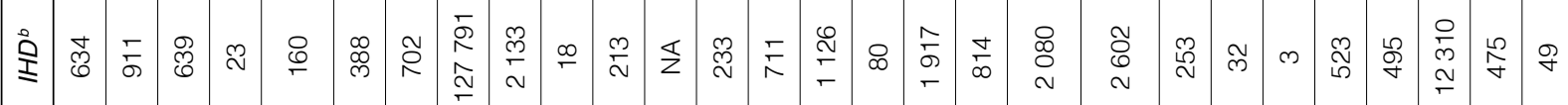

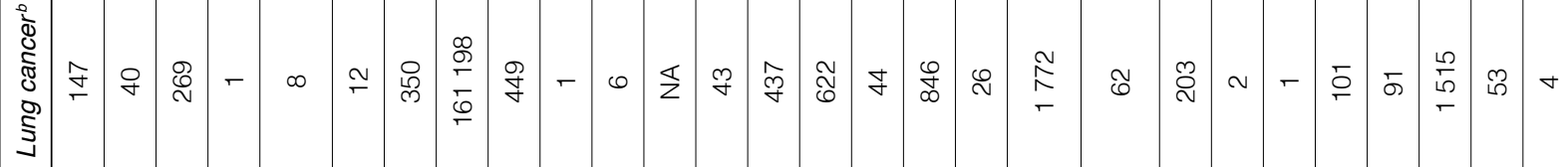

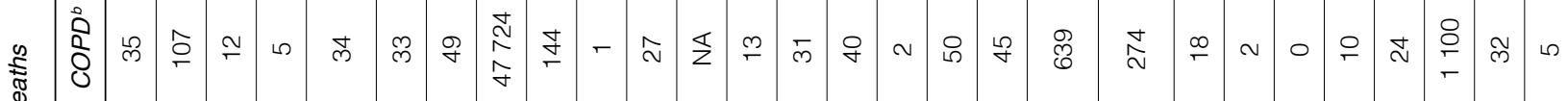

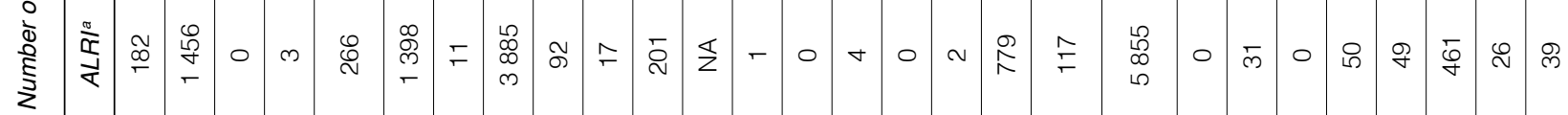

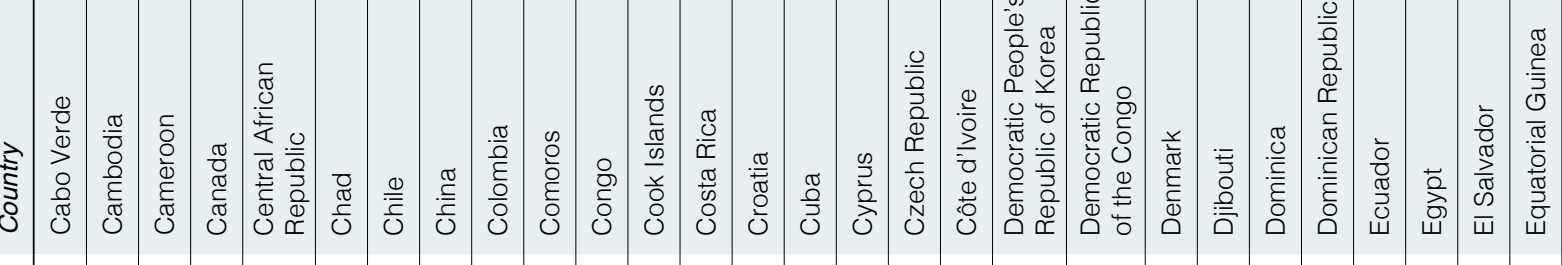

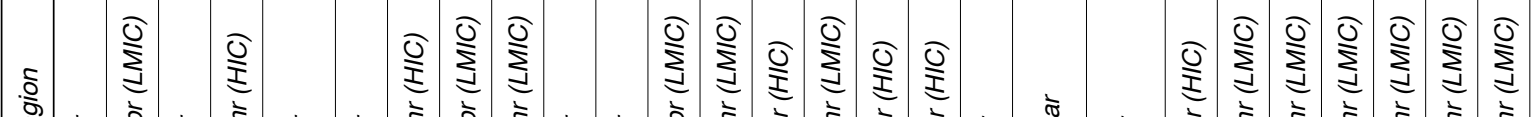

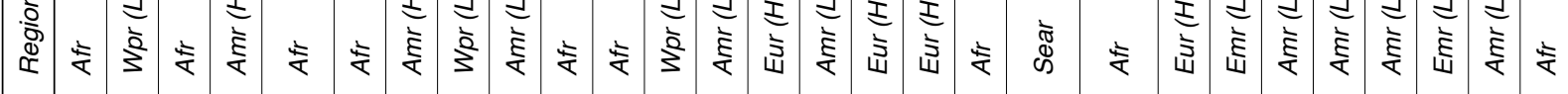




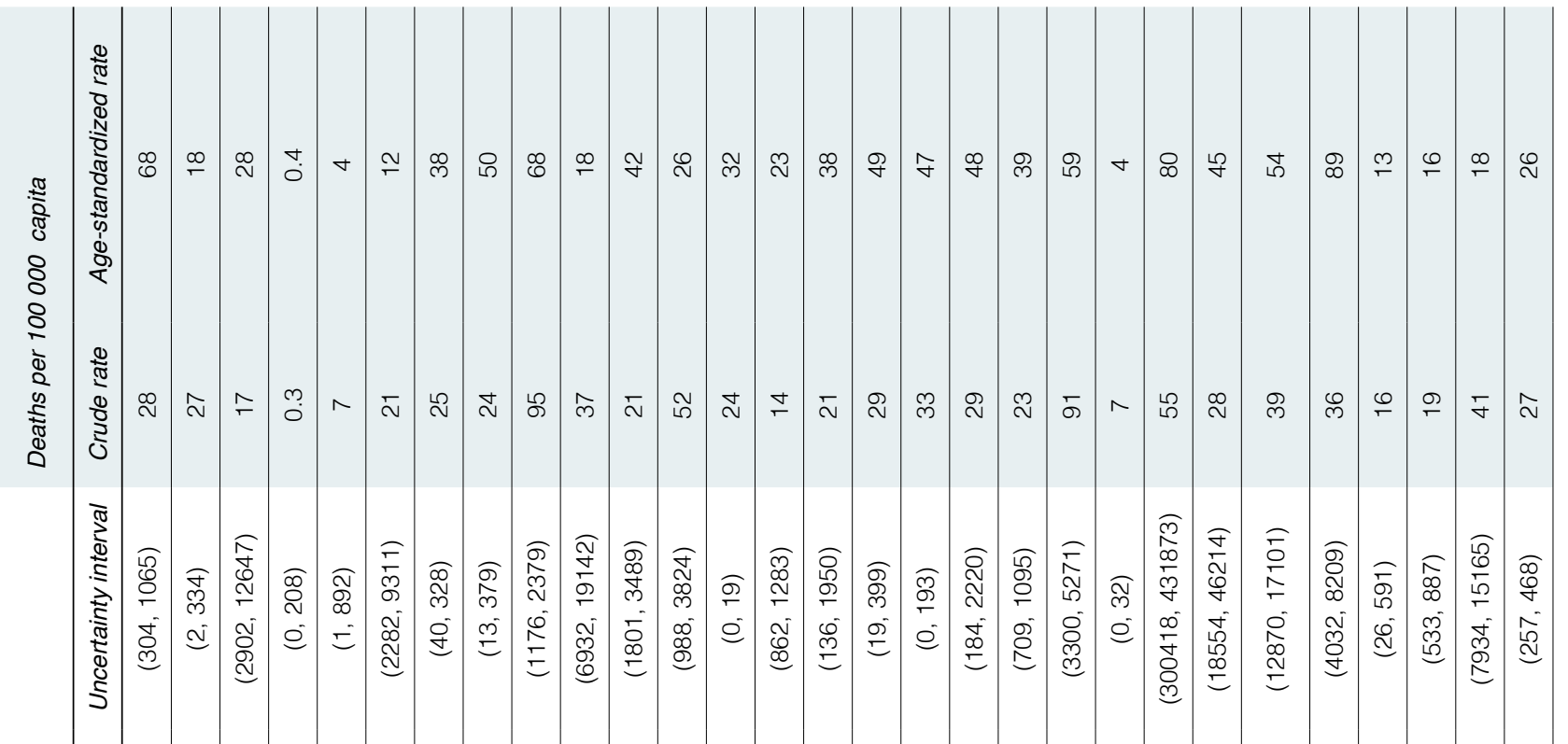

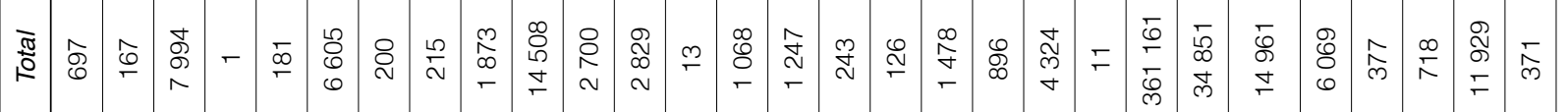

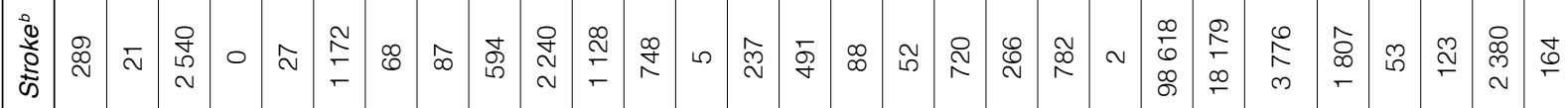

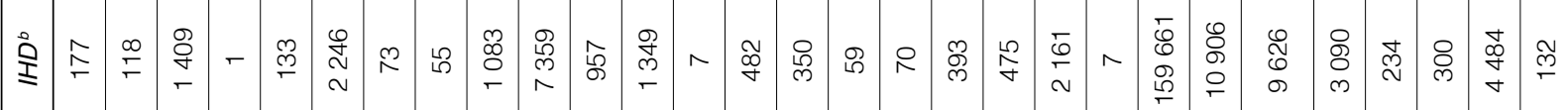

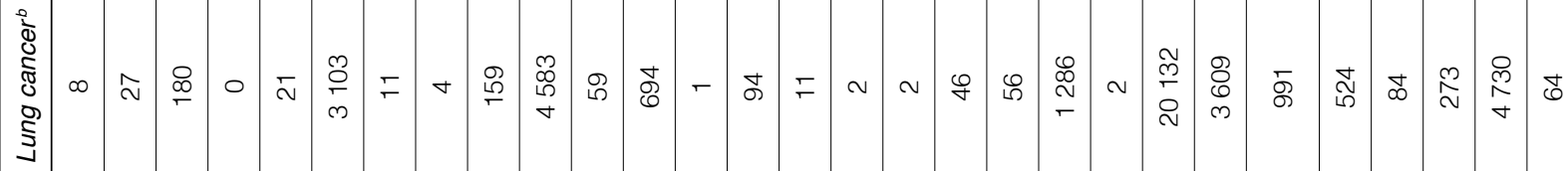

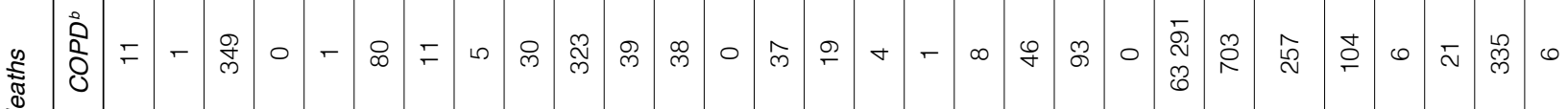

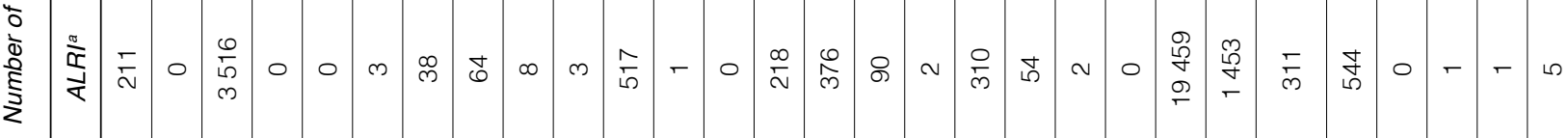

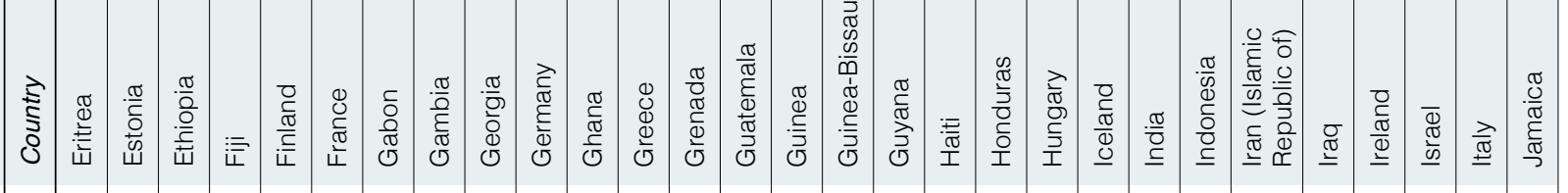

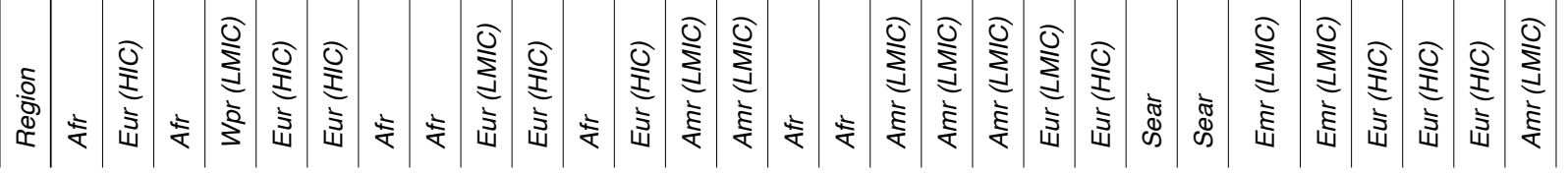




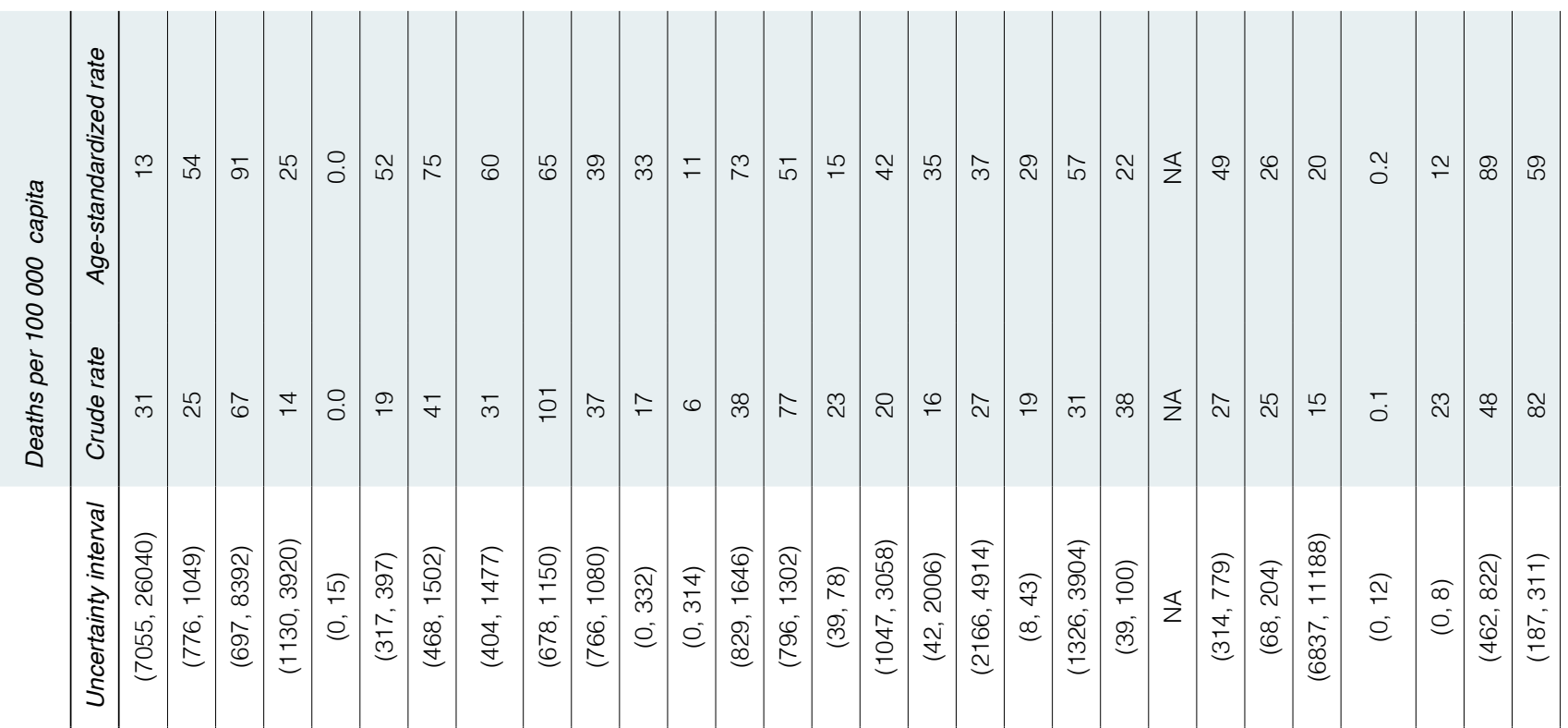

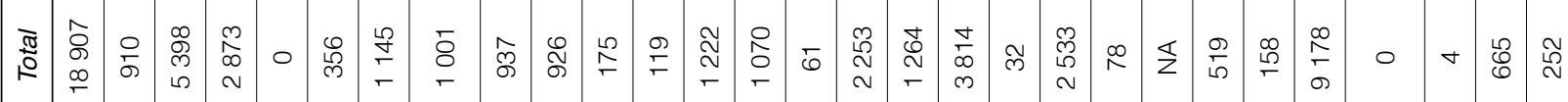

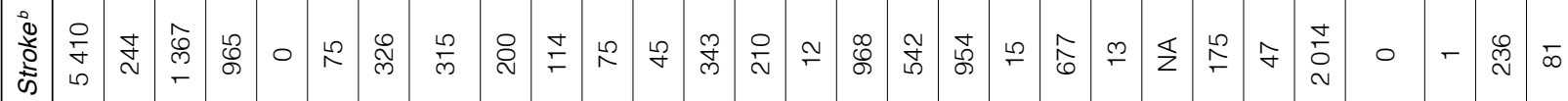

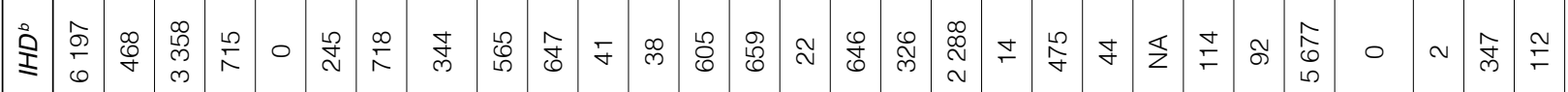

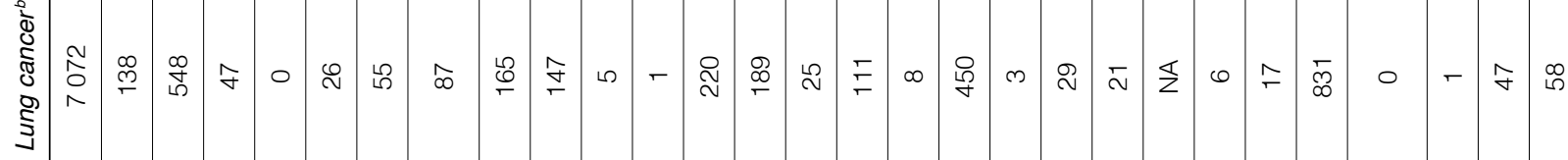

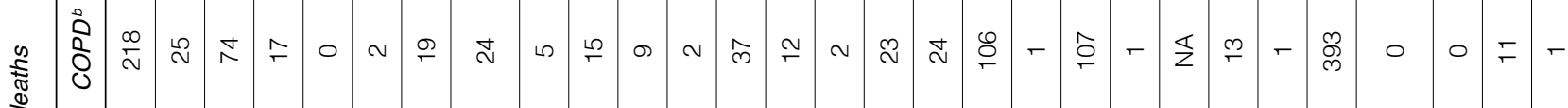

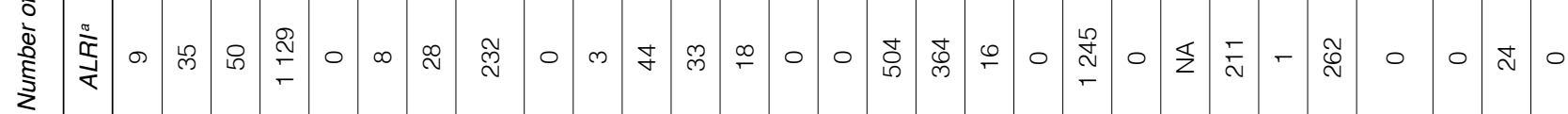

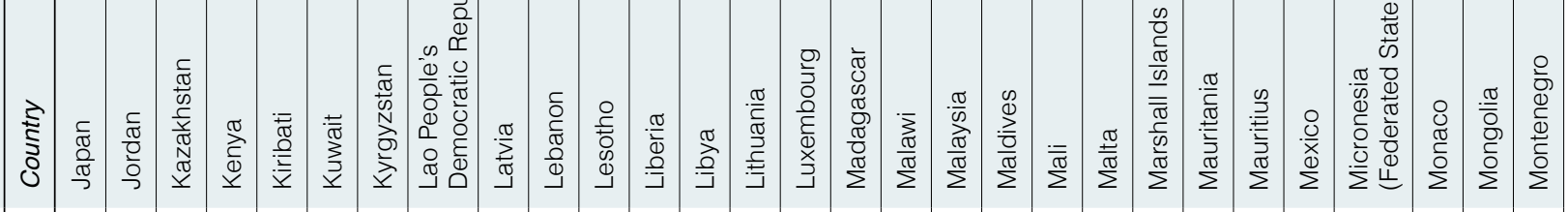

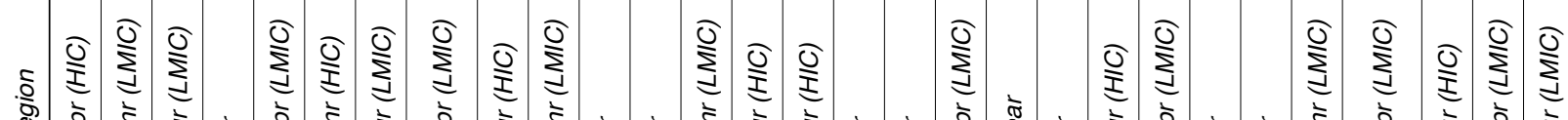

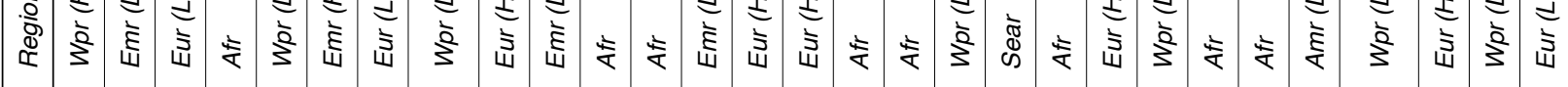




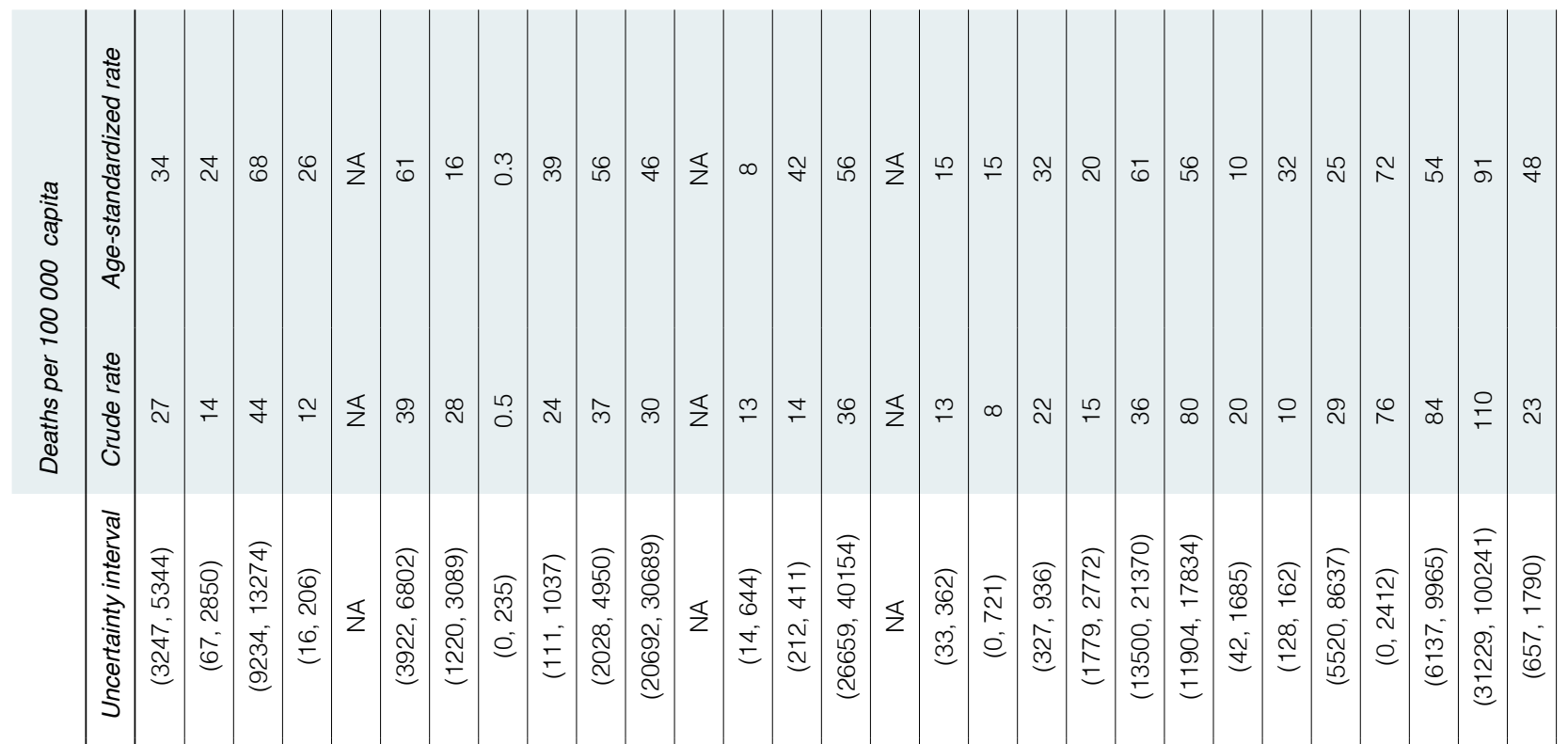

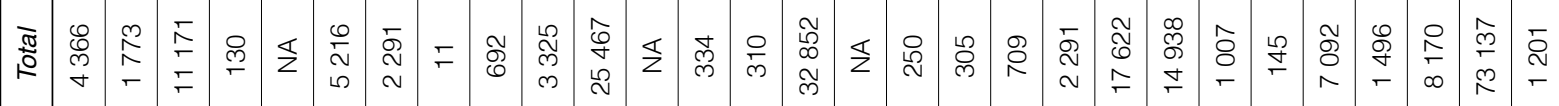

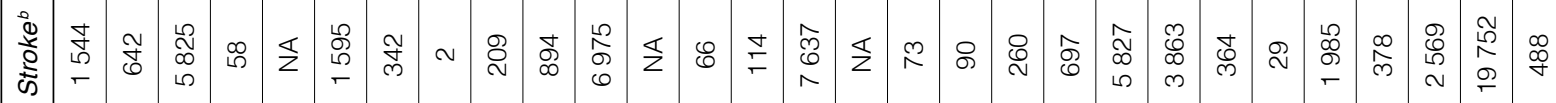

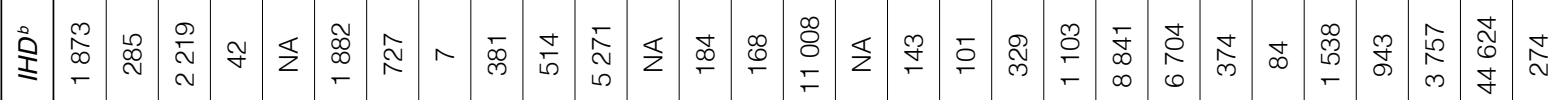

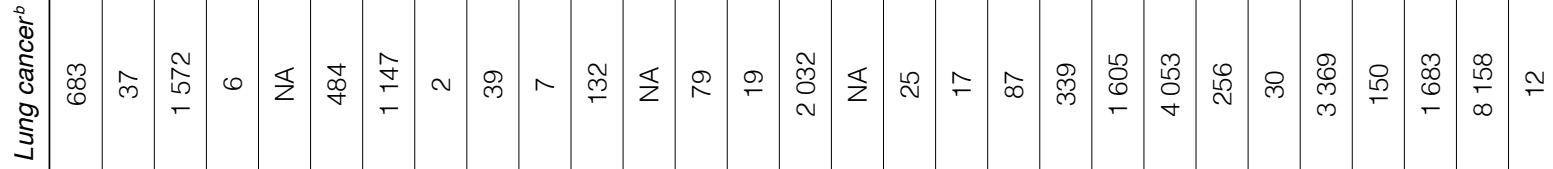

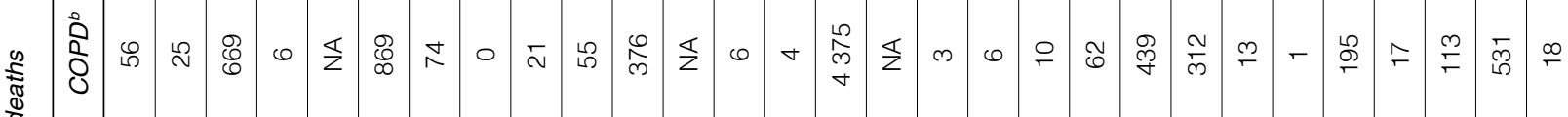

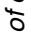

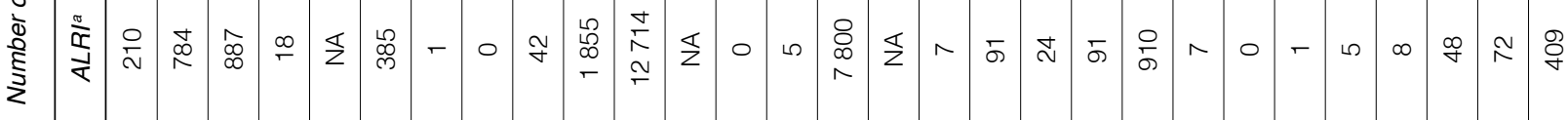

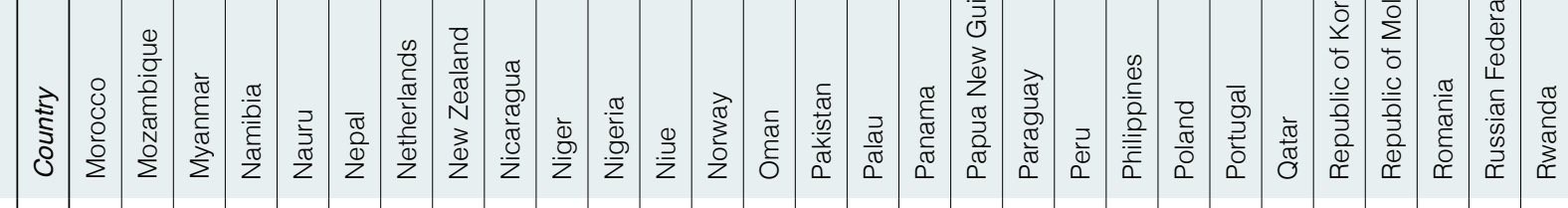

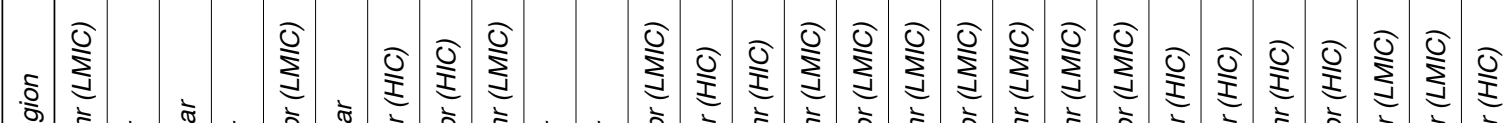

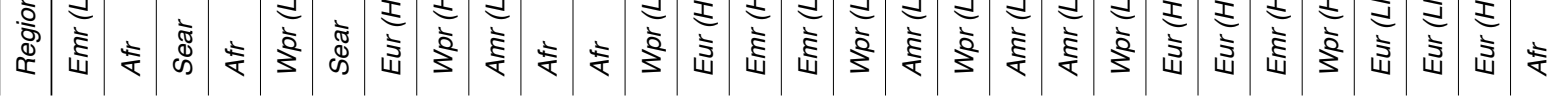




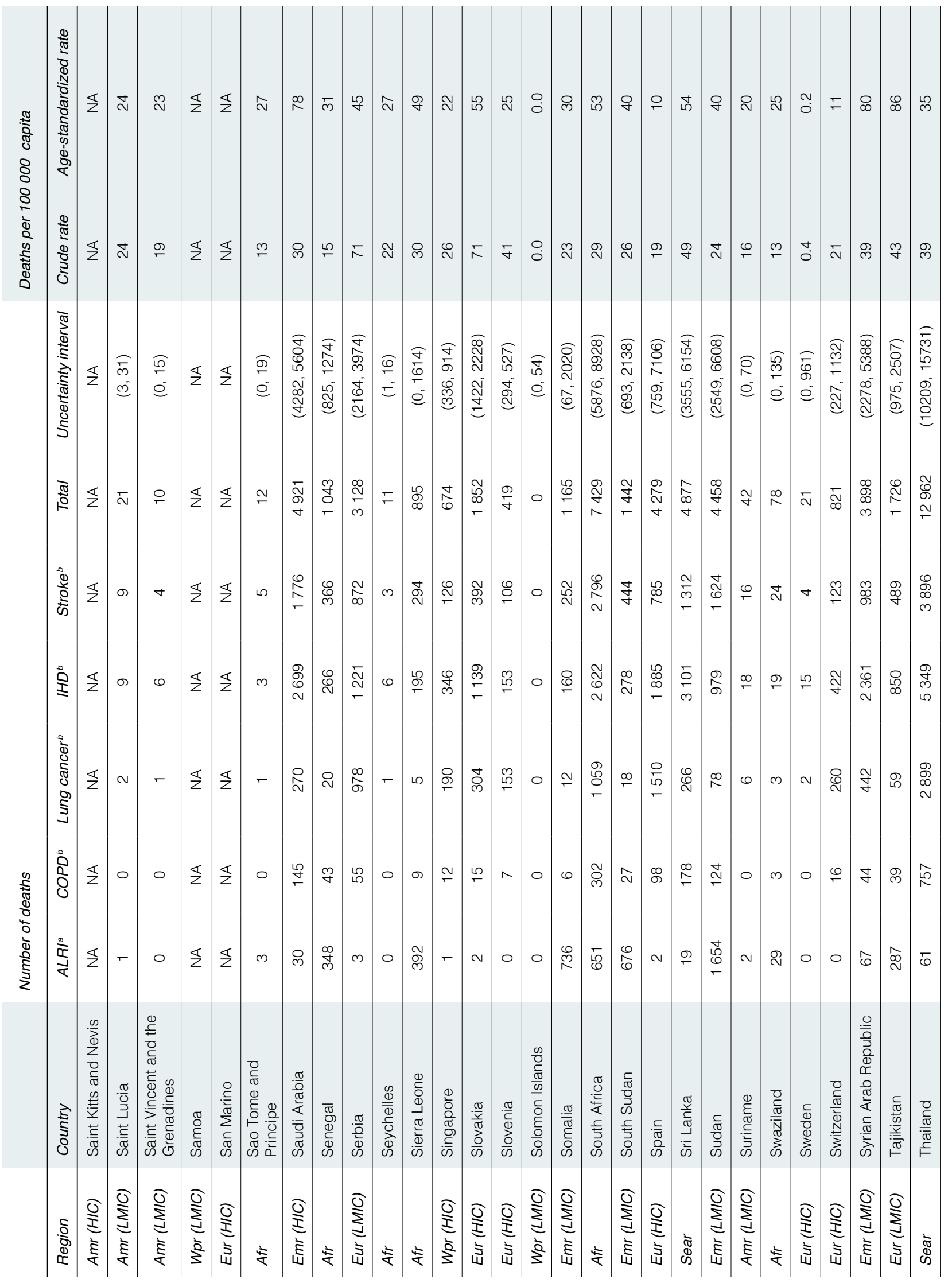




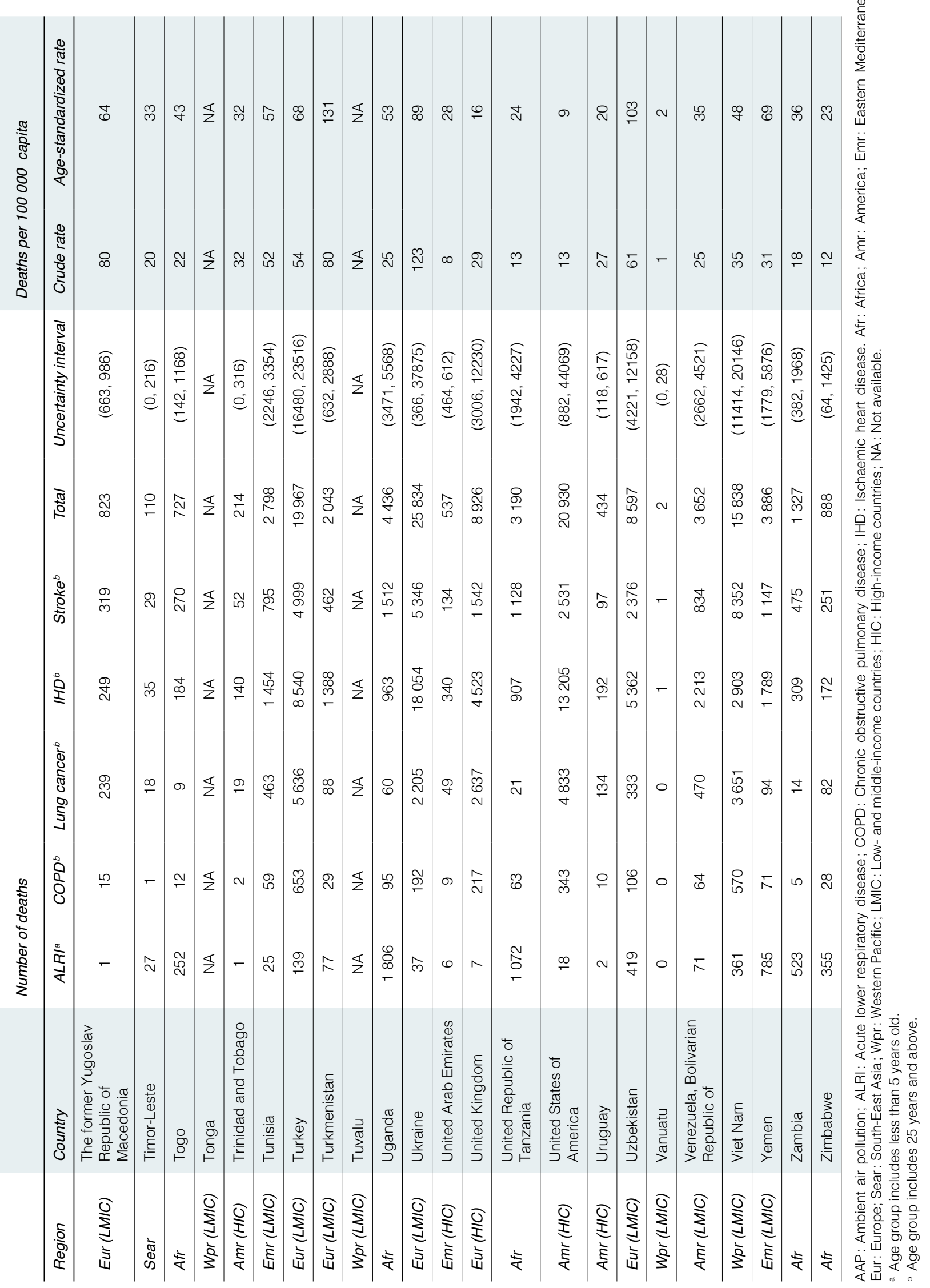




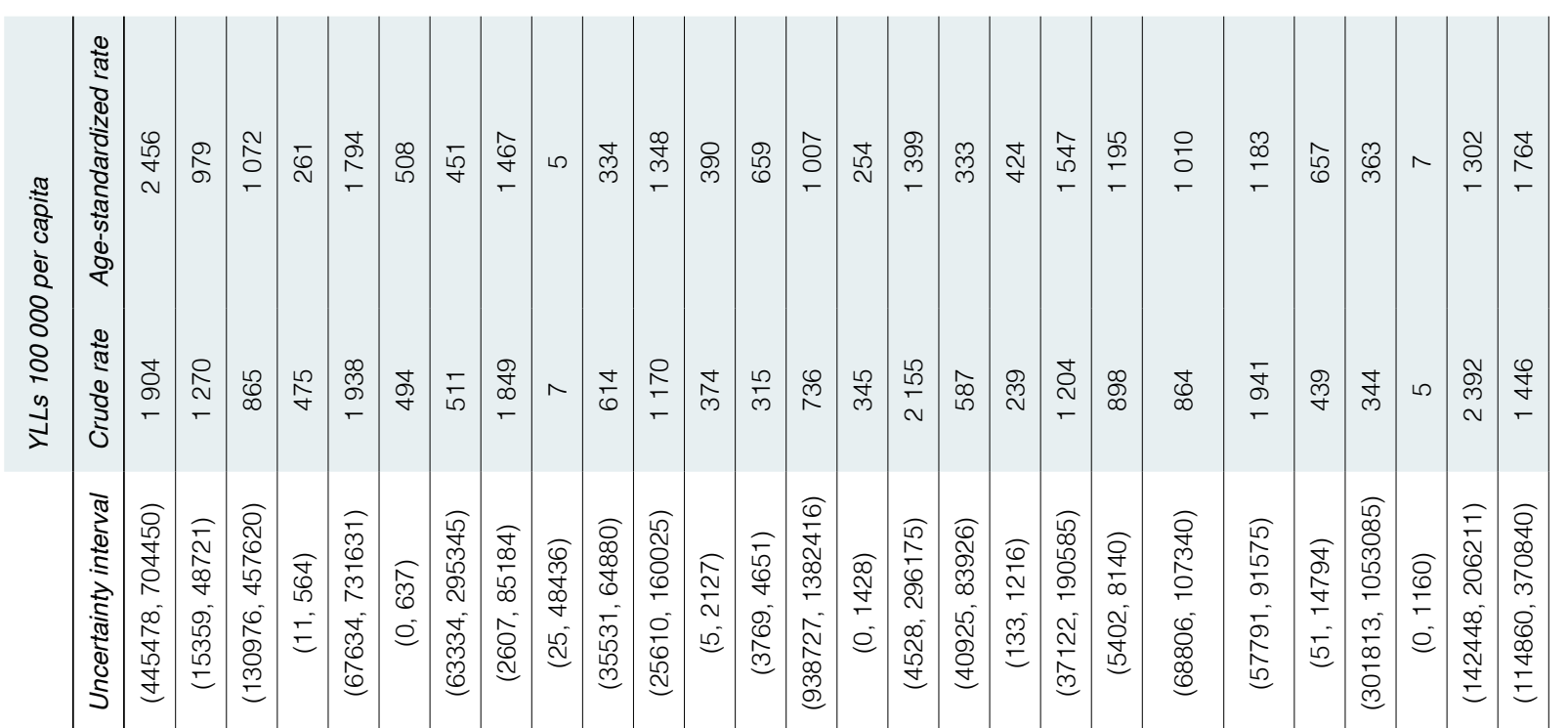

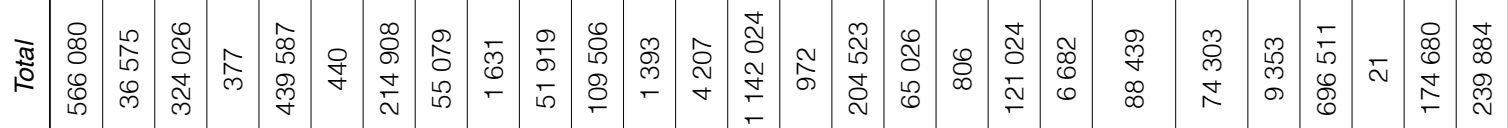

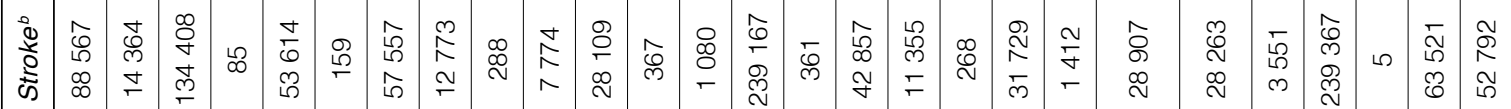

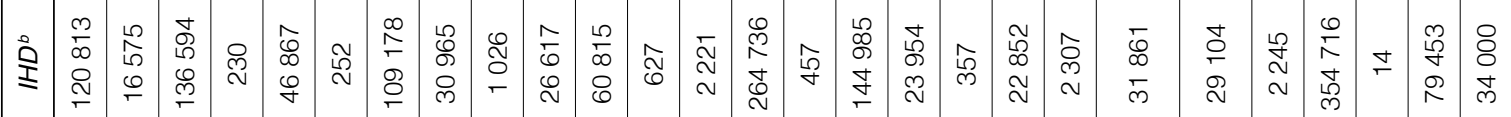

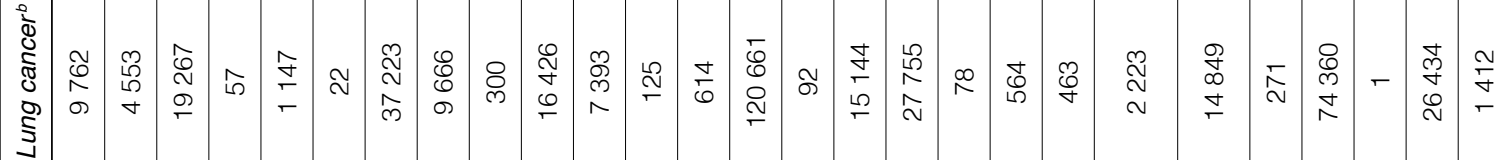

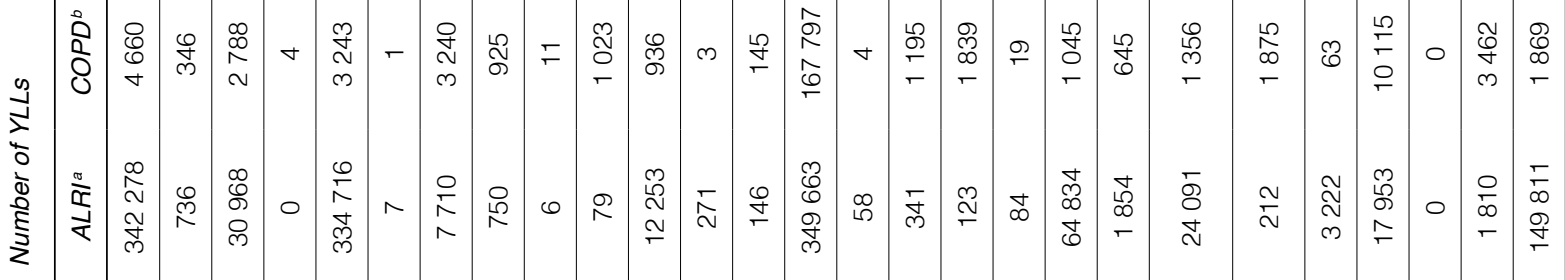

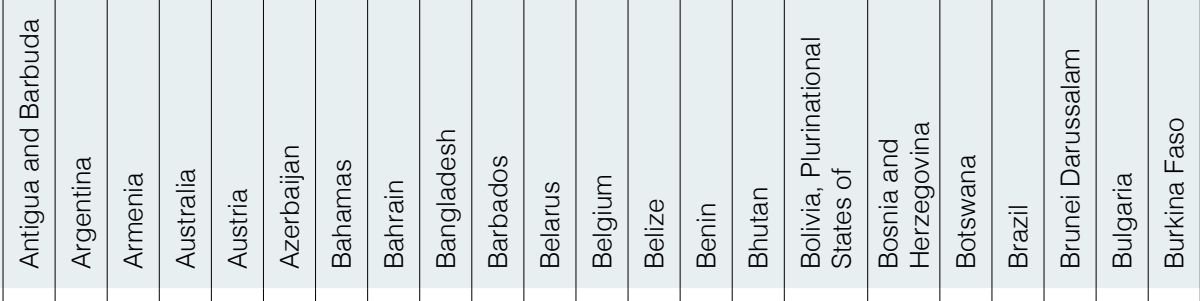

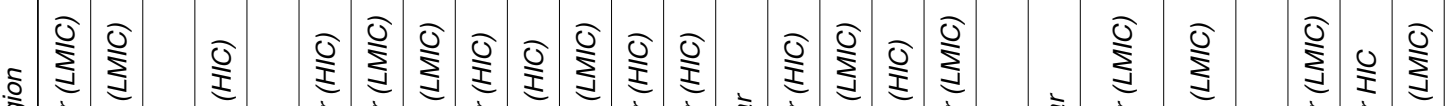

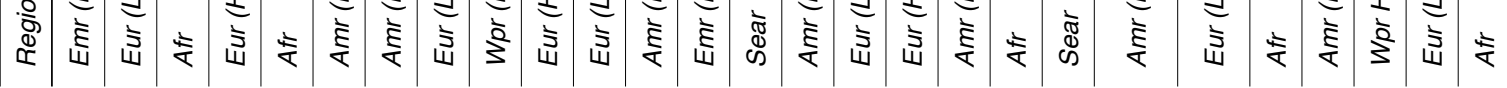




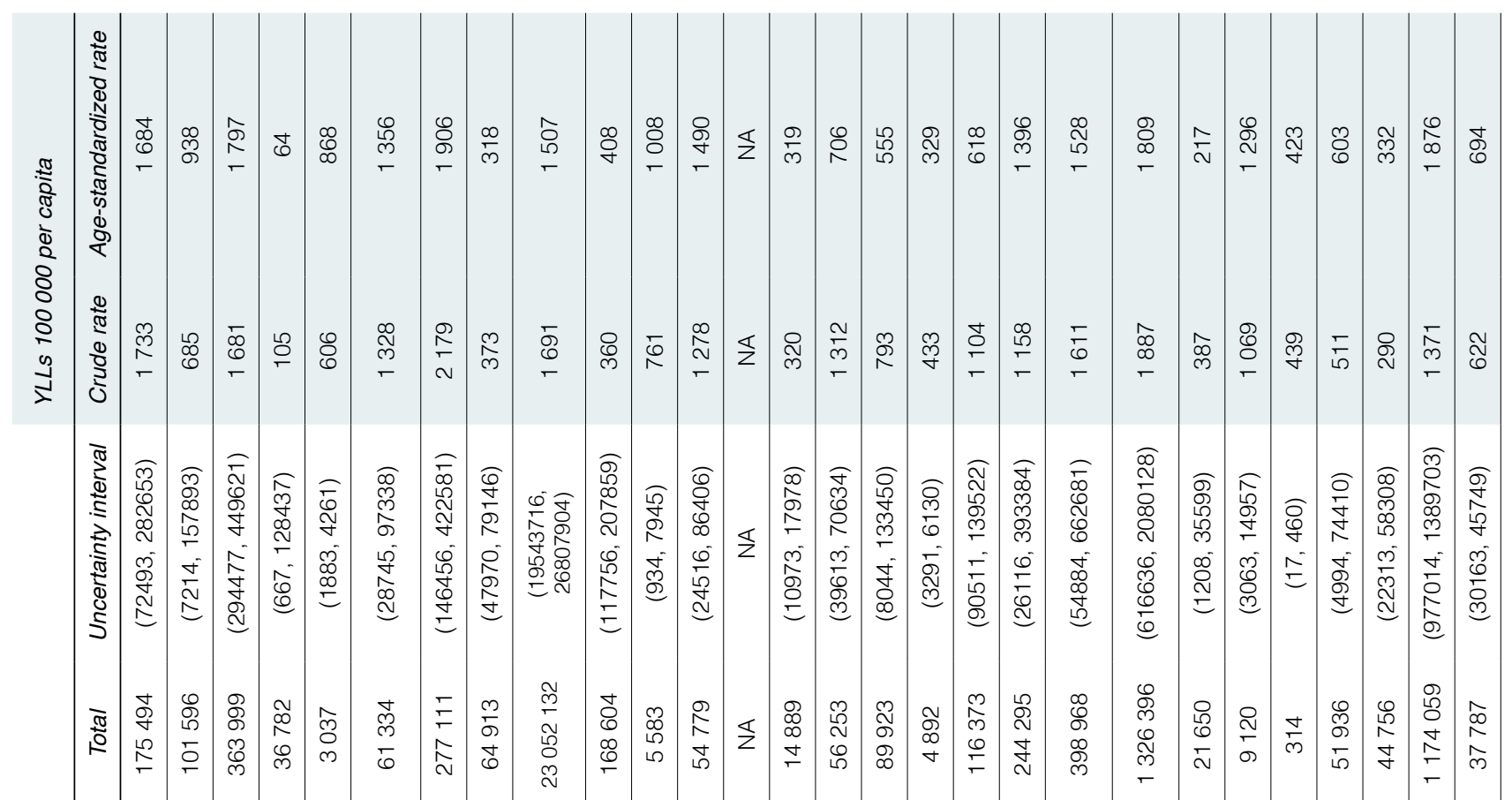

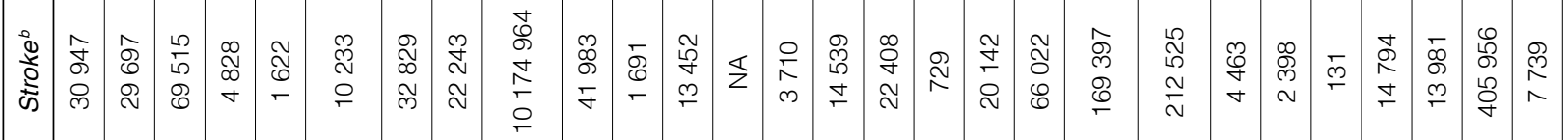

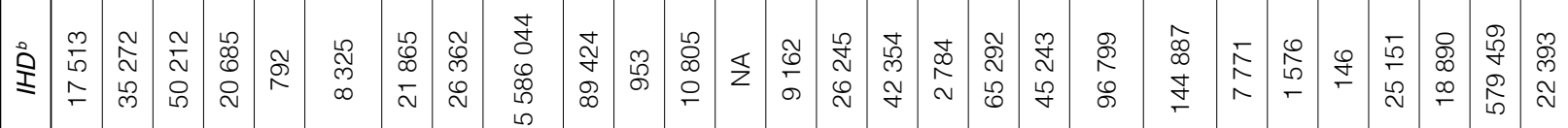

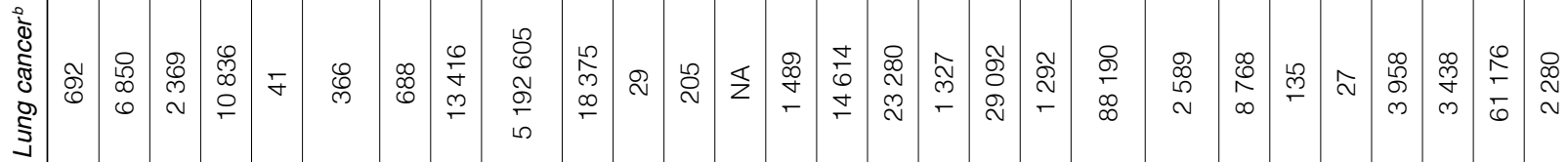

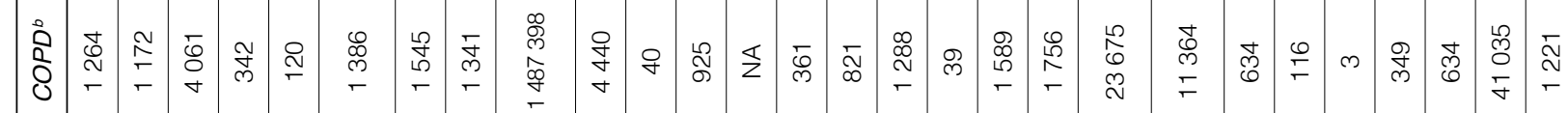

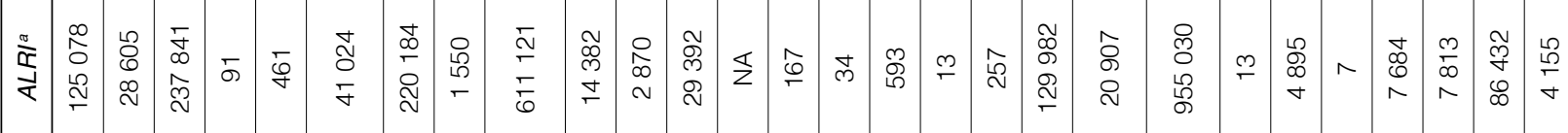

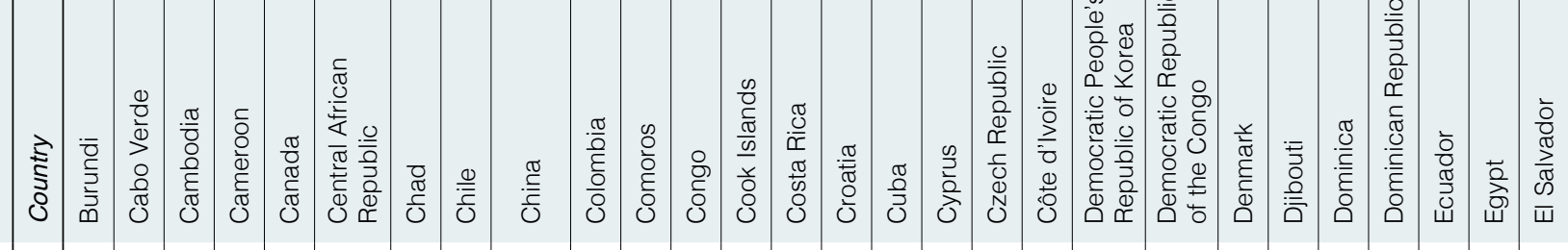

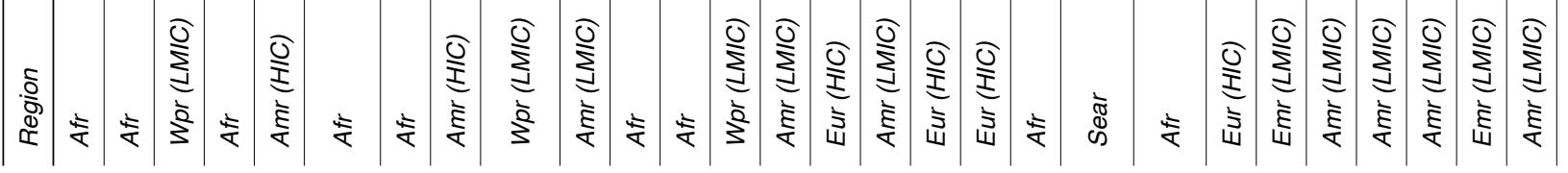




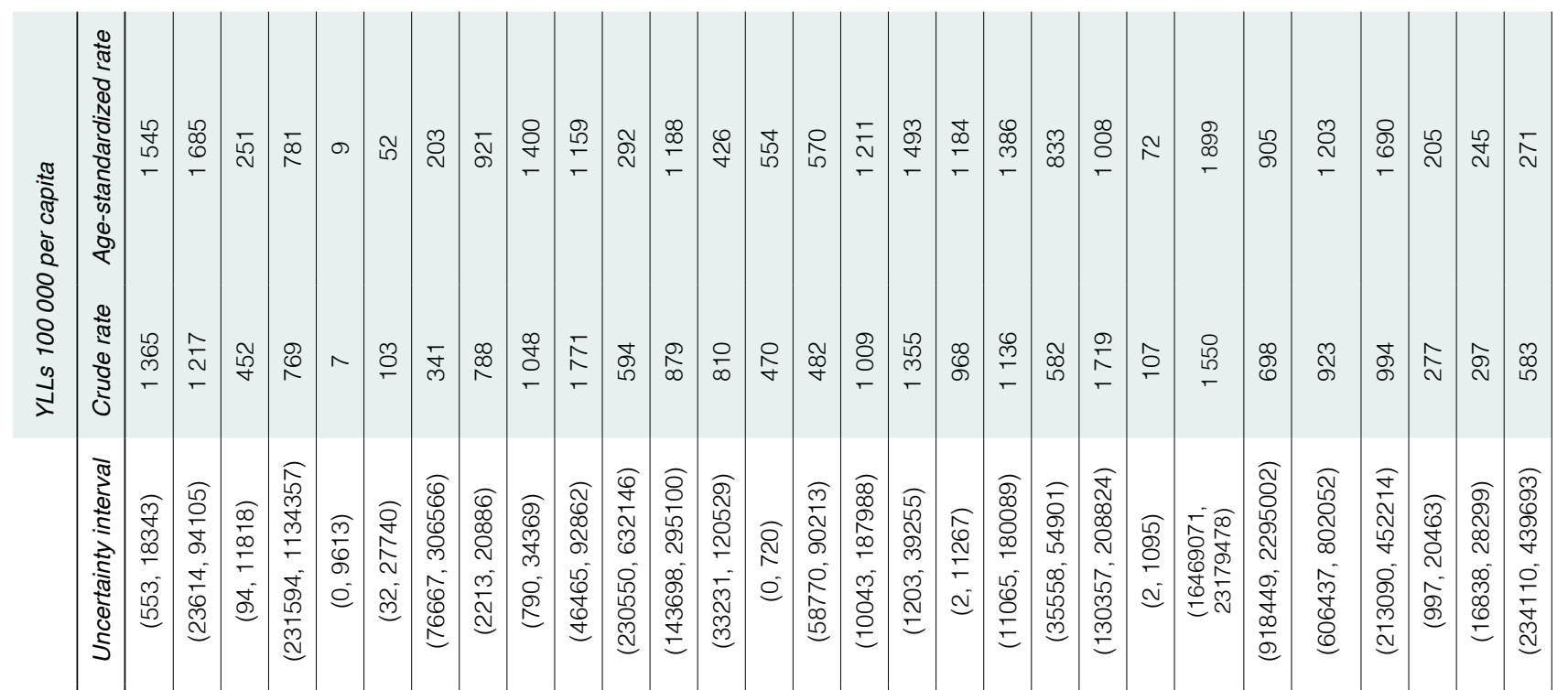

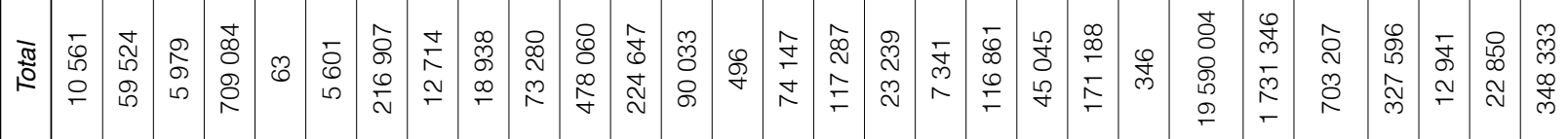

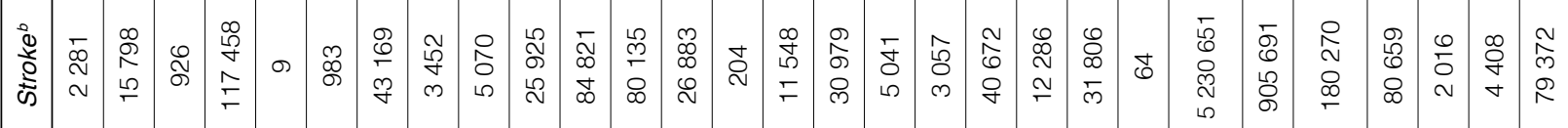

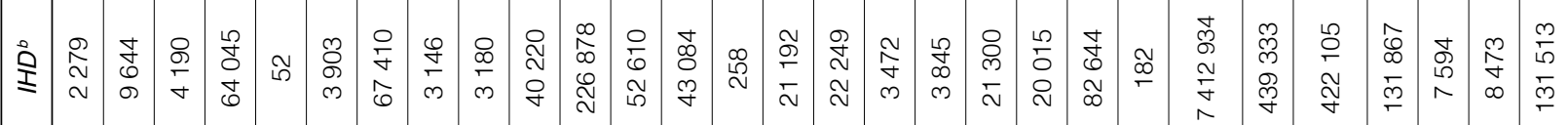

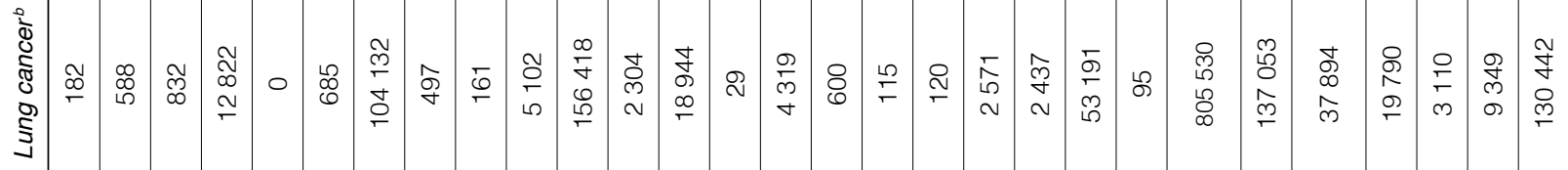

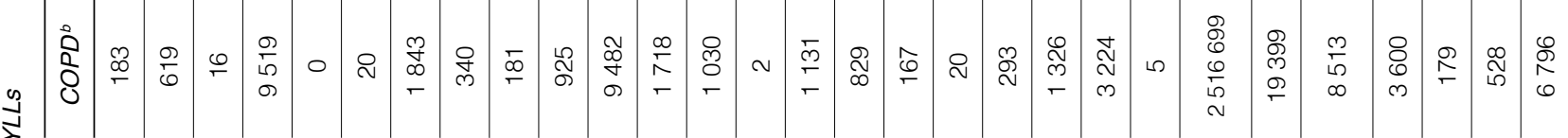

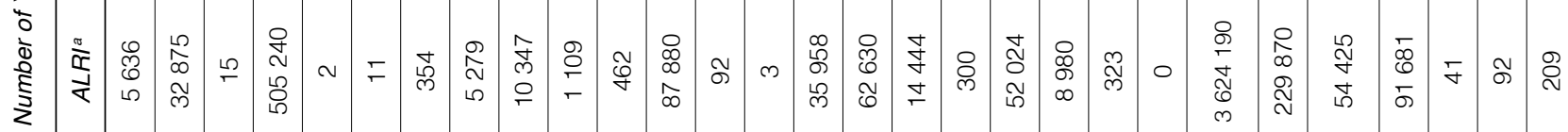

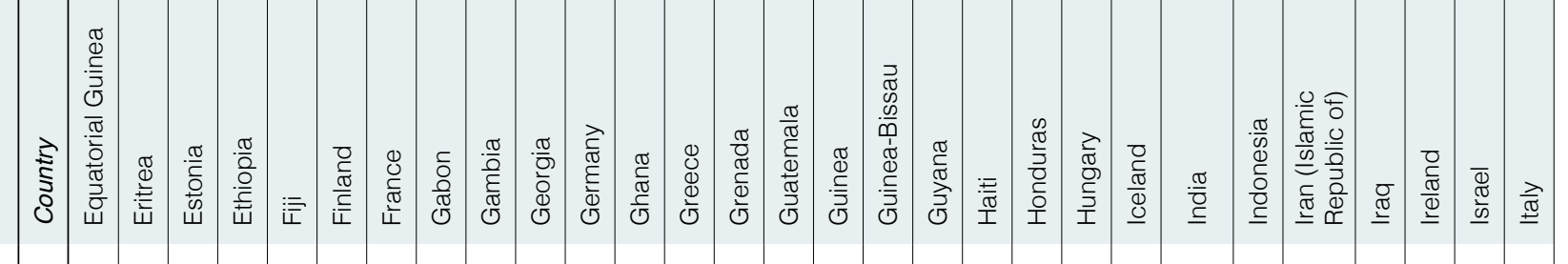

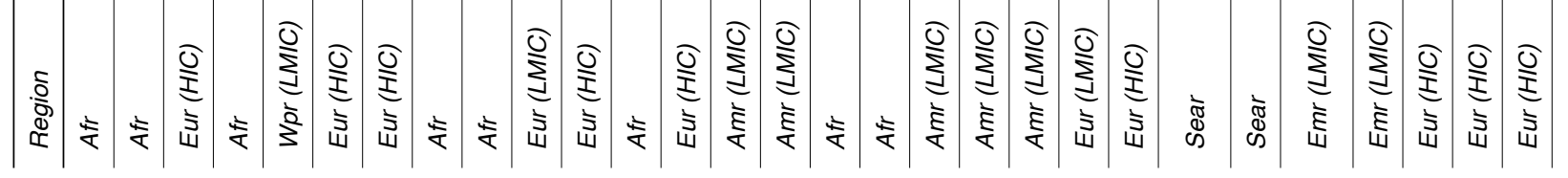




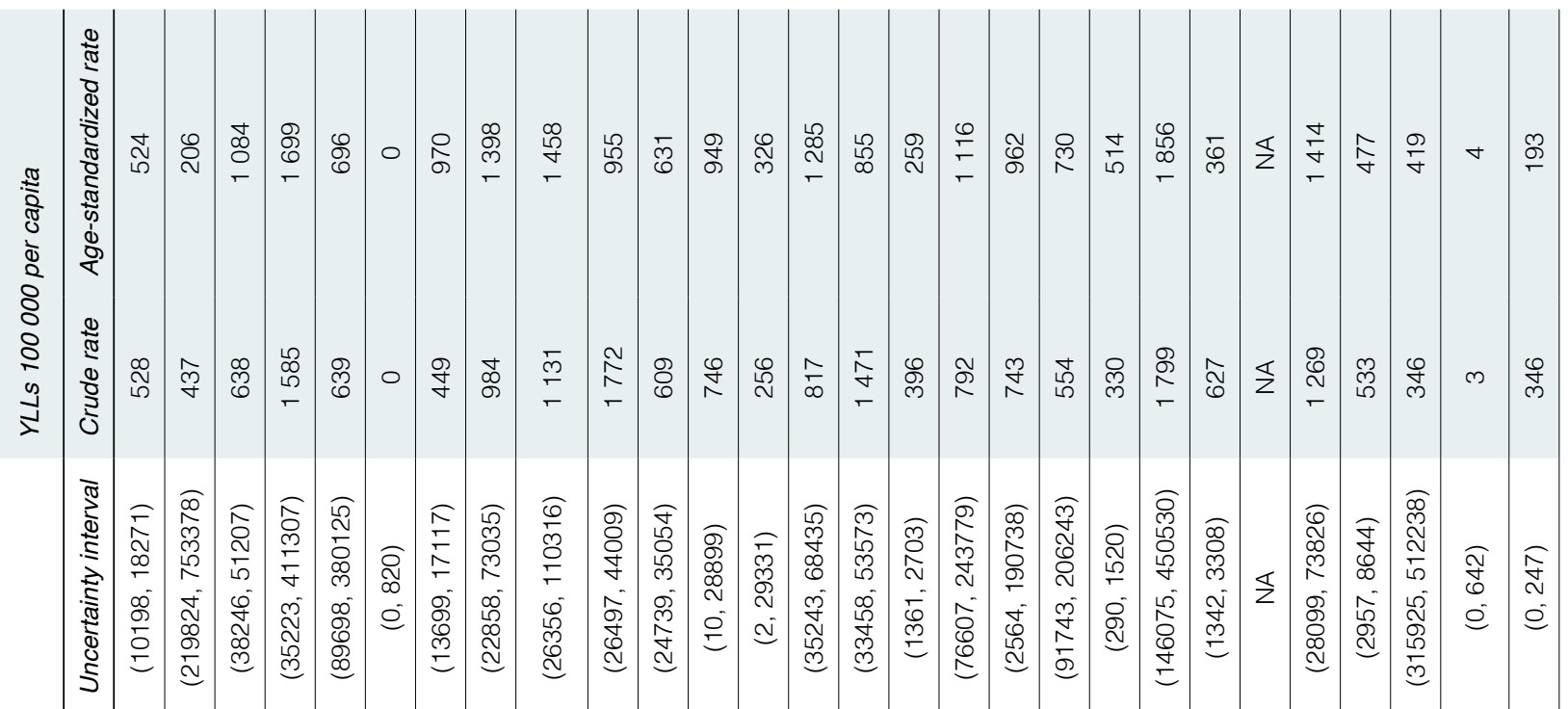

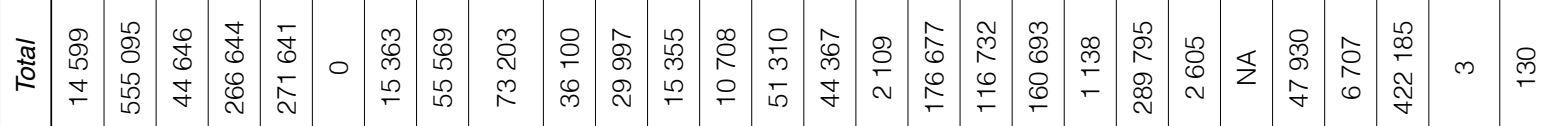

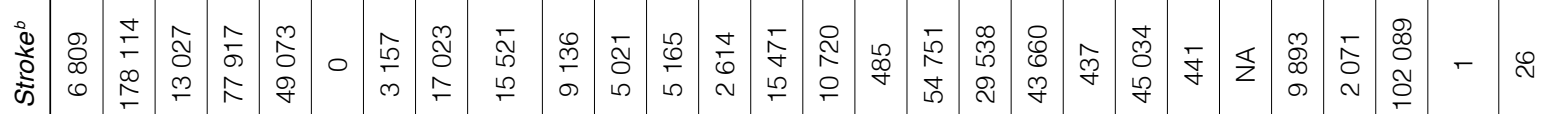

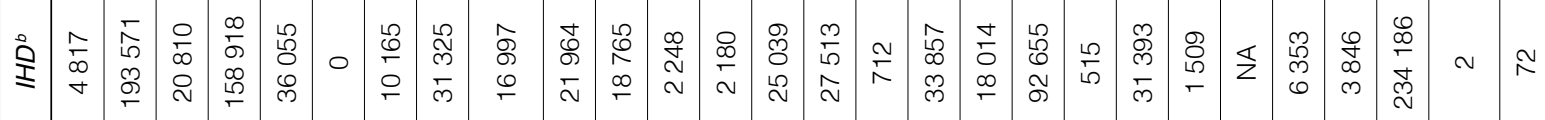

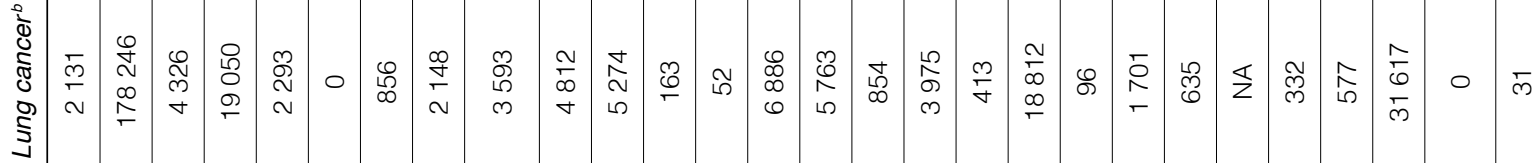

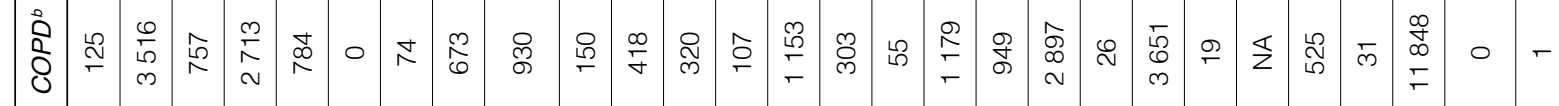

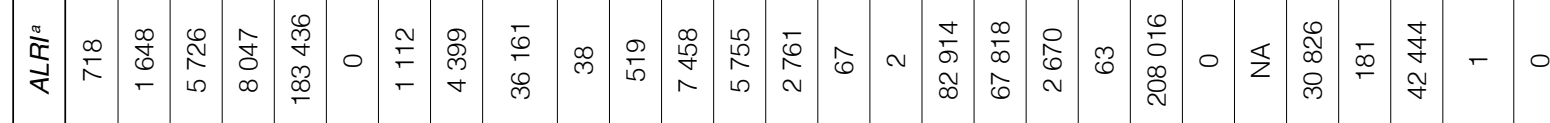

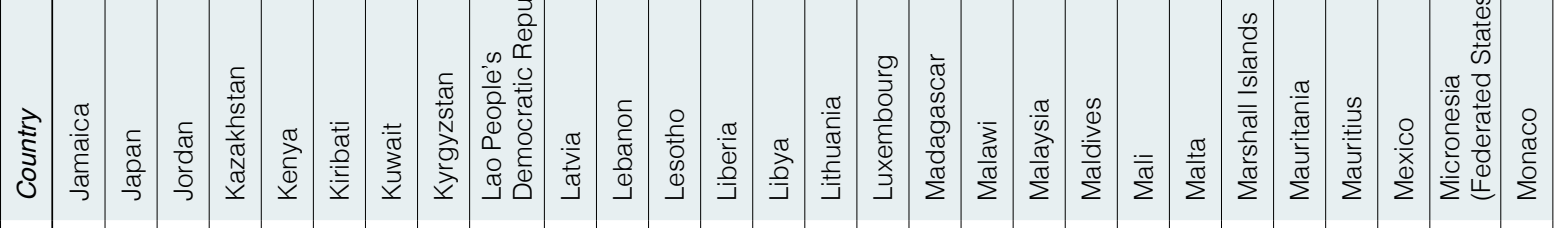

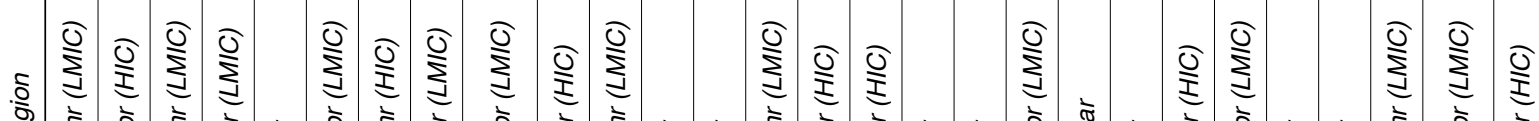

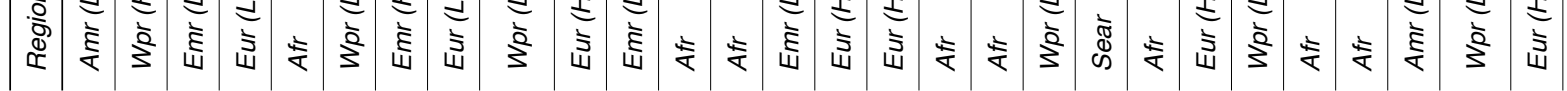




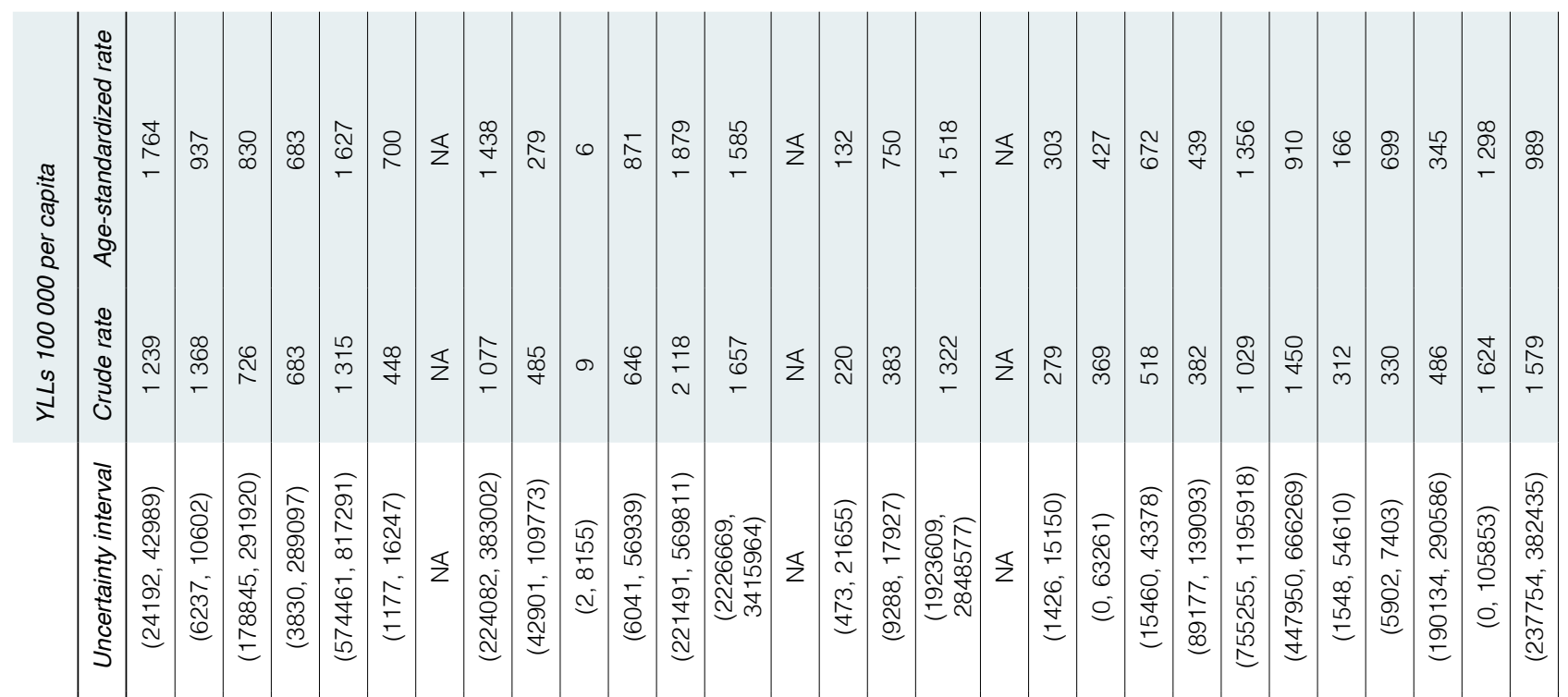

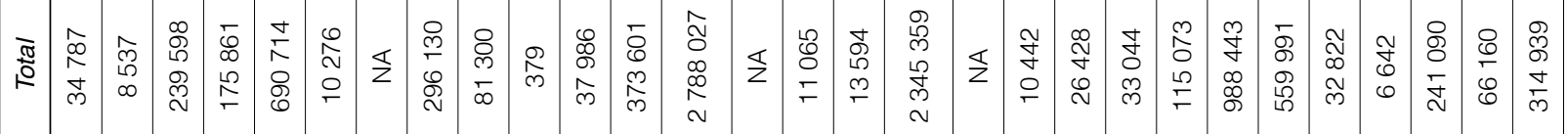

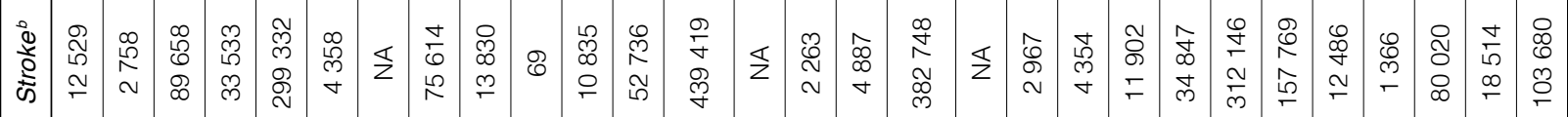

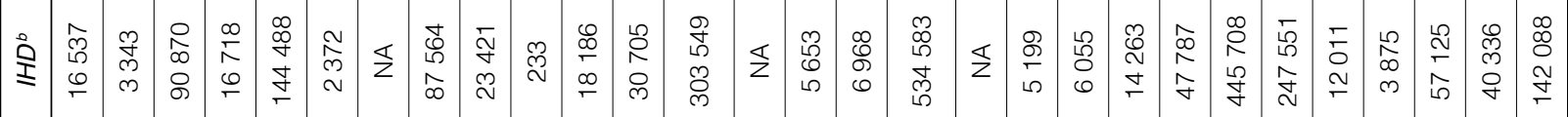

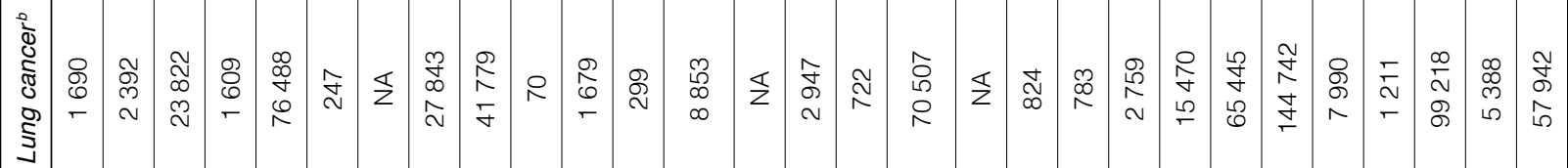

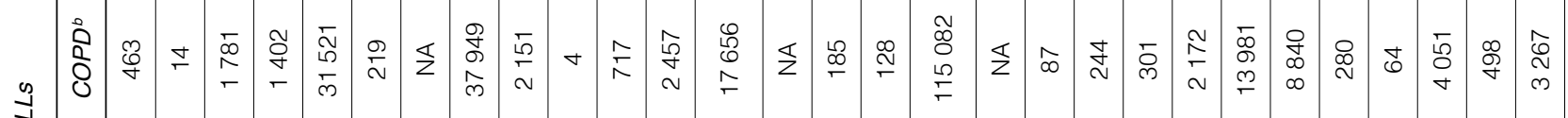

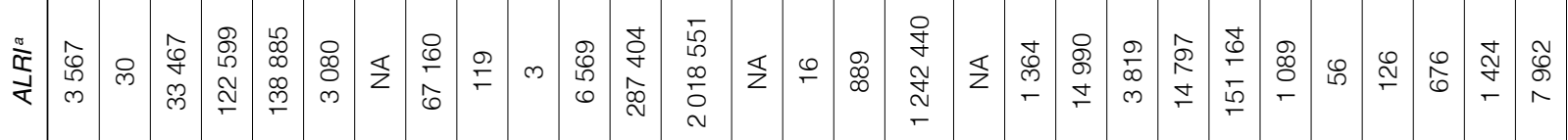

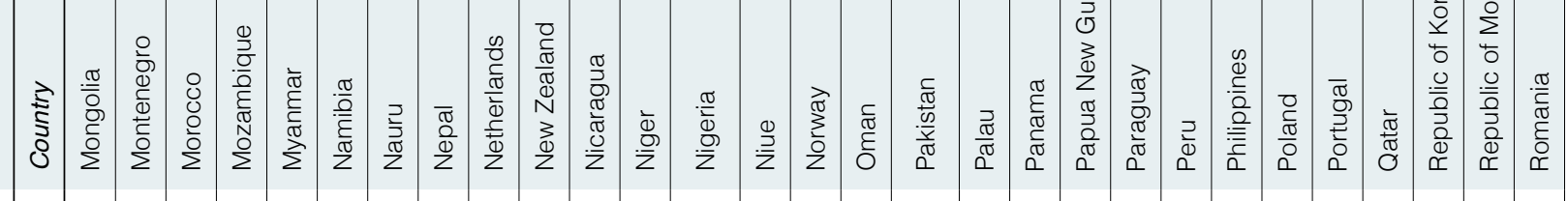

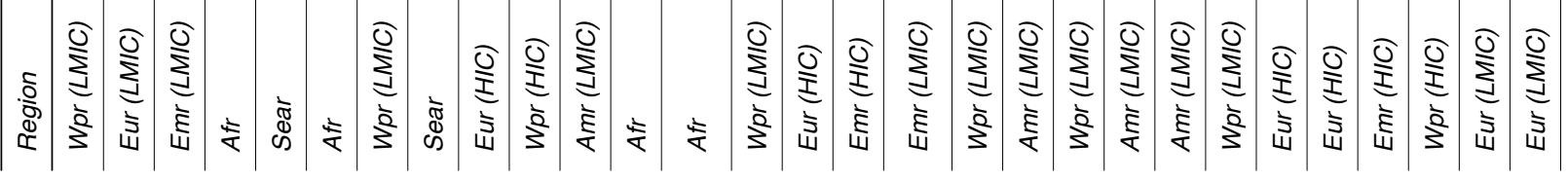




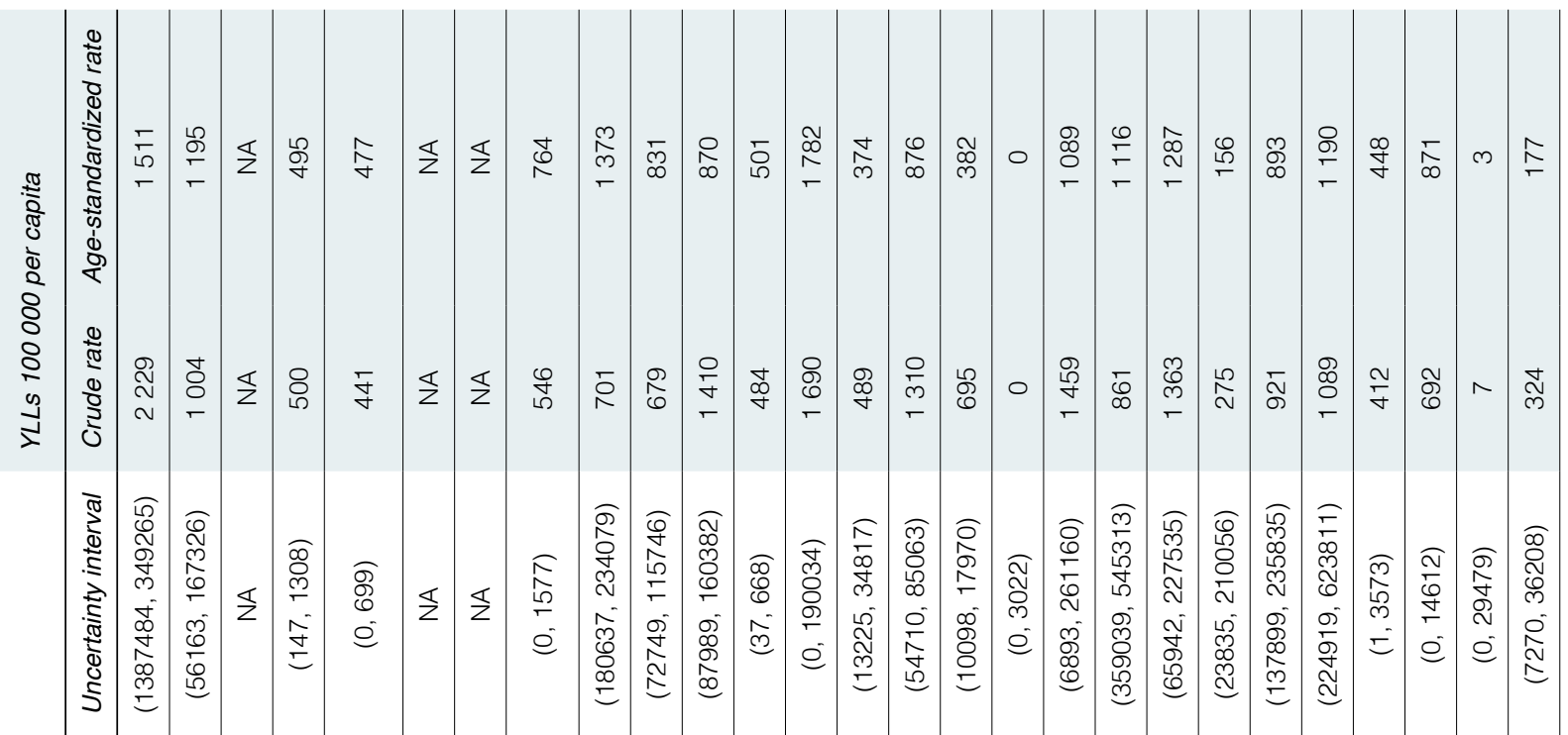

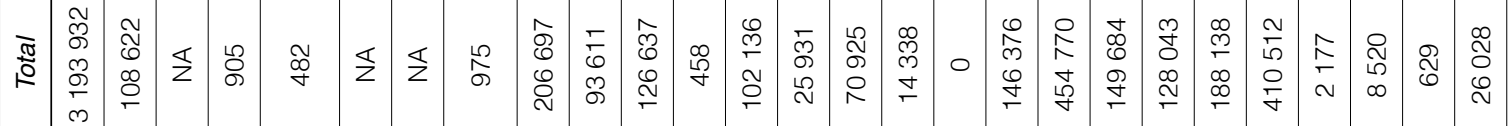

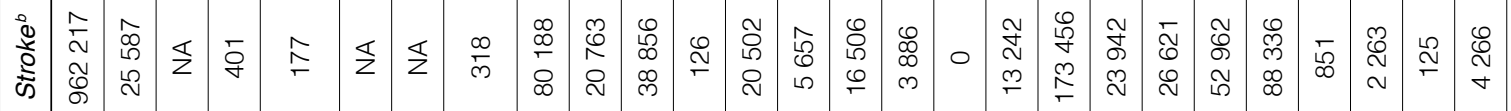

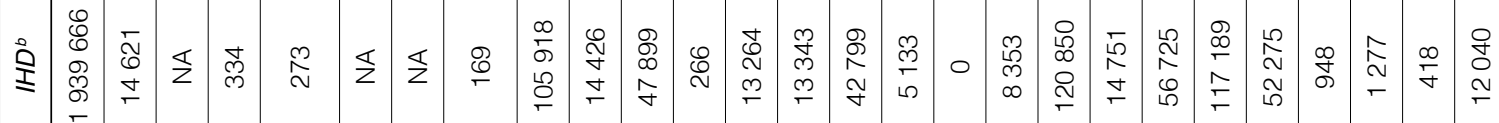

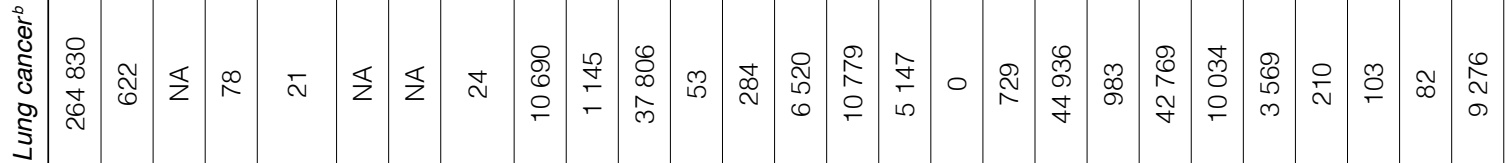

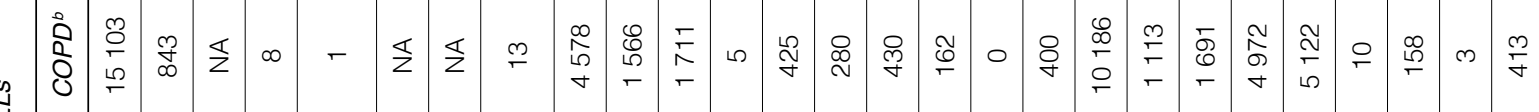

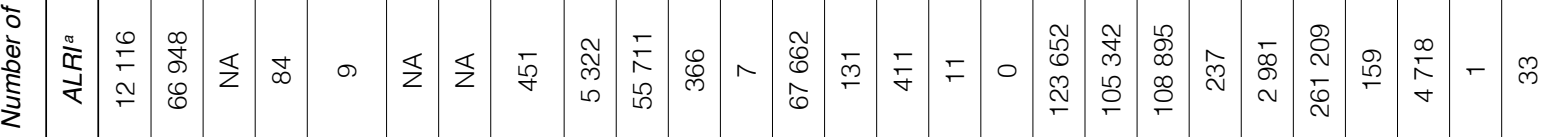

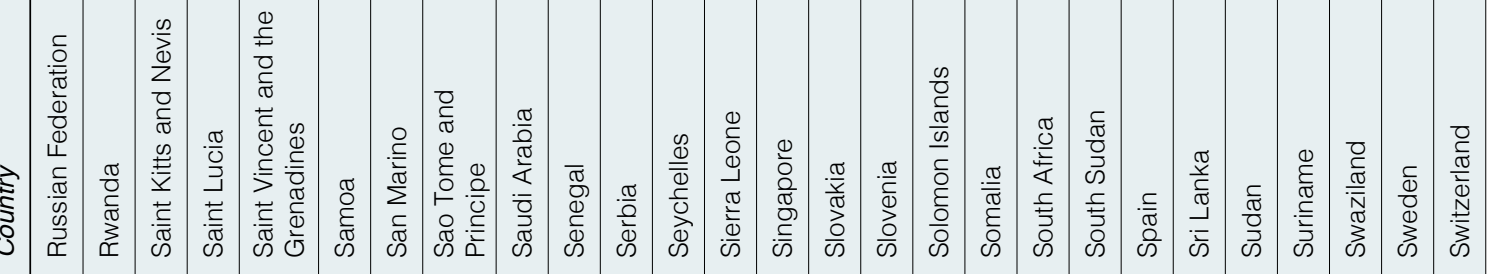
.

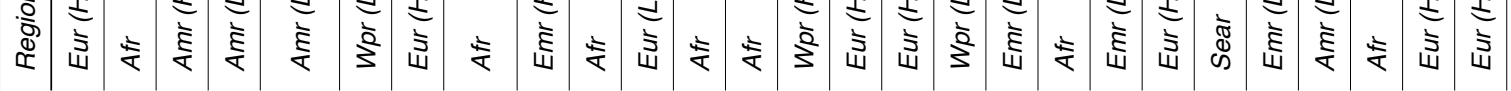




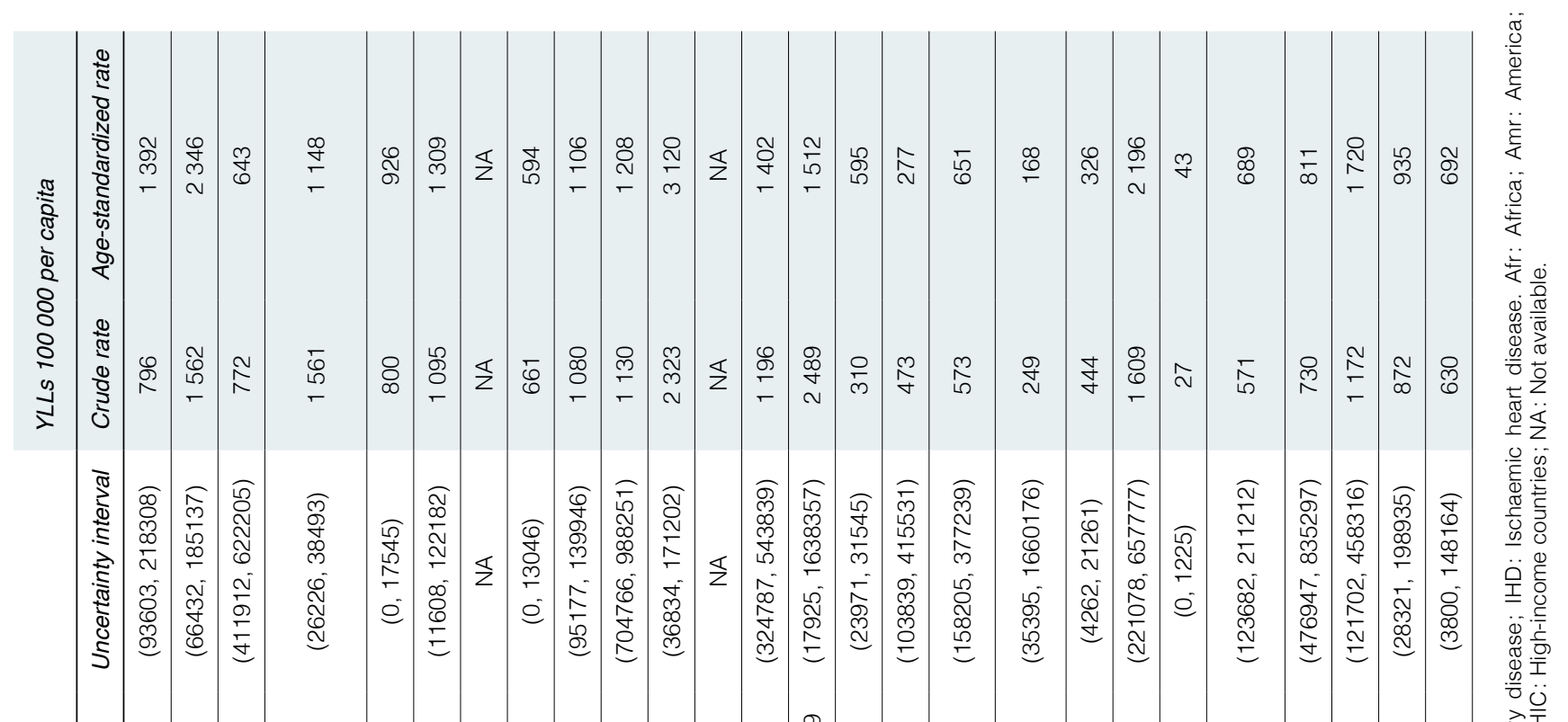

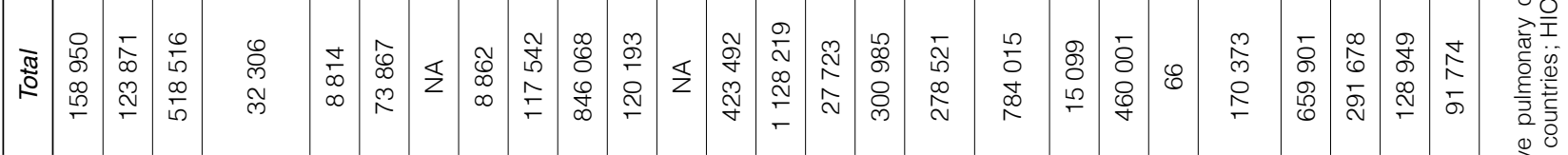

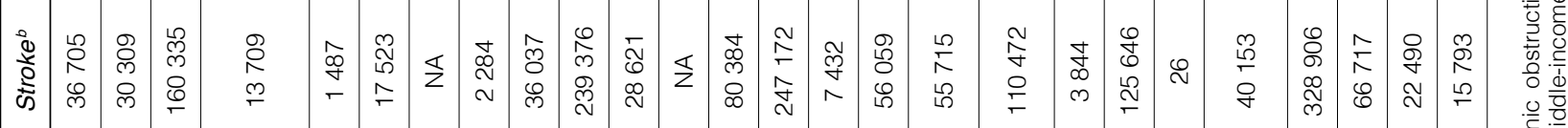

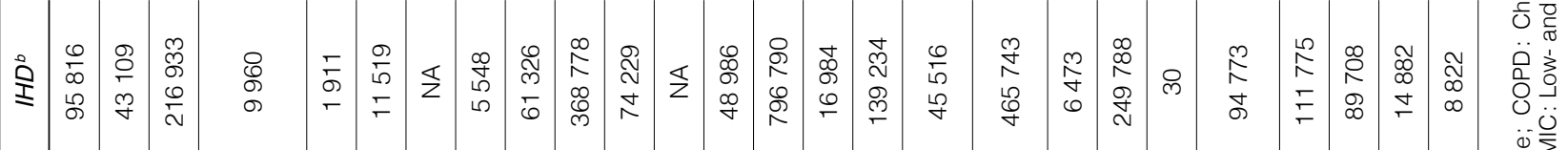

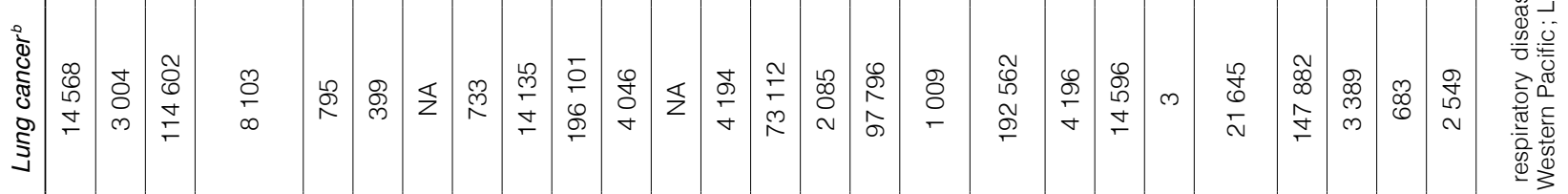
空

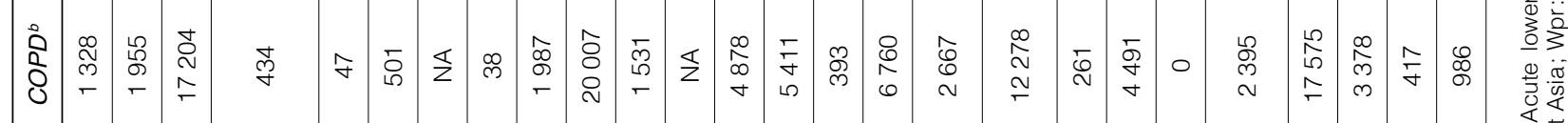

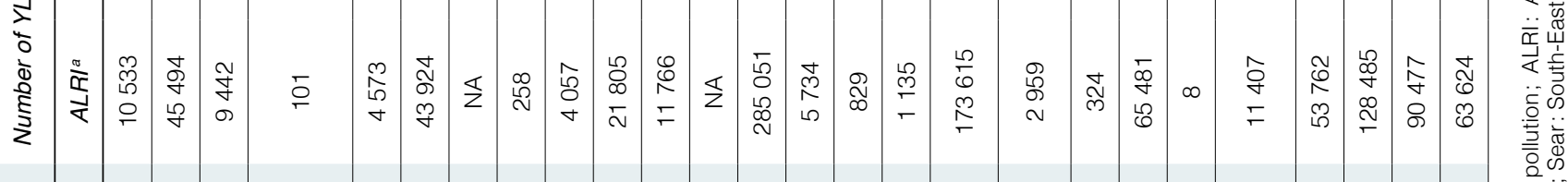

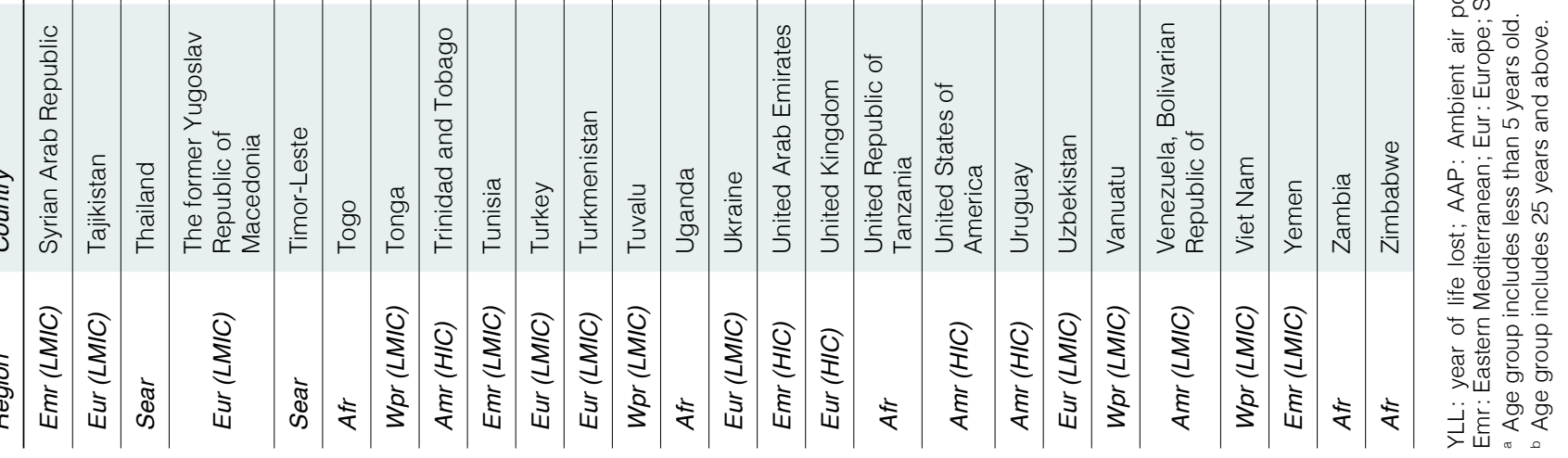




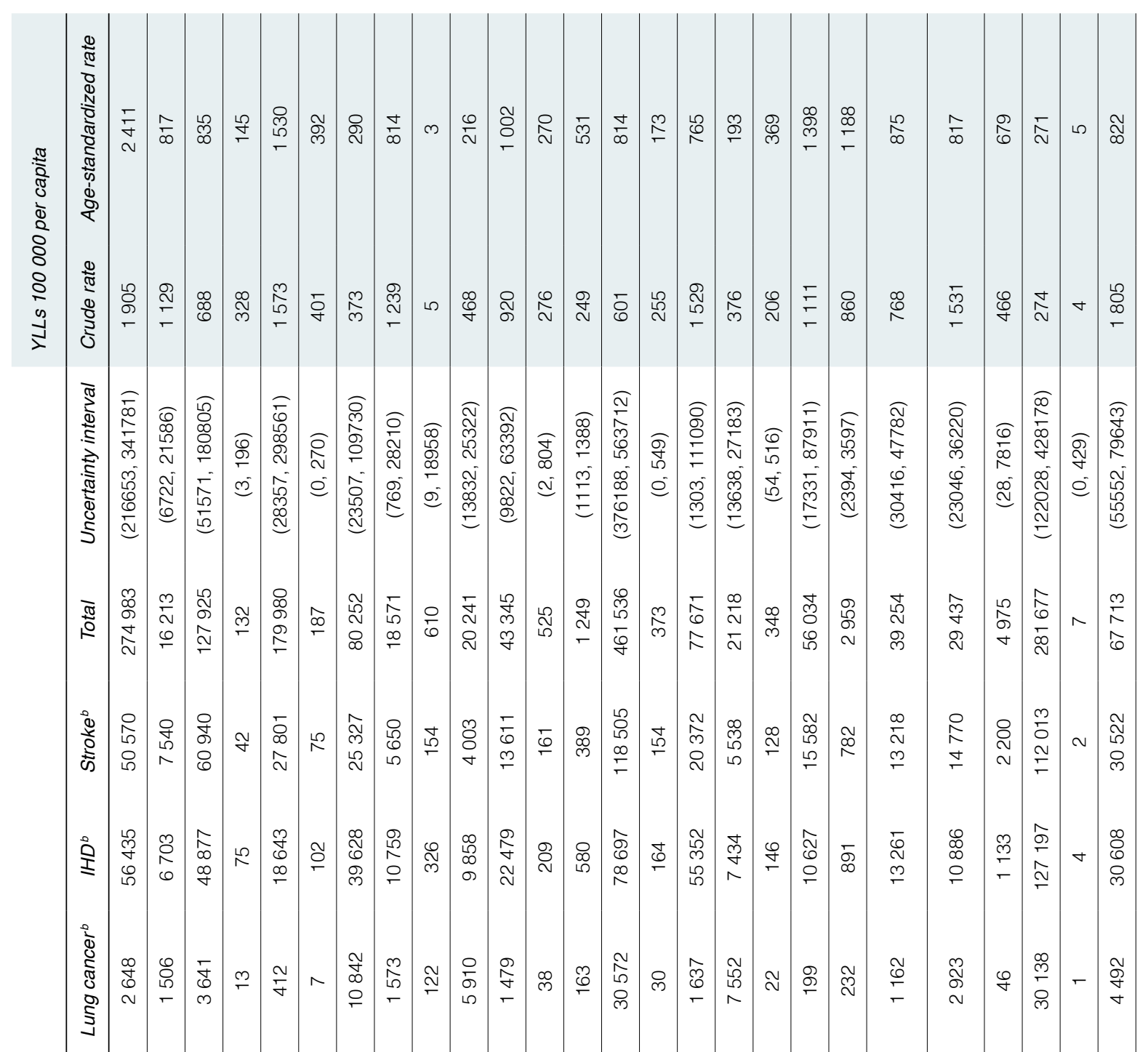

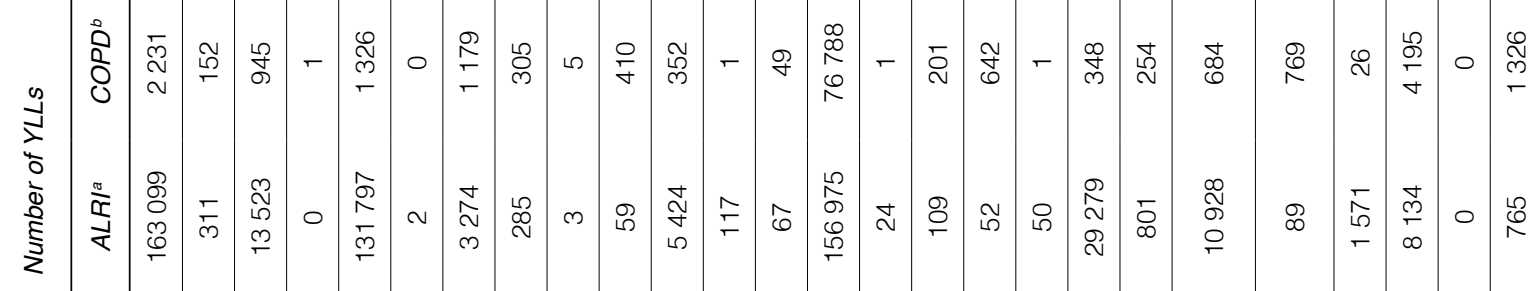

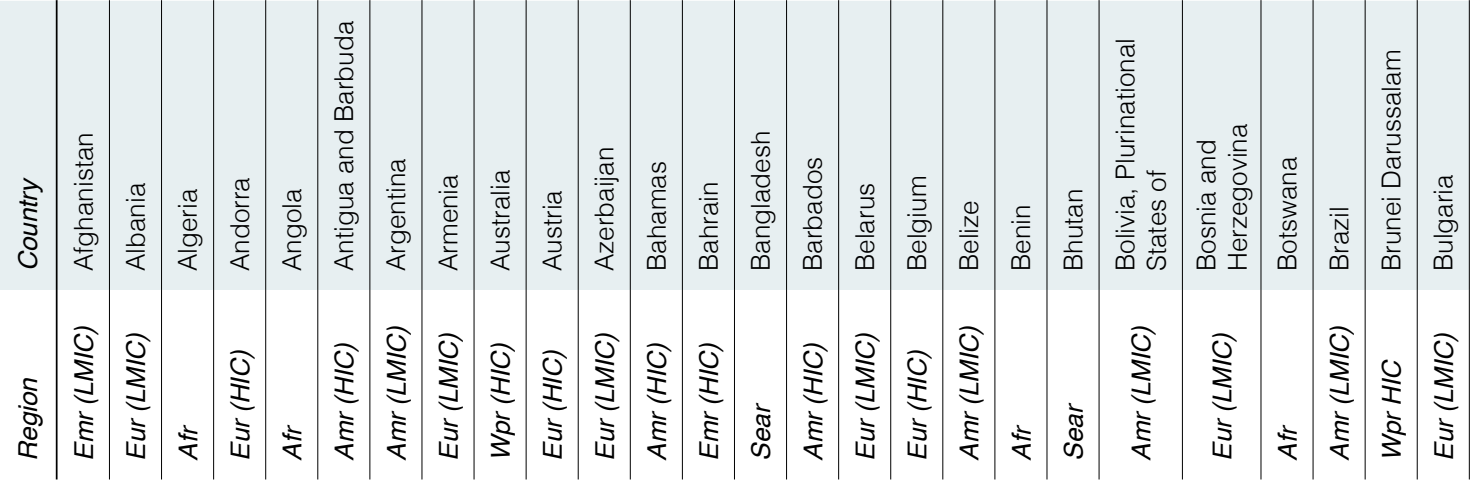




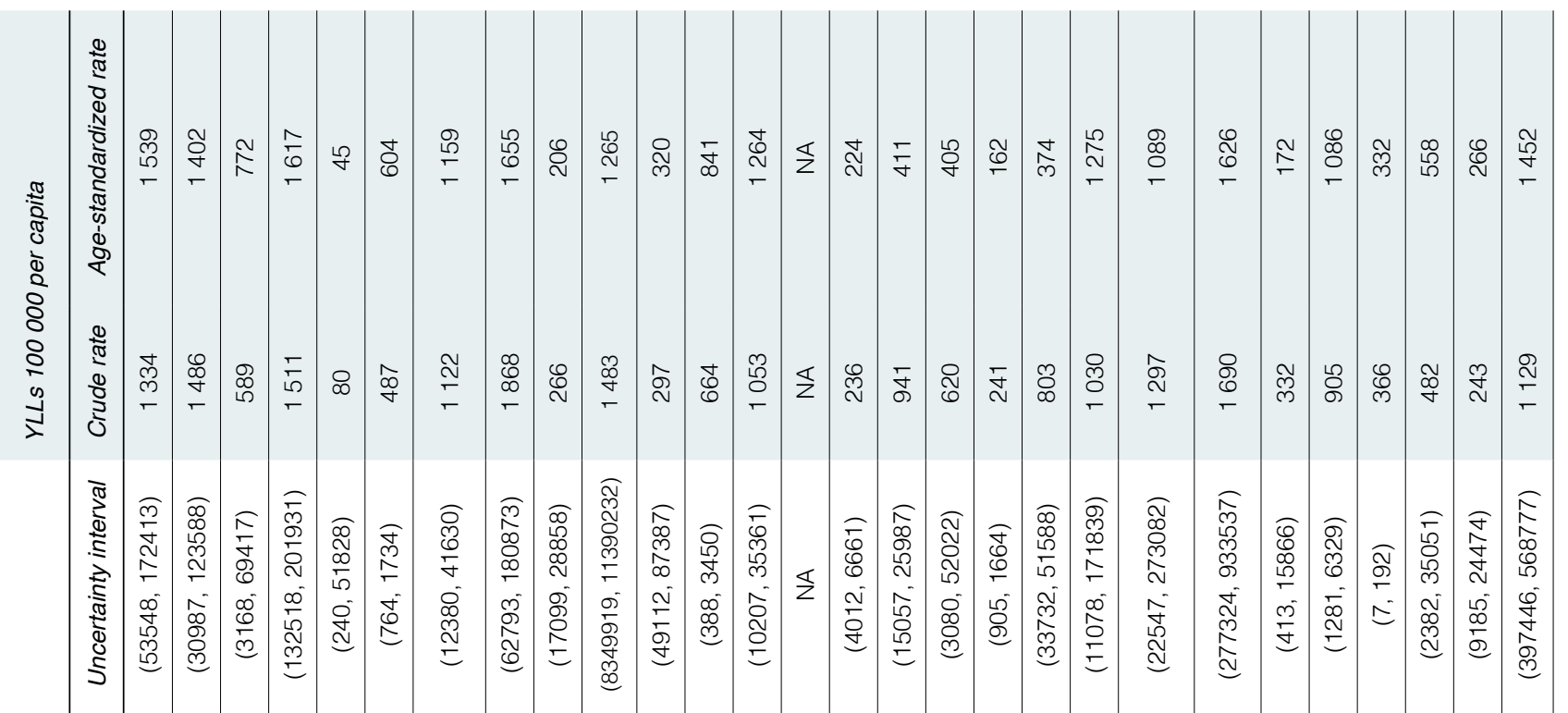

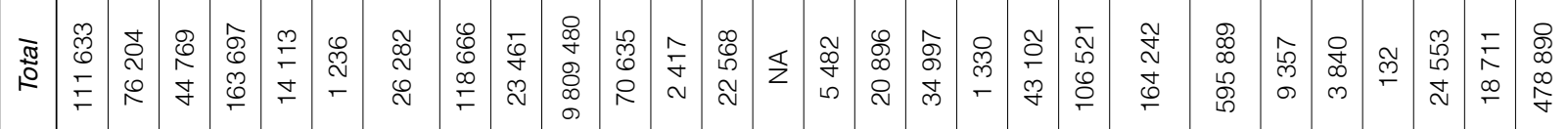

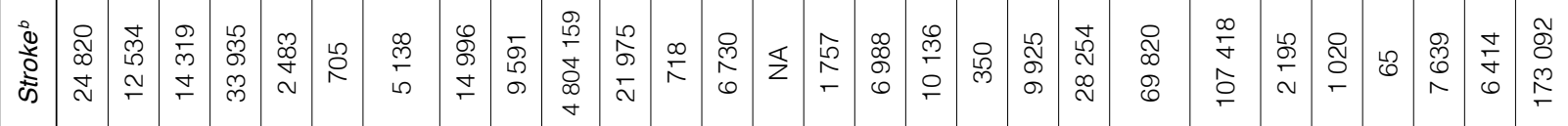

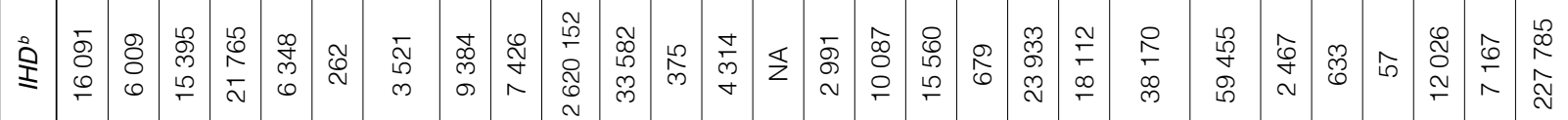

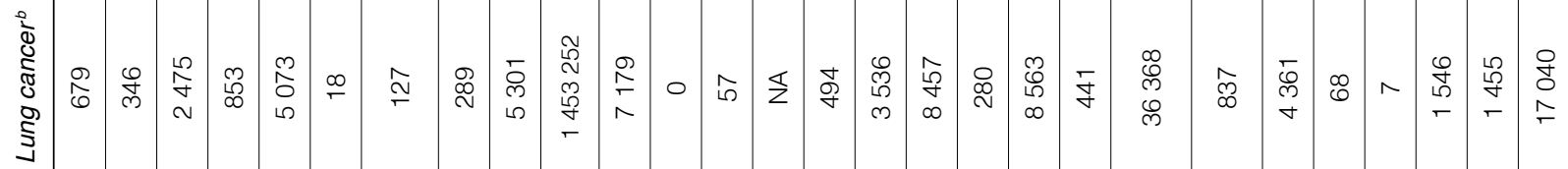

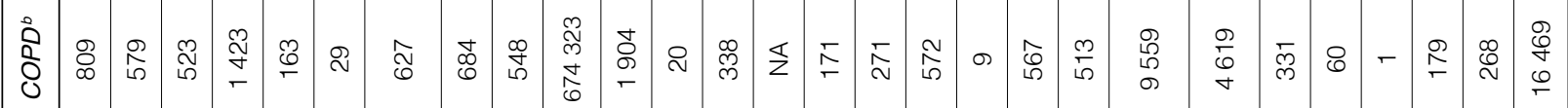

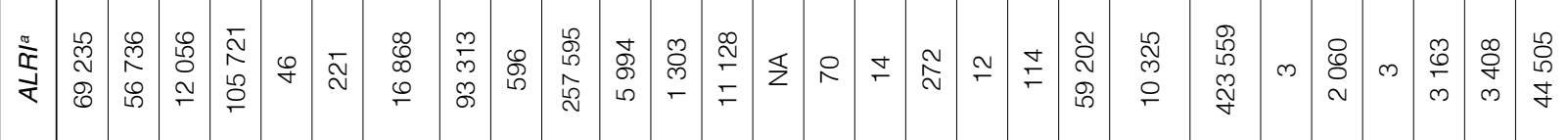

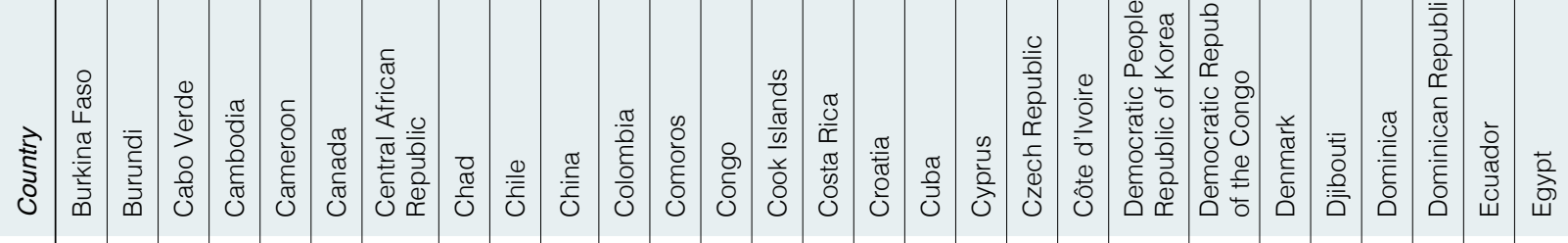

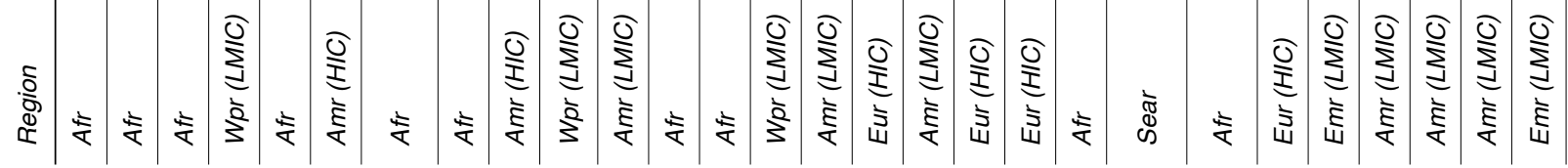




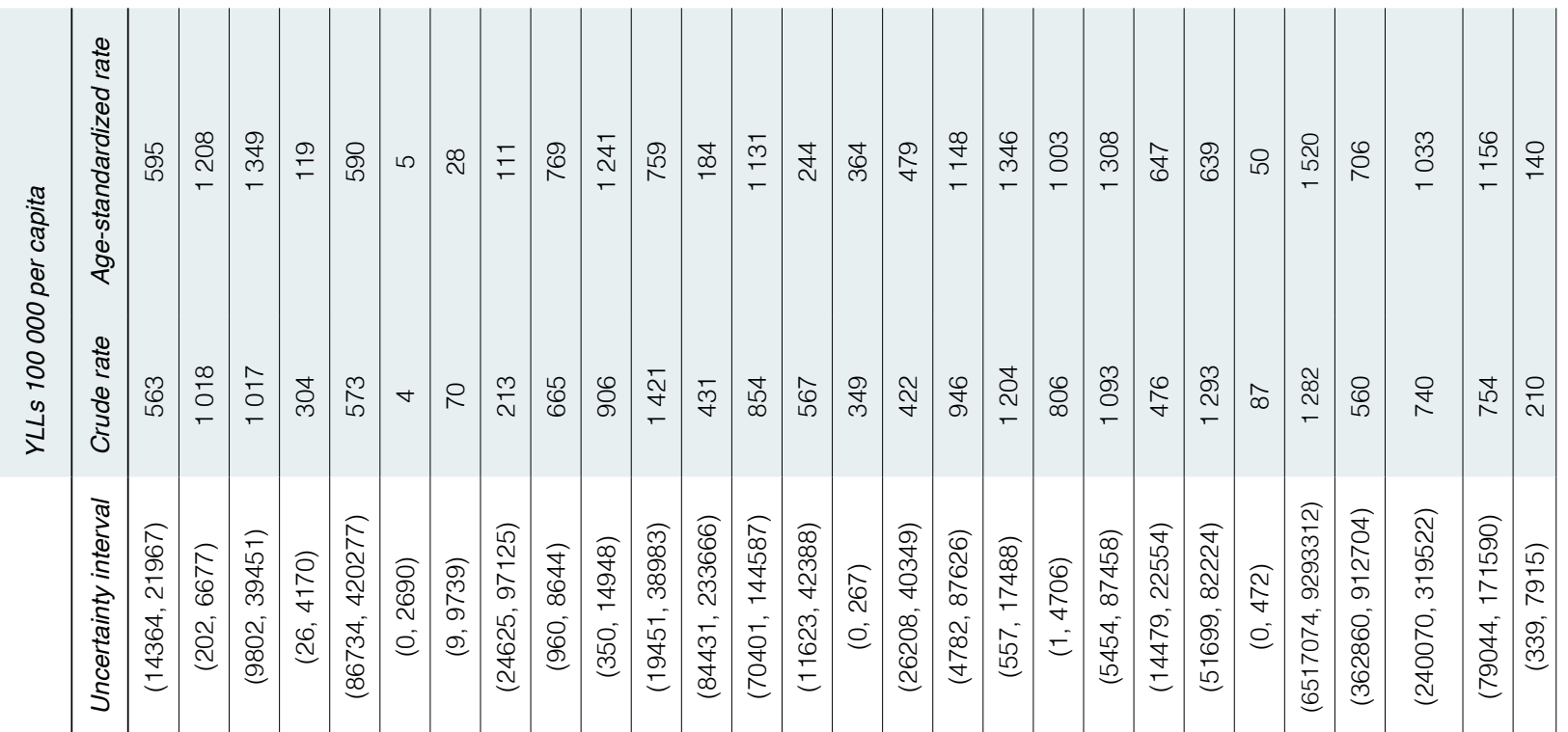

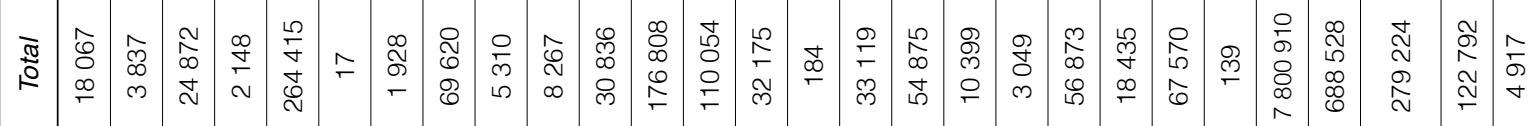

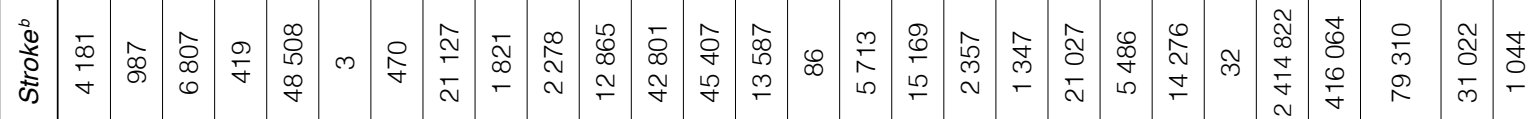

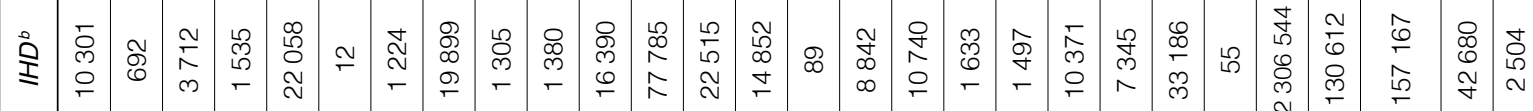

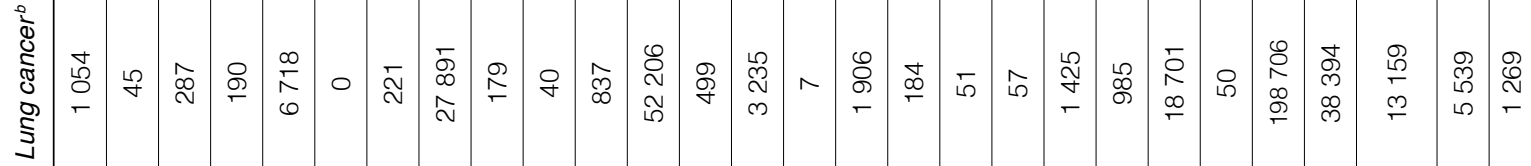

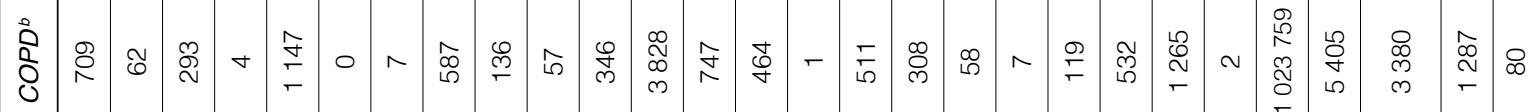

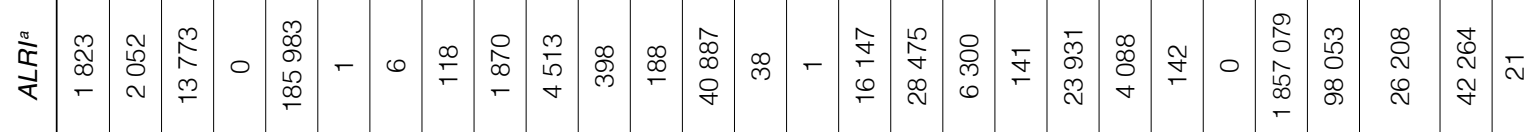

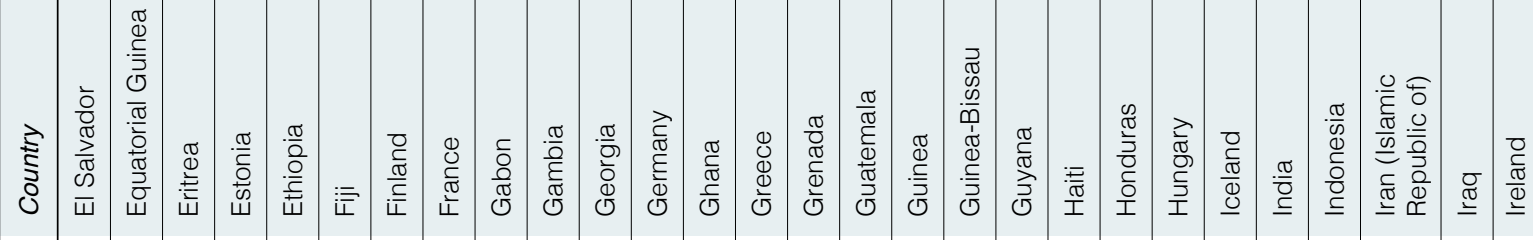

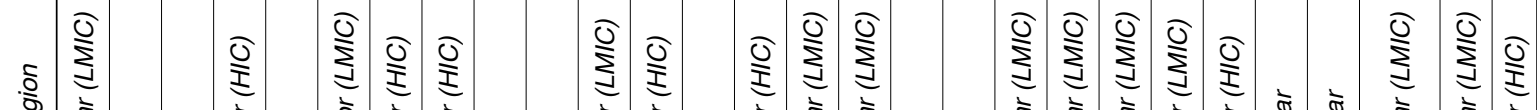

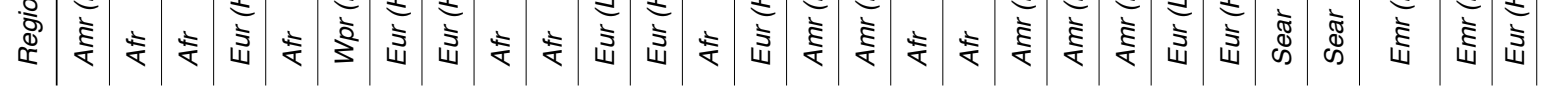




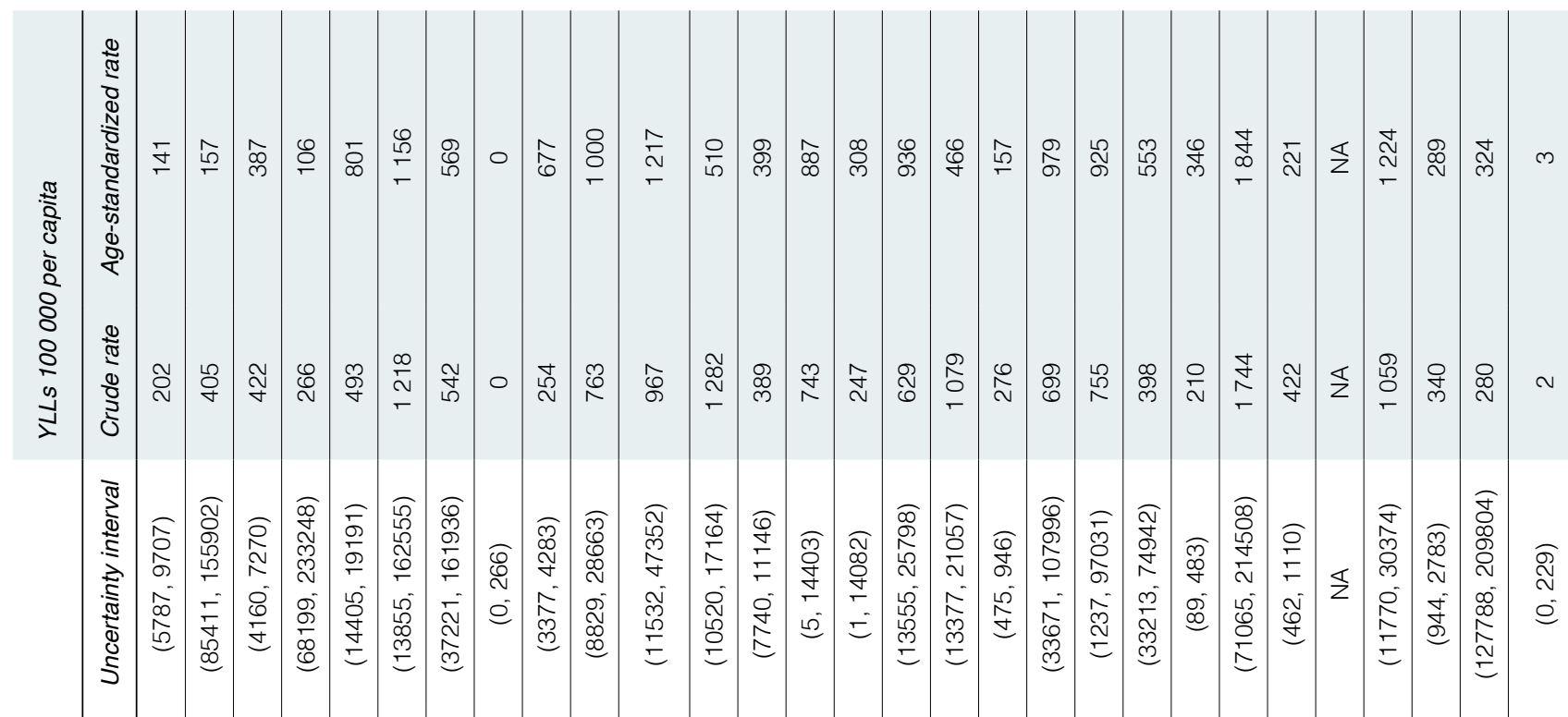

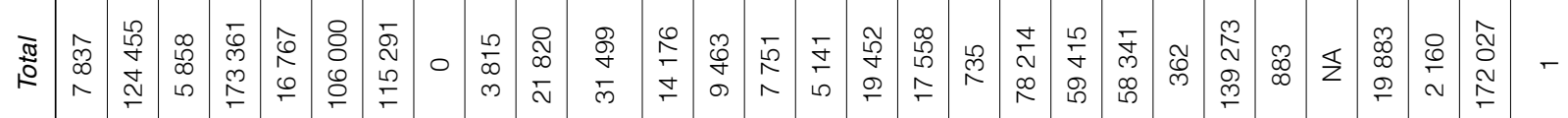

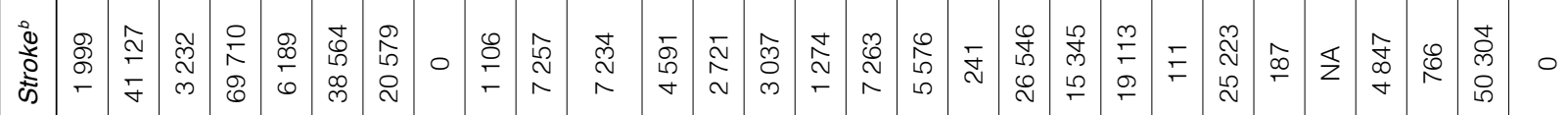

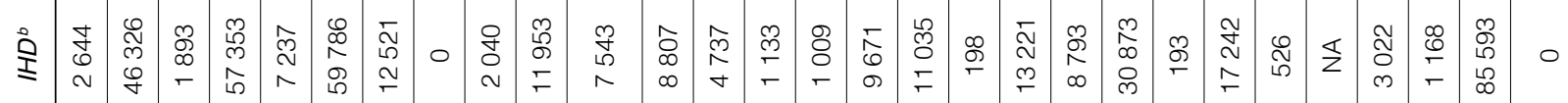

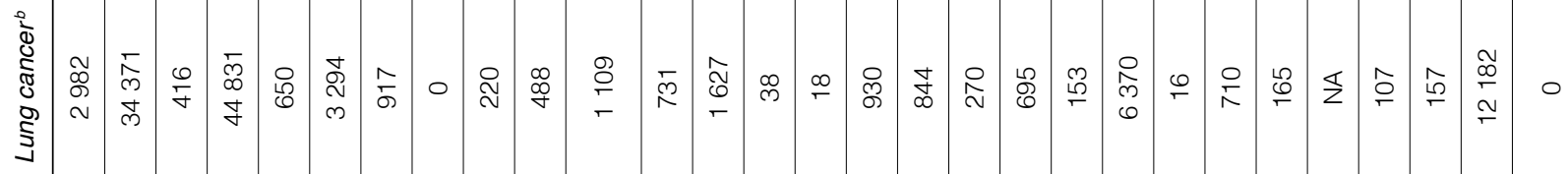

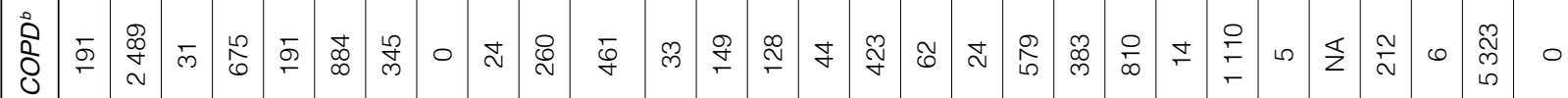

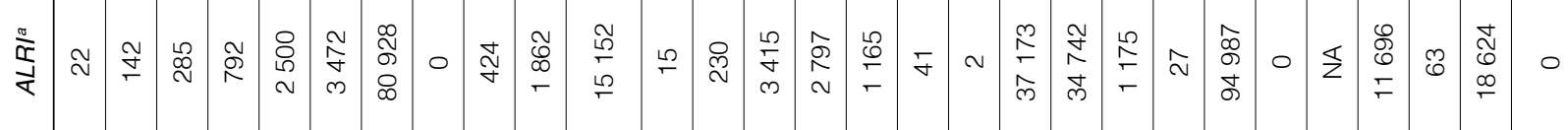

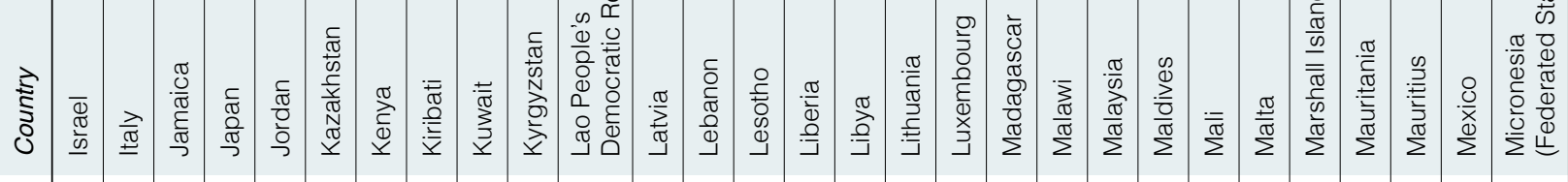

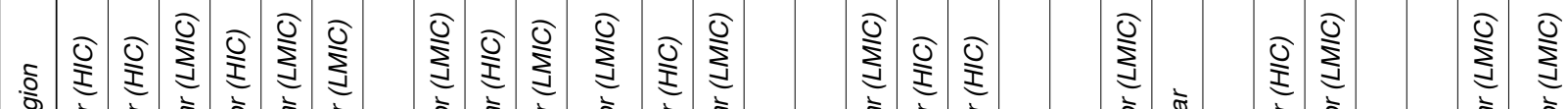

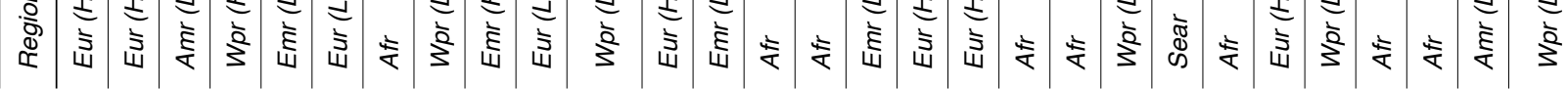




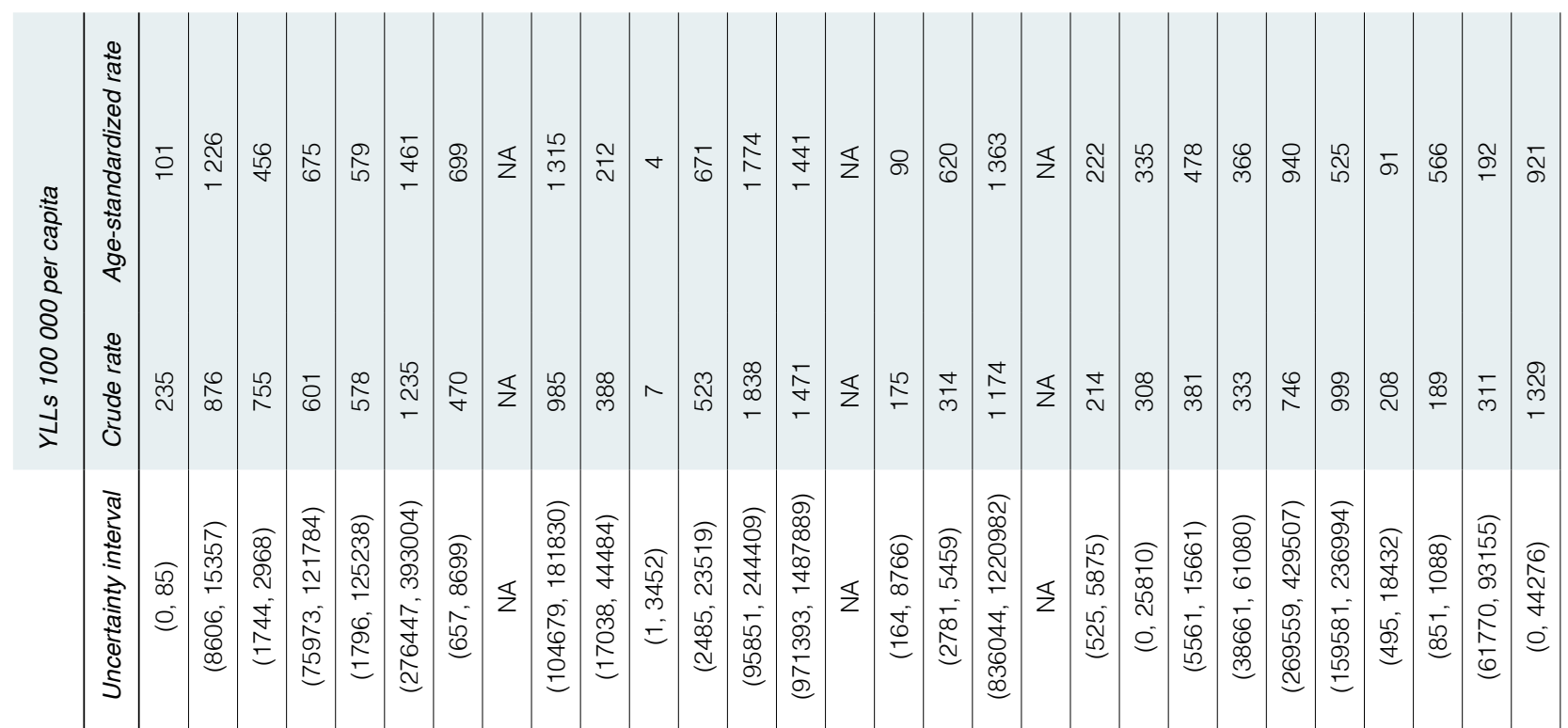

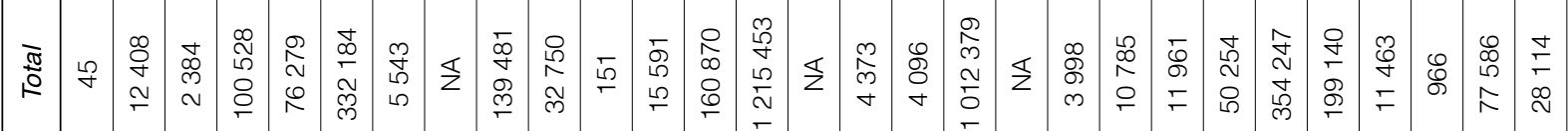

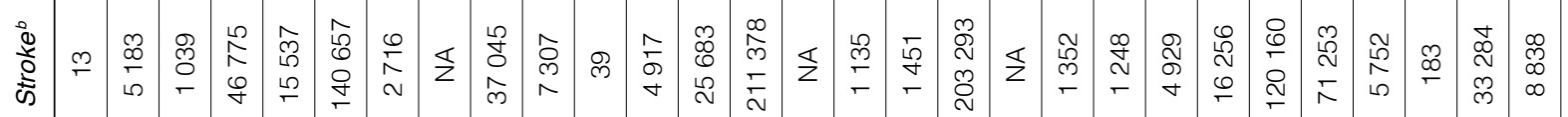

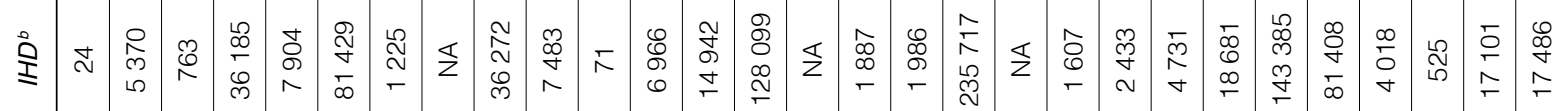

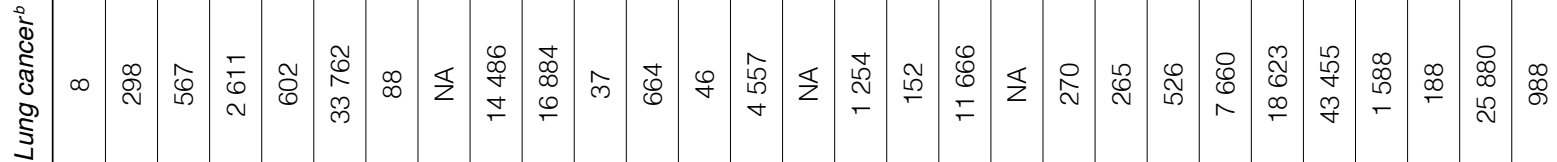

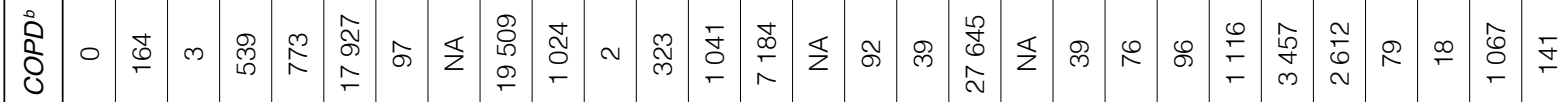

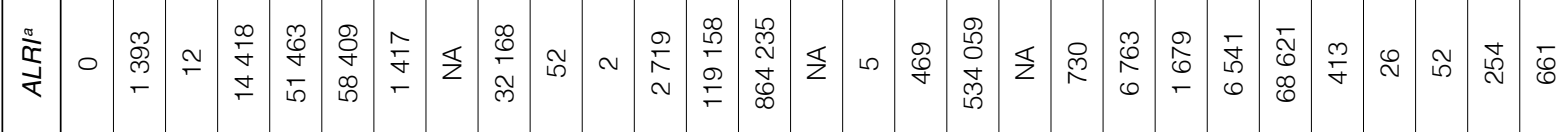

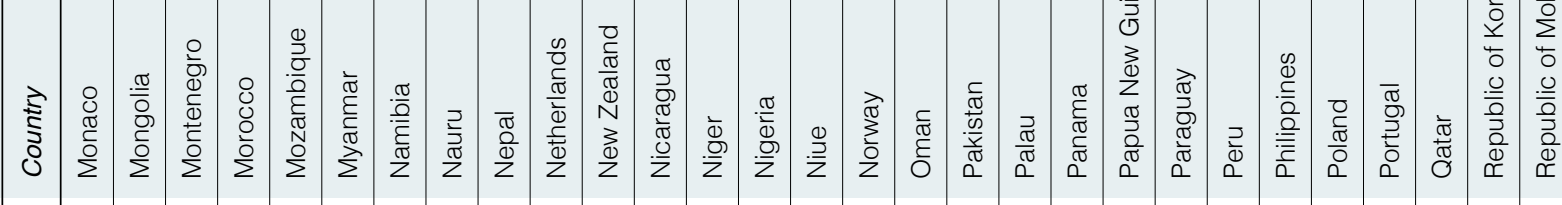
.

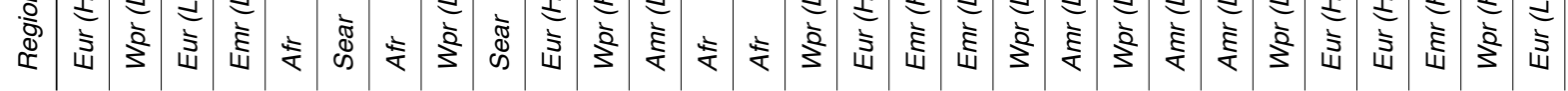




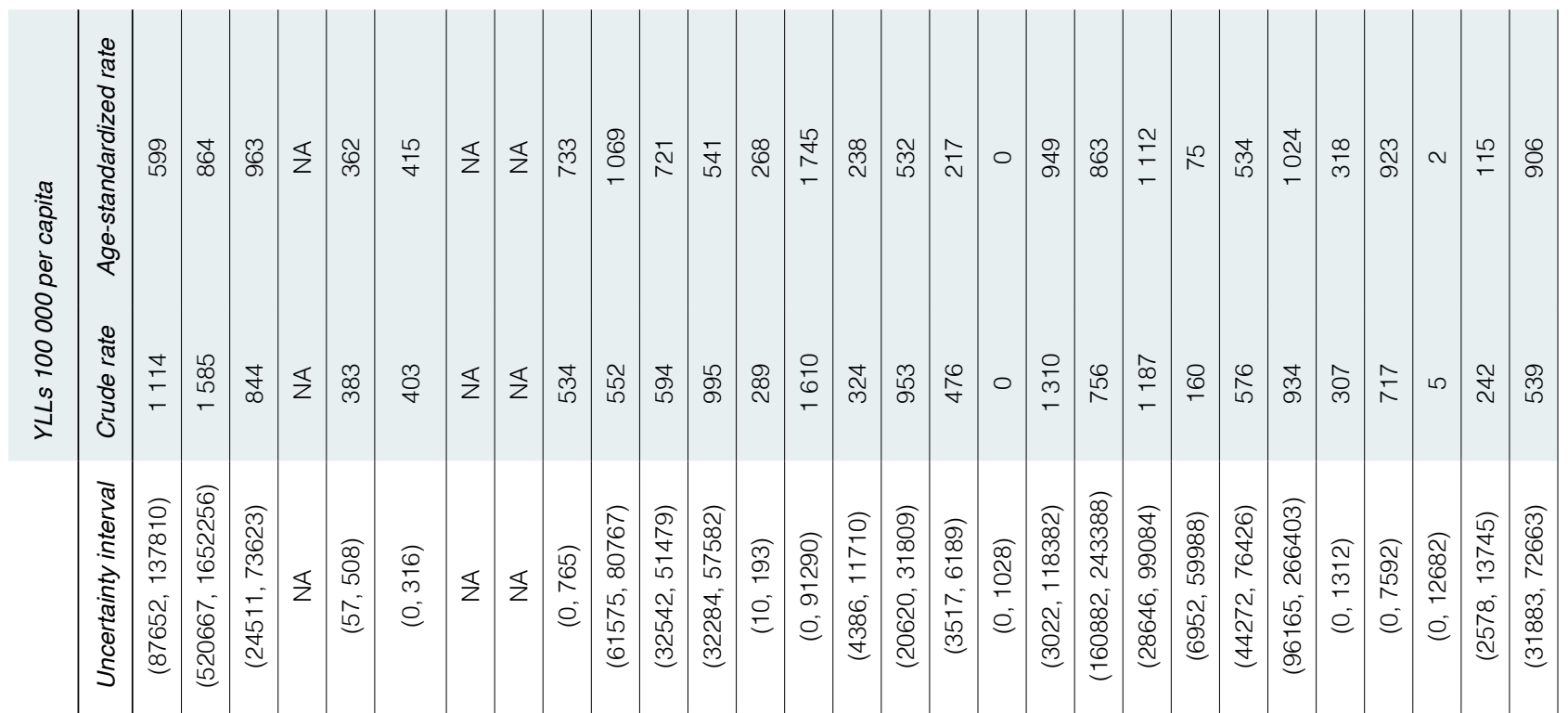

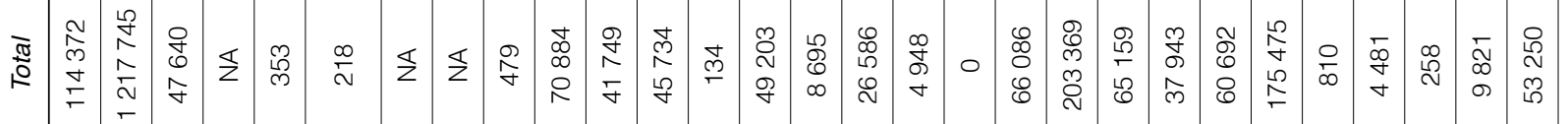

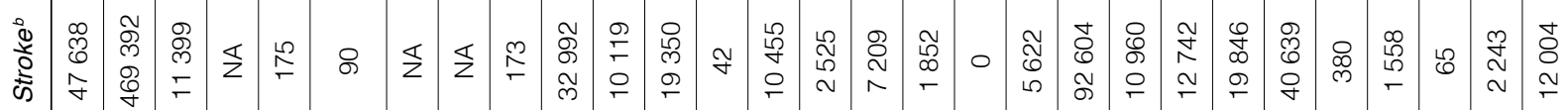

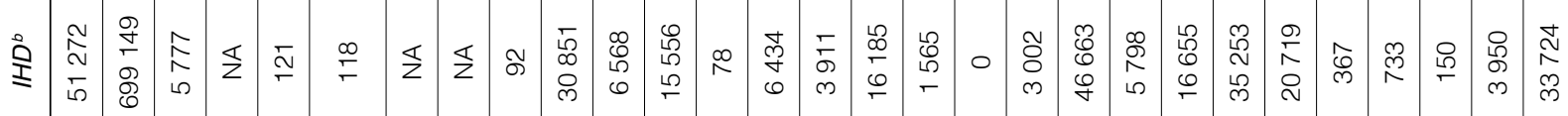

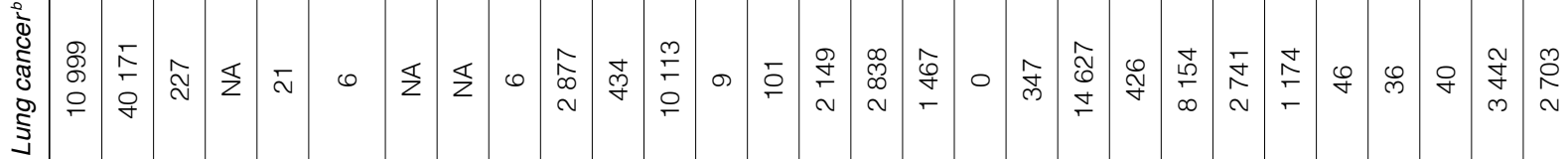

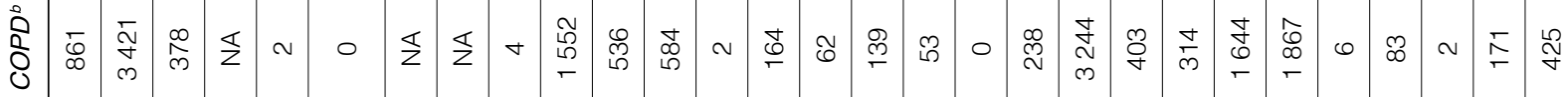

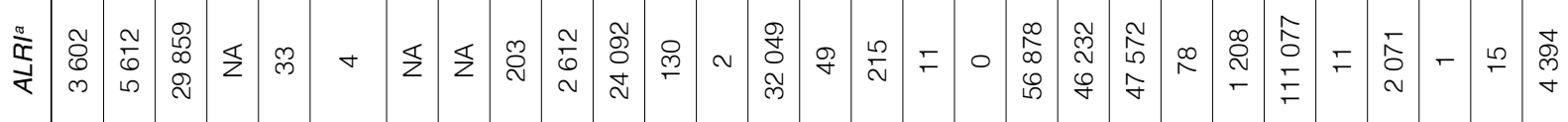

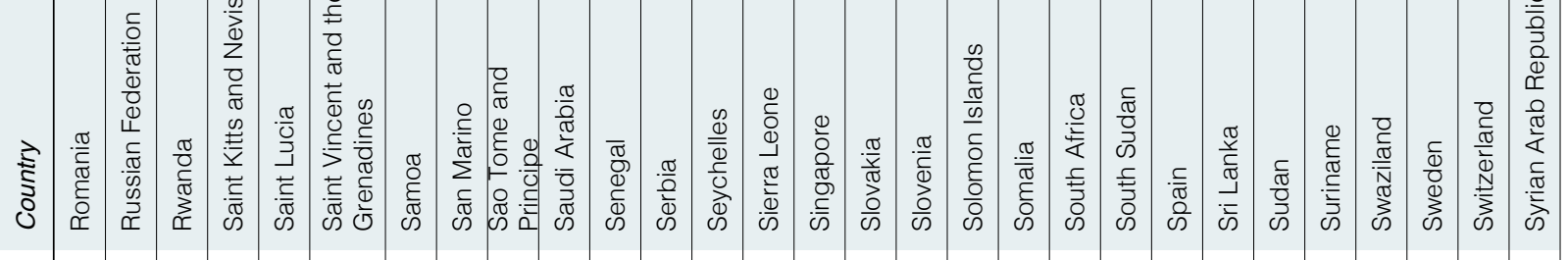

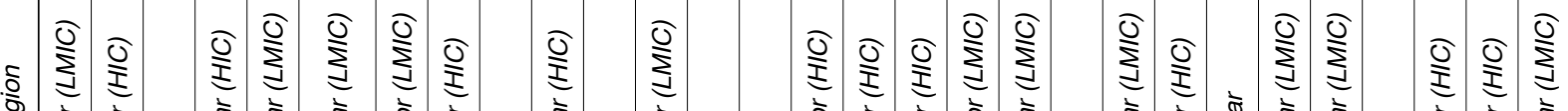

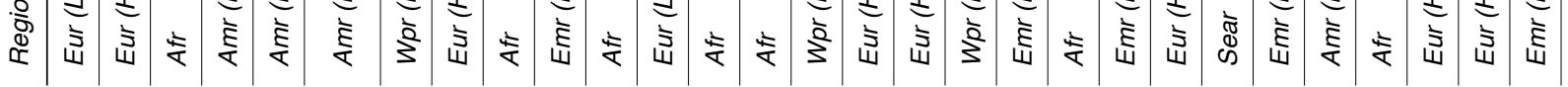




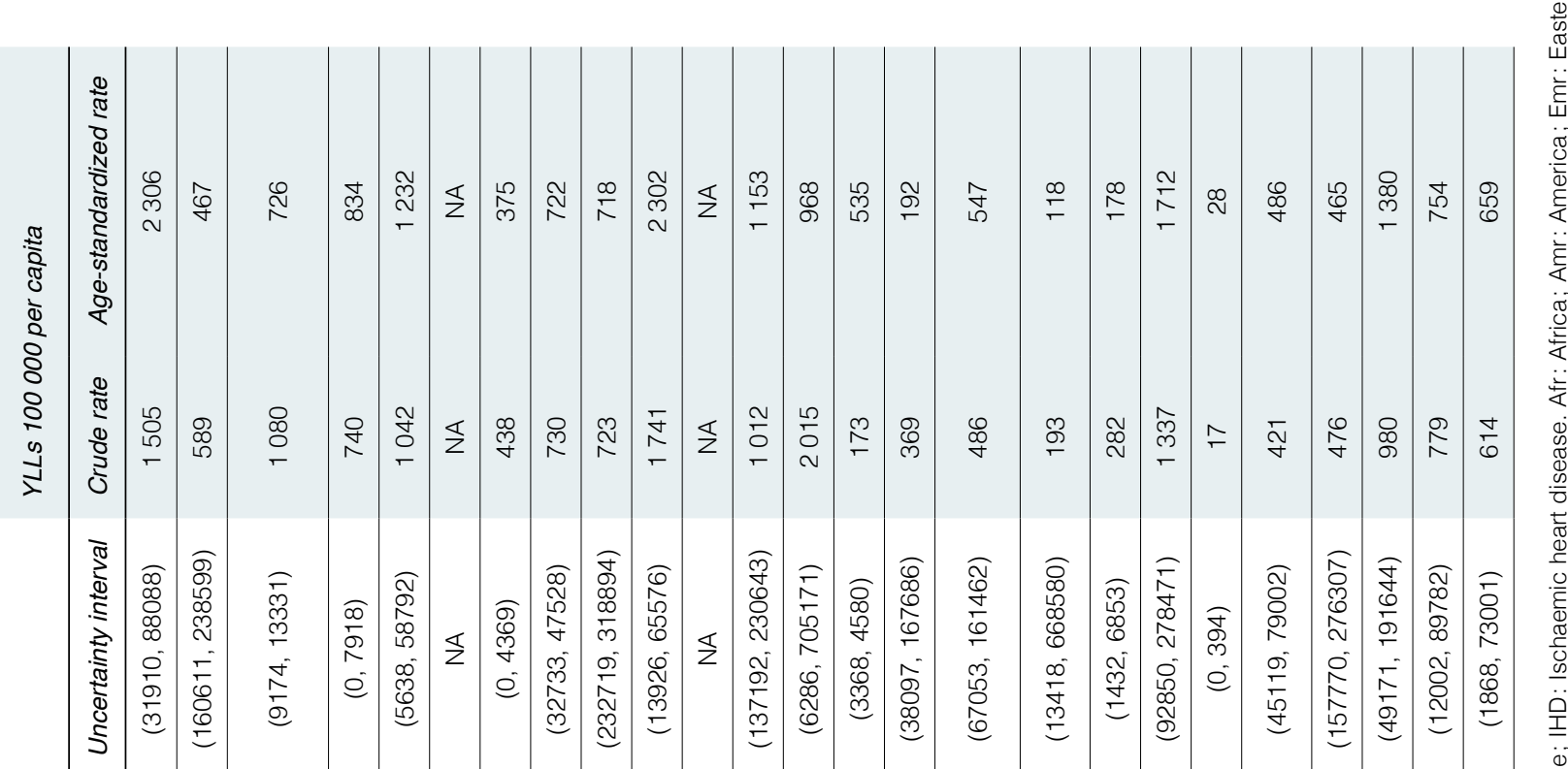

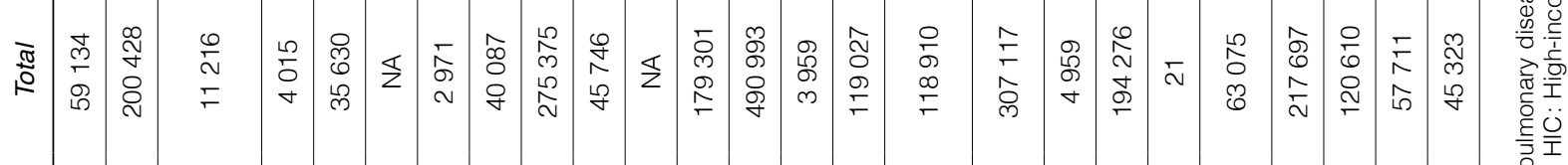

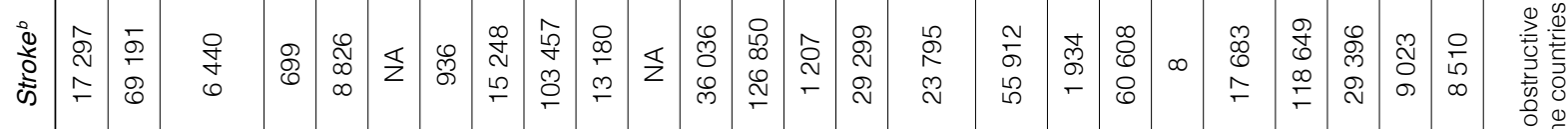

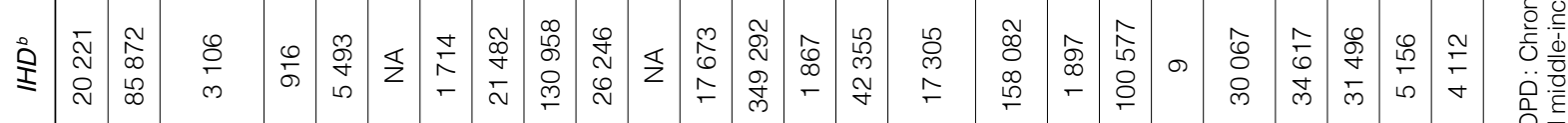

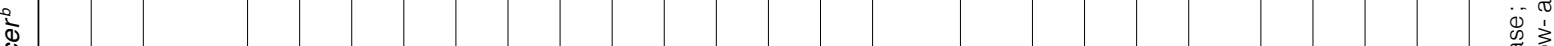

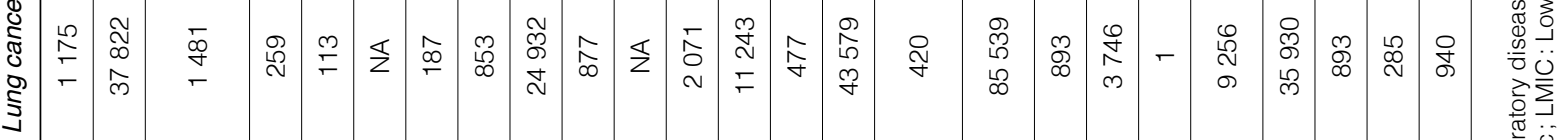

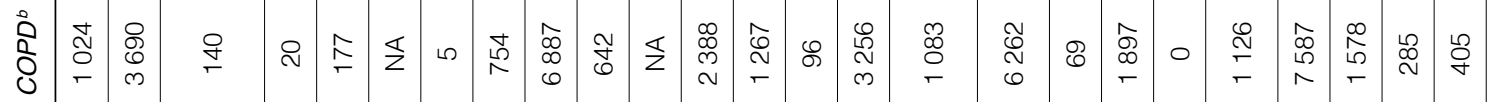

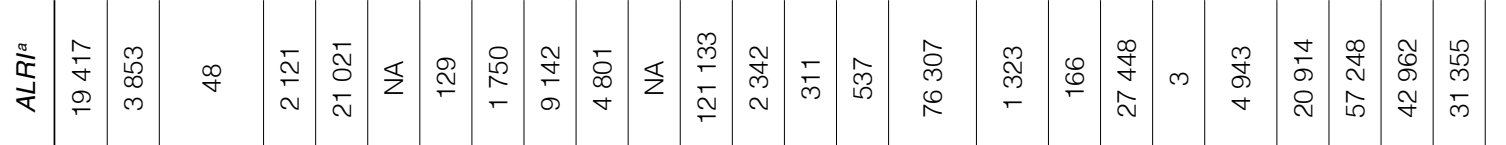

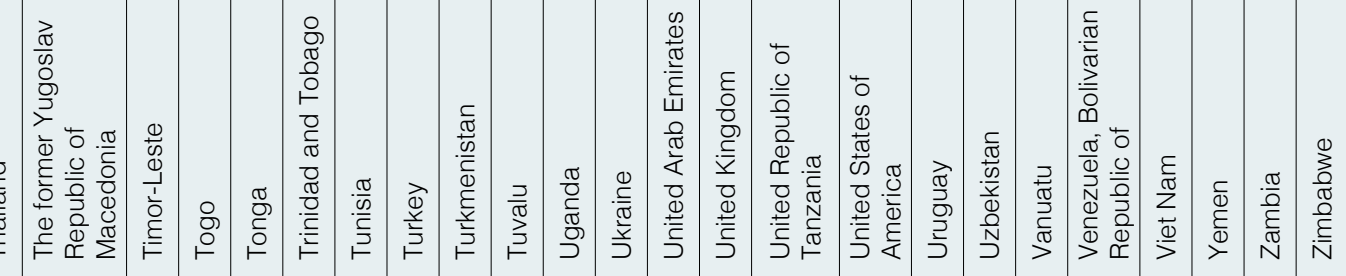

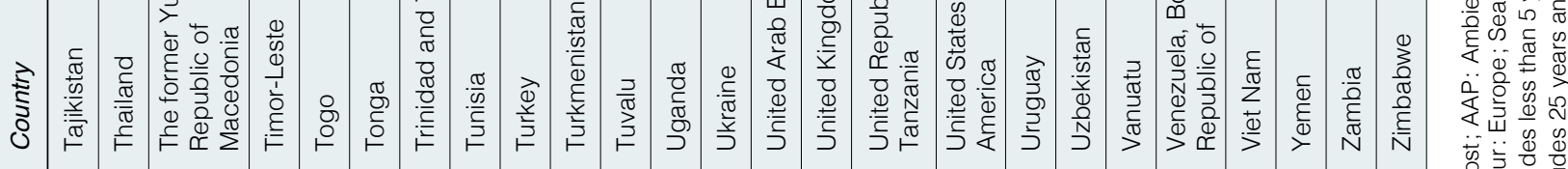

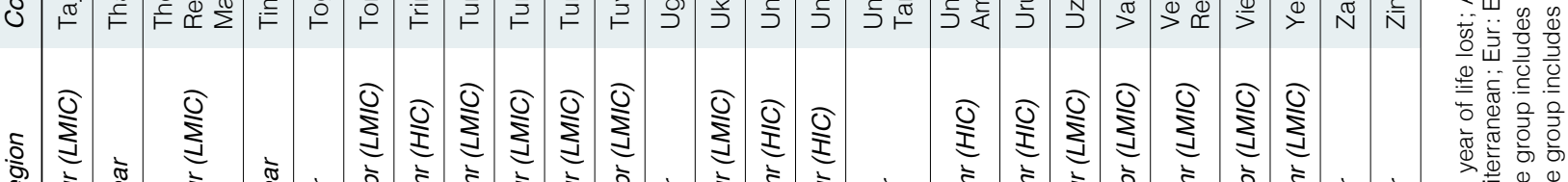

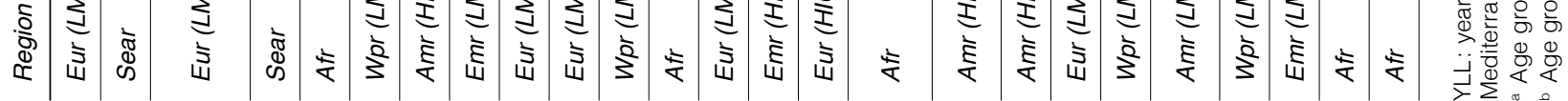




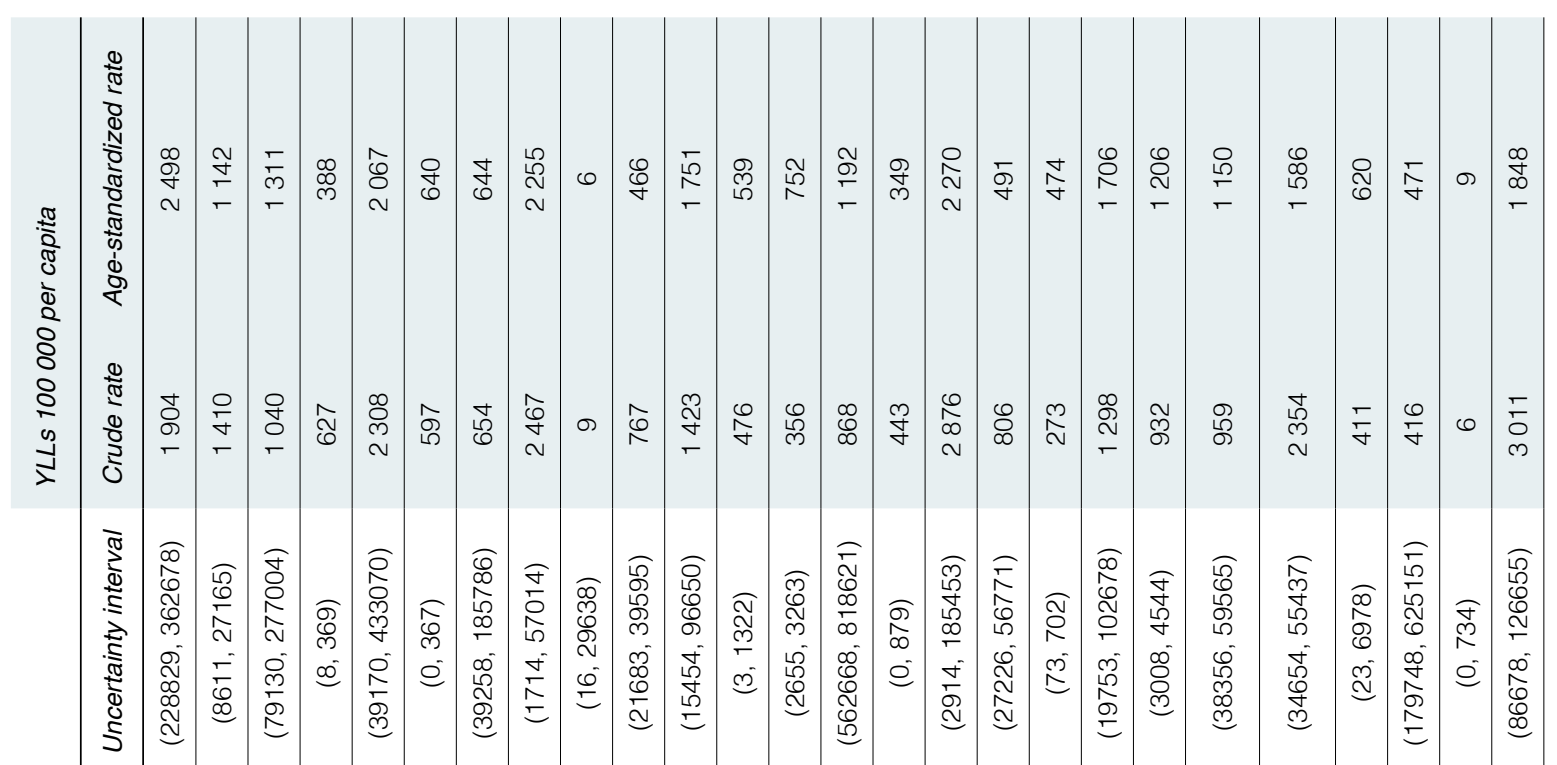

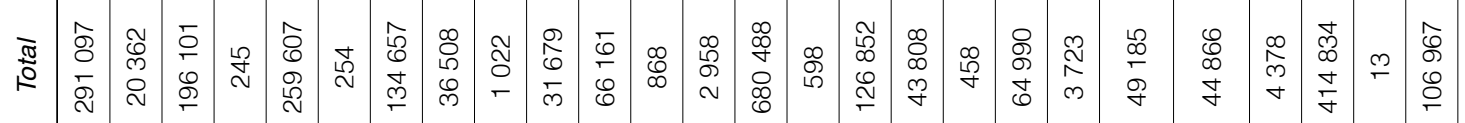

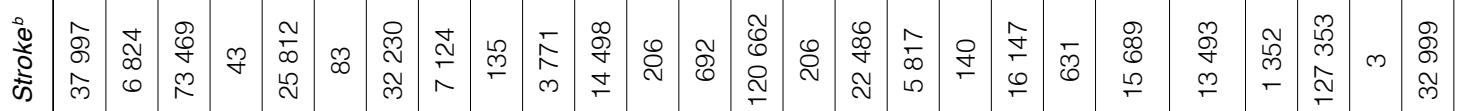

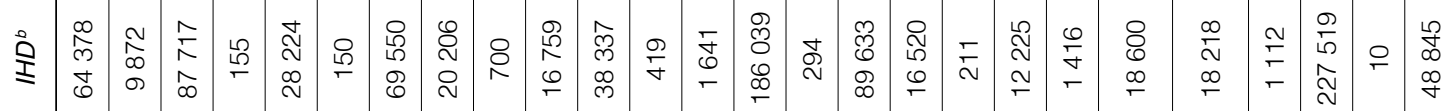

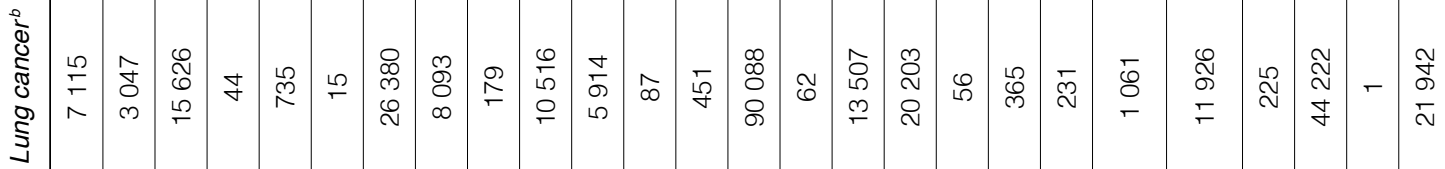

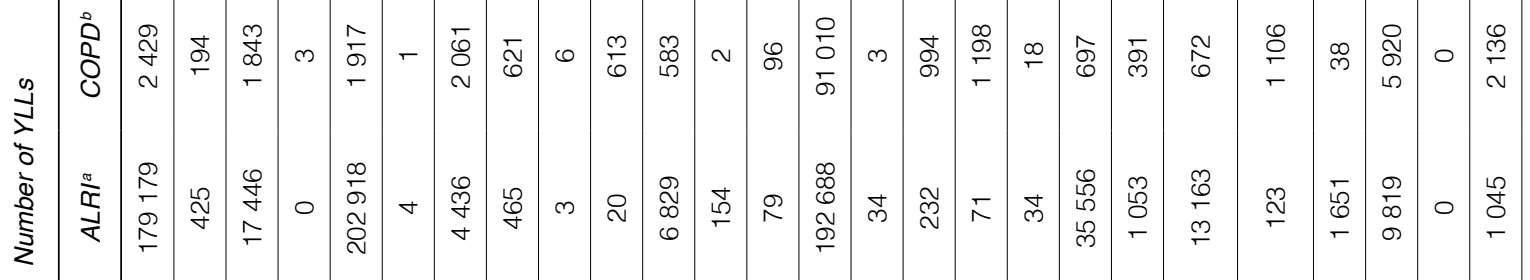

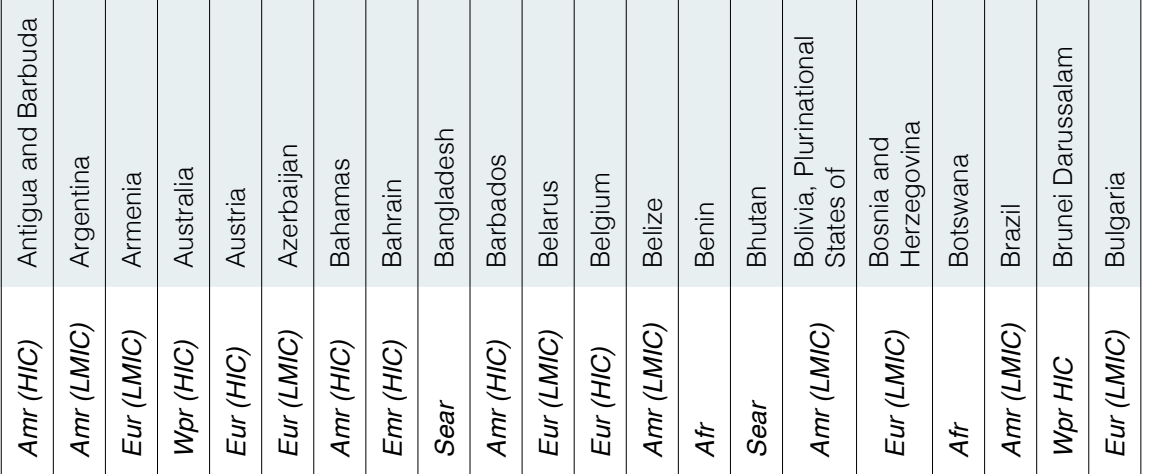




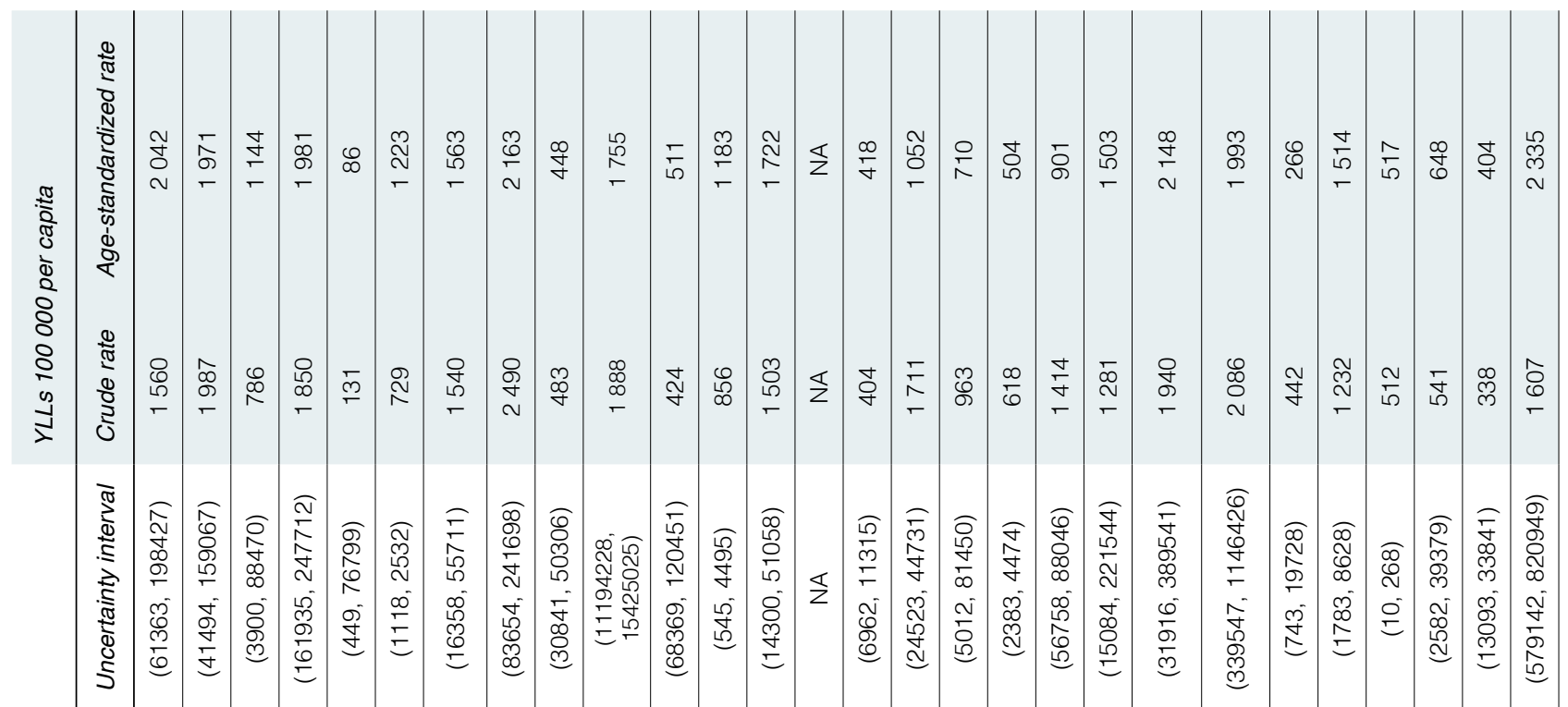

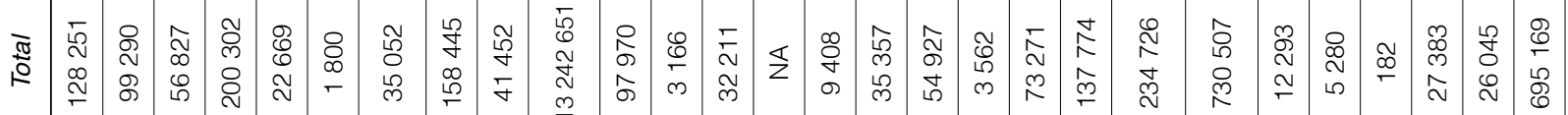

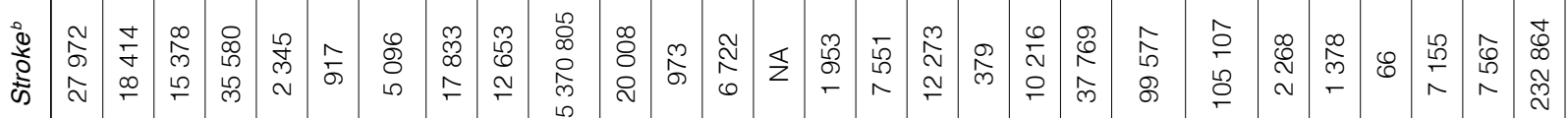

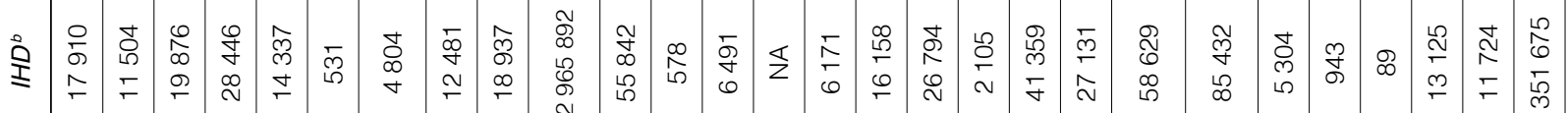

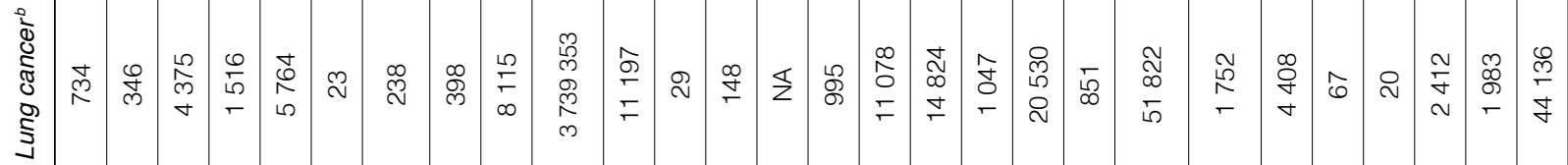

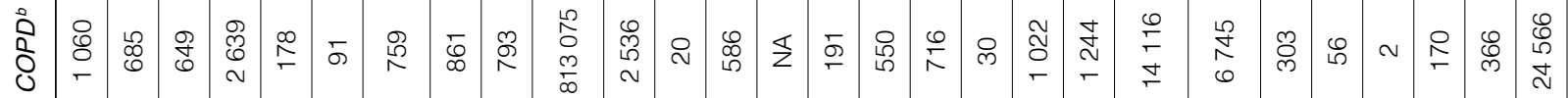

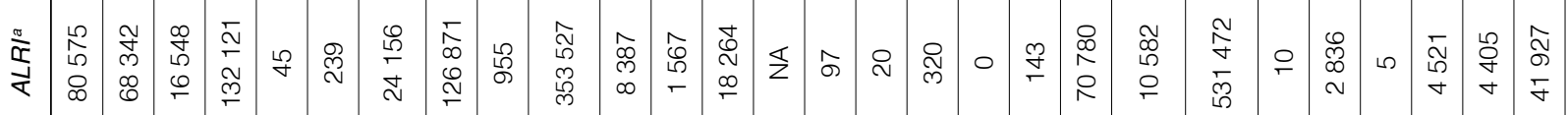

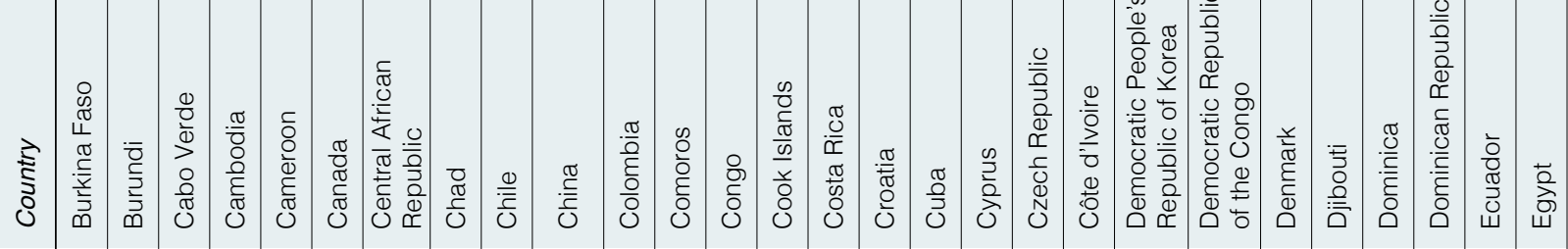

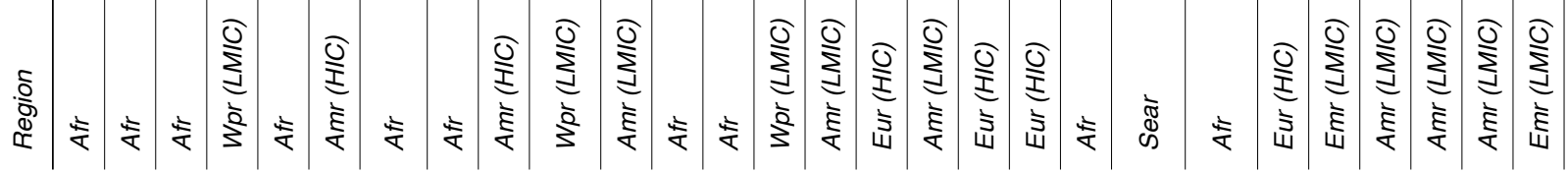




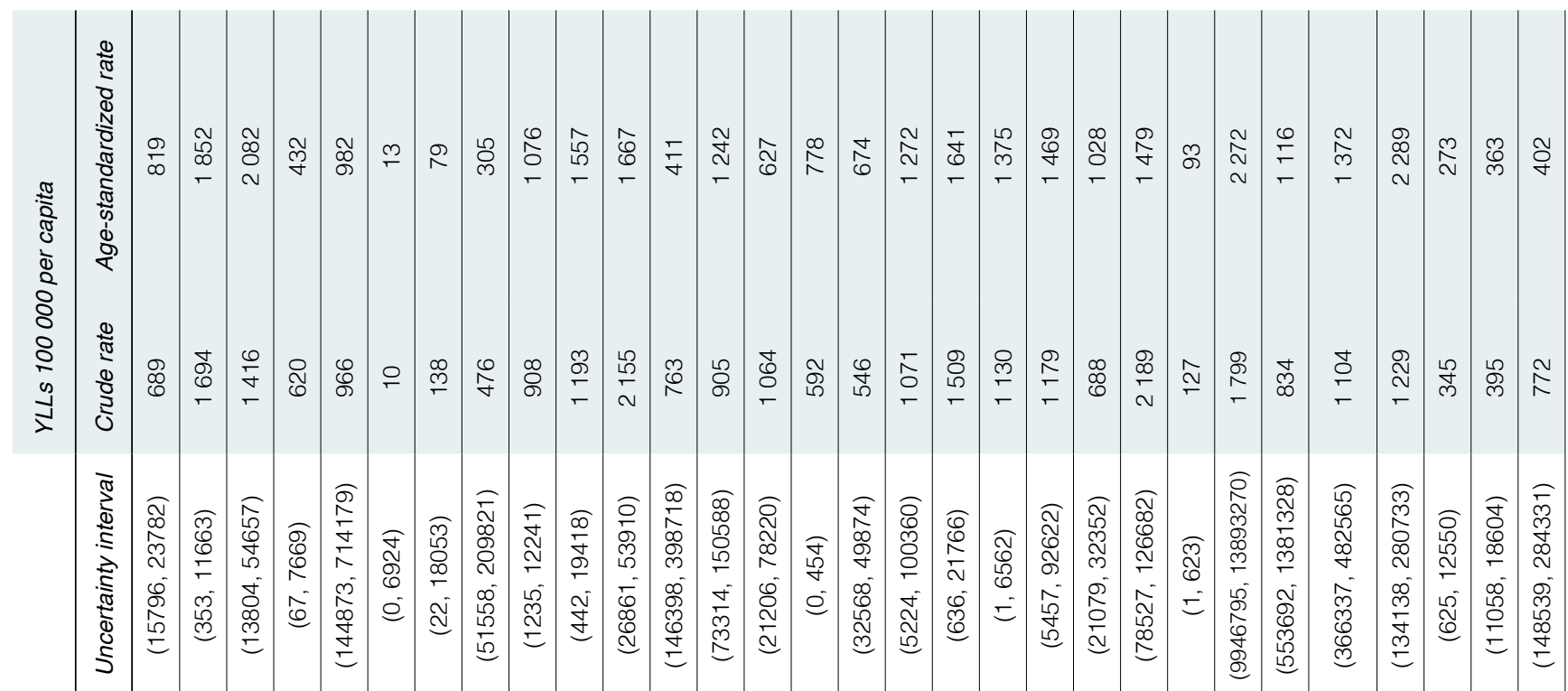

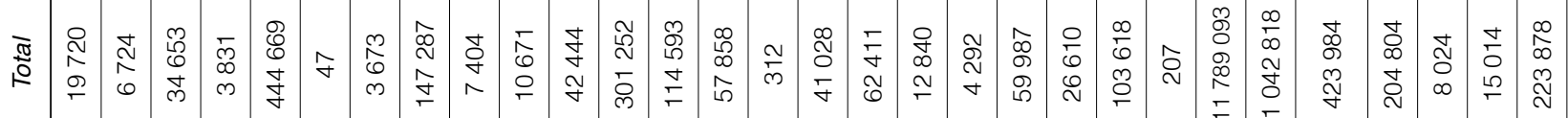

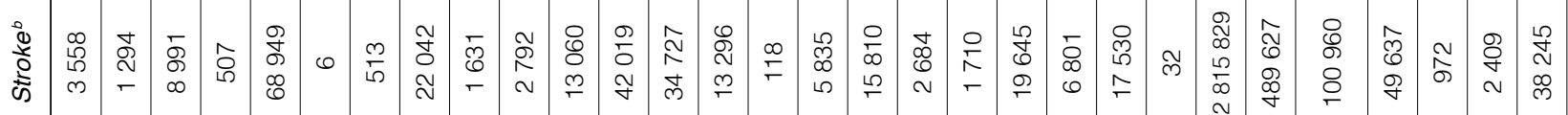

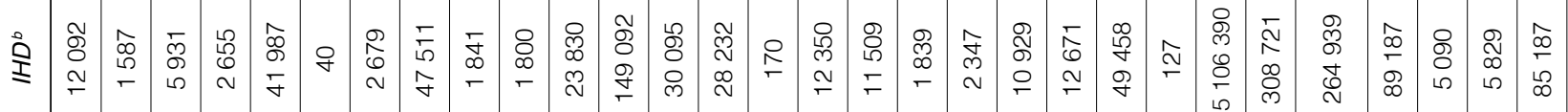

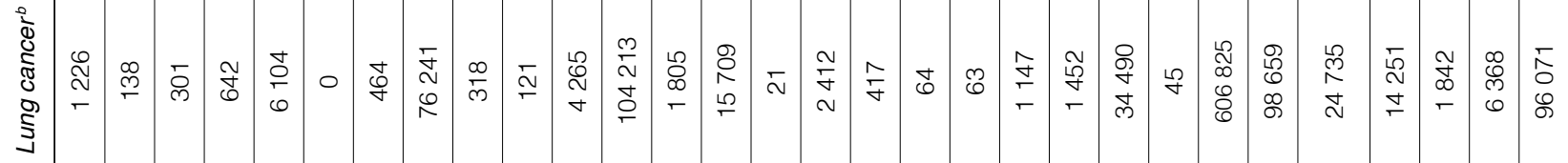

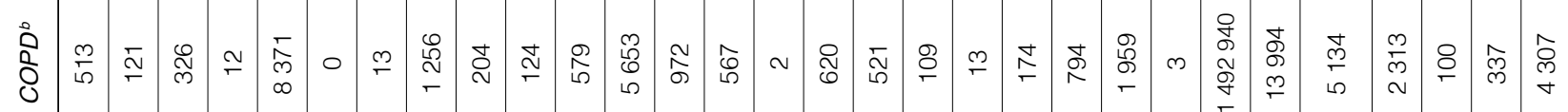

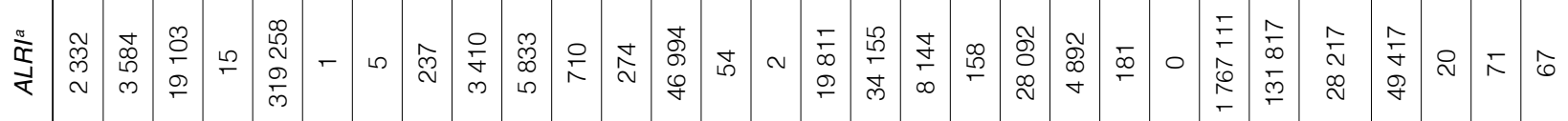

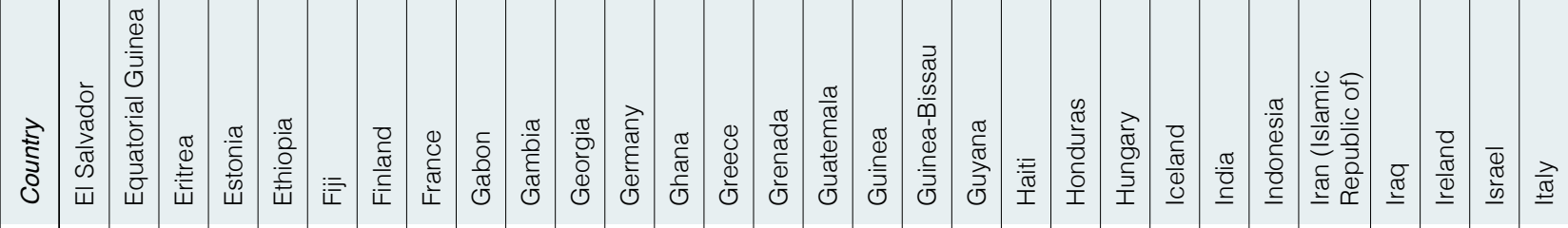

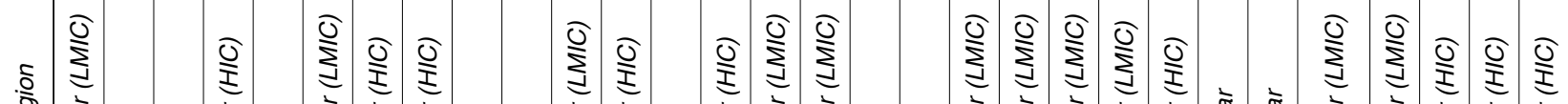

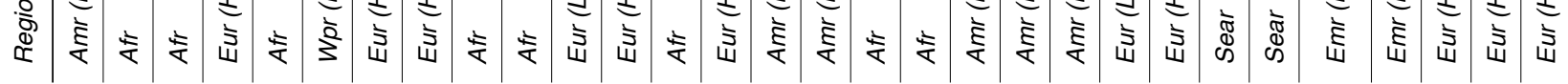




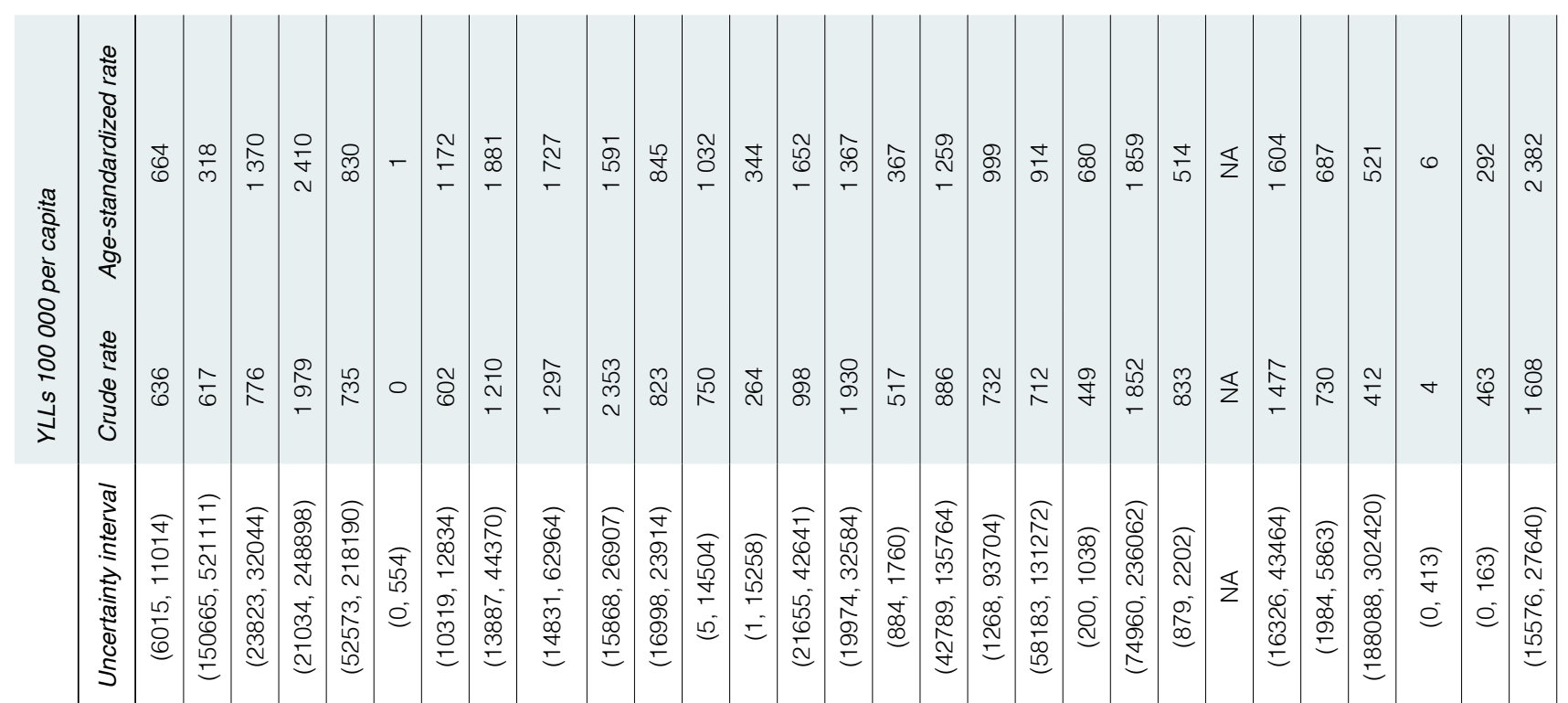

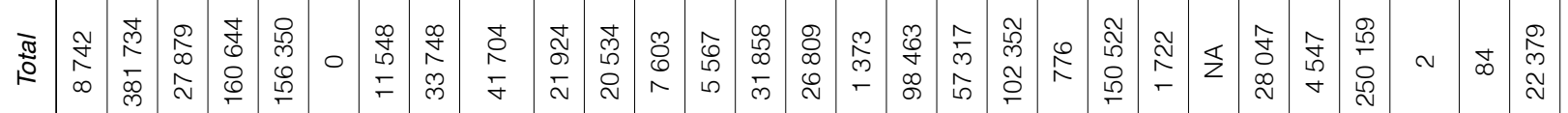

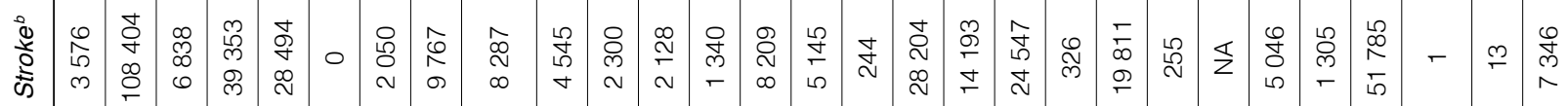

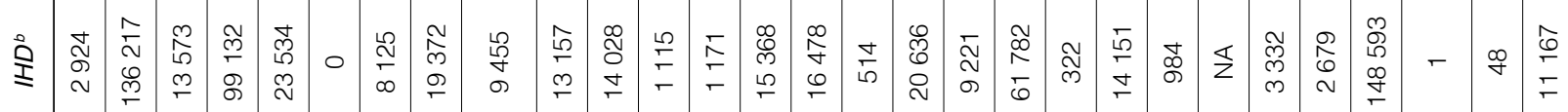

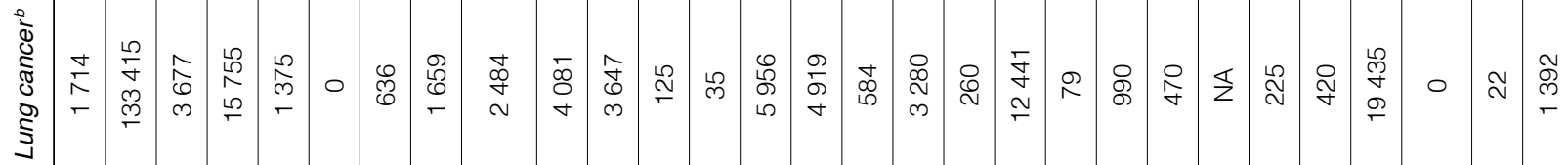

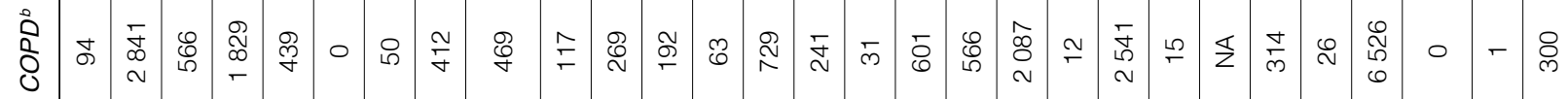

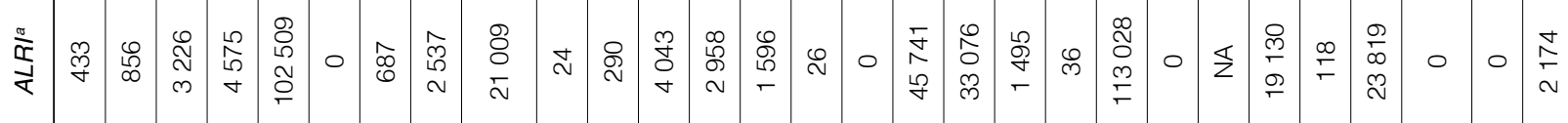

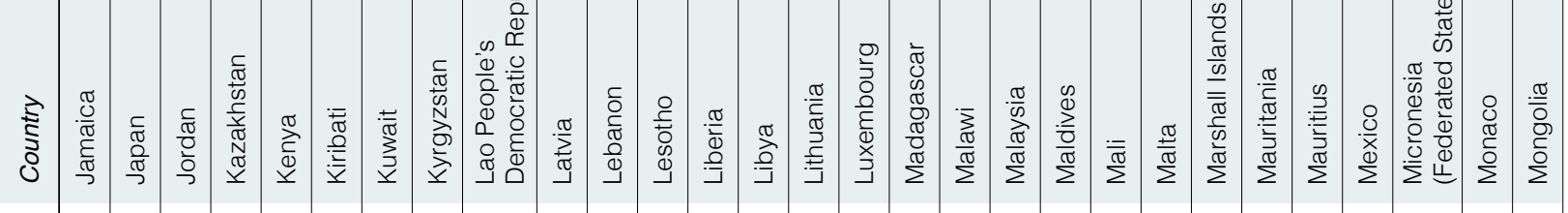

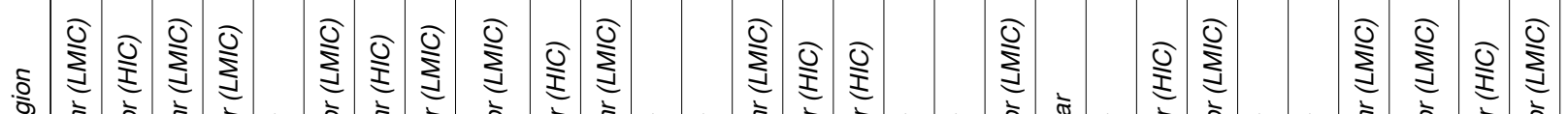

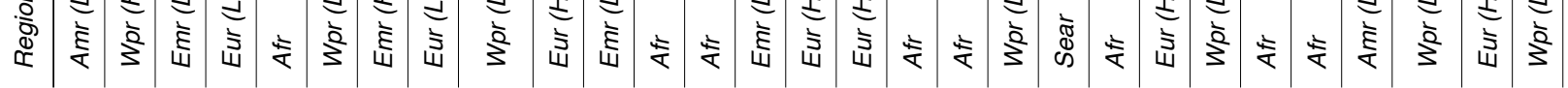




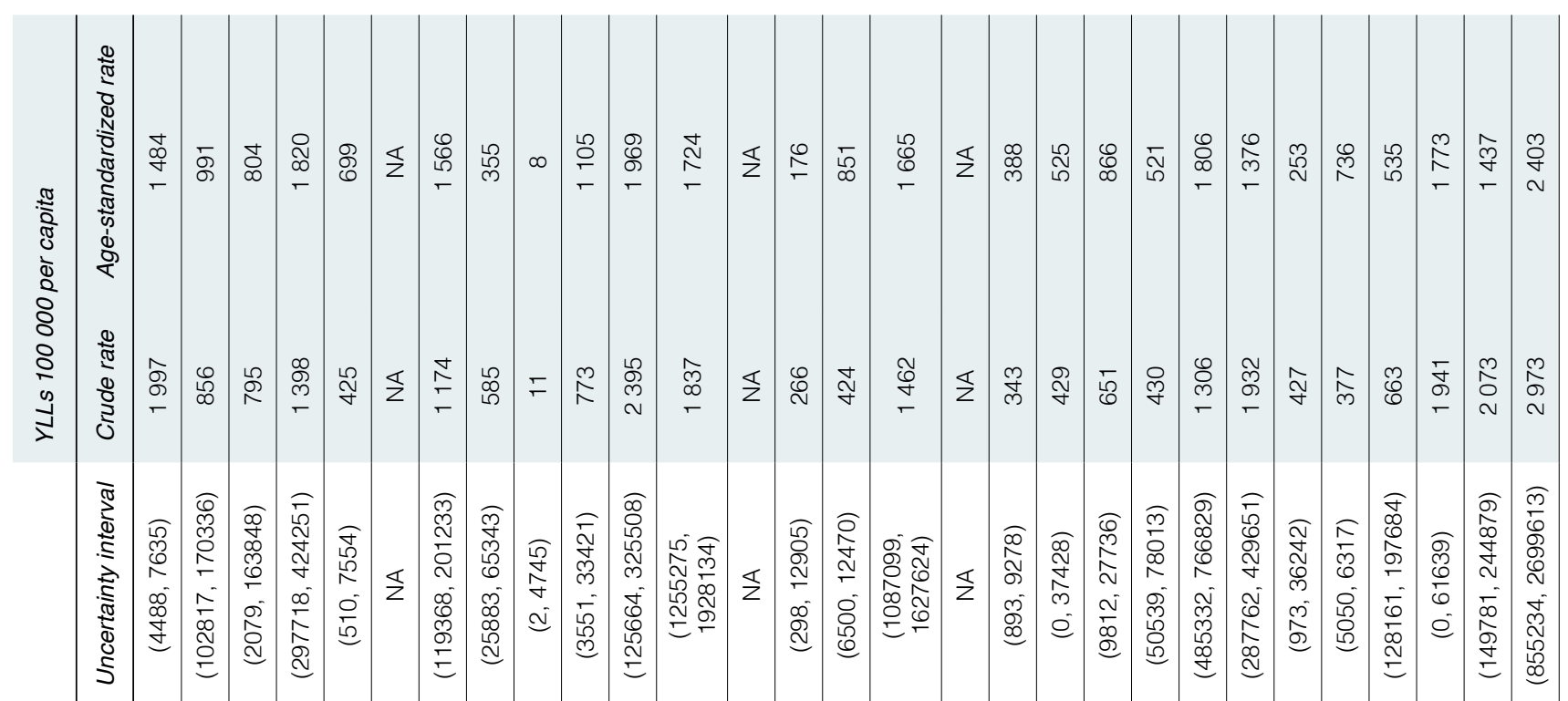

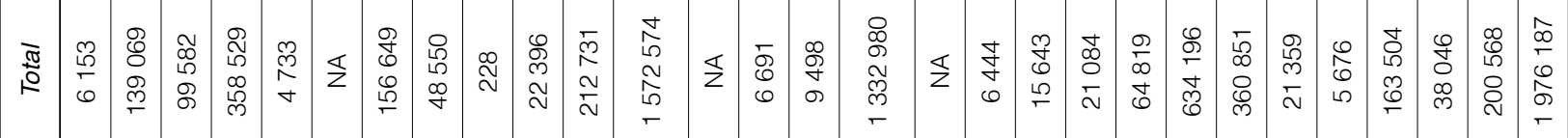

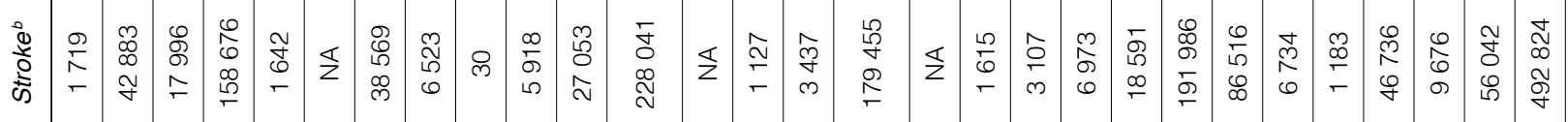

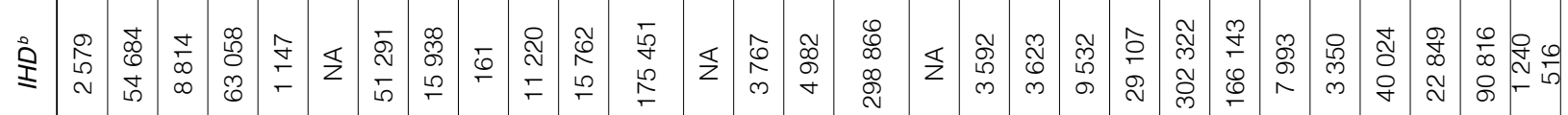

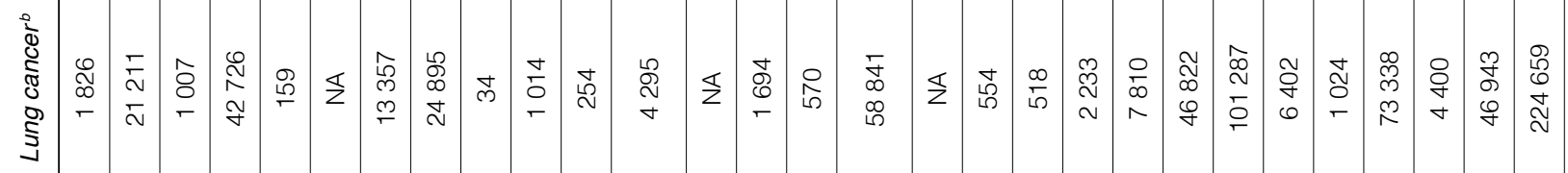

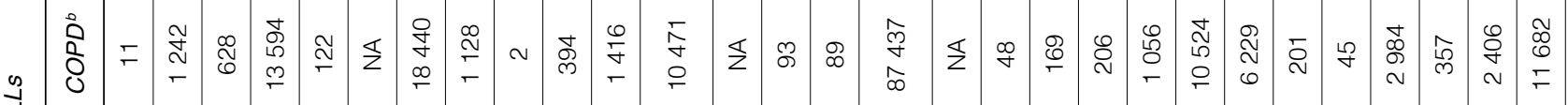

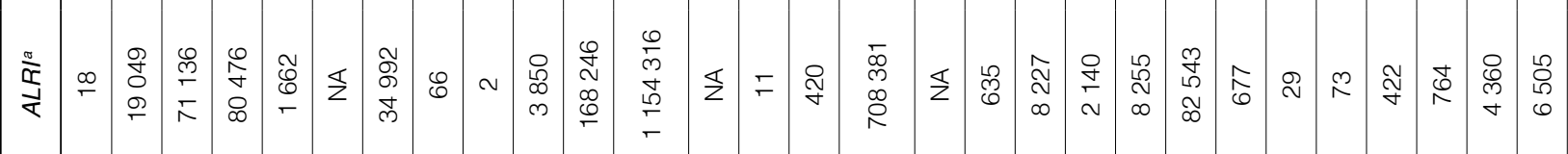

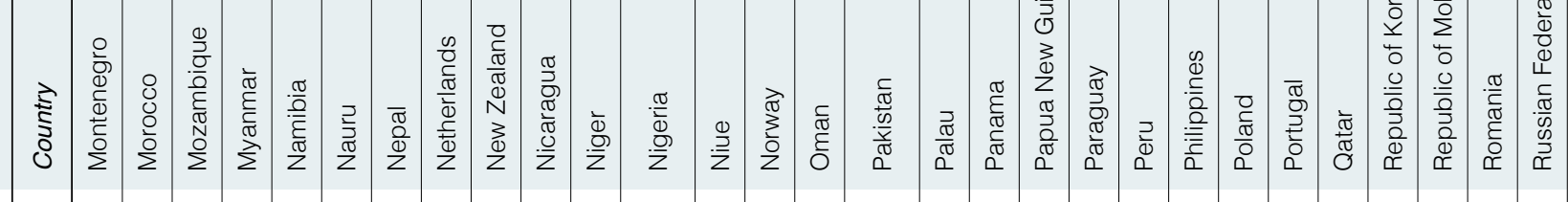

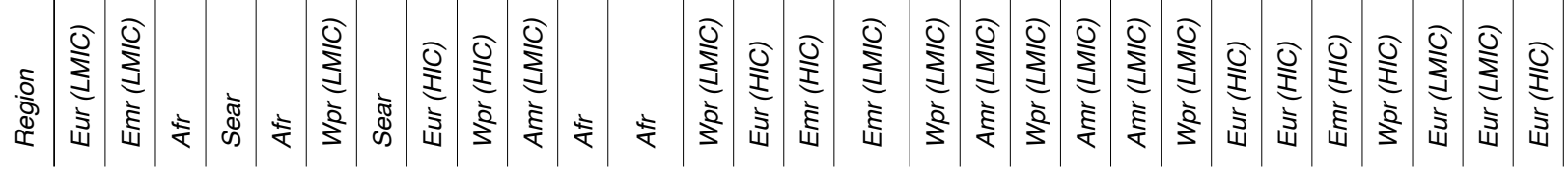




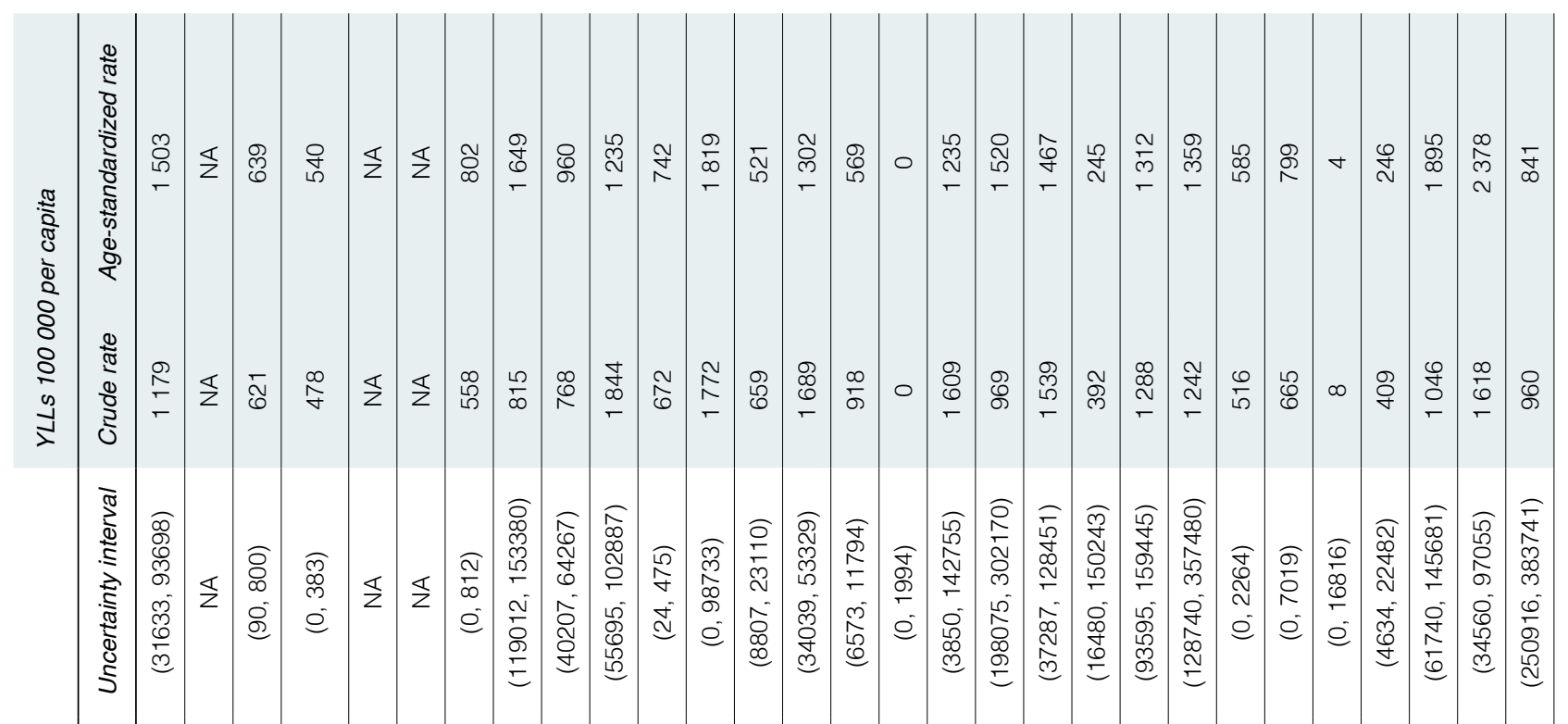

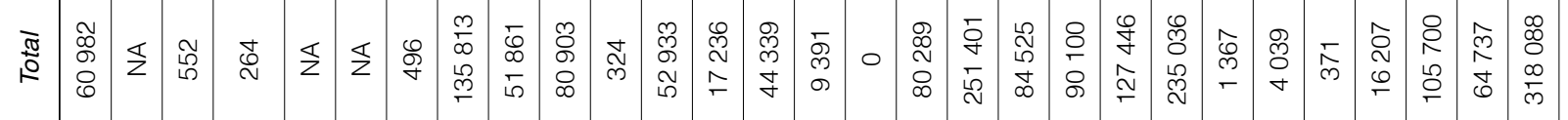

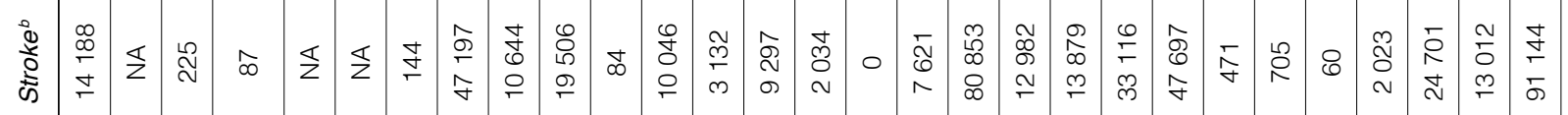

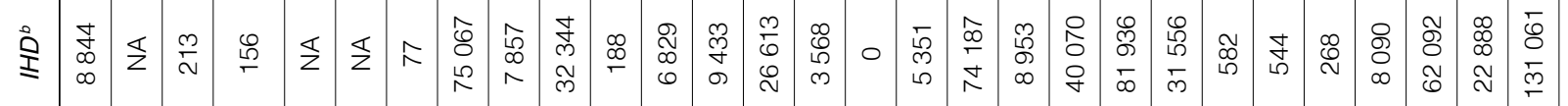

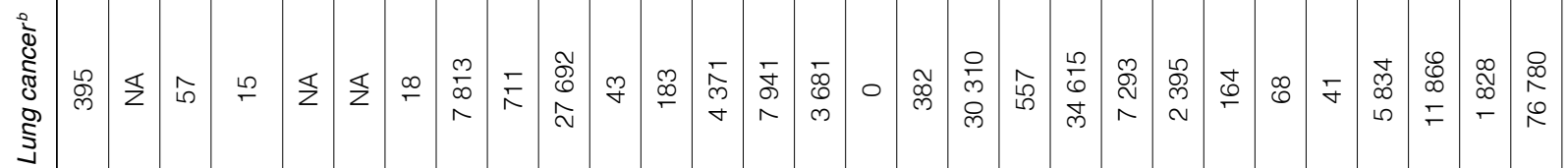

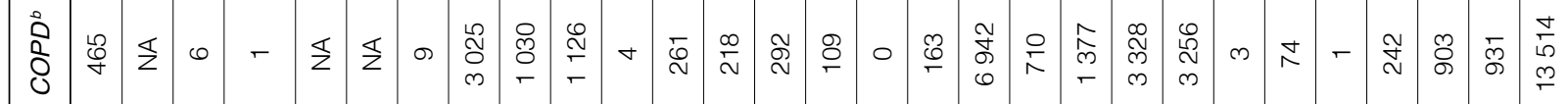

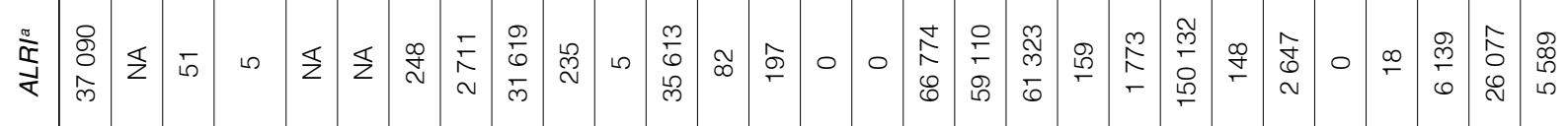

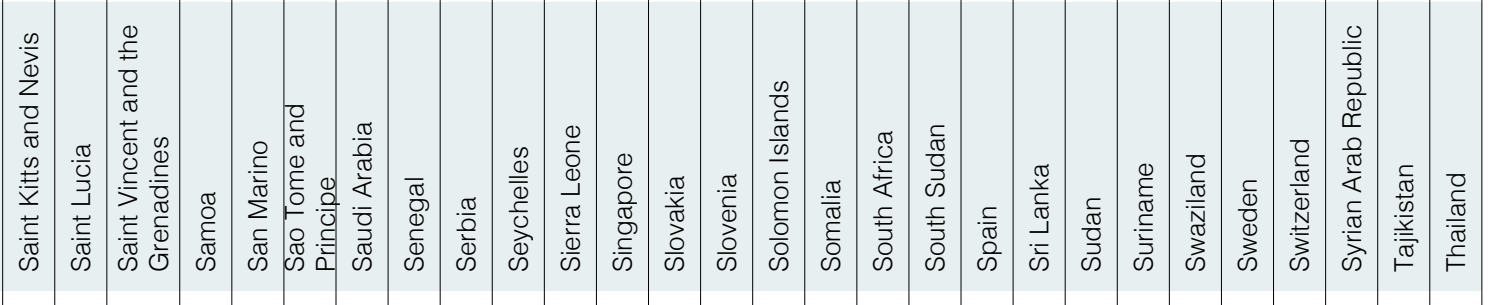

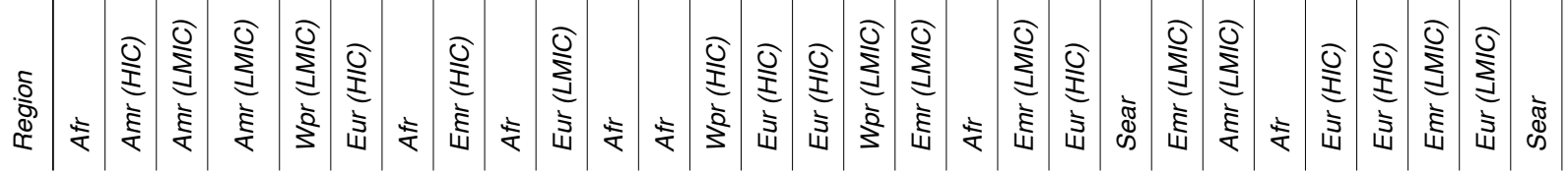




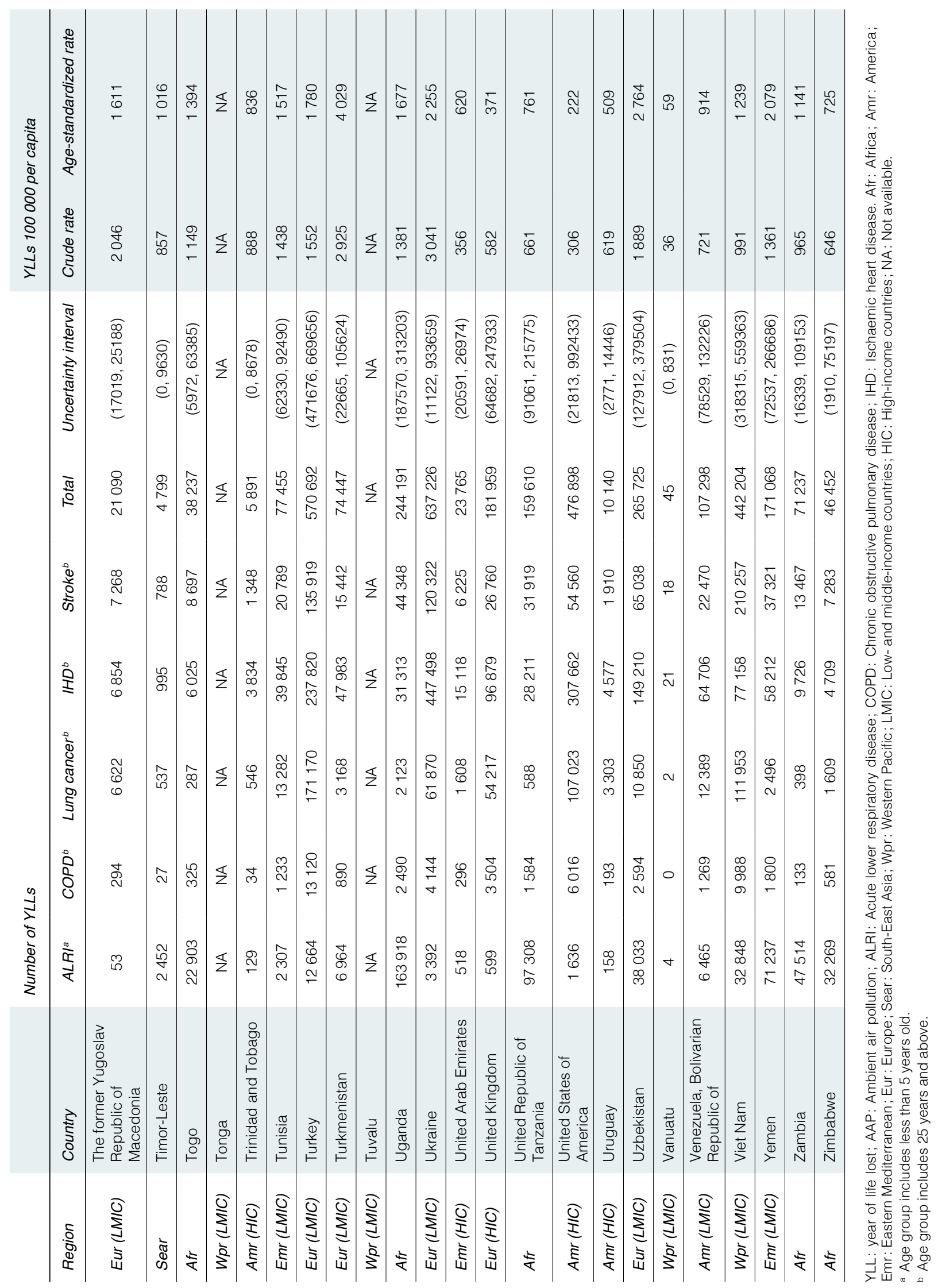




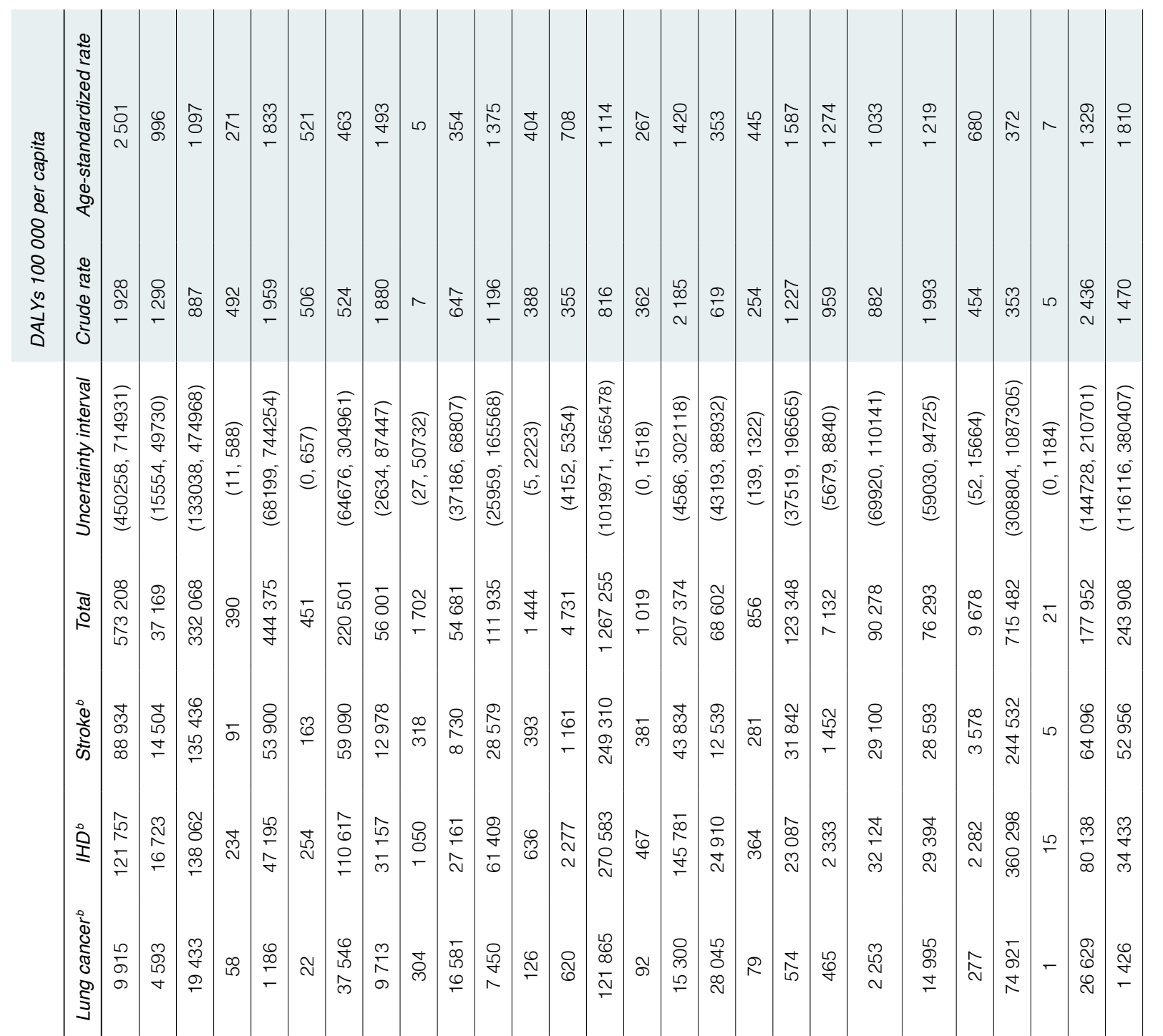

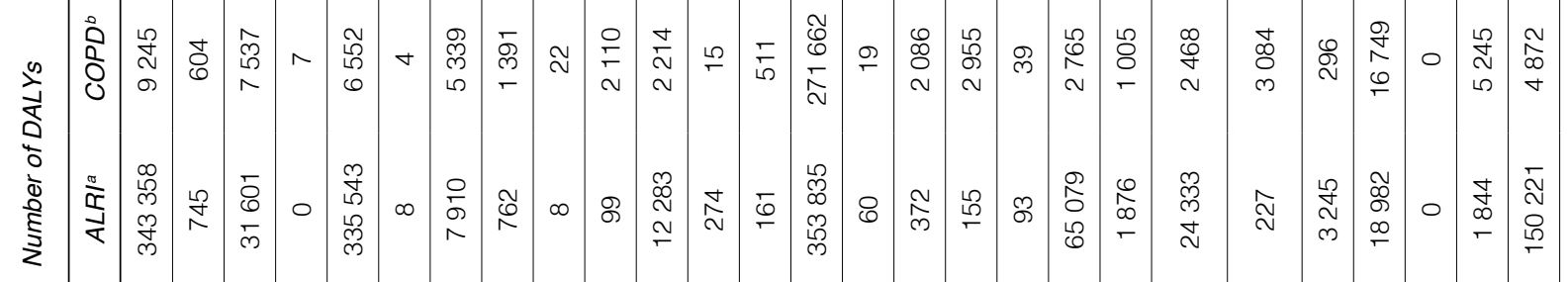

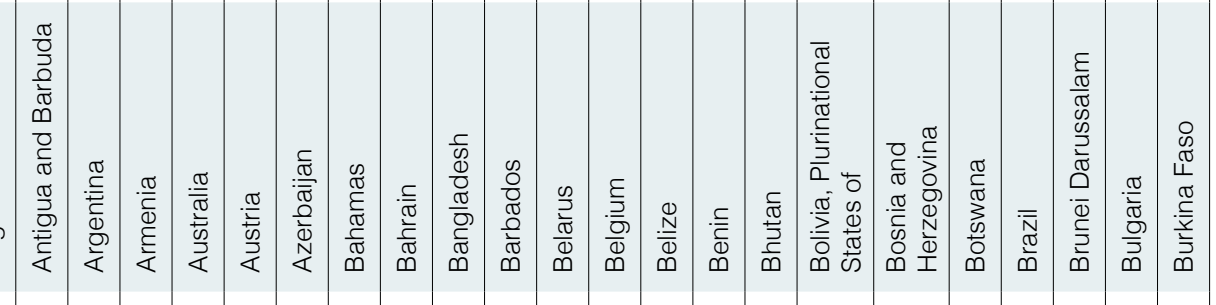

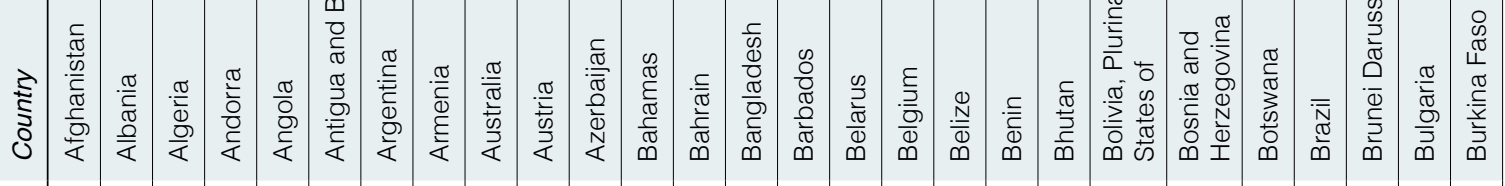

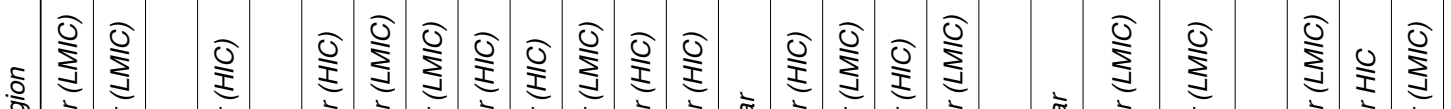

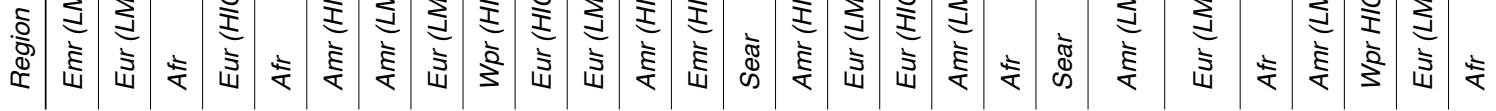




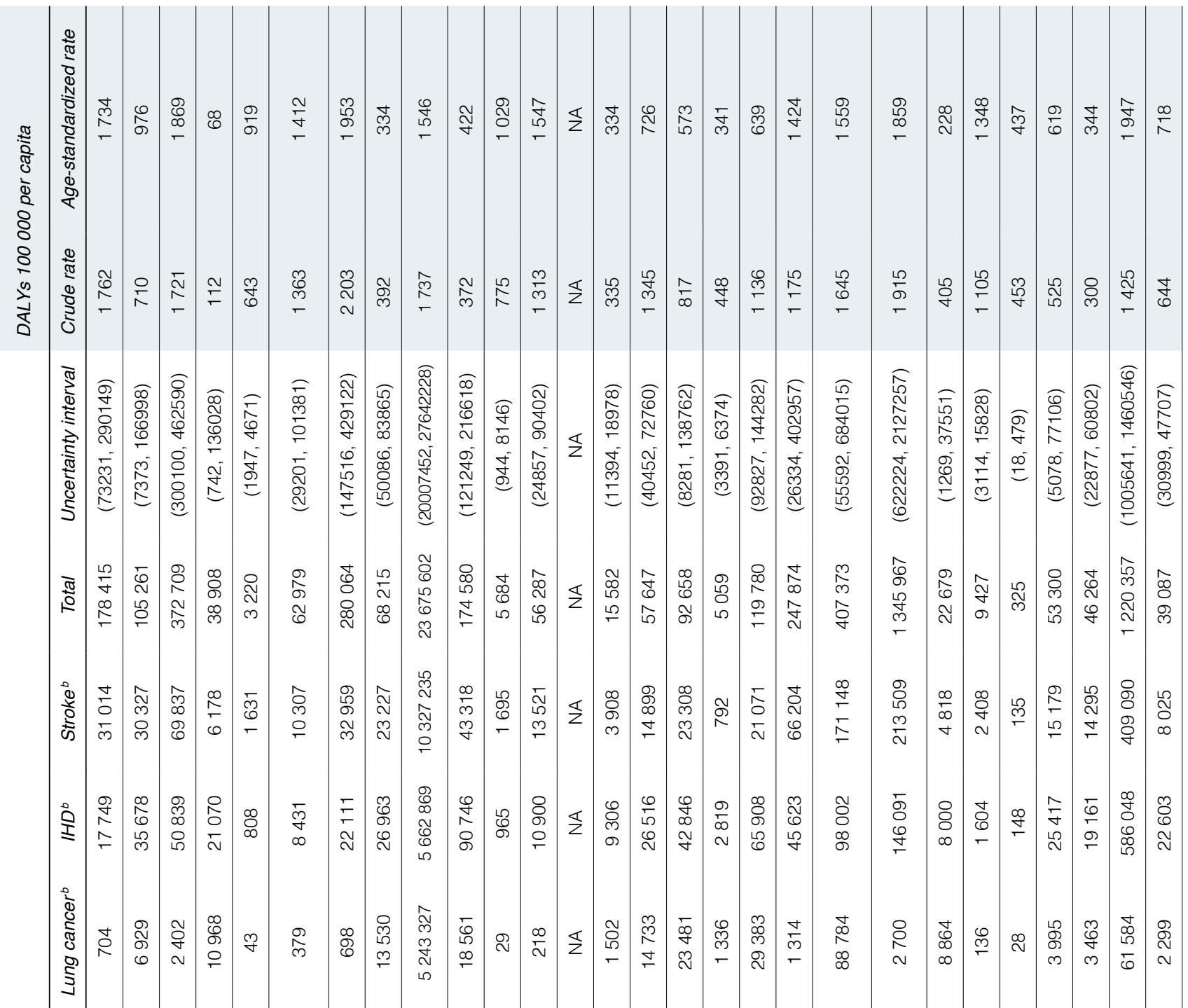

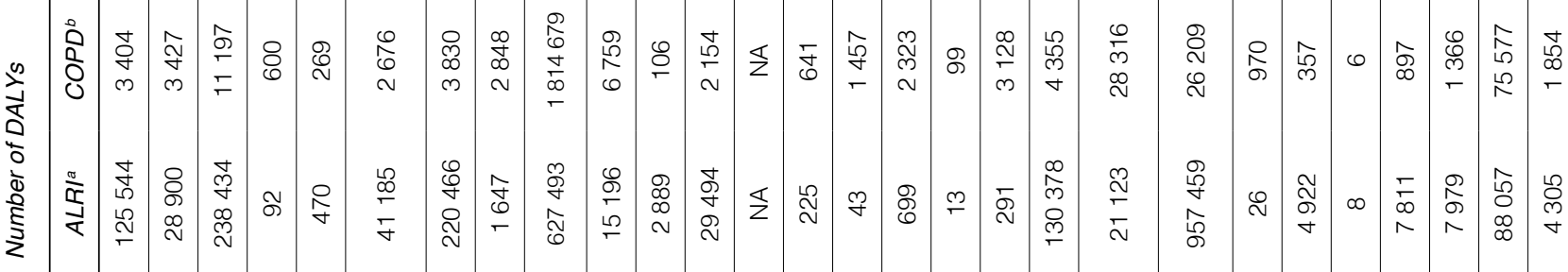

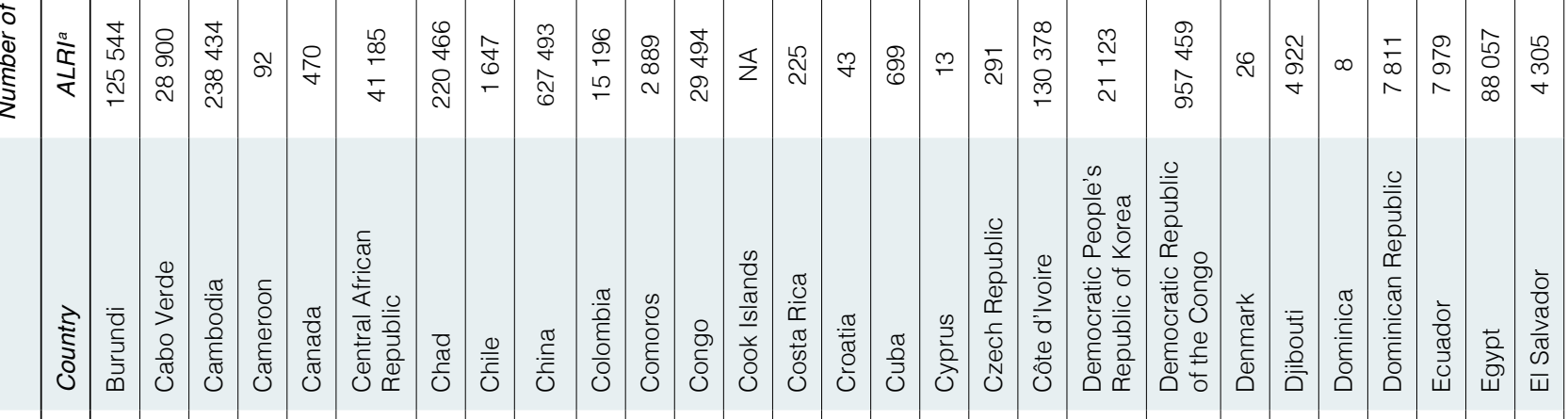

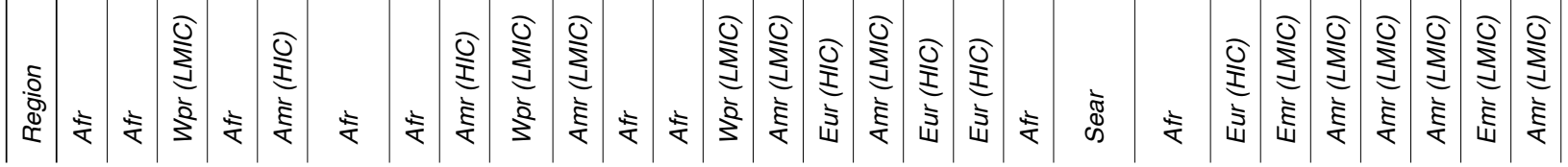




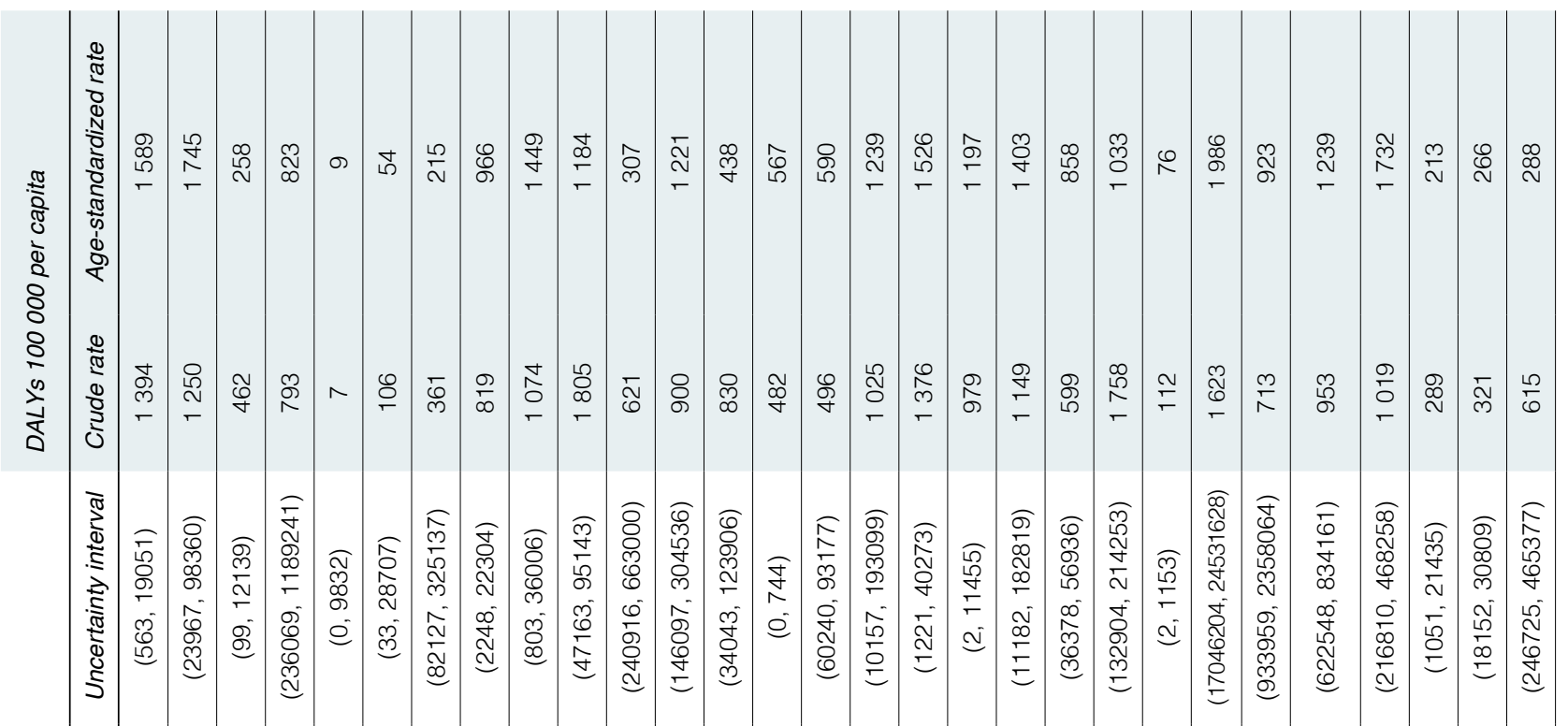

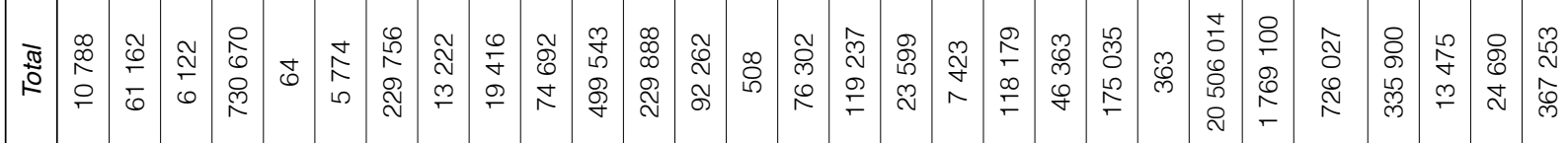

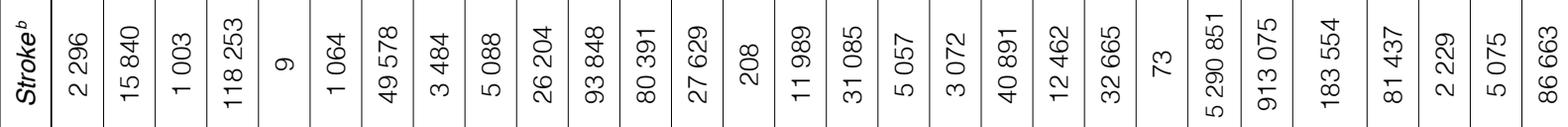

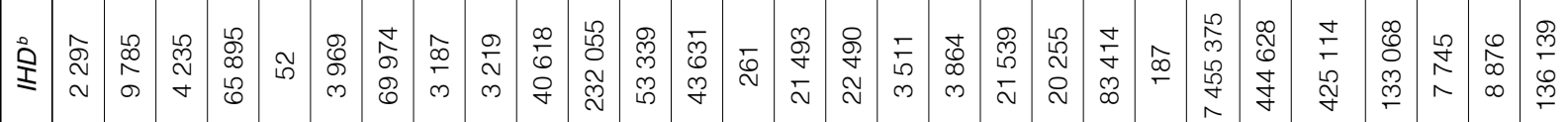

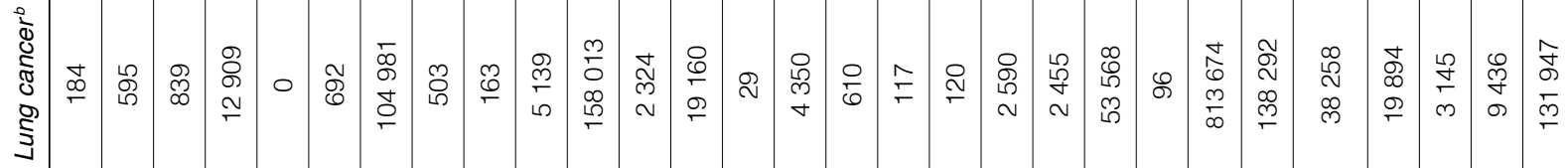

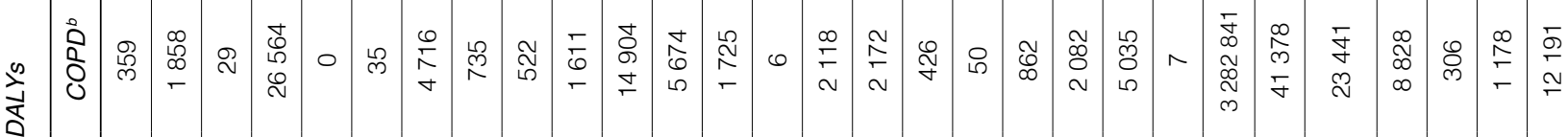

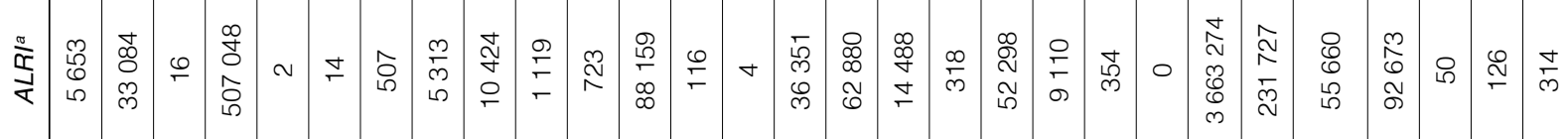

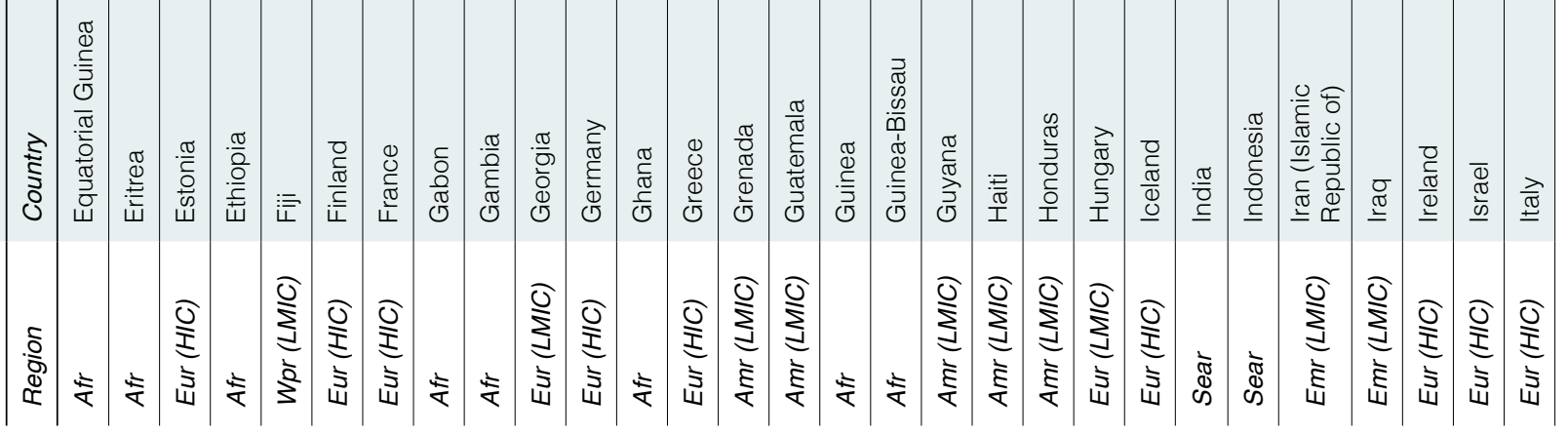




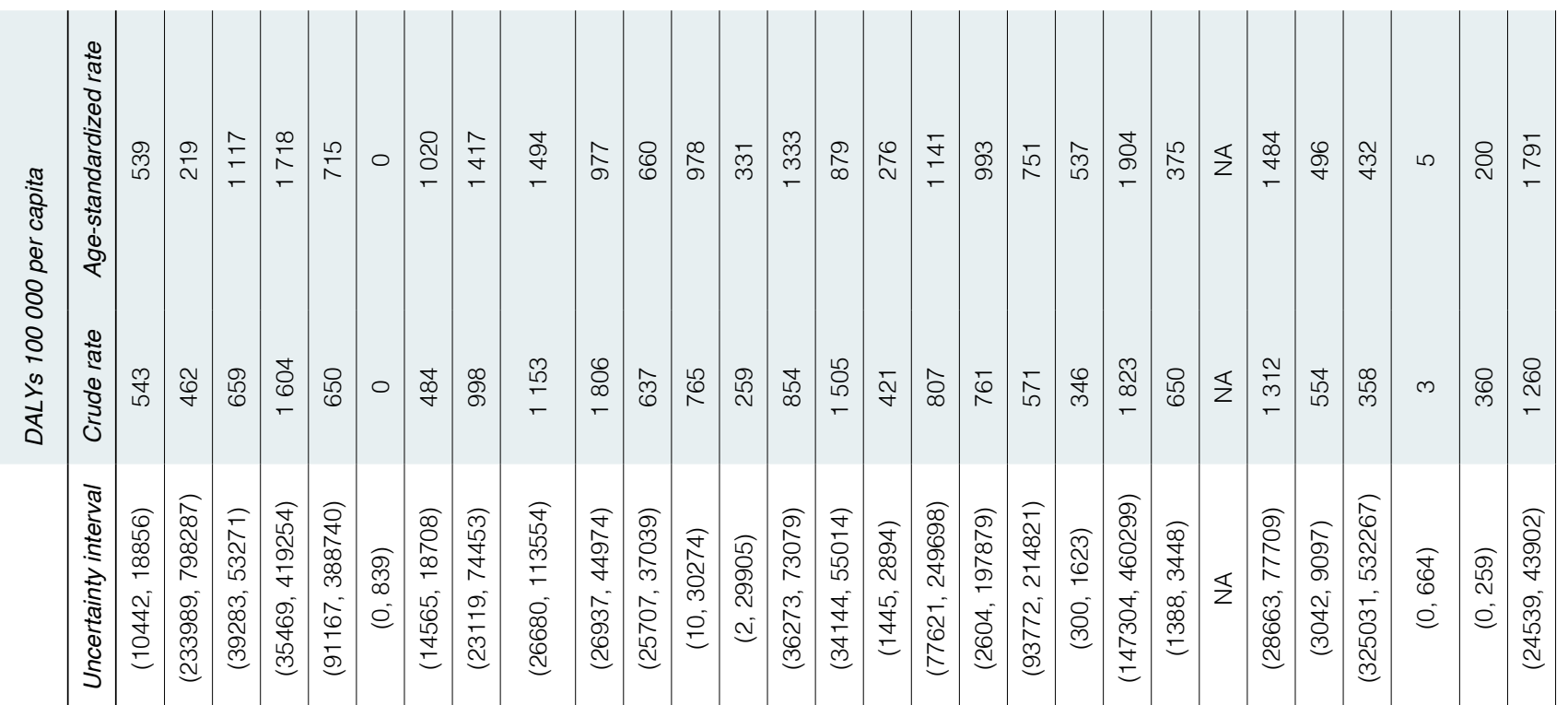

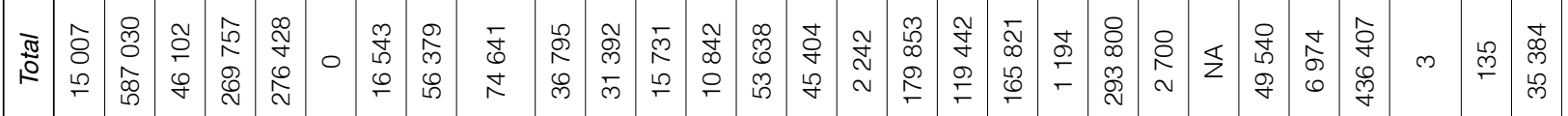

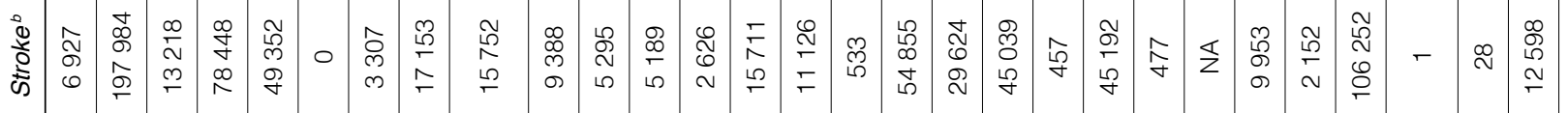

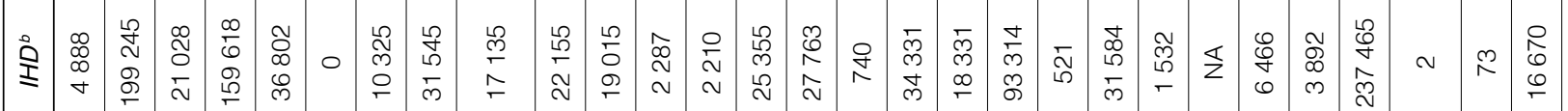

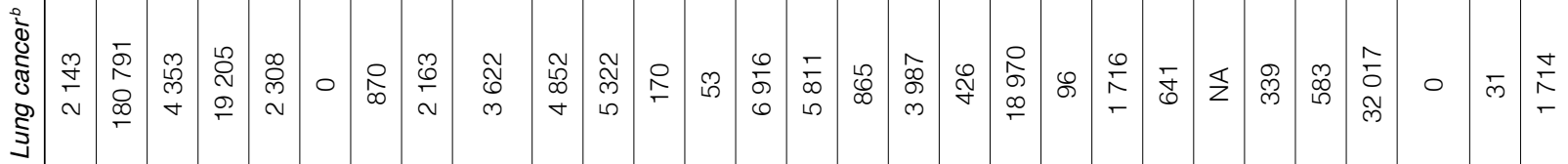

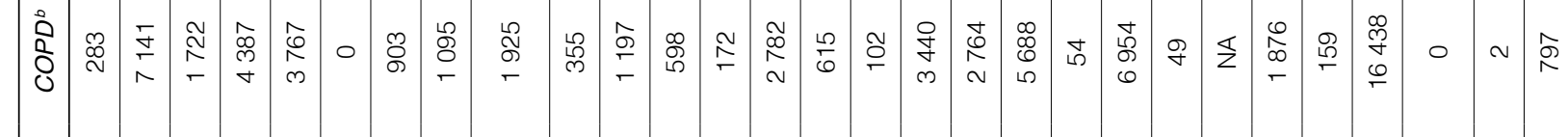

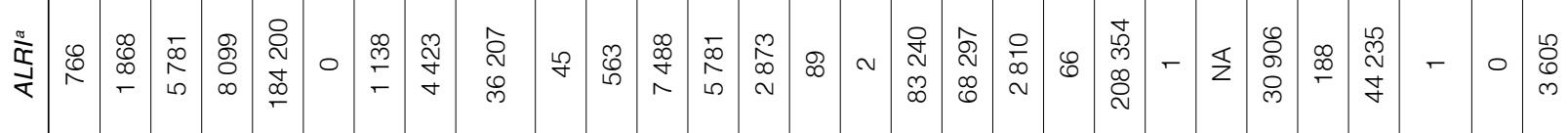

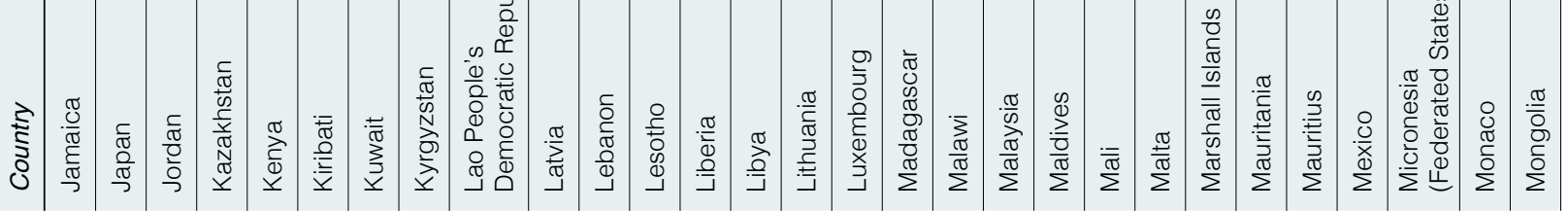

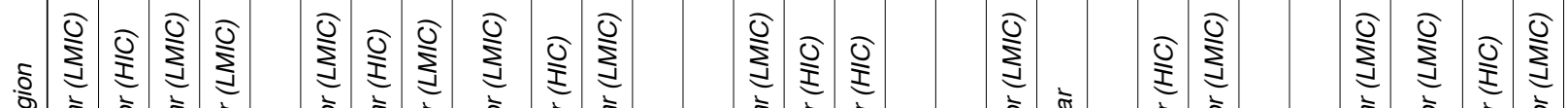

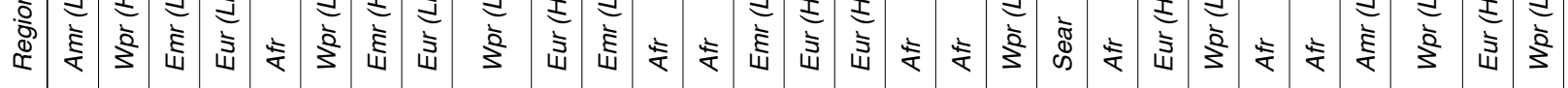




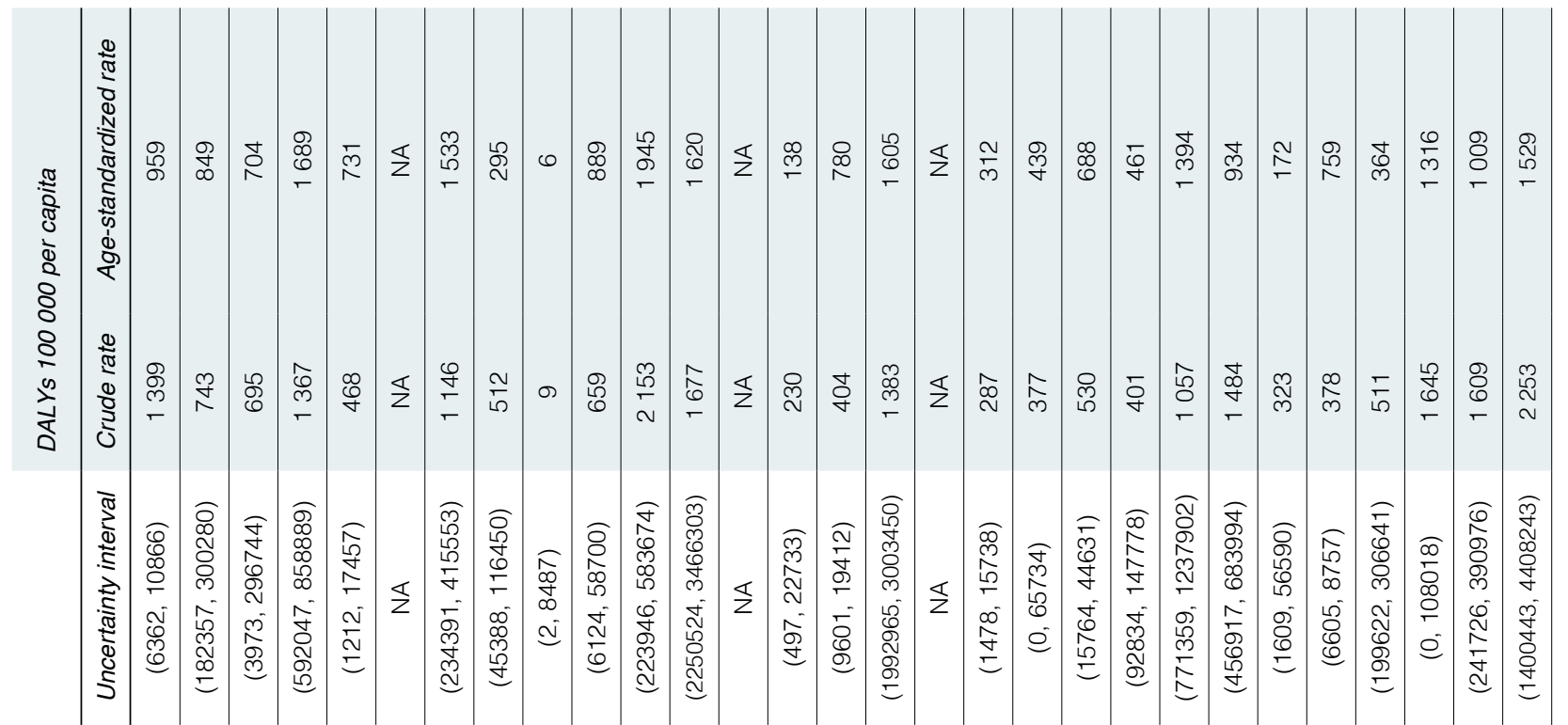

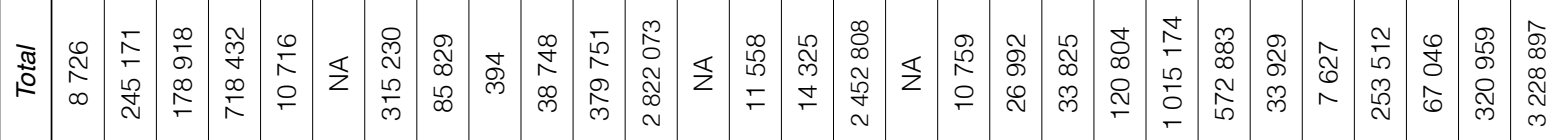

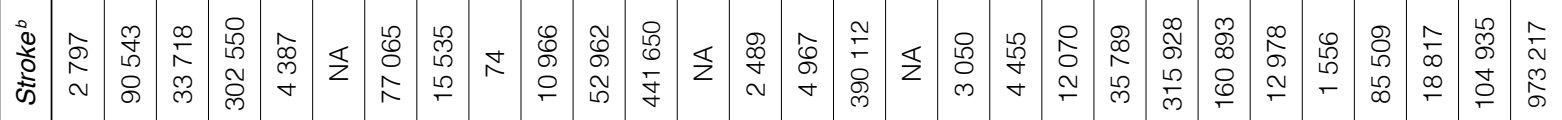

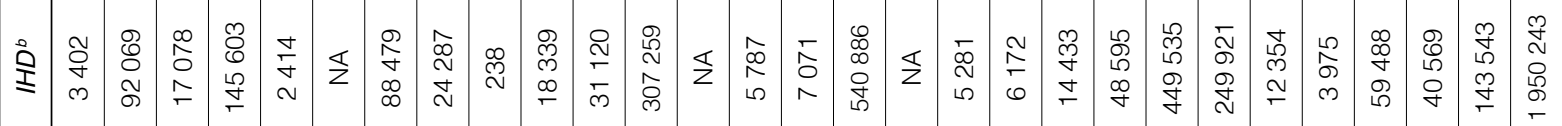

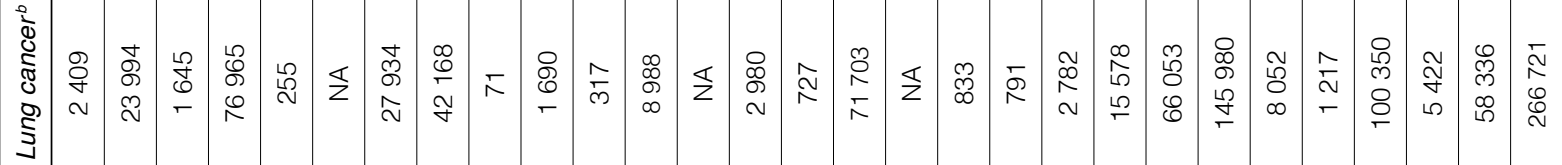

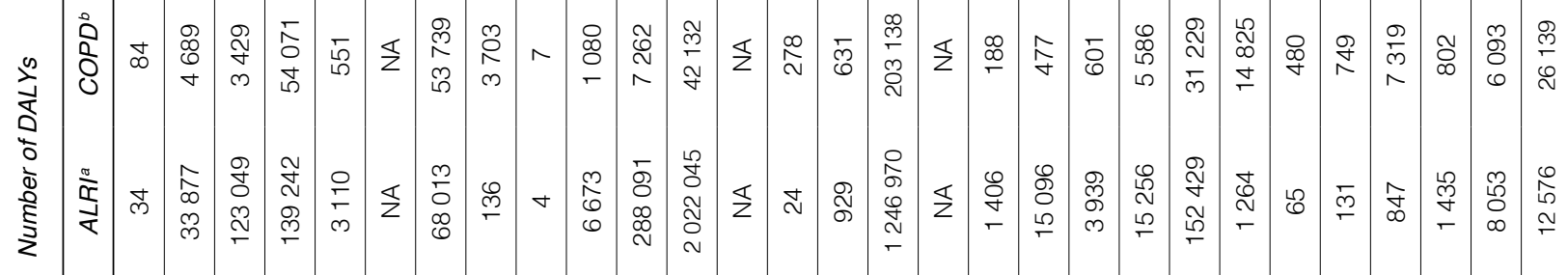

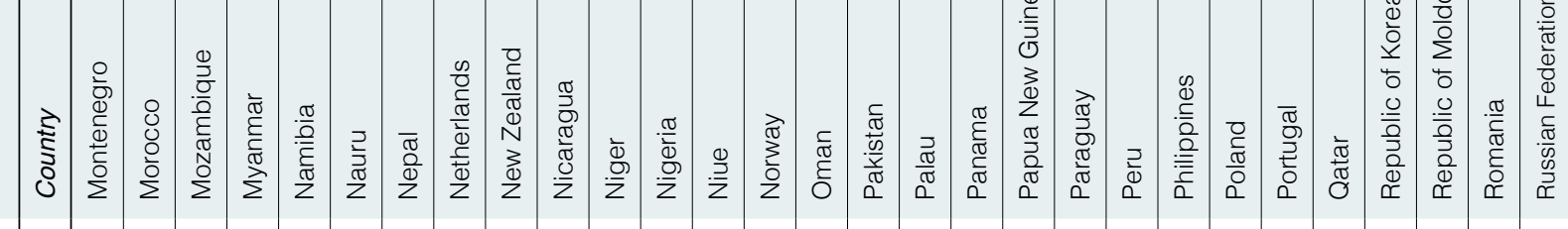

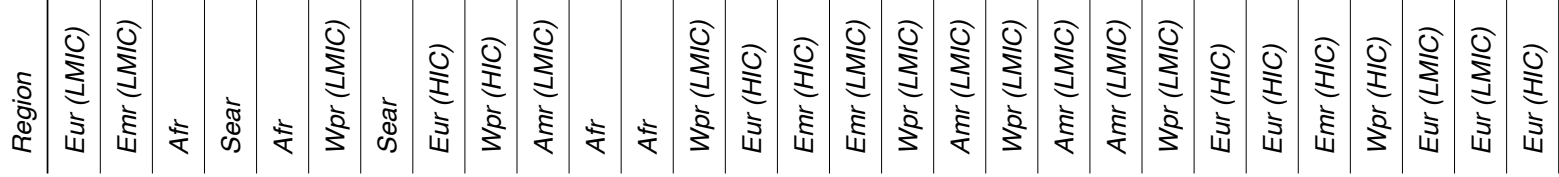




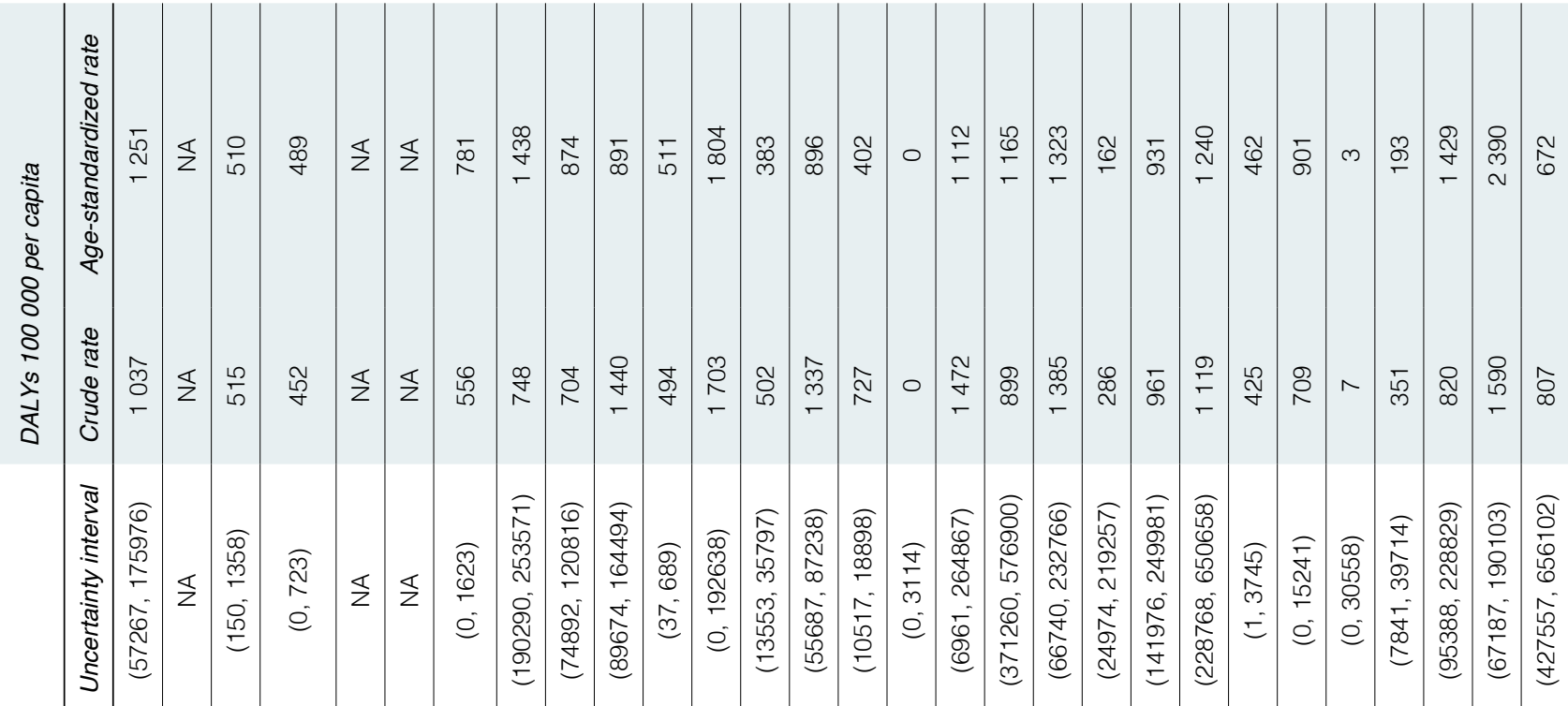

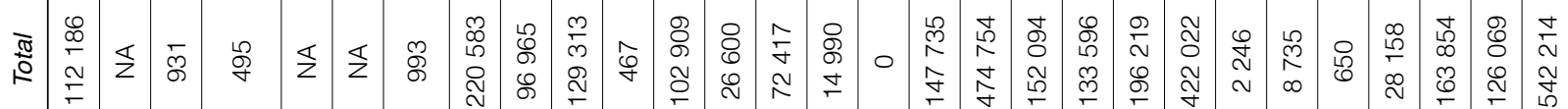

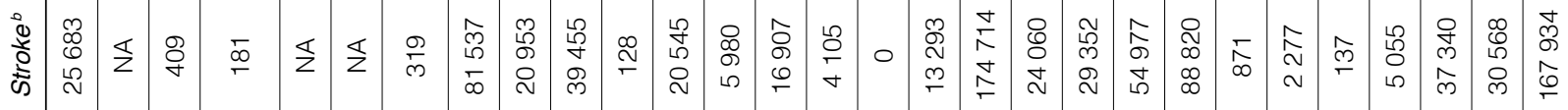

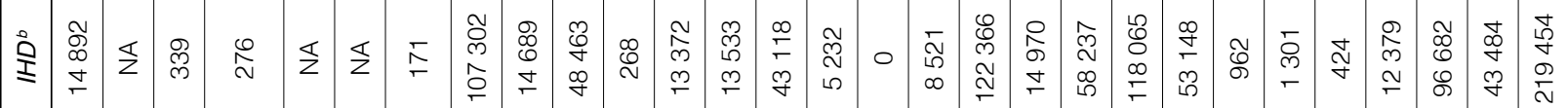

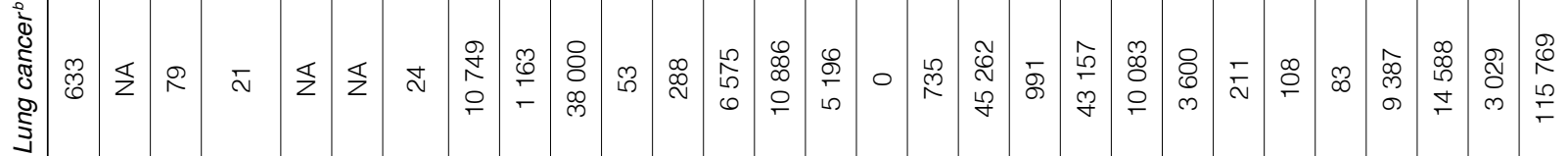

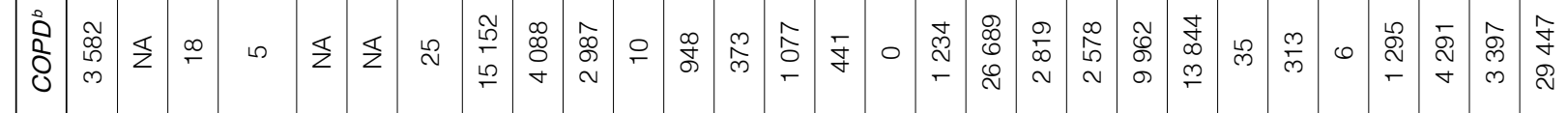

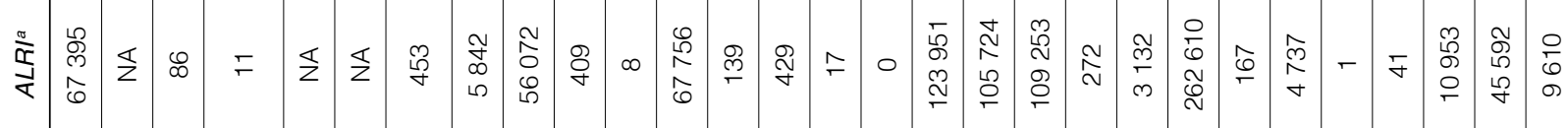

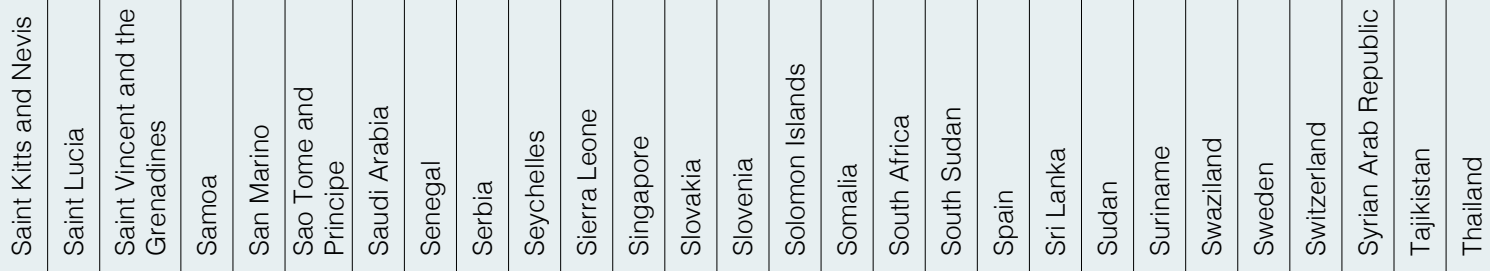

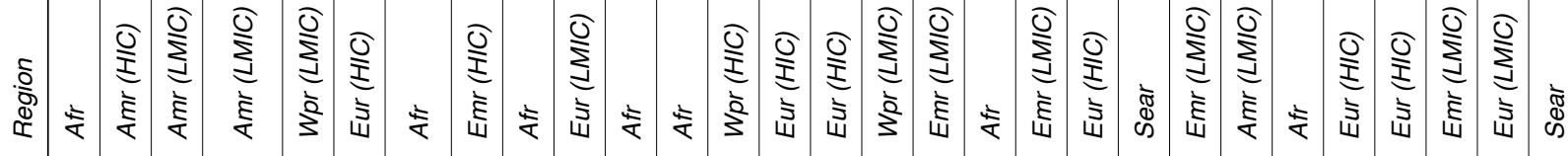




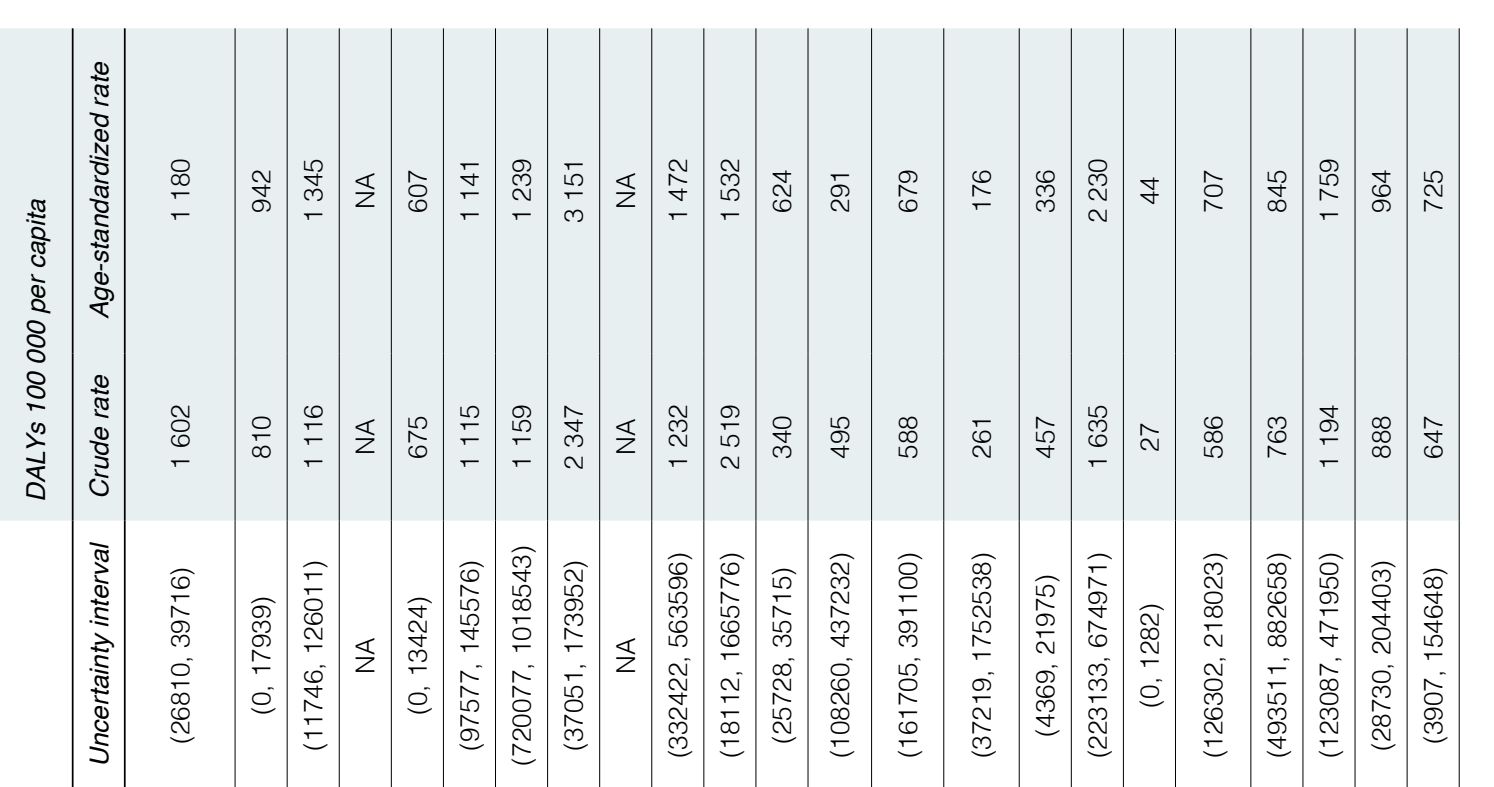

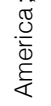
芒 离 $\frac{\sqrt{0}}{\frac{0}{0}}$

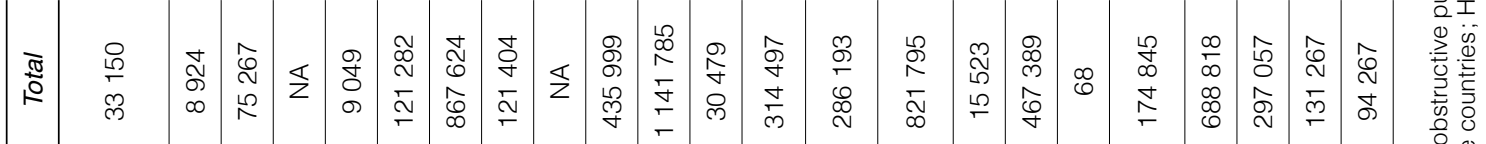

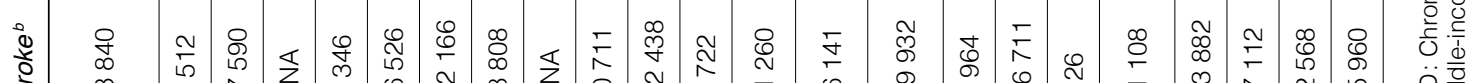

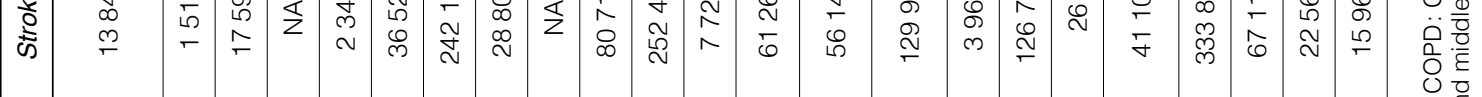

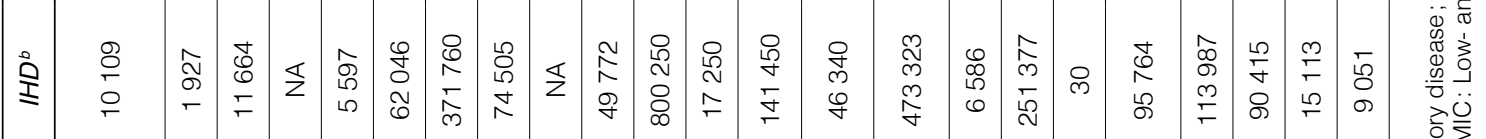

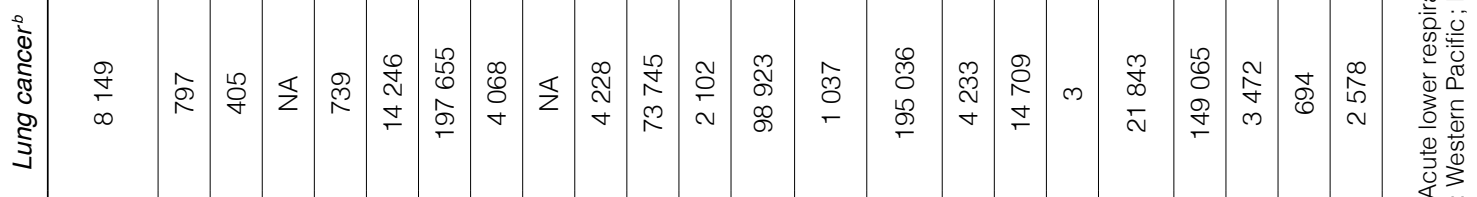

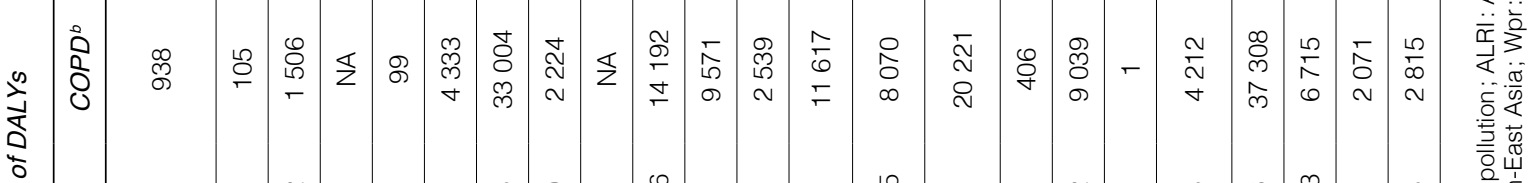

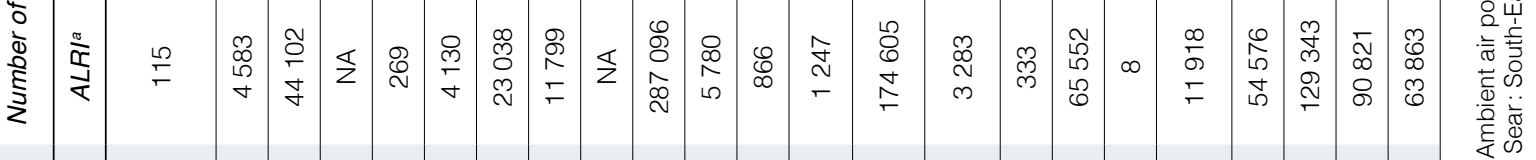

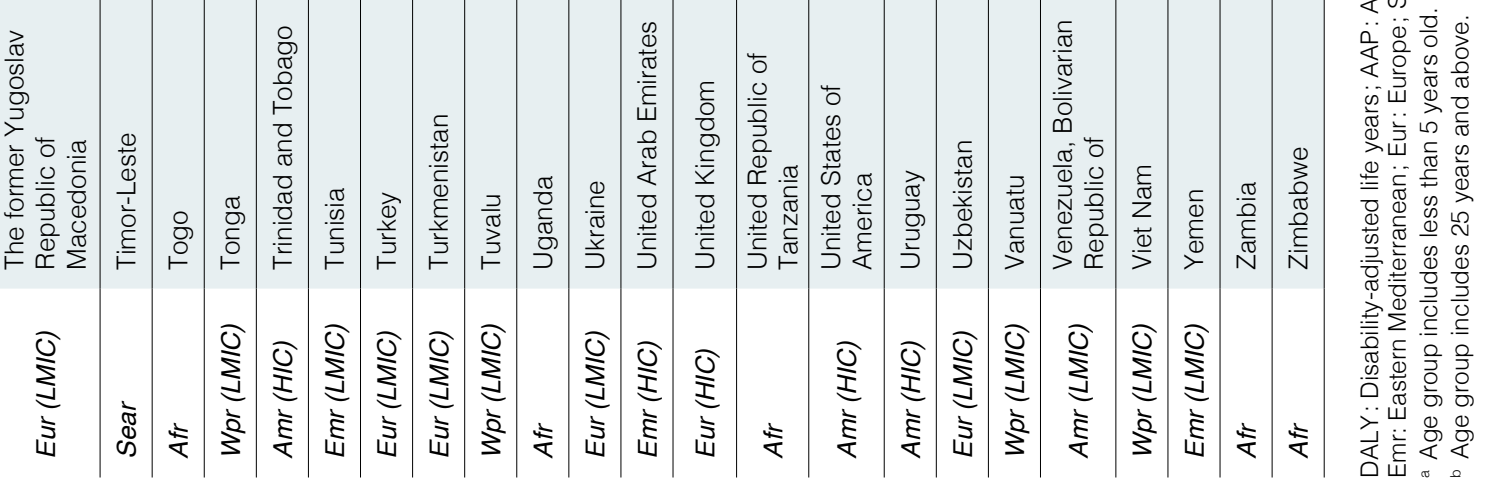




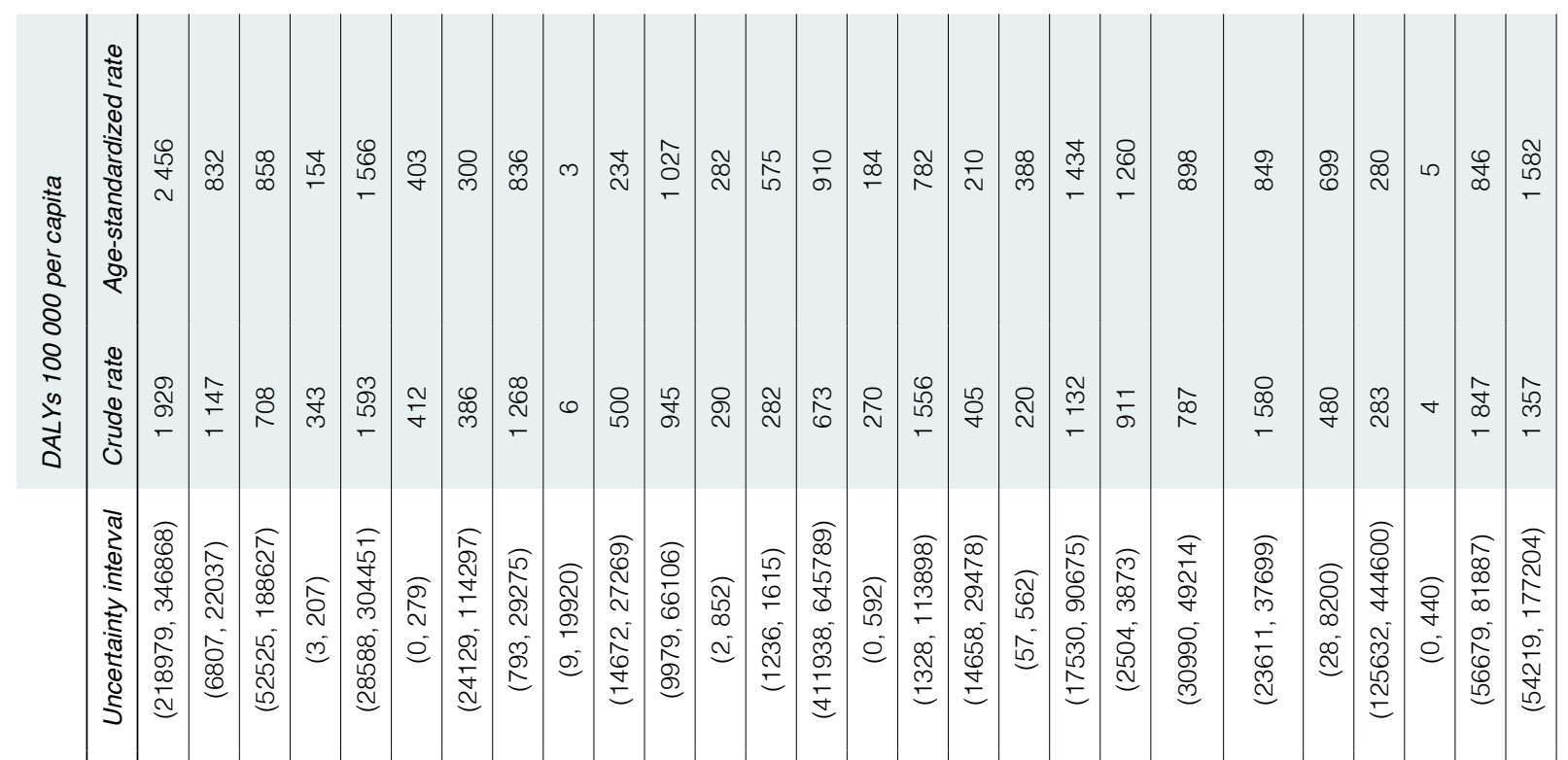

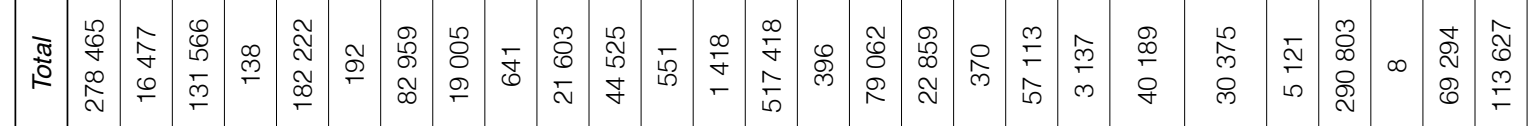

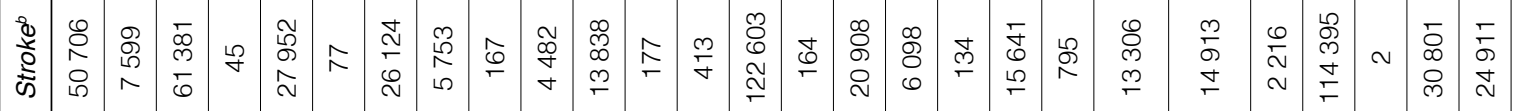

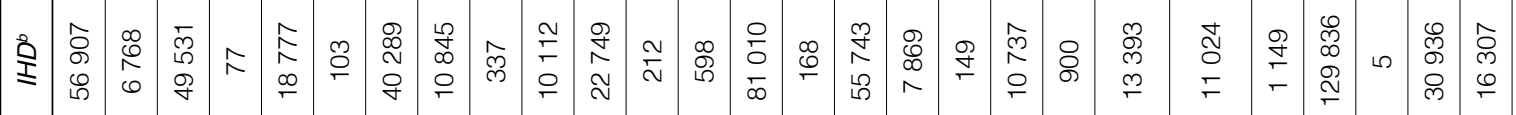

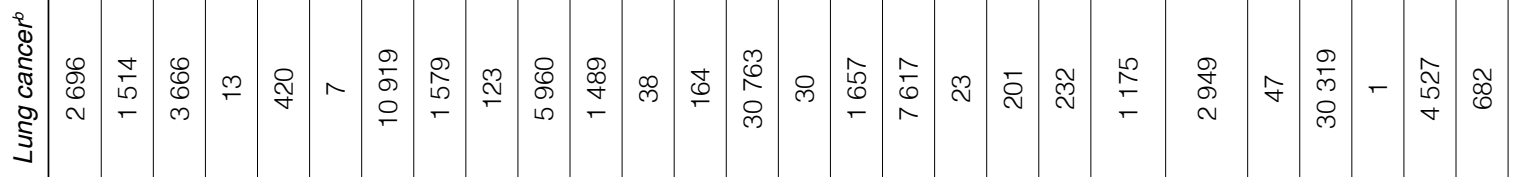

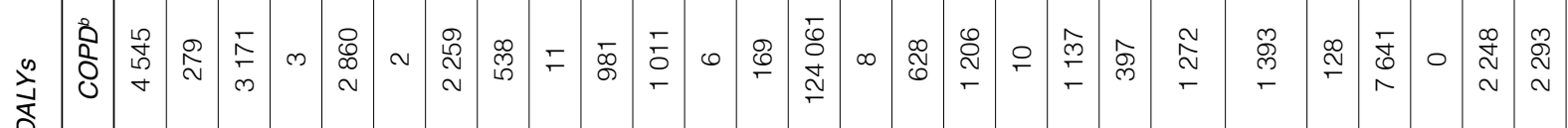

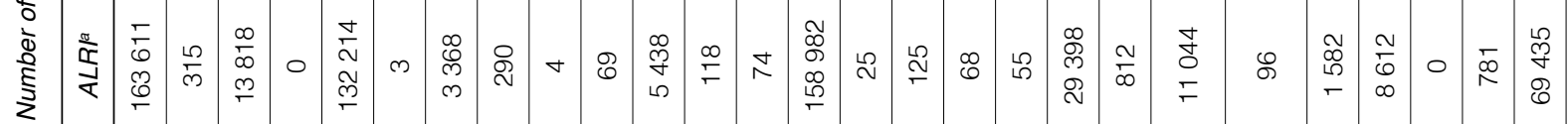

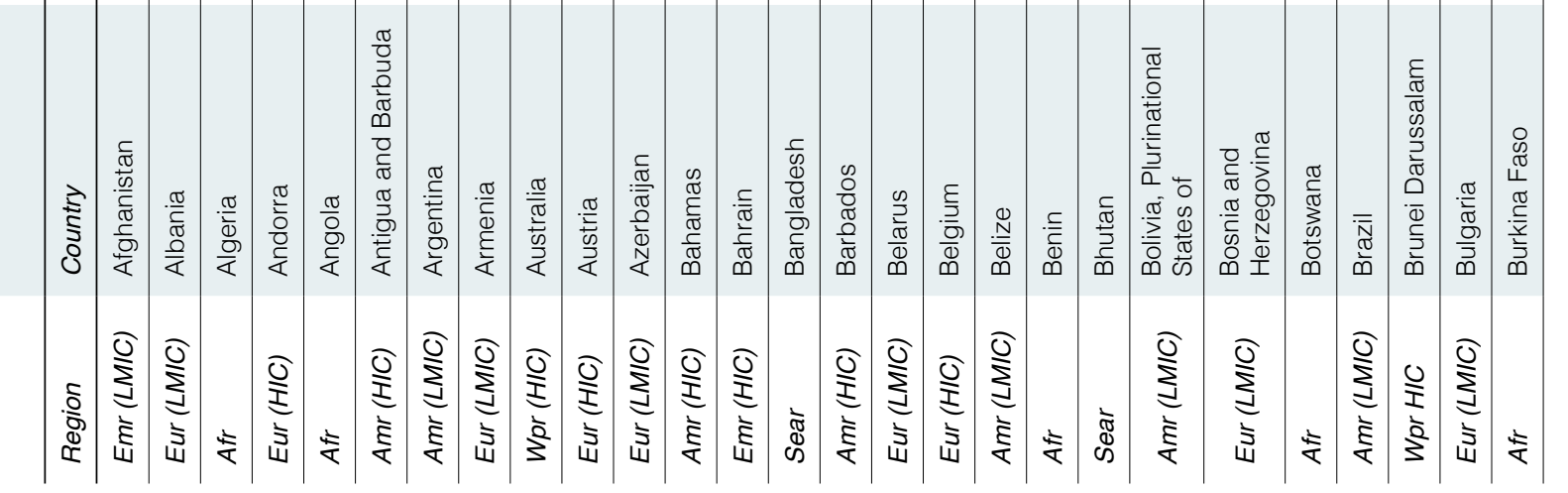




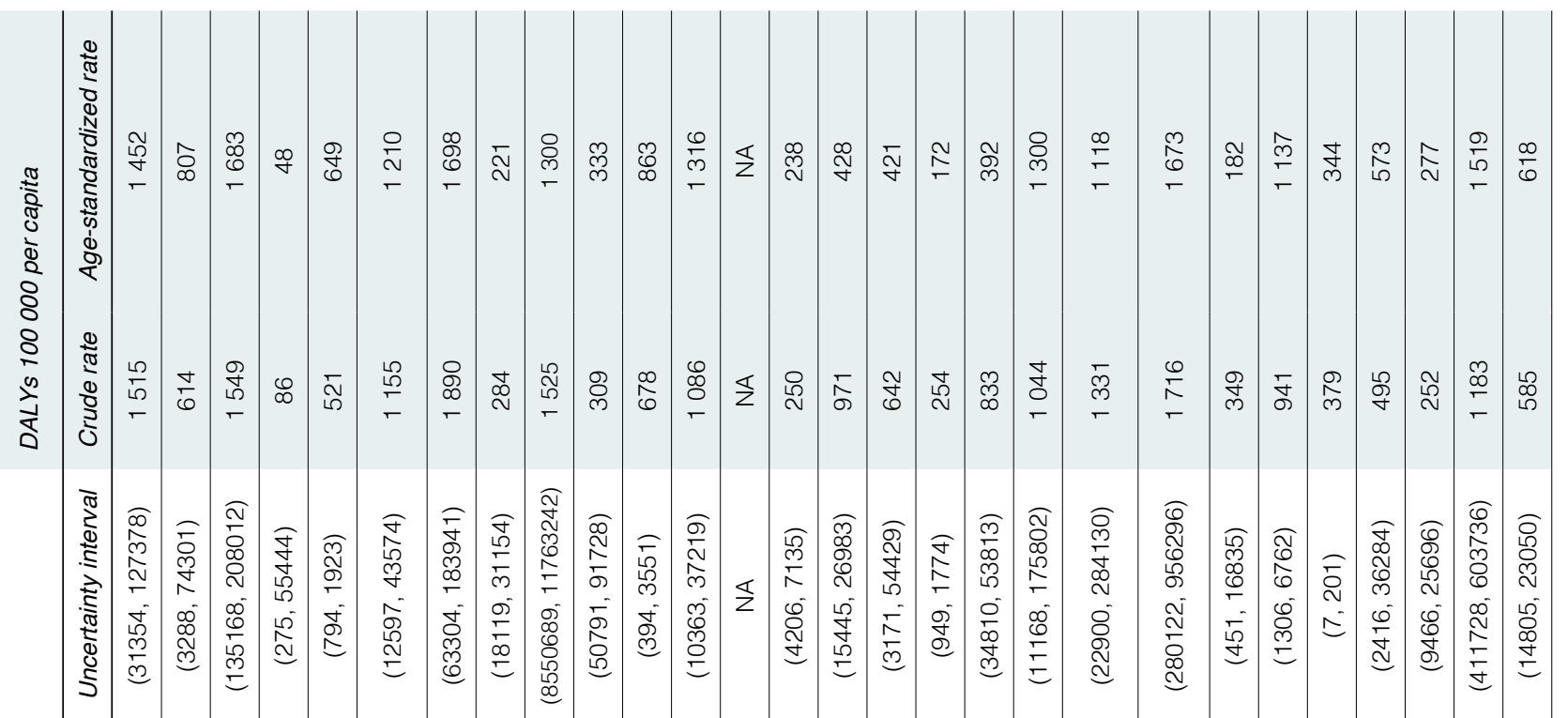

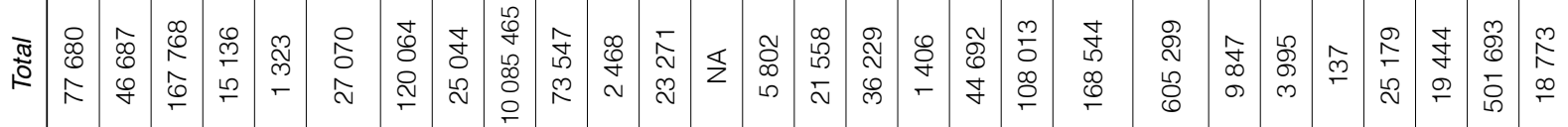

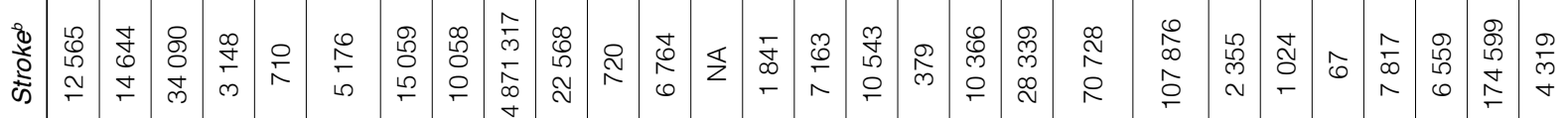

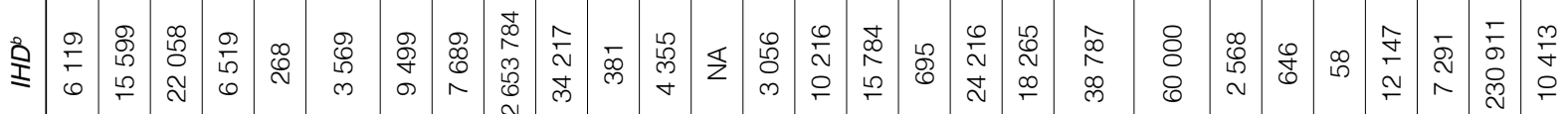

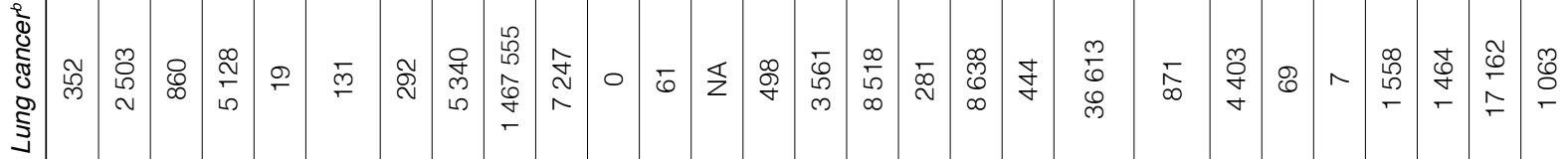

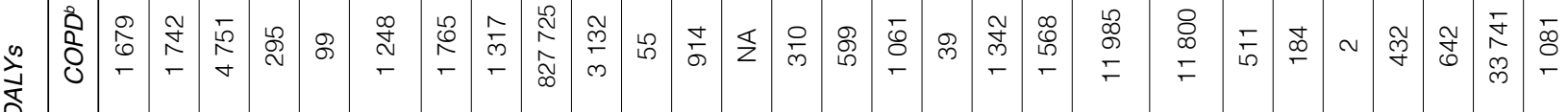

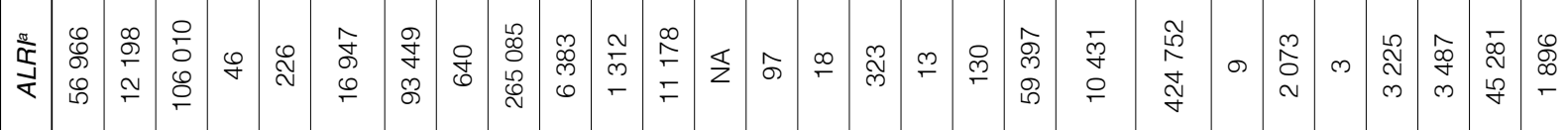

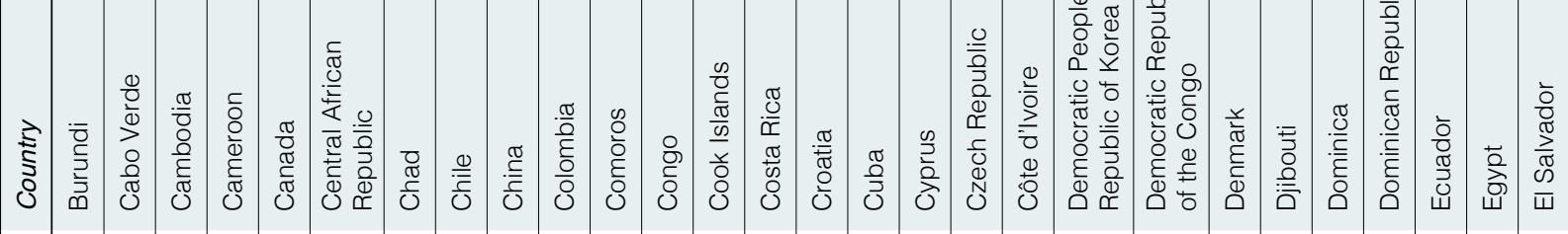

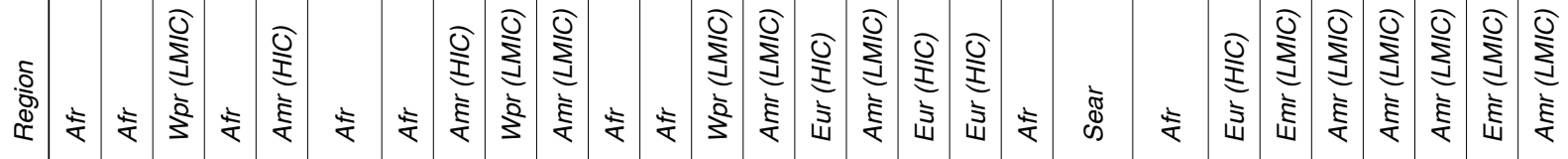




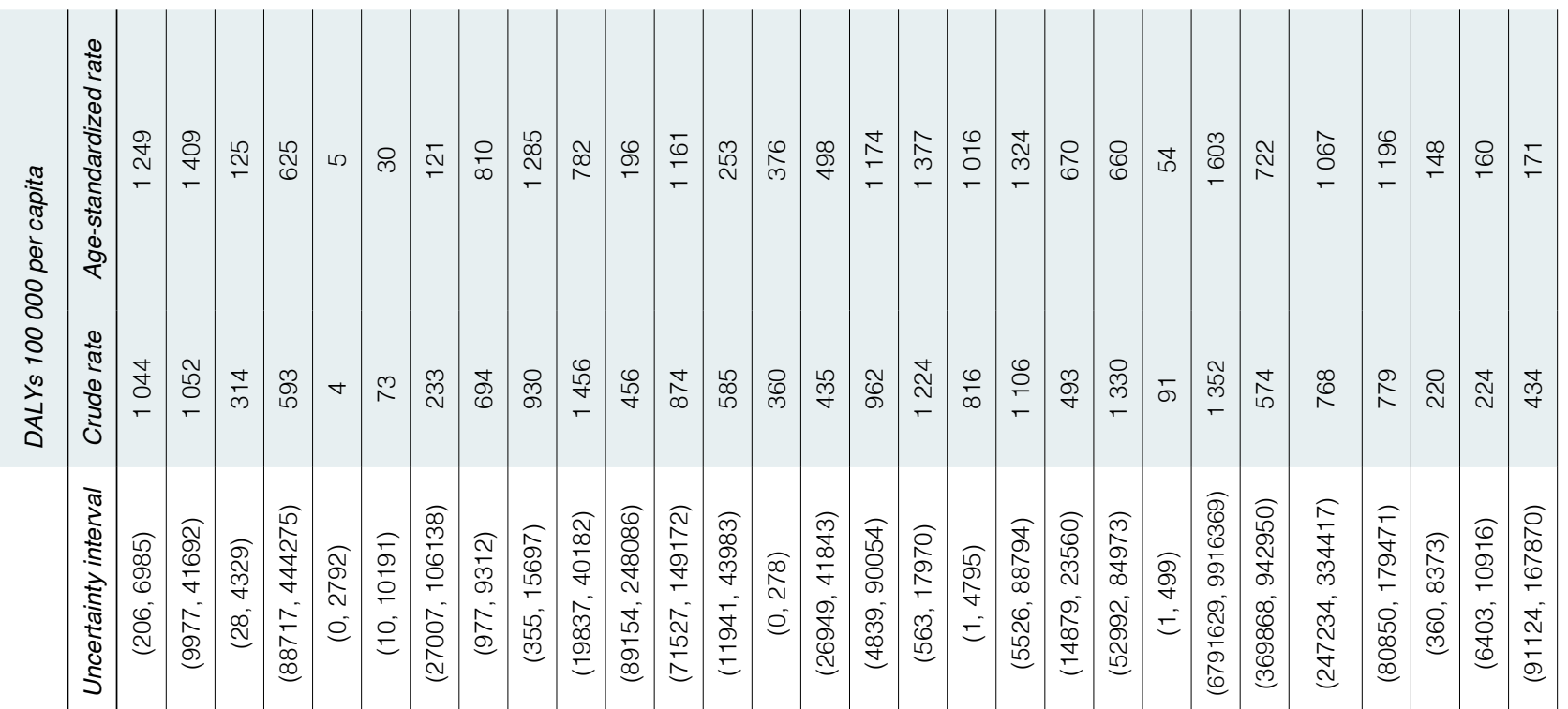

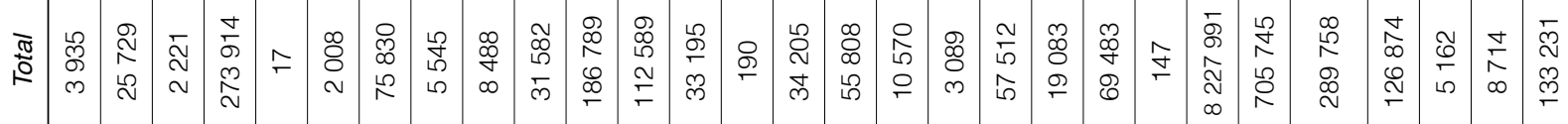

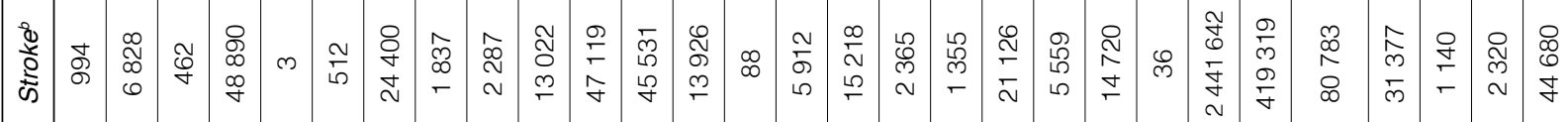

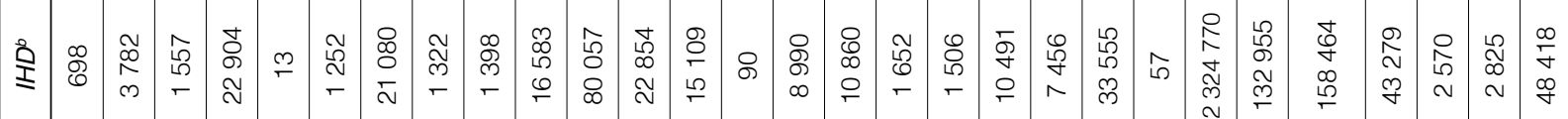

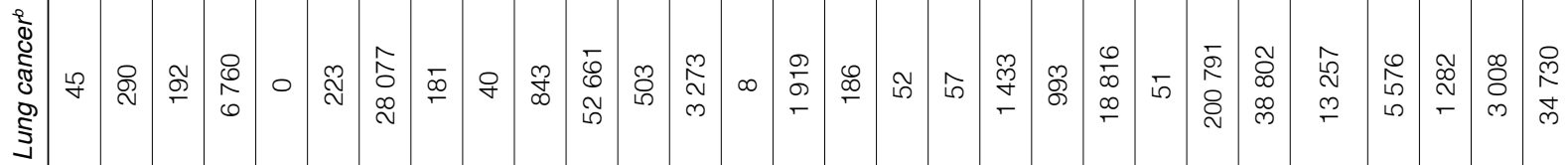

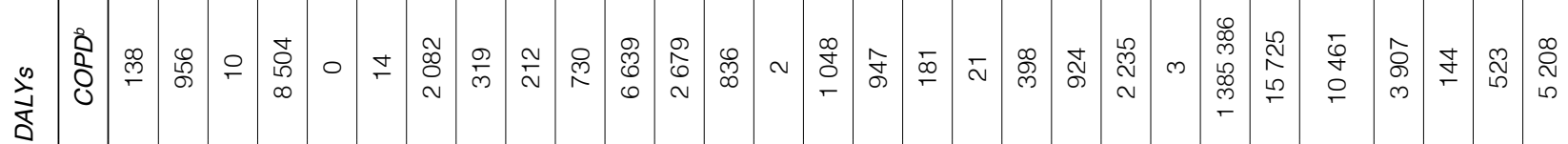

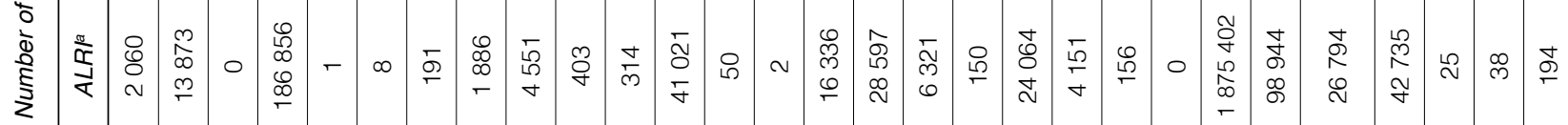

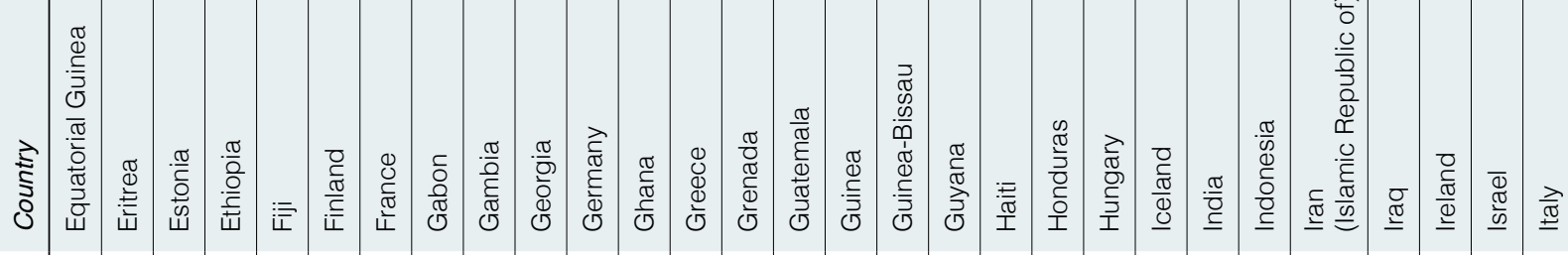

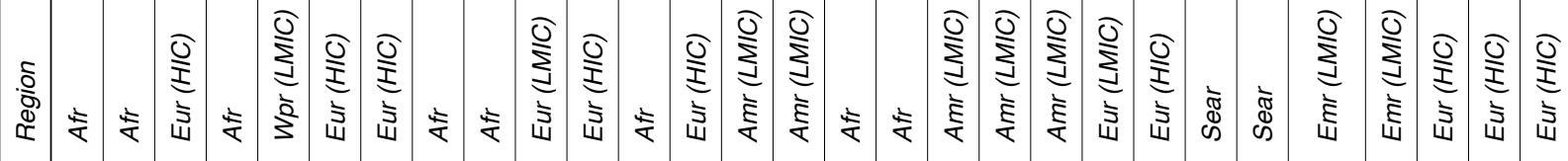




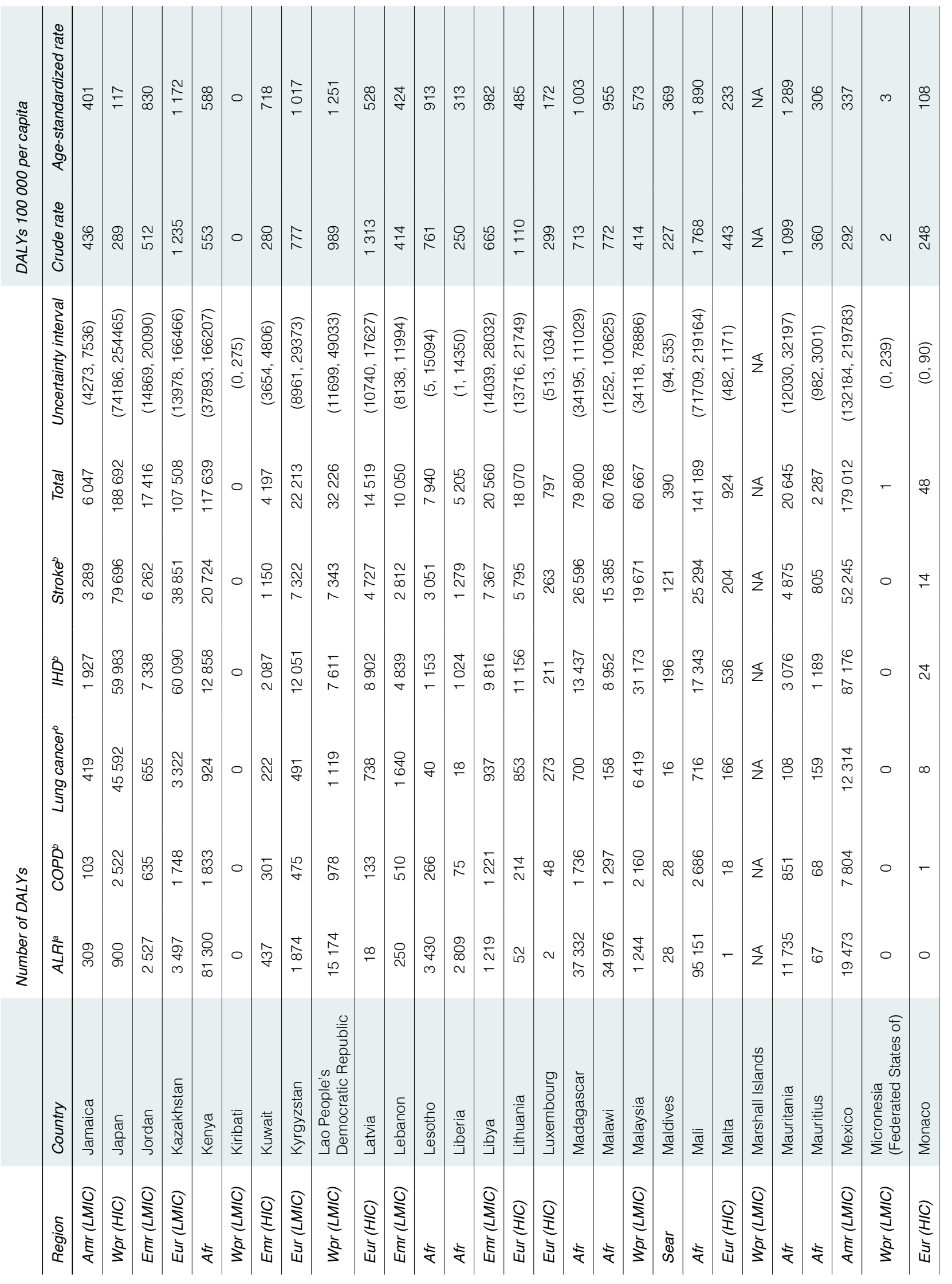




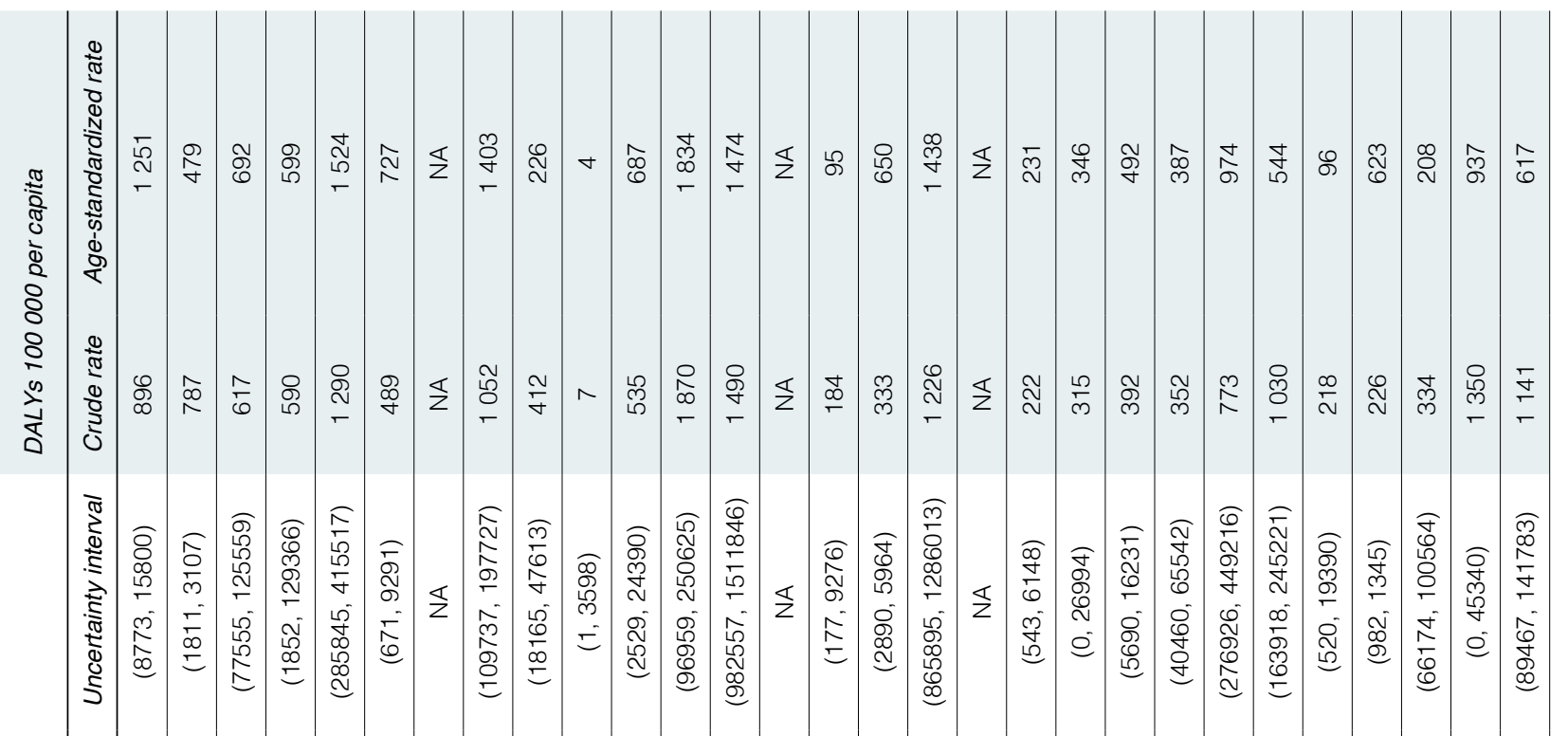

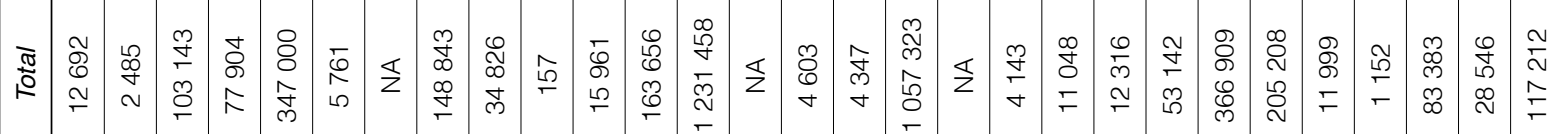

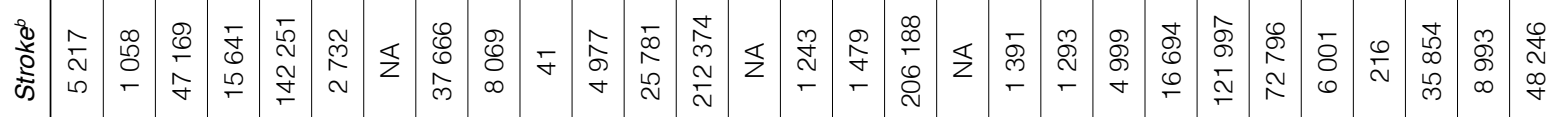

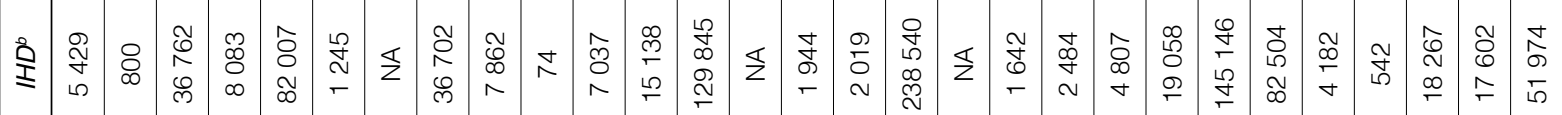

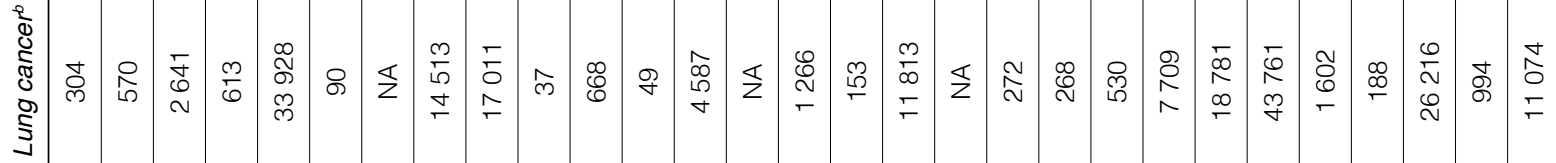

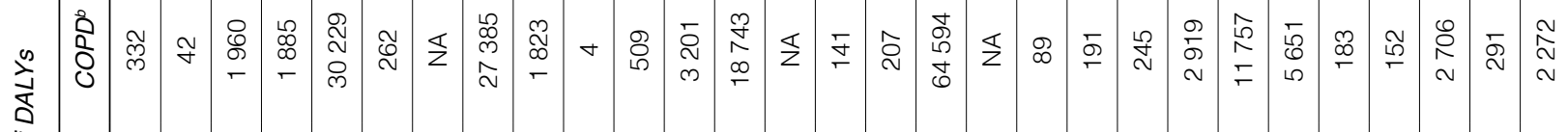

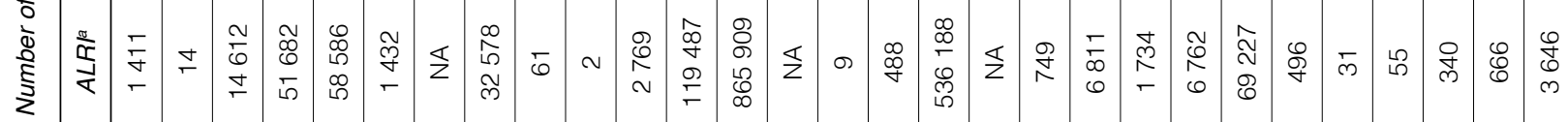

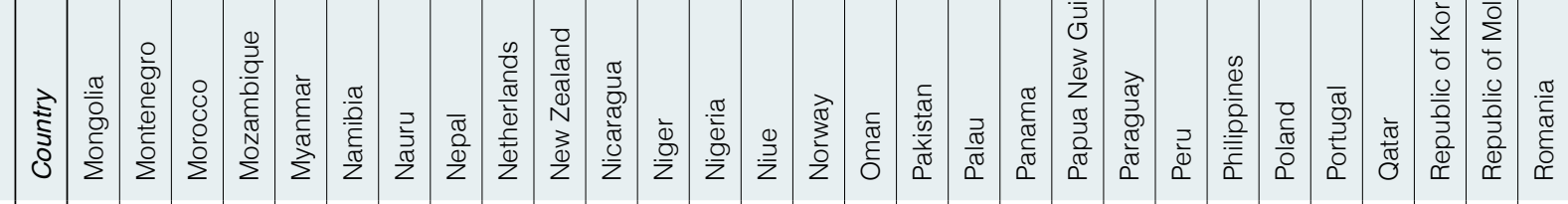

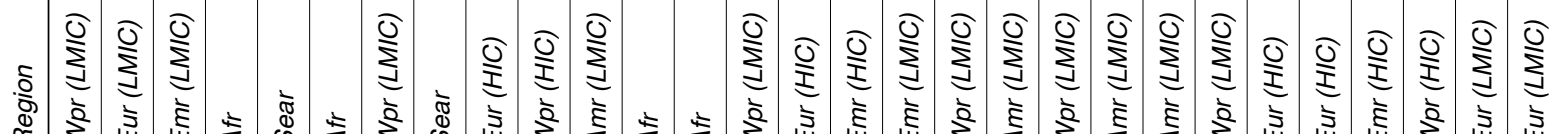




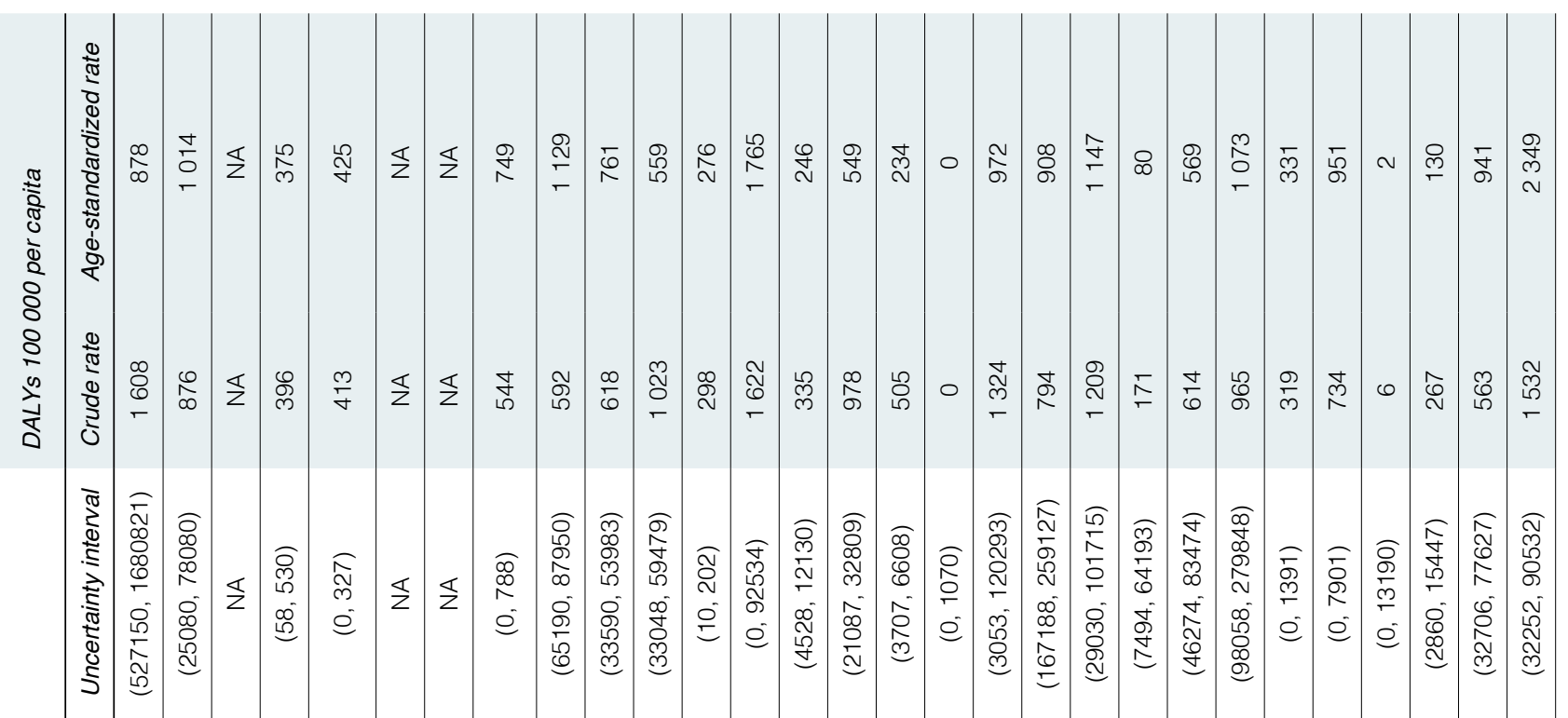

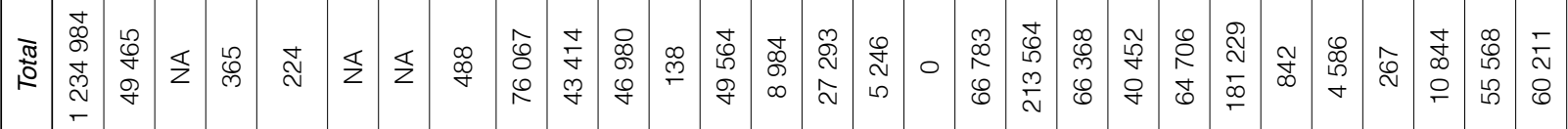

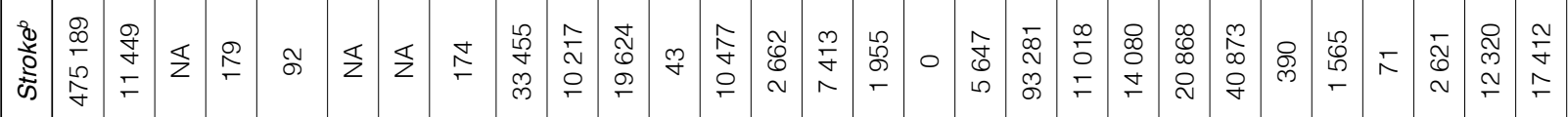

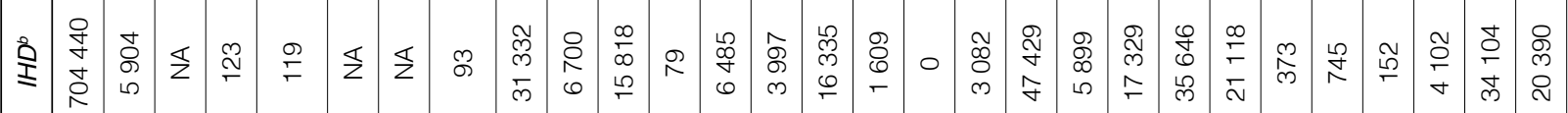

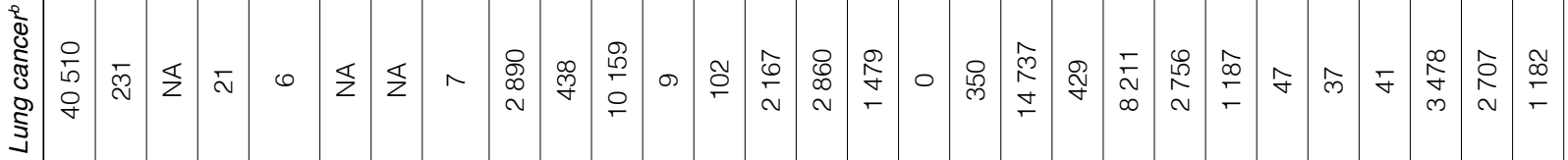

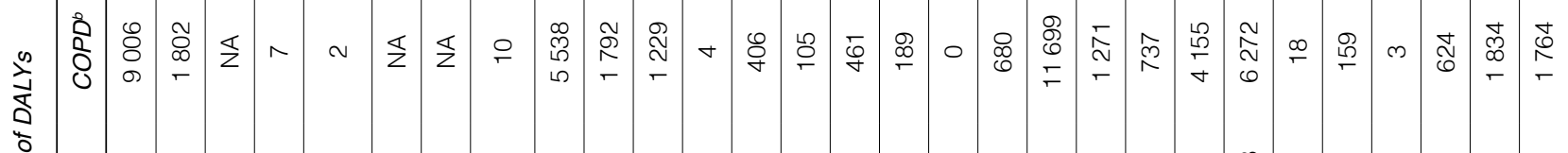

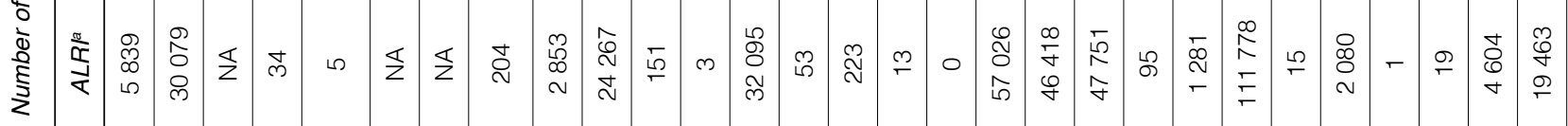

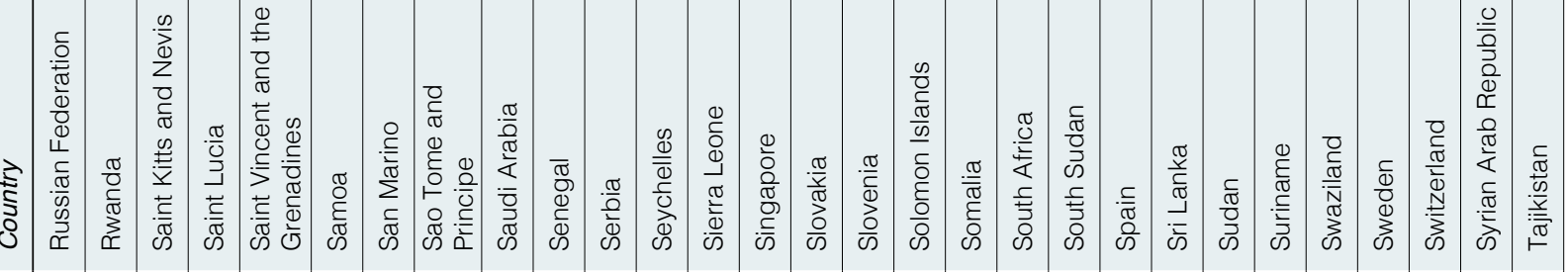

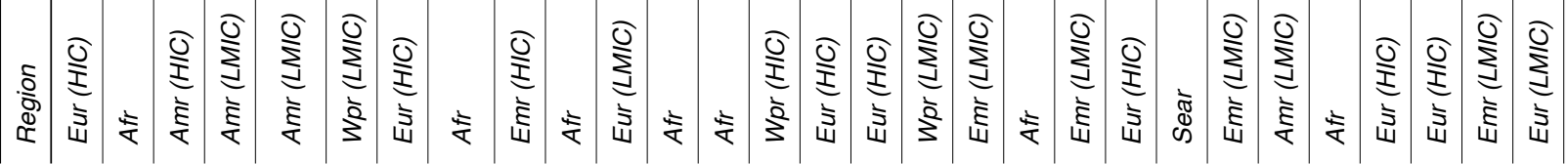




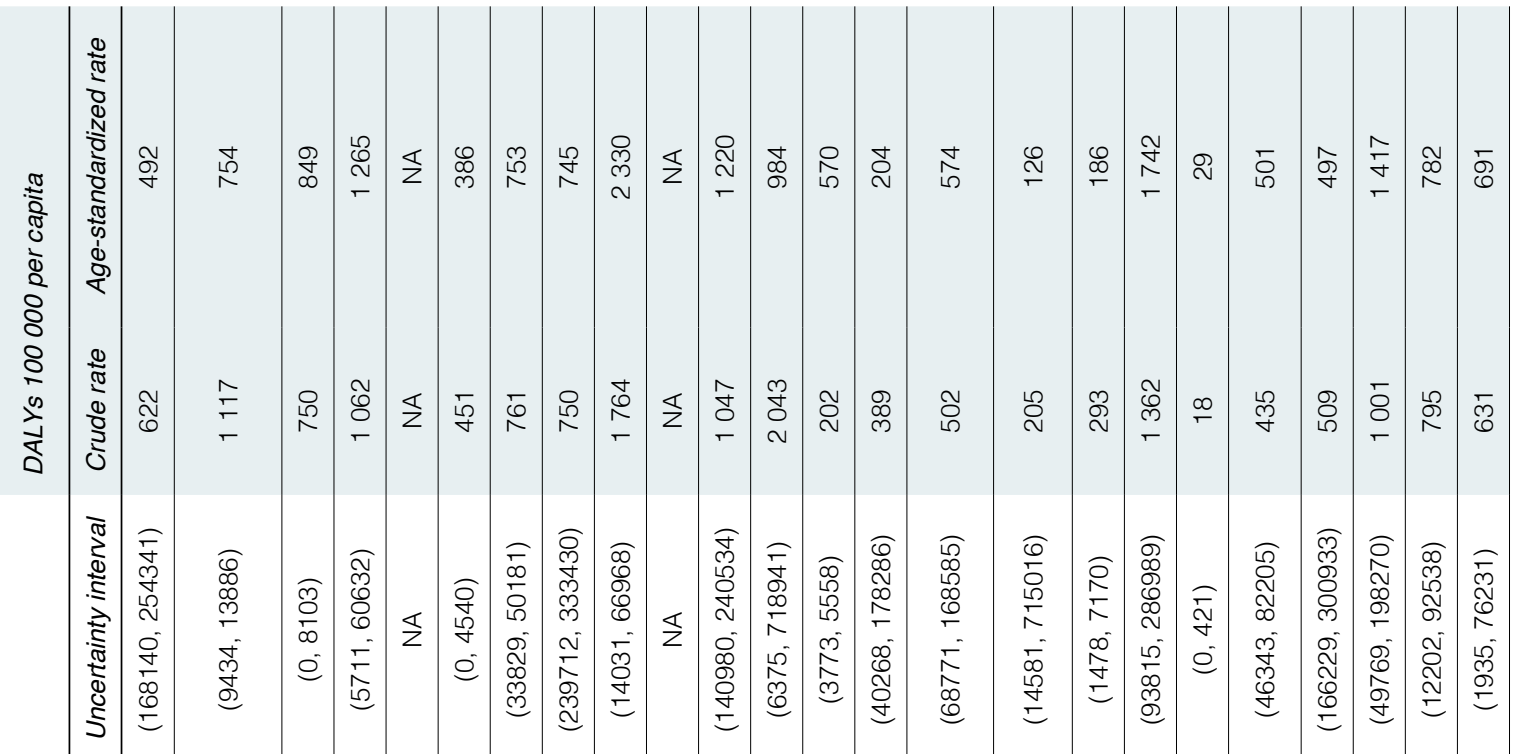

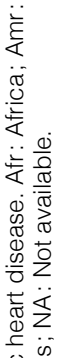

오 잉

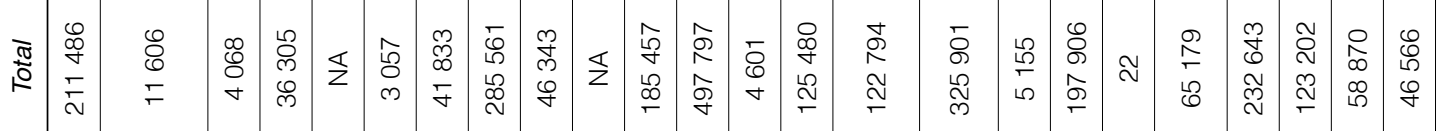

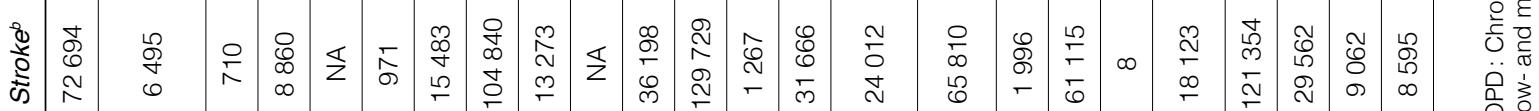

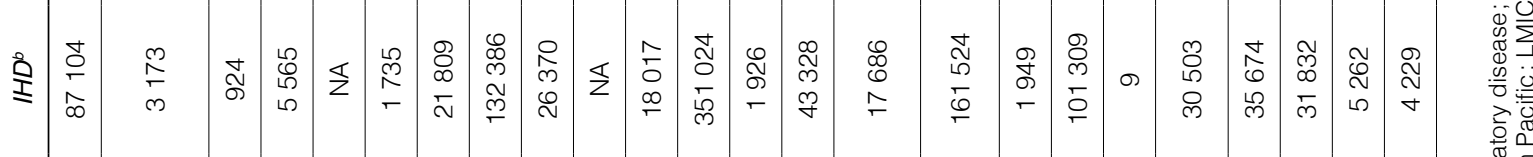

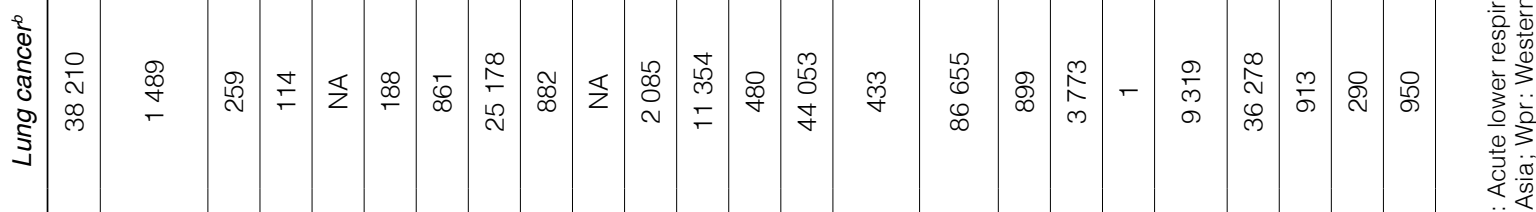

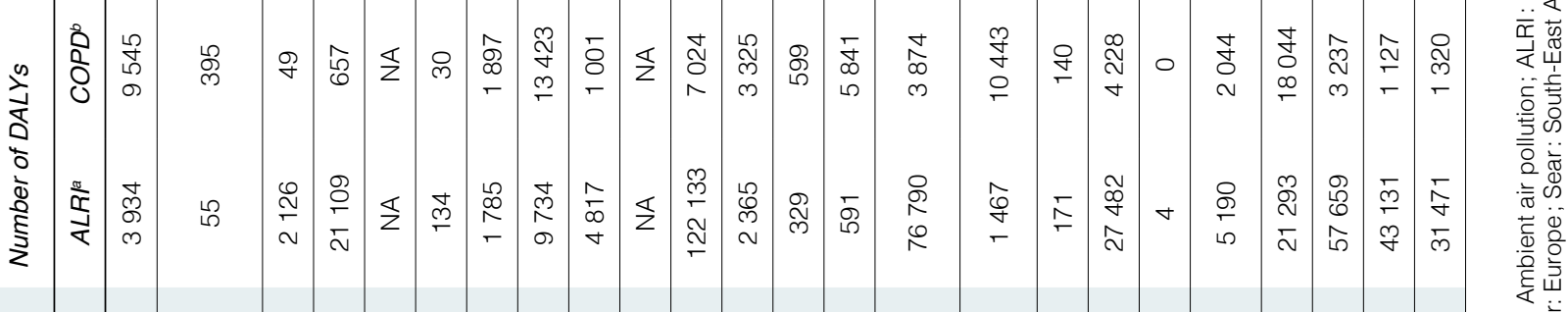

\begin{tabular}{|c|c|c|c|c|c|c|c|c|c|c|c|c|c|c|c|c|c|c|c|c|}
\hline 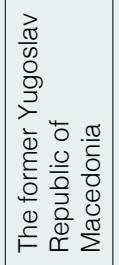 & 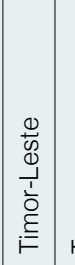 & $\begin{array}{l}\stackrel{\circ}{\circ} \\
\stackrel{\circ}{\circ}\end{array}$ & $\begin{array}{l}\text { J } \\
\stackrel{0}{\circ} \\
\vdash\end{array}$ & 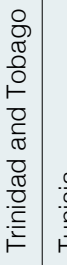 & 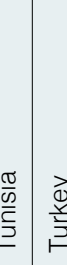 & 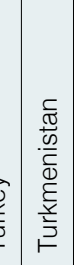 & 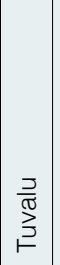 & 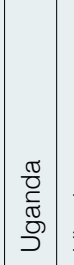 & 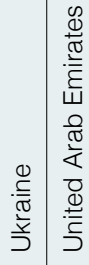 & 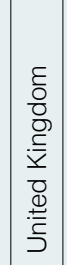 & 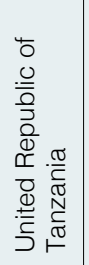 & 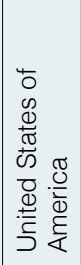 & 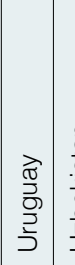 & 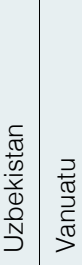 & 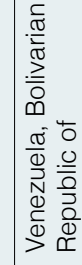 & 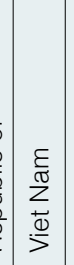 & & . & & 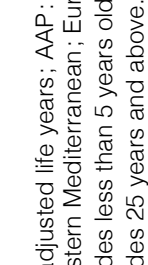 \\
\hline$\widehat{O}$ & \begin{tabular}{|l|l} 
& $\mathbb{\Phi}$ \\
$\infty$ & $:$
\end{tabular} & $\dot{*}$ & 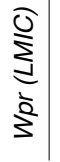 & 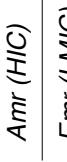 & 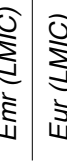 & 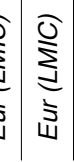 & 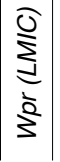 & 安 & 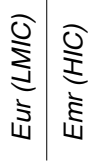 & 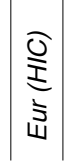 & $\dot{*}$ & 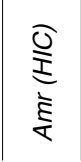 & 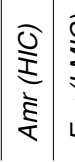 & 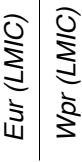 & 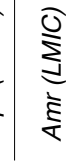 & 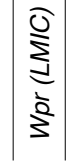 & 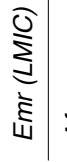 & 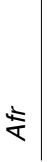 & & $\frac{0}{\bar{\alpha}}$ \\
\hline
\end{tabular}




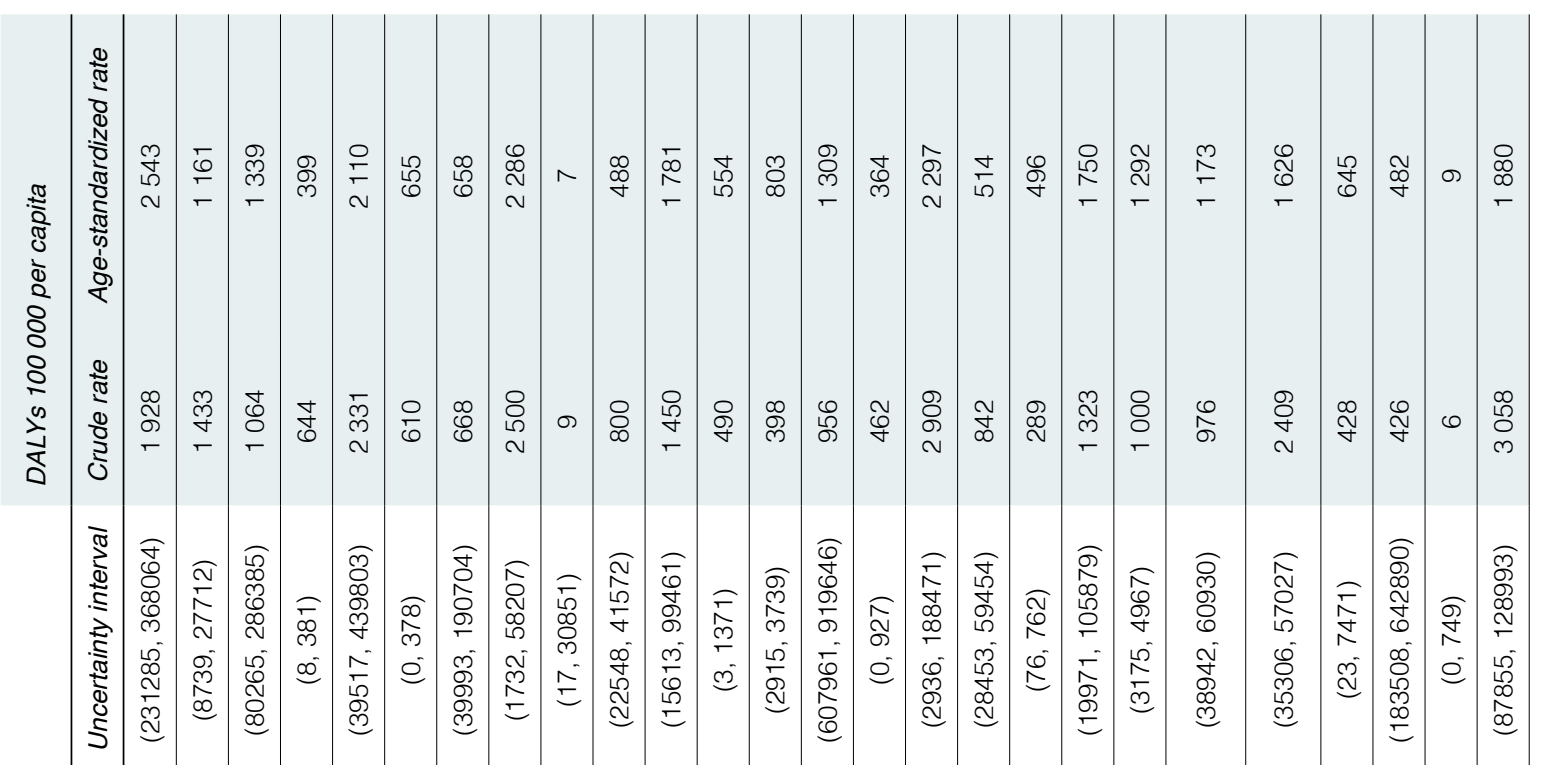

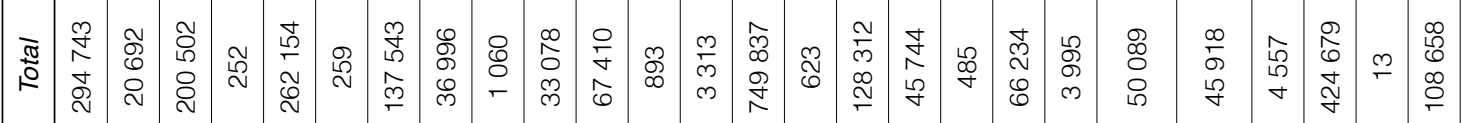

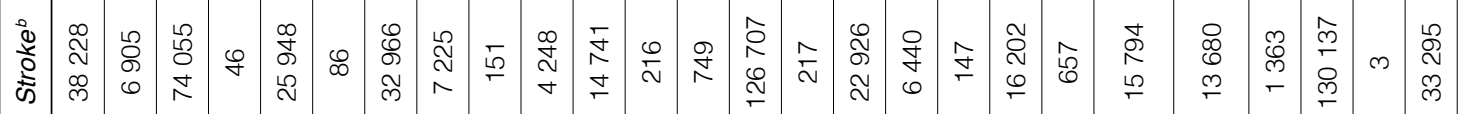

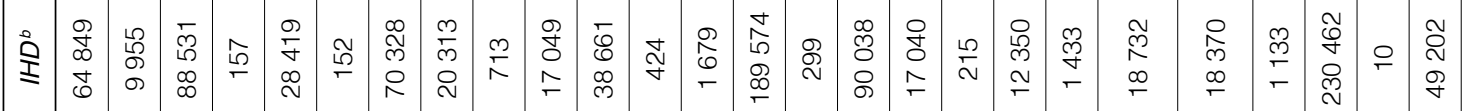

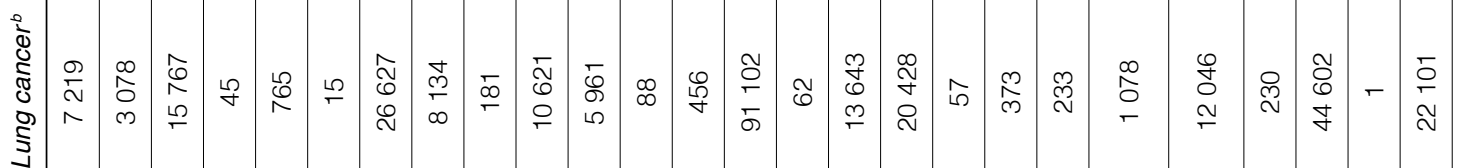

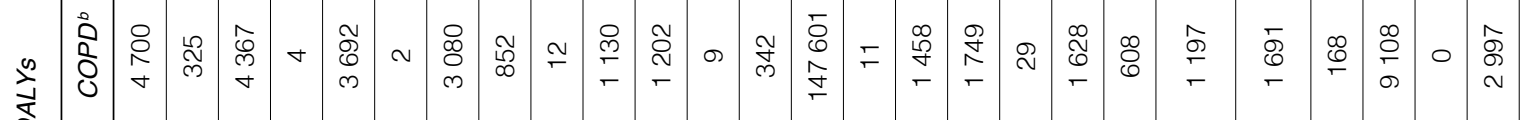

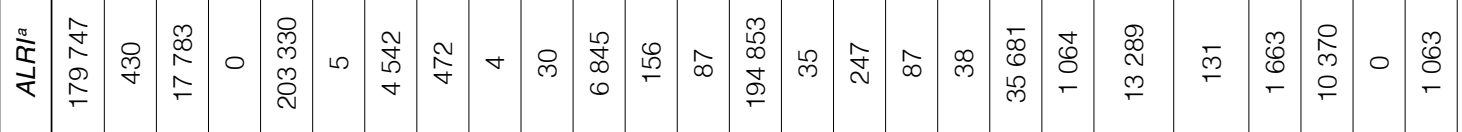

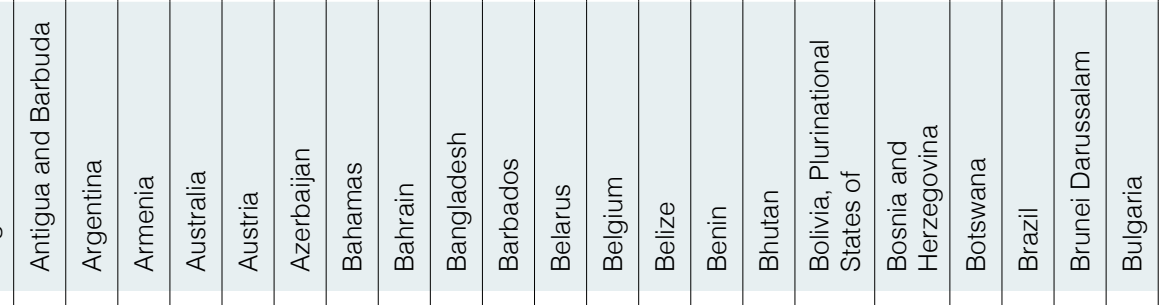

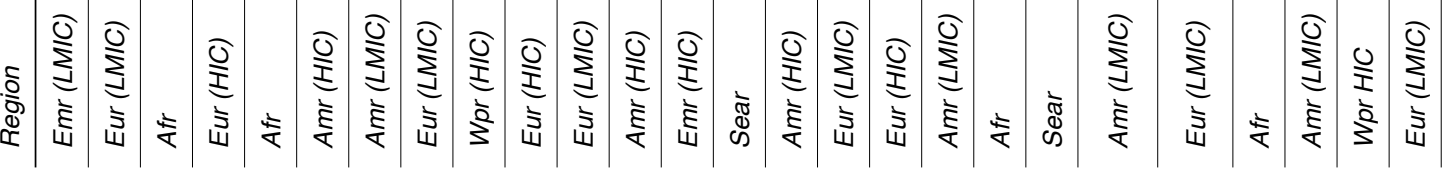




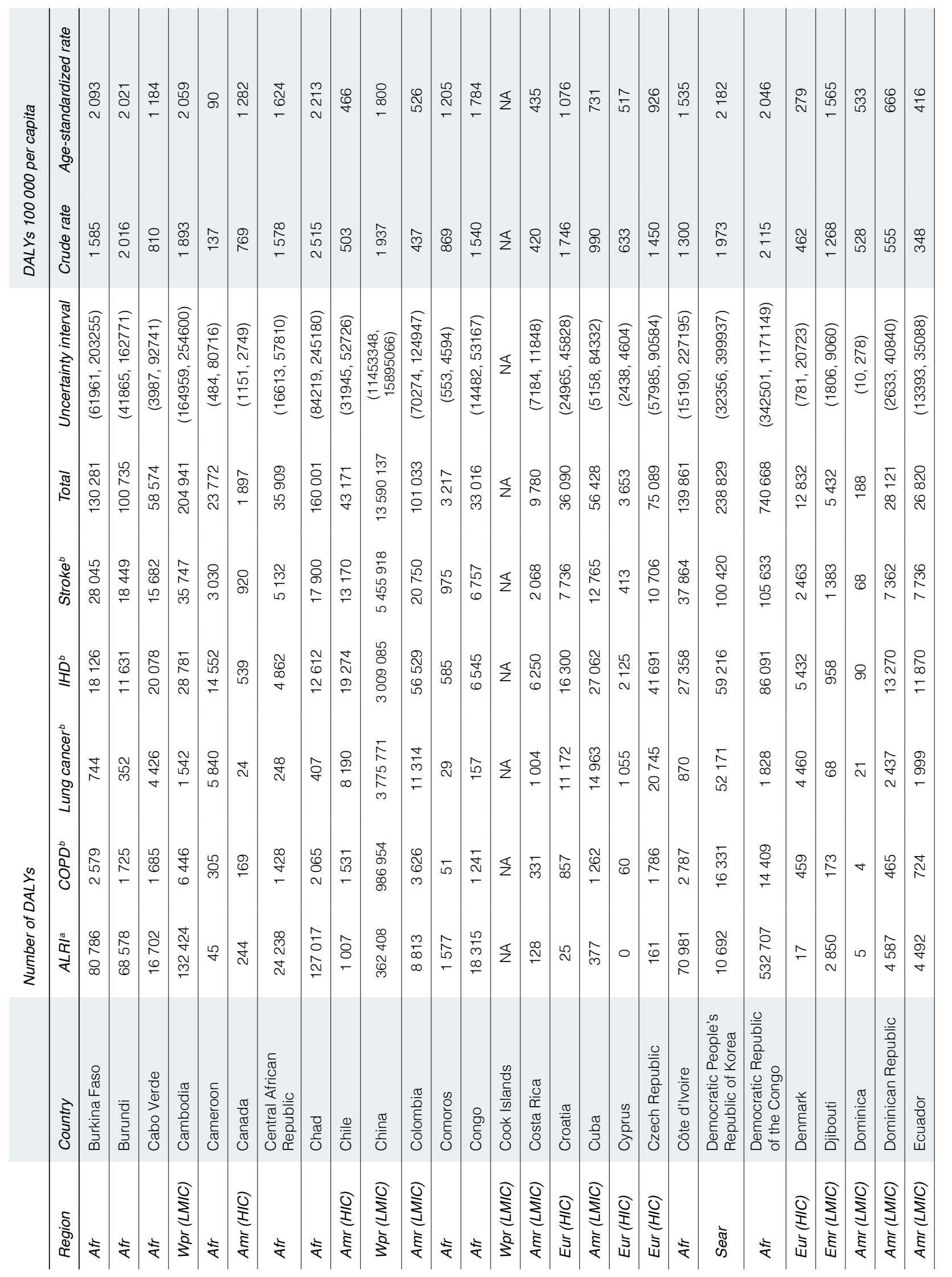




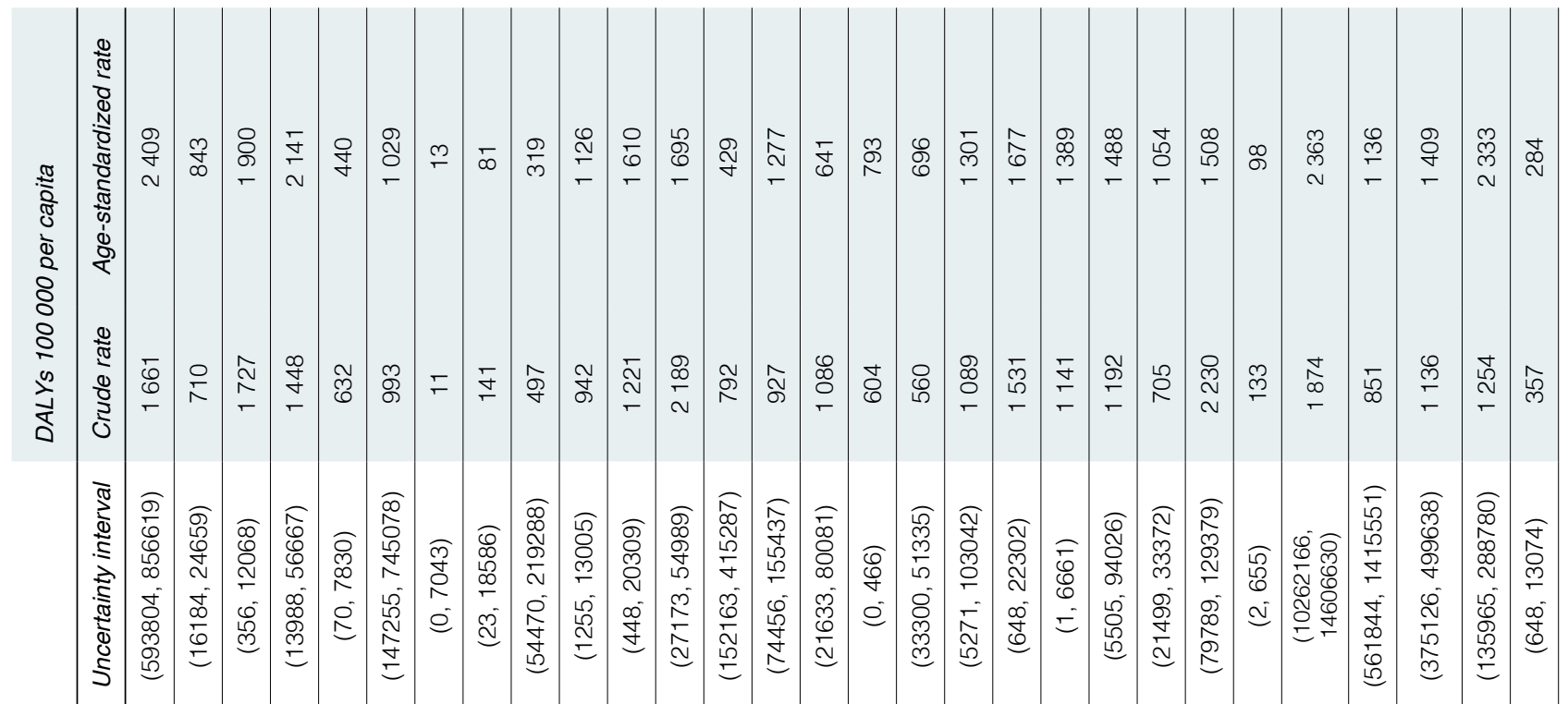

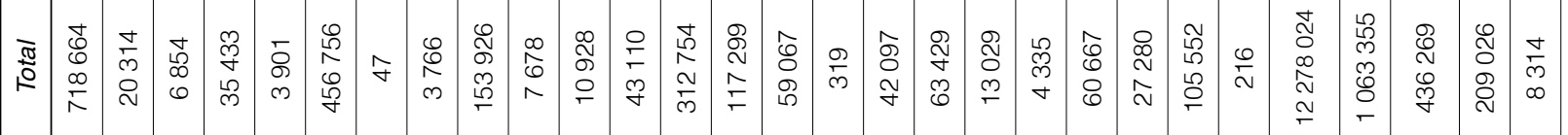

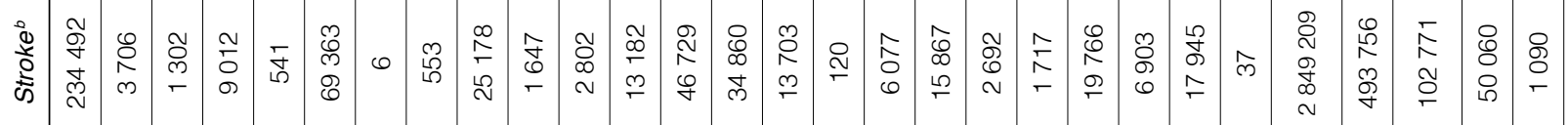

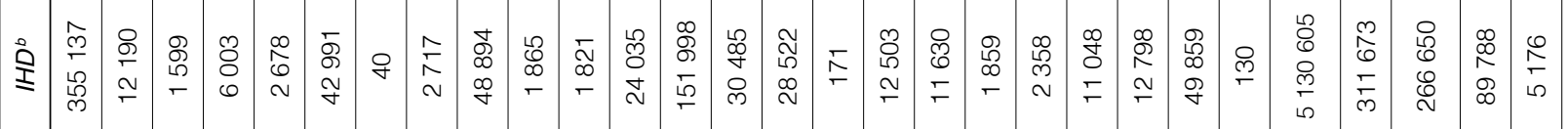

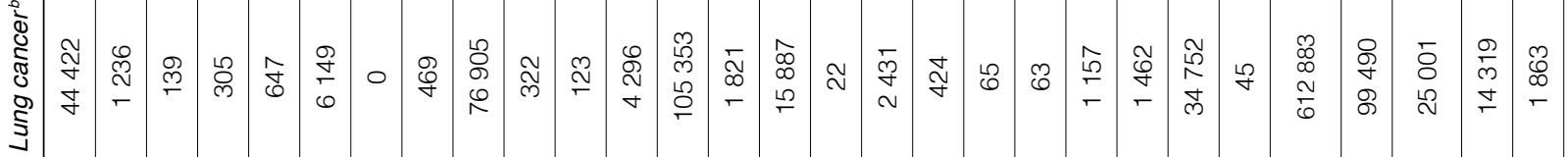

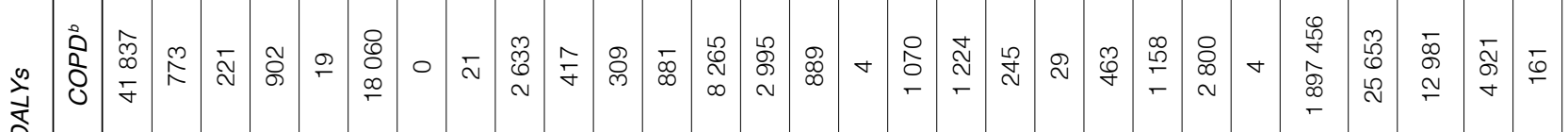

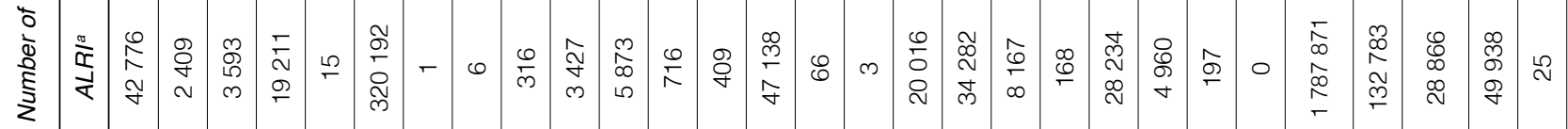

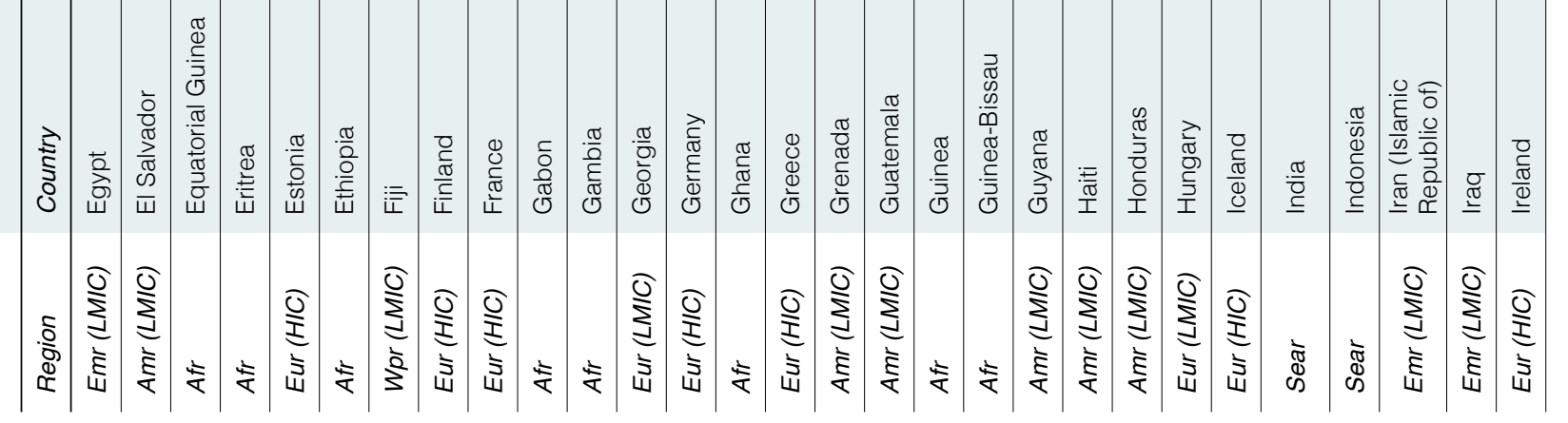




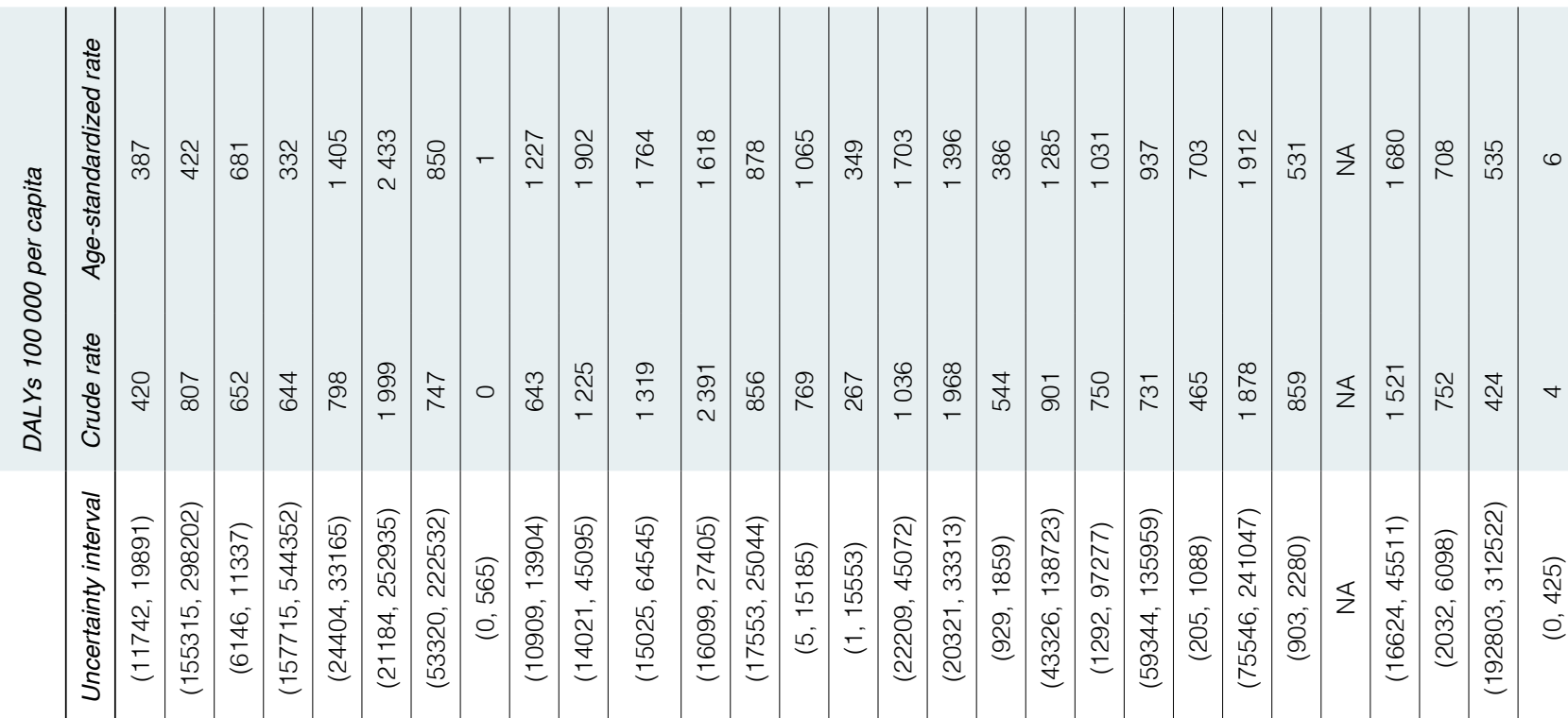

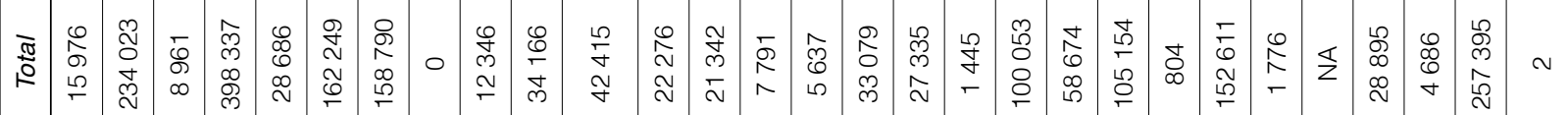

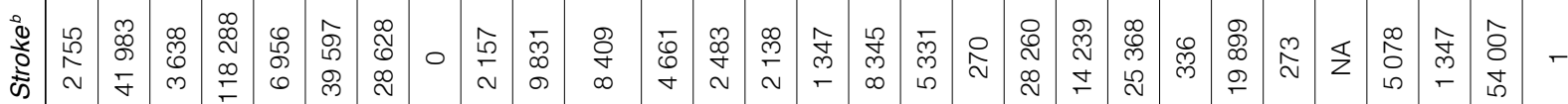

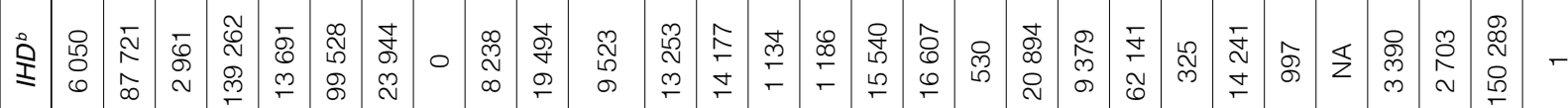

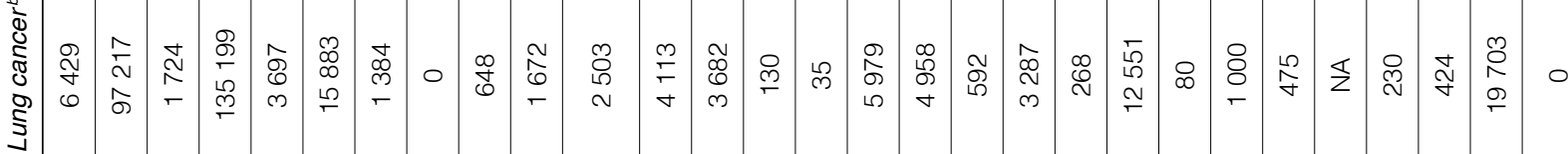

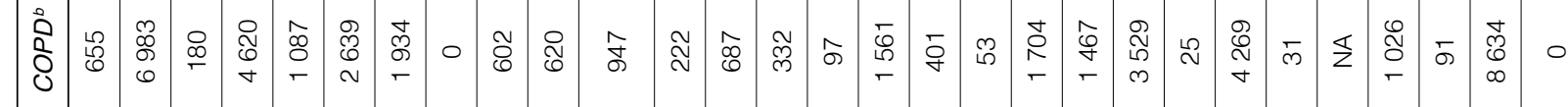

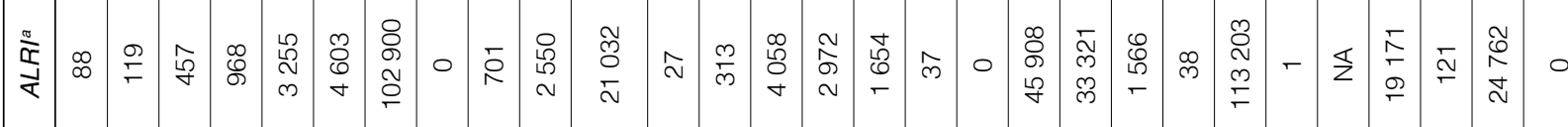

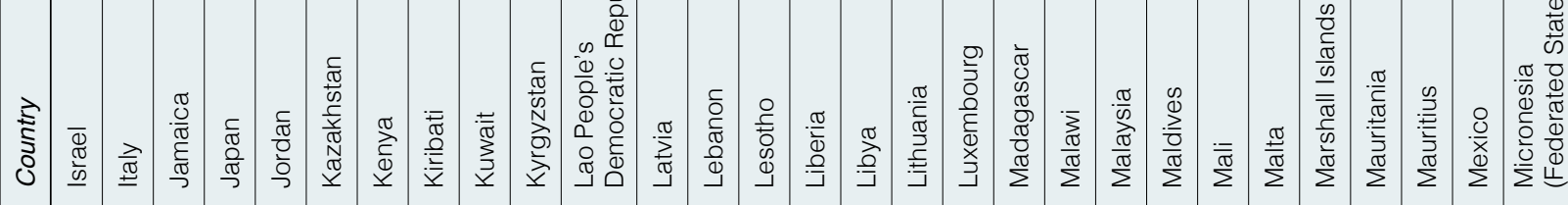
.

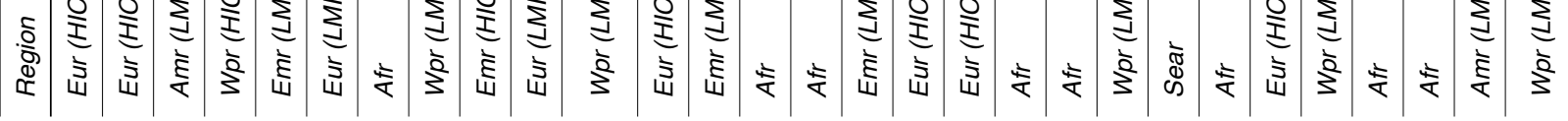




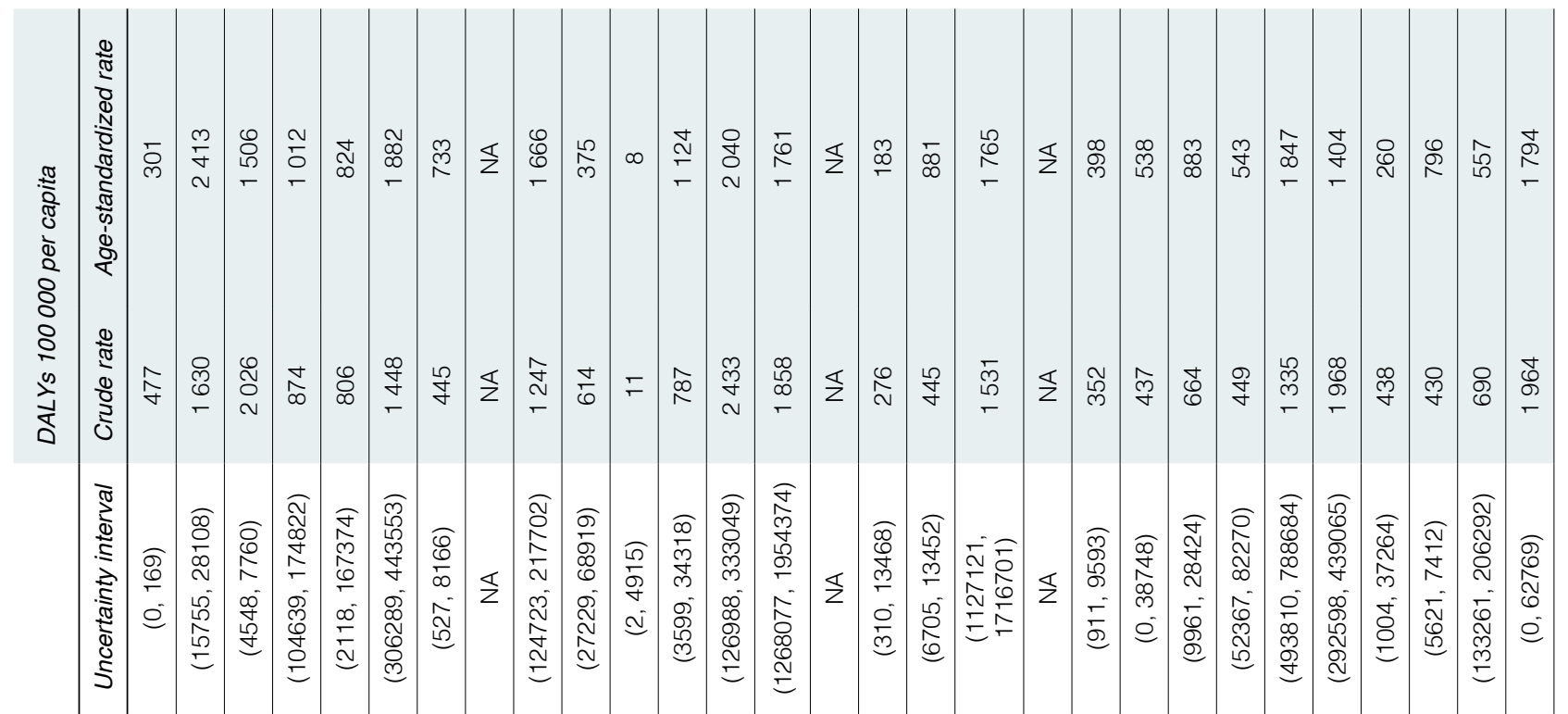

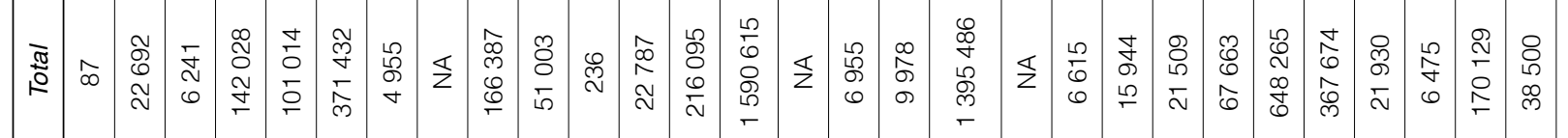

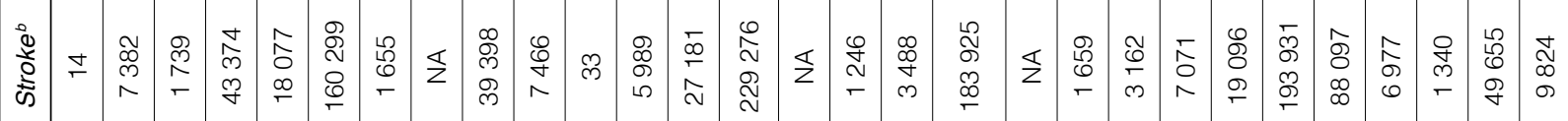

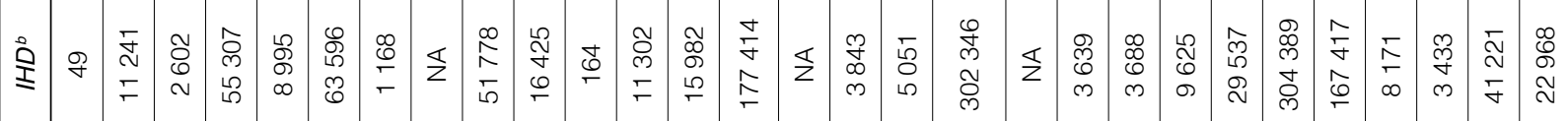

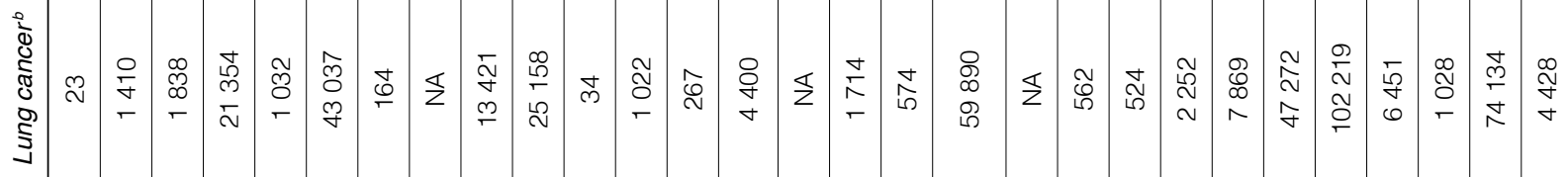

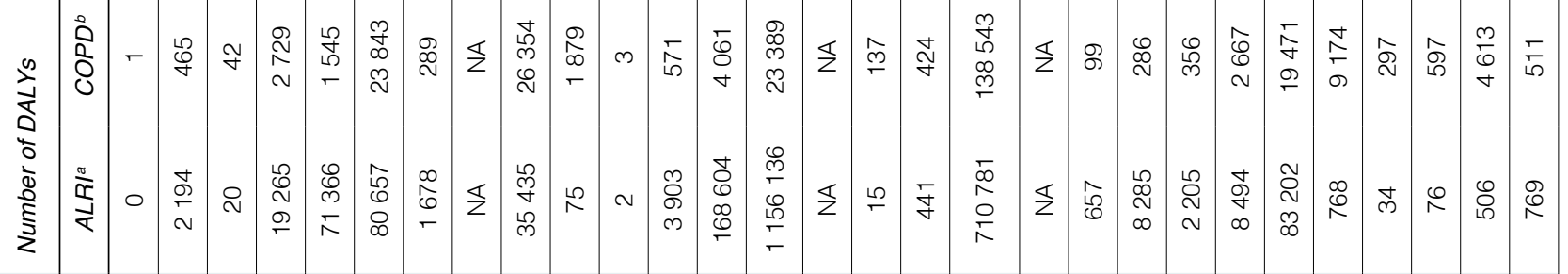

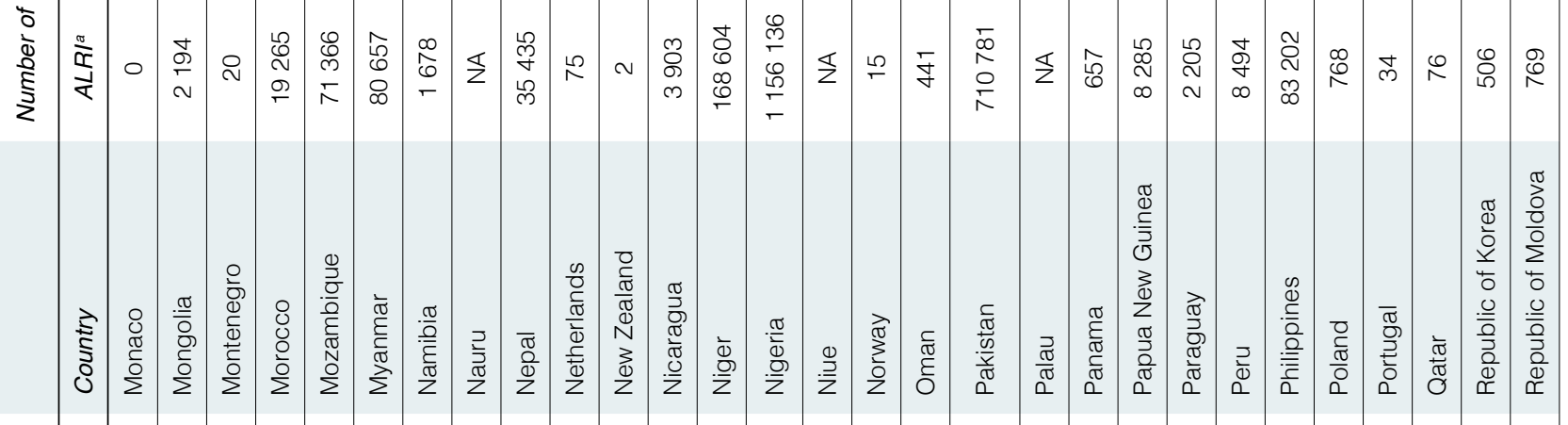

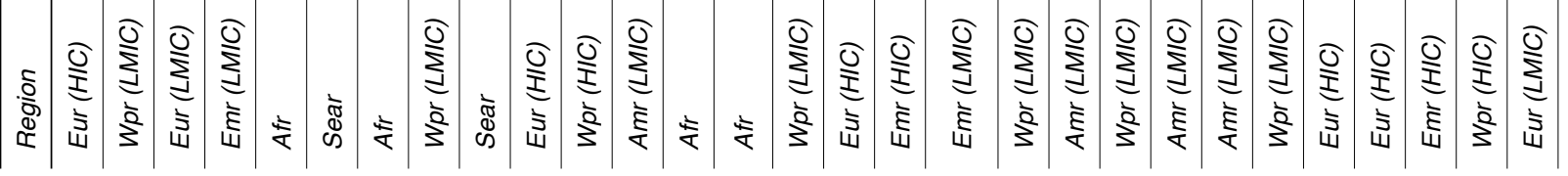




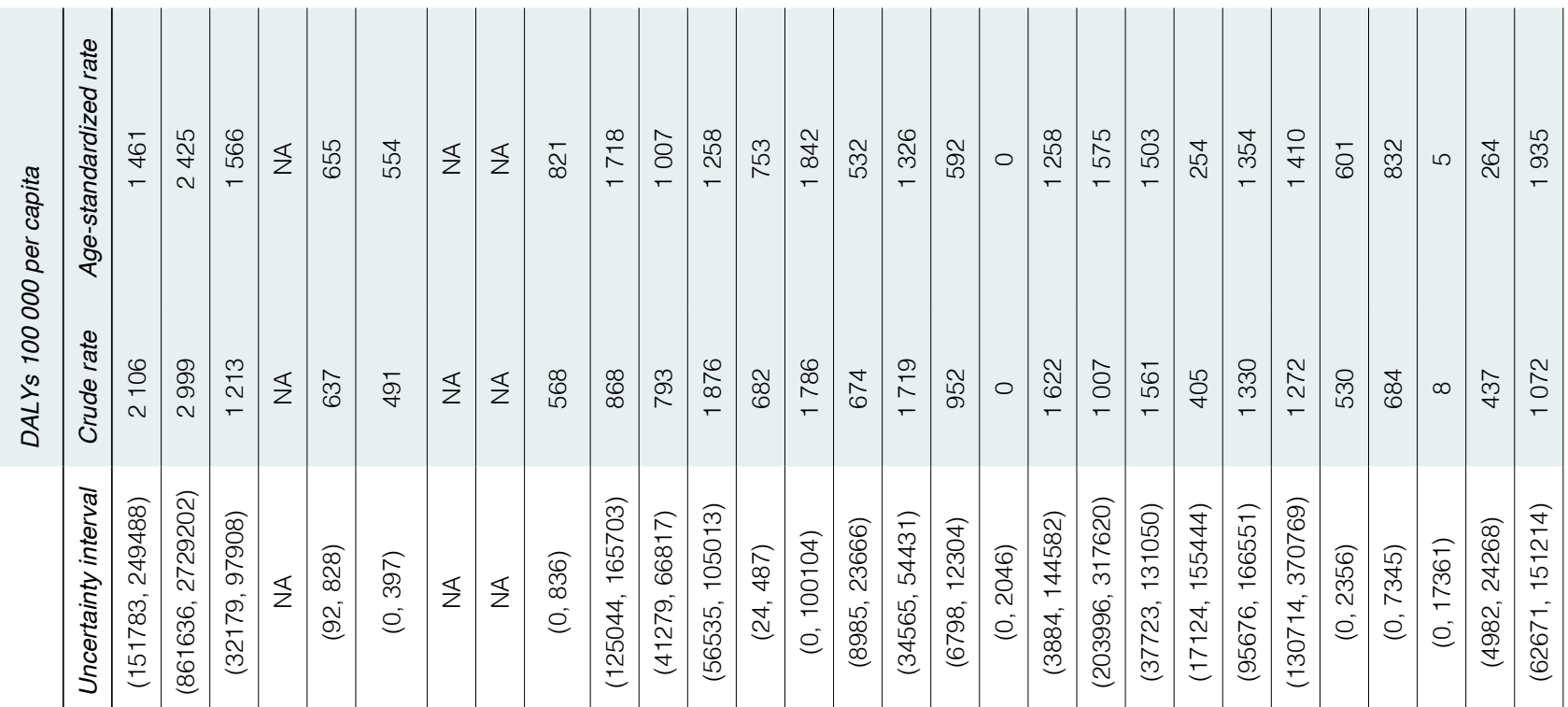

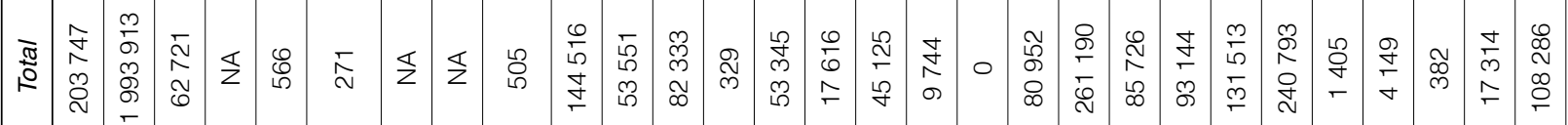

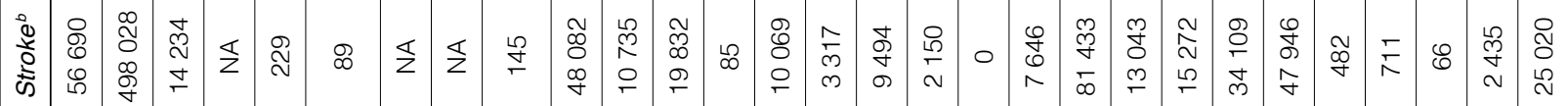

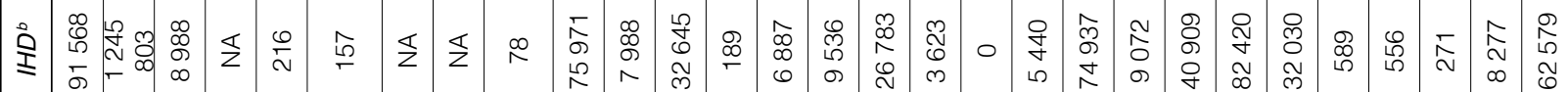

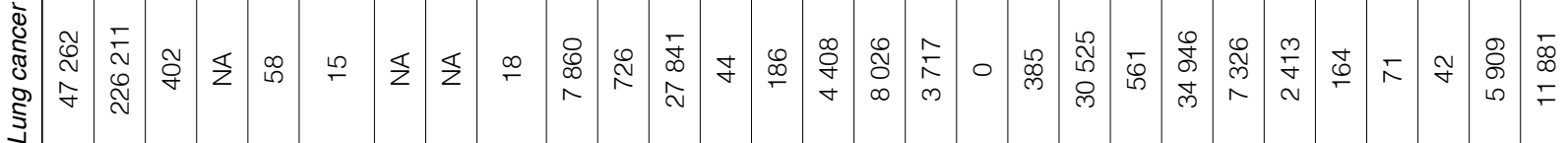

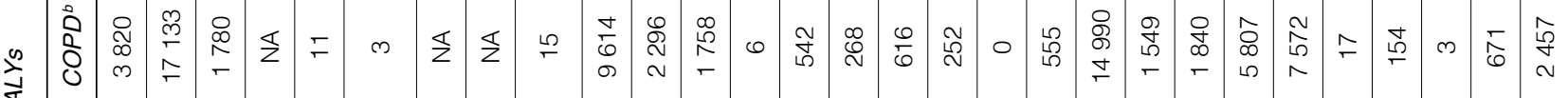

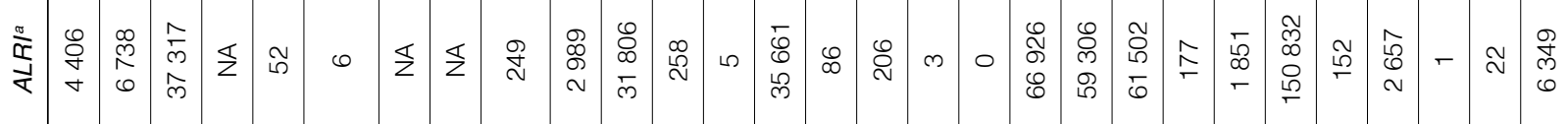

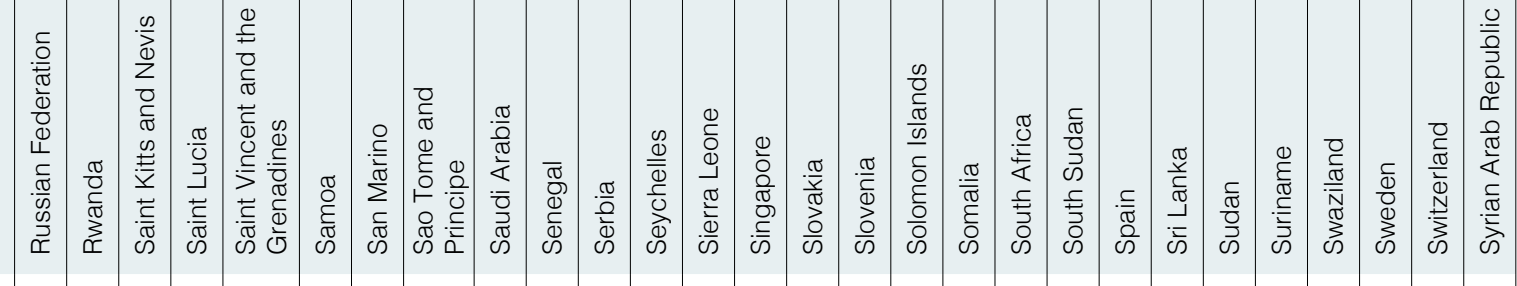

.0

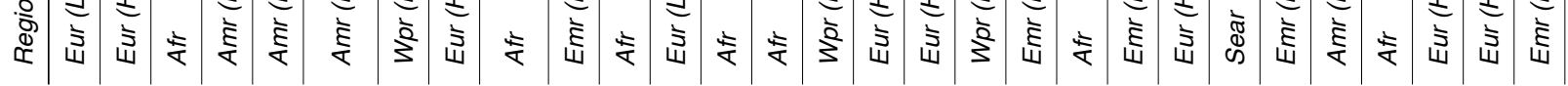




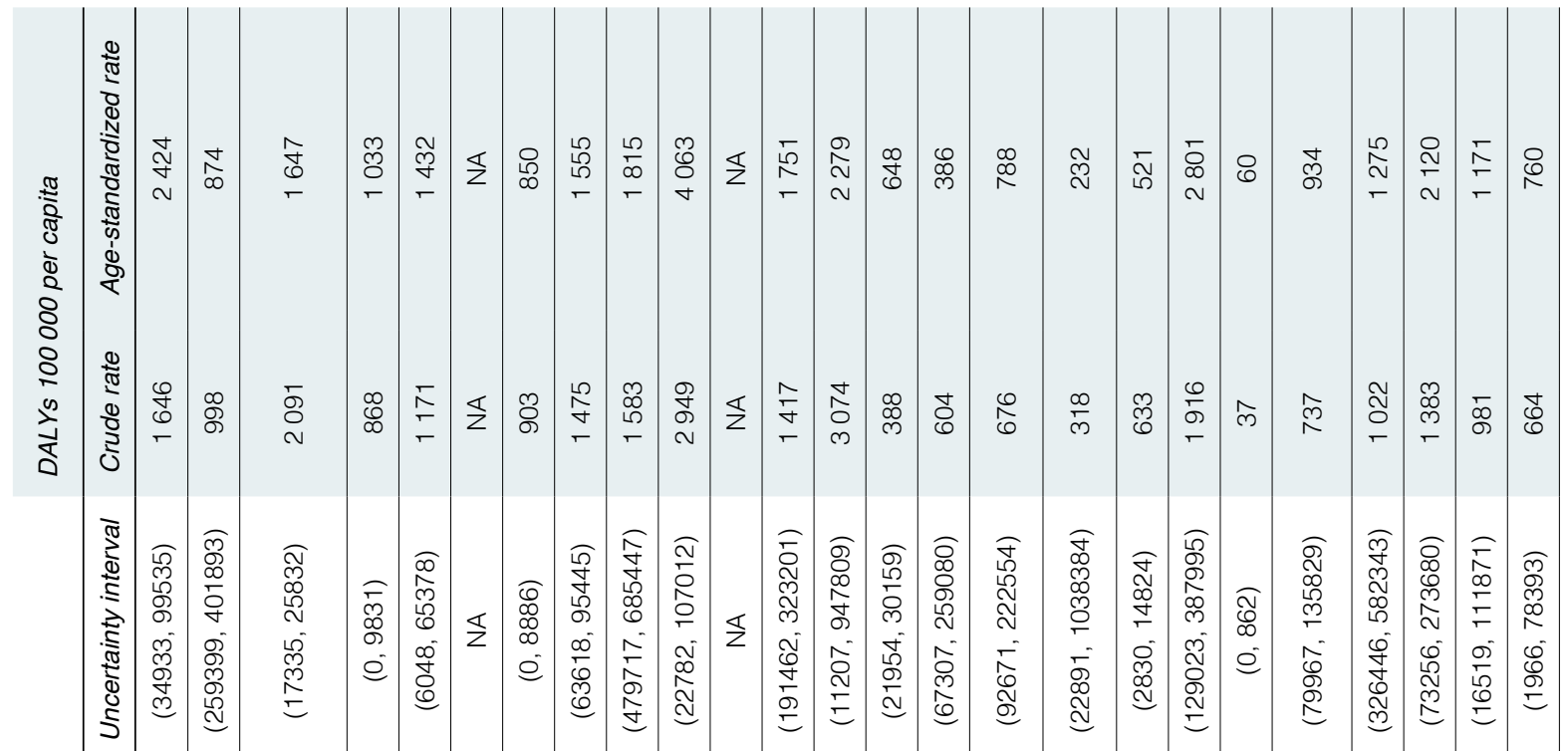

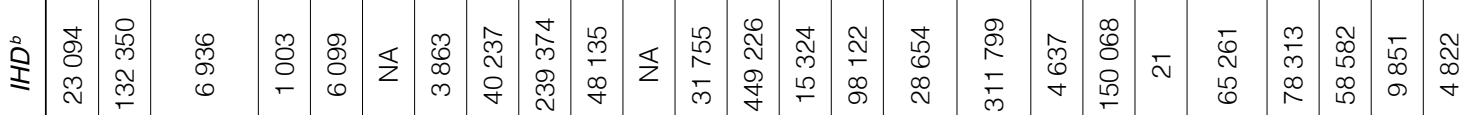

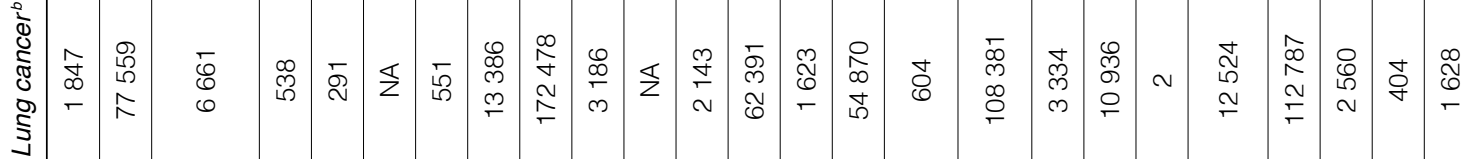

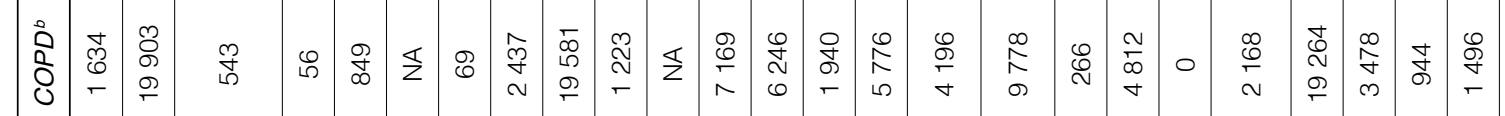

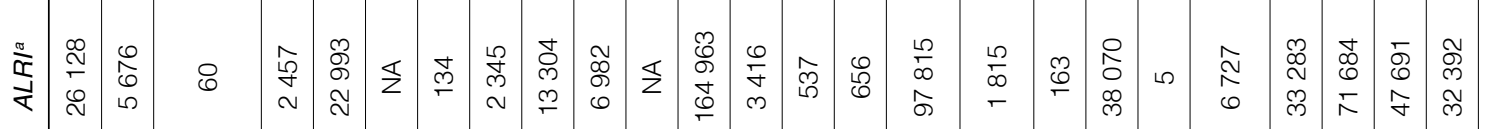




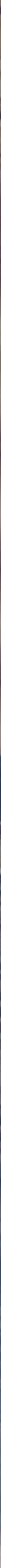

Contact:

Department of Public Health, Environmental

and Social Determinants of Health (PHE)

World Health Organization

Avenue Appia 20

$\mathrm{CH}-1211$ Geneva

www.who.int/phe 